\title{
TURKISH GLASS CULTURE AND ITS RELATIONSHIP WITH CONTEMPORARY GLASS AND EDUCATION
}

\author{
LÂLE ANDIÇ \\ THESIS SUBMITTED FOR THE DEGREE OF DOCTOR OF PHILOSOPHY
}

\author{
HERIOT-WATT UNIVERSITY \\ EDINBURGH COLLEGE OF ART \\ SCHOOL OF DESIGN AND APPLIED ARTS \\ GLASS DEPARTMENT
}

This copy of the thesis has been supplied on condition that anyone who consults it is understood to recognise that the copyright rest with its author and that no quotation from the thesis and no information derived from it may be published without the prior written consent of the author or the University (as may be appropriate) 
"A Nation Deprived of Fine Arts is a Nation Deprived of a Primary Resource for Vitality"

Mustafa Kemal Atatürk (1881-1938) 


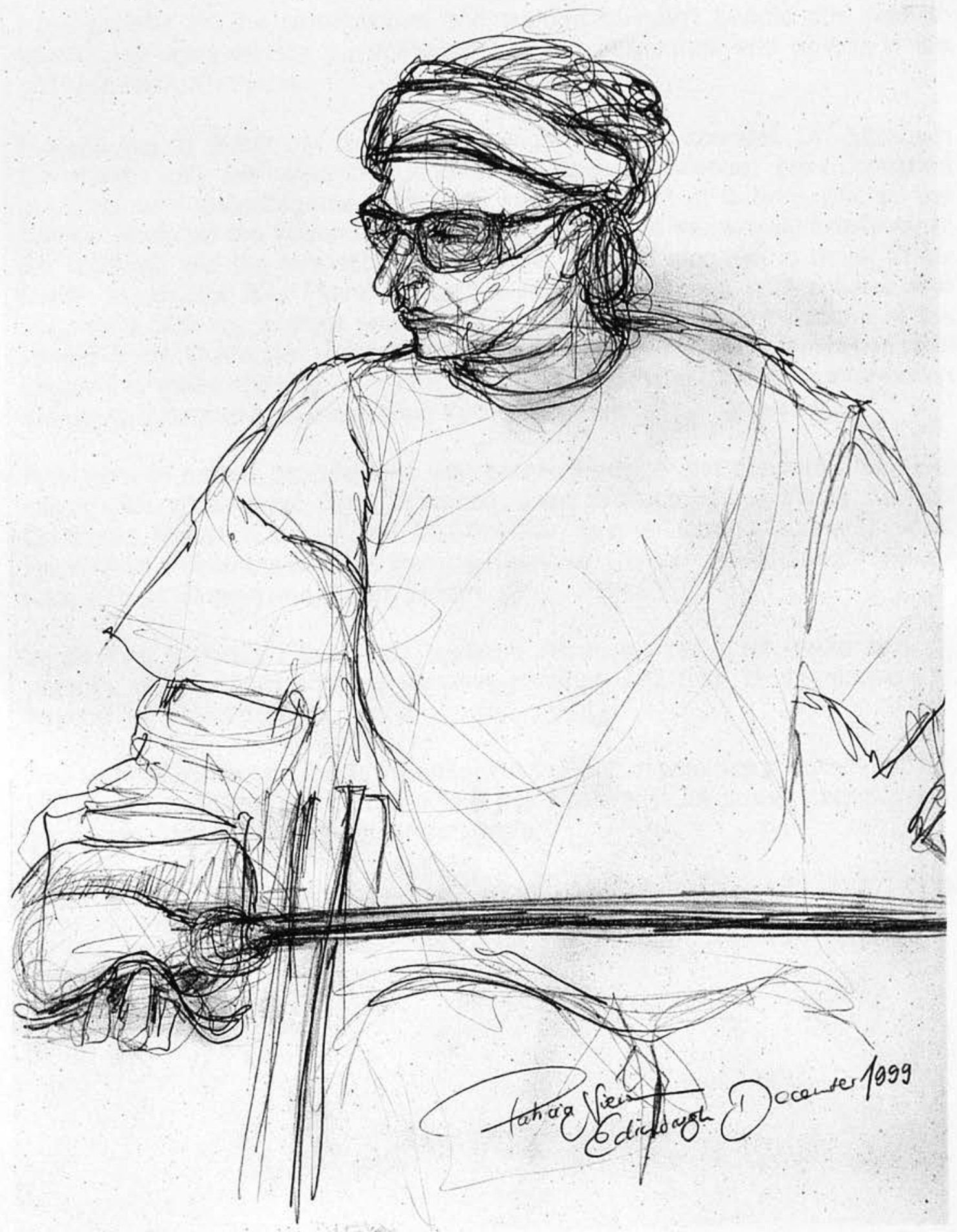




\section{ACKNOWLEDGMENT}

I am grateful for the contributions and support of many people and wish to specifically acknowledge the following for their assistance and advice in the completion of this thesis.

I would like to thank my current supervisors for their counsel, Dr. Elizabeth Cumming, with her extensive knowledge and experience, gave constant guidance and encouragement and Les Mitchell, Head of School, offered me precise ideas for the structure of my study. Both were immensely beneficial to my research and the formation of my thesis. I would also like to thank to my former supervisor Ray Flavell, Head of Glass Department, who initiated and supported both my interest and research in this study. Also, my tutors at the Dokuz Eylül University, Prof. Sevim Çizer who ignited my interest in and impulse for glass, together with Prof. Dr. Zeliha Mete who gave both information and motivation and kept me smiling throughout.

A number of people provided me with practical advice and support throughout my studies, these were Jane Thomson, Joan Wallace, Derek Walls, Marena Chapman, Robert Wilson, Alison McConachie, Zeynep, David Maule and Hülya, Hayri llhan and others such as Patricia Niemann, Candan, Şefik Güngör, Fatma Kadı, Füsun Uludinç and Özlem Erdem.

In addition to these I thank my husband Altan, my daughter Berke and my parents, all of whom showed extreme patience and faith in me above and beyond the call of duty.

And last but not least, I thank my editor Olivia Boulton who has programmed her life according to this study and edited my thesis with diligence, patience and endeavour together with her positive insight.

The Higher Educational Council in Turkey and Dokuz Eylül University, Izmir provided the funding for me to complete my studies. 


\section{SUMMARY OF CONTENTS}

SUBJECT

PAGE

INTRODUCTION

PART 1.

CHAPTER 1.

GLASS

13

CHAPTER 1. 1.

THE STRUCTURE OF GLASS AND ITS DISTINCTIVE QUALITY

CHAPTER 1. 2.

THE DEVELOPMENT OF GLASS

PART 2.

CHAPTER 2.

CHAPTER 2. 1.

CHAPTER 2. 2.

CHAPTER 2. 3.

CHAPTER 2. 4.

CHAPTER 2. 5.

CHAPTER 2. 6.
TURKISH GLASSMAKING

THE HISTORY OF TURKISH GLASS 37

GLASSMAKING IN ANATOLIA

THE CULTURAL ASPECTS OF TRADITIONAL TURKISH

GLASSMAKING

THE UNIQUE PROPERTIES OF TURKISH GLASS

NEW DIRECTIONS IN GLASSMAKING AFTER THE

FORMATION OF THE TURKISH REPUBLIC

TURKISH CONTEMPORARY GLASS ART AND

EDUCATION

PART 3.

CHAPTER 3.

THE AMERICAN STUDIO GLASS ART MOVEMENT

CHAPTER 3. 1.

THE WAY FORWARD? STUDIO GLASS MOVEMENT AND HARVEY LITTLETON

CHAPTER 3. 2.

AMERICAN GLASS: ART AND EDUCATION

(SINCE 1962-PRESENT)

PART 4.

CHAPTER 4.

"MARCHING ON" - A GLASS EXHIBITION BY LÂLE ANDIÇ

CONCLUSION

APPENDIX

LIST OF ILLUSTRATIONS

TRANSLITERATION FOR TURKISH

GLOSSARY

BIBLIOGRAPHY 


\section{INTRODUCTION}

INT. 1. ABSTRACT OF THESIS

INT. 2. OBJECTIVES, METHODOLOGY AND LITERATURE REVIEW

INT. 2. 1. OBJECTIVES

INT. 2. 2. METHODOLOGY

6

INT. 2. 3. LITERATURE REVIEW

8 


\section{INT. 1. ABSTRACT OF THESIS}

The aim of this study is to discuss the connection and interaction between traditional Turkish glassmaking and contemporary glass art and education. This study, in tandem with my own work, will be put into practice.

Contemporary glass art education derived from the American Studio Glass Art Movement which began in the 1960's, taking form in a university environment and going on to develop in institutions of higher education. It spread quickly throughout America and abroad. There are a number of points which should be considered, for instance, Turkish art schools have not been affected by the spread of this rapid and influential movement; there was a twenty year gap before its influence was finally seen in Turkey. On closer examination the prevailing factors seem to be cultural and economic. Neither of these factors individually provide the answer, however collectively they form a far clearer picture. At the same time, it is necessary to find where the educational direction of Turkish glass art lies in relation to historical, cultural, economical, political and aesthetic concepts. It is important to analyse these concepts in order to reveal the connections between them.

This thesis is based on anthropological and geographical fieldwork, undertaken in order to create a picture of traditional and contemporary glassmaking. Information has been gathered from interviews done in U. K., Turkey, U. S. A. and data has been researched from museums, galleries, art schools, historical and archaeological references and individuals. Many points are illustrated by photographs:

This thesis includes four parts. Part one is an introduction to glass, its structure and its development. Part two describes the many aspects of glassmaking in Turkey, from traditional to contemporary. Part three discusses the development of studio glass art specifically in U. S. A. Part four interprets the connection between the cultural values of Turkish glassmaking and studio glass. This concept is demonstrated in an exhibition of contemporary glasswork designed and made by the author mounted in Edinburgh College of Art in June 2000. 


\section{INT. 2. OBJECTIVES, METHODOLOGY AND LITERATURE REVIEW}

INT. 2. 1. OBJECTIVES

The initial quiver of the Turkish studio glass movement, the direction it took and the purposeful steps to create a tangible outcome, form the core study of this thesis. The Government of the Republic of Turkey has supplied scholarships to provide an overseas education for scientists, social scientists and artists, which has produced many research studies. This government support aimed to bring higher standards in education, contributing to the educational developments of these scholars and to allow different understandings and points of view to participate in education. For this reason, at the beginning of this study, it was the Head of the Ceramics Department at Dokuz Eylul University, Prof Sevim Çizer, a great influence on the direction of this study, whose good sense proved of great importance in showing that this use of education was taking a worthwhile direction. She has seen that the Turkish studio glass movement, in reality, will only start to take form and develop within an academic environment. She has taken important steps in evaluating the potential and making best use of the possibilities and opportunities. In the light of the concentrated effort and support that she gave to the academic development of glass, it is not surprising that Prof. Çizer is thought of as the spark which originated this way of working in Turkey. 
This study starts with discussing glass in its historical context, considering the interaction between culture and material, the harmony between the traditional and the contemporary and the impact of developing an academic education in the discipline; and the answers to these phenomena that come from the artists.

The reason for my interest in the development of the studio glass movement in America is in relation to the future establishment and development of a studio glass department in Dokuz Eylul University in Izmir, Turkey. I believe that to study the important evolutionary stages of this movement will enable a more considered introduction through the transformation of prescient values and elements. Clearly the different cultural and social forces within individual countries will have there own effects upon the development of movements such as the studio glass movement. Nevertheless, with economic and social ties developing throughout the world there must inevitably be points of conjunction within specific areas for the benefit of artistic development, the exchange of techniques and the growth of trade. These points may be more readily ascertained by the recognition of both similarities and differences within the developments and practices of the studio glass movement. The connection therefore, between the American studio glass movement and Turkish glass making lies in the necessary investigation and modification of one to benefit developments in the other.

In spite of this study taking a written form, there is another, invisible purpose which has been laboured over for a long time: this is to comprehend the application techniques of glass as an art material; to practise in the subject; and to improve and develop skills. Thus, the material will reflect the ideas and it will 
be easier to tackle the difficulties thrown up by glass in the creation of art objects. This is one of the important aspects that has helped form the study and brought a distinct approach to it. The inclusion of my exhibition in this study is to provide a contemporary visual example of the practical developments of the studio glass movement. Cultural and traditional elements of my heritage are present in my works and as a contemporary artist I am influenced by modern approaches. This relationship is likewise evident in my choice of medium, glass amalgamates both my cultural background in its history and the developments of the contemporary studio glass movement.

\section{INT. 2. 2. METHODOLOGY}

As this study covers different historical periods, different countries and cultures, these must be evaluated in relationship to one another and brought together in a single framework. Therefore, varying means of gathering data have been employed.

For this purpose field research trips and interviews with artists and inf figures have been compiled. Data has been gathered in regards formation and foundation of the studio glass movement. In order to anal subject in depth interviews were necessary to record the many vari important points, they took place with people like Harvey Littleton, the origi of the American contemporary studio glass movement, his student, Micha Taylor, and artists, educators, directors and curators throughout America and other countries. Some of these were Claus Moje, Steve Edwards, Marjorie Levy, William Travor and Susanne Frantz. Glass artist, Ray Flavell, has an 
extensive knowledge on the subject of studio glass in Great Britain and throughout the world: his directions and experience in themselves formed very valuable sources. In 1997 a fieldtrip to the USA took place, on which Harvey Littleton's Spruce Pine Studio, The Corning Museum of Glass, The Studio of The Corning Museum of Glass, Pilchuck Glass School and also many glass studios and museums and galleries in Seattle and Corning were visited. The artists working in these studios and many influential people in the field were interviewed. In 1998 a visit to CERFAV "The European Centre for Research and Education in Glass" in France was very productive. Here, The European Glass Symposium with 40 international glass artists in attendance took place, this was extremely beneficial as it provided the opportunity to speak with many contemporary and influential figures on the subject.

In technical and specialised subjects it is vital to gain references from academics from different countries to utilise their knowledge and experience, especially on the subject of the technical specifications of glass and its chemistry, amongst these the individual support and contributions of Prof. Zeliha Mete were significant.

In July 1999, a field trip to Turkey constituted the focal point on the subject of both traditional and industrial based glass making in the study. This field trip enabled the compilation of historical and contemporary data and visits to museums and buildings, which are of importance to the subject. These trips were of use in providing the forms of visual and leading data which were not available through written sources and therefore brought an added understanding and originality to the subject. For the purpose of obtaining 
detailed primary knowledge on the subject of the Turkish glass industry it was necessary to visit Paşabahçe glass factory and its subsidiaries, where, top level administrators were interviewed. As well as these, the other glass studios in the region of Beykoz/Akbaba have been analysed. In July and August 1999 trips were also made to Bodrum Underwater Archaeology Museum/Muğla and to Görece village to a bead making family (see Map 1). In the interest of investigating Turkish glass art education, various institutions of higher education, such as Marmara University, Fine Arts Faculty, were visited, observed and interviews conducted.

\section{INT. 2. 3. LITERATURE REVIEW}

The Literature search has included works on the subject of world glass art history, and individual and group studies of American glass and studio glass artists. Exhibition catalogues, works on techniques and new applications in the field were available and proved very valuable. However, contrary to this broad research and publication spectrum, the literature belonging to Turkish glass art is scarce. In particular it was not easy to scrutinise works on the history of Turkish glass as this is an unreported field and works are difficult to access. As a result, few scholars have attempted to produce works on this subject and most were compiled by one man, Prof. Önder Küçükerman. These publications analyse glass from the point of view of an industrial product designer and therefore provided little insight into the most involved research in this subject. On the other hand, these works were of value in creating a focussed starting point. 
During this study I have utilised many valuable sources, some of which are listed below. Publications by George F. Bass, covering many archaeological finds including the Serçe Limanı glass excavations, such as Bodrum Sualtı Arkeoloji Müzesi'ndeki Batıklar (Ankara, 1996) and "The Nature of the Serçe Limanı Glass", Journal of Glass Studies, The Corning Museum of Glass (1984), Vol. 26, these are historical presentations of the events surrounding many important archaeological finds, they help to expand our understanding of the history of Islamic glass by making with reference to trade routes, techniques and designs. Similarly, Marilyn Jenkins' book, Islamic Glass (The Metropolitan Museum of Art, 1986) refers to these excavations at Serçe Limanı, however, it is also an extensive and authoritative historical work in a limited field. Godfrey Goodwin's many publications about Ottoman architecture, such as A History of Ottoman Architecture (London, 1971), Islamic Architecture: Ottoman Turkey (London, 1977) and Sinan: Ottoman Architecture and Its ValuesToday (London, 1993), were helpful visually as they contained many illustrations displaying the extent of the skills and influences of Ottoman designs, whilst also intimately detailing the application of the works and their historical relevance. Although there are many publications on the Ottoman Empire and its art, such as Halil Inalcik's The Ottoman Empire, The Classical Age, 1300-1600 (London, 1973), I found that the information they contained was not as relevant to my study as were others. Likewise, a book of great use to those wishing further understanding of contemporary developments in both the Middle East and the post Soviet Balkan World is Halil Inalcik's and Donald Quataert's An Economic and Social History of the Ottoman Empire, Vols. 1 and 2 (Cambridge University Press, 1994). The information relevant to my study in this expansive book could however, be gained from other works, which contain more specific information 
about glass. Rachel Ward's Gilded and Enamelled Glass from the Middle East (London, 1998) is a compilation of papers, presented at a conference "Gilded and Enamelled Glass from the Middle East", which was organised by the Association for the History of Glass and the Department of Oriental Antiquities, British Museum and held at the British Museum from 6 to 8 April 1995, and edited by Ward, this collection provided a wide range of views, including both historical and critical analysis, such as investigations into Islamic enamelled beakers, their design and projected uses. Fuat Bayramoğlu's publications about Beykoz glassware, Türk Cam Sanatı ve Beykoz Işleri (Istanbul, 1974 and Ankara, 1996), "Beykoz Işi Cam Eşya”, Türkiyemiz (October, 1982), No.38, 1-7, "Glass Distinction", Turquoise (Spring, 1990), 20-21, written from the point of view of an interested layman, these works provide both a thorough and personal interpretation of Beykozware, backed up by his own research and collection, they were influential in promoting the work to the general public. Finally, Tina Oldknow's Pilchuck: A Glass School (Pilchuck Glass School, Seattle, 1996), at the start of this study this was the most recent publication about Pilchuck, it contains historical and factual notes on its development, alongside comments, interviews and tales about the school, its students, artists and working practices.

Two sources in particular which were extremely useful for discussion and enlightenment were R. J. Charleston's "The Import of Western Glass into Turkey: Sixteenth - Eighteenth Centuries" The Connoisseur (May, 1966), 18-26 and Mehmed Önder's "Selçuklu Devrine Ait Bir Cam Tabak" Türk Sanat Tarihi Araştırma ve Incelemeleri II, Istanbul Devlet Güzel Sanatlar Akademisi (Istanbul, 1969), 1-5. In the case of R. J. Charleston's work, its value 
lay in the opportunity to compare it with my own findings and thus help to develop more cohesive arguments. The article is an analytical discussion, which provides interpretation of the style and use of glassware in Turkey over a two hundred-year period. The importance of this work to my own was that it gave me the opportunity to objectively contrast and therefore collate my own ideas and research into a broader and clearer discussion. However, Charleston's work is not definitive as some of the sources he used were inadequate. Mehmed Önder's archaeological notes were the main historical and factual source on Seljuk glass and contain the only reference to the glass plate found at the Palace of Kubad- Abad, an important article from the Seljuk period. The paper is one of the most academic sources and is extremely detailed and specific in its descriptions and references.

One of the most pleasurable and up to date sources of information was The Illustrated London News (London, 1842, 51). It provided me with detailed and objective reporting from the time of events, such as The Great Exhibition at the Crystal Palace, this was enjoyable as, in relation to Turkish sources, which require an understanding of languages different to those in use today, it was an accessible and different source of information. In order to create a contrast with the past, two more recently published books which provided constant sources were Peter Layton's Glass Art (London, 1996) and Henry Halem's Glass Notes: A reference for the glass artist (Ohio, 1996), these provided an artistic, historical and technical point of view. Both were valuable reference books for the artist, the production of their works, techniques and applications. Henry Halem's is predominantly a technical book, providing information from glass calculations to 
health and safety. Peter Layton's book, on the other hand, is involved more with the artistic development of the studio glass movement.

To access original documents in Turkey on Ottoman glass art history, required special permission from the Ministry of Culture, this was a barrier to the punctual retrieval of documents and archives. Difficulties in finding and obtaining sources meant it was necessary to do my own fieldwork. The fieldwork undertaken included the trips and interviews mentioned previously in the Methodology. This was useful in that it provided original contributions not available in accessible written sources and therefore was encouraging as it gave an added value to my thesis. Another barrier was that of language as the written sources from the Ottoman period used a different alphabet and language to that of today. This presents a major difficulty for research undertaken by the current generation. 


\section{GLASS}

\section{PREFACE}

For thousands of years glass has astonished mankind and become an unwavering part of their lives. The first part of this chapter dissects the materials used in the formation of glass, their general characteristics, their compositions, the physical and chemical qualities of glass and its unique behaviour as a material. In the second part, the 5000-year journey of glass, from its beginnings until the start of the $20^{\text {th }}$ century, will be assessed, considering its progress, and its technical and formal developments. In addition to this the methods and techniques, which were at various times stepping stones for glass art, will be analysed. 


\section{CONTENTS OF CHAPTER 1.}

1.1.

THE STRUCTURE OF GLASS AND ITS DISTINCTIVE QUALITY

1. 2. THE DEVELOPMENT OF GLASS

CONCLUSION 


\subsection{THE STRUCTURE OF GLASS AND ITS}

\section{DISTINCTIVE QUALITY}

The history of glass begins millions of years ago with volcanic activity forming obsidian, however its most important era started when man began to manipulate and form the material. Obsidians are shiny, black igneous ${ }^{1}$ rocks, they form when magma cools rapidly and are the most common type of volcanic rock. After the evaluation of obsidian as a cutting material, efforts were made to utilise its qualities in the form of arrow, axe and spear heads. Later, with the increase in the skills and intellect of man the material was developed accordingly, thus they adopted the material to their particular period and lifestyles. From jewellery and the production of daily utility ware it developed to the point it is at today. This journey has taken place across the centuries and the place of glass in the form of functional ware has not been shaken but is also prevalent as an art material.

From the beginning of the oldest civilisations glass has been involved almost inseparably with our existence. With its use in buildings and vehicles for the expansion of light and visibility and with its domestic purposes, it gives the impression of always having been part of our lives. The initial functions of glass are still evident in the function of glassware today. However, there have naturally been changes in the composition, quality, production methods and fields of application of glass. 
Glass makes remarkable transformations in its process in connection with heat. Whilst it is in a melted state it is fluid, malleable and incandescent in appearance. With its cooling it becomes transparent and preserves the shape that was formed when it was hot, it takes on a completely different appearance with its gleaming and shining surfaces. Whist in its melted state, it can be cut by shears and blown out, it is easily submissive to physical powers, such as gravity and centrifugal forces. When cool and hard it is possible to smash but becomes toughened against weathering. This contrast created by its physical structure is unique. It is easily breakable and as such it obviously looses its function, but when it is preserved it is one of the materials which is less susceptible to the ravages of ageing. According to its stage in production, the surfaces of glass exhibit differences which mean it can be transparent, opaque, matt or coloured. It is one of the most suitable materials for recycling.

In accordance with the qualities of the transparency of glass, the most commonly seen use of glass is as a window material. However, nowadays the scope of glass has broadened, it is used in chemistry, medical sciences, electronics, it also displays its wide variety in use as a building material, laboratory equipment, light bulbs, television/ computer tubes and heat resistant kitchen ware. The optical qualities of glass combined with the advancements in high technology have found an important role in a wide range of applications. This glass with its special mechanic and electrical qualities has been produced for many technical purposes. It has a high refraction index and uses different production techniques. The most common examples of this are spectacle lenses, magnifying glasses, telescopes and binoculars. 
In today's developing technology some of the explanations accepted previously without scientific conclusion can be refuted, for example it was generally thought that the material imperative for glass was silica, but nowadays, the artificial production of glass can be realised without the use of such materials ${ }^{2}$. Below is a description of glass in the light of development and one of the newest scientific interpretations:

“...an amorphous solid completely lacking in long range, periodic atomic structure and exhibiting a region of glass transformation behaviour."

From the liquid phase of glass to the solid phase, the changes which occur in structure are in appearance as it maintains in its solid state the molecular structure of a liquid ${ }^{4}$. Due to this behaviour it is known as 'a super cooled liquid $^{5}$. The chemist, Rex Grimshaw, provides a description of glass in light of this trait:

'Substances of this nature are termed 'glasses' and they are non-crystalline, isotropic and usually transparent. ${ }^{6,}$

The components of glass are naturally abundant and this is one reason for the increase in its use. When the individual components are combined in varying amounts and compositions they form glass of differing qualities. When the silica is the sole ingredient it is possible to form glass, however, its melting point is too

2 Shelby, James E., Introduction to Glass Science and Technology (Cambridge, 1997), p 3. Shelby, p 3. Every glass exhibits the time-dependent behaviour known as glass transformation behaviour.

${ }_{4} \quad$ Klein, Dan and Lloyd, Ward, The History of Glass (London, 1997), p 9.

5 Grimshaw, Rex W., The Chemistry and Physics of Clays and Other Ceramic Materials (London, 1971), pp 170, 171, 172.

Grimshaw, p 170. 
high $^{7}$. Nevertheless with the addition of fluxes: alkaline oxides such as sodium, potassium and lithium, or lead oxides, it is possible to lower the melting point by around $1300^{\circ} \mathrm{C}$.

Glass is categorised in accordance with the specifications of the components which form the batch. Lead glass: formed by the use of lead oxide, together with silica and alkaline oxides such as sodium and potassium. It is called crystal or more usually 'flints' ${ }^{8}$. This type of composition is melted at a much lower temperature because it contains a high level of flux. In comparison to other types of glass, it is much heavier and brighter. Lead glass is convenient for etched and cut decorations, as it is much softer than other glasses such as soda glass. In addition to this, lead glass remains at a suitable working temperature for longer than other glass. Glass which contains a high silica content and sodium oxide, usually soda ash, calcite and/ or magnesium, which

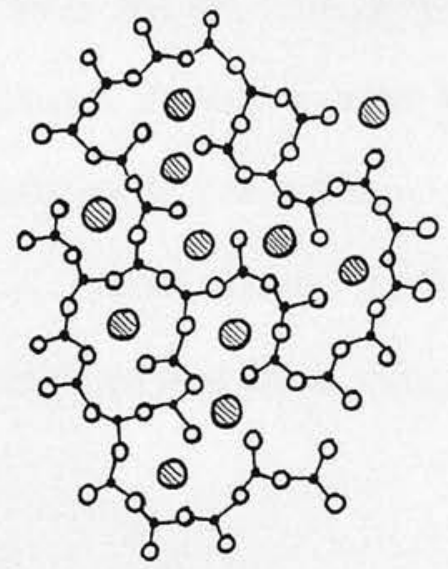

Figure 1

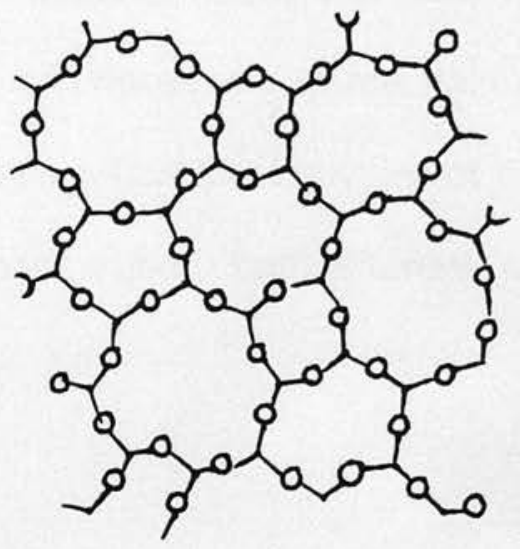

Figure 2

Deer, W. A., Howie, R. A. and Zussman, J., Rock Forming Minerals, Framework Silicates (London, 1963), Vol. 4, p 180. For example $\beta_{2}$ Tridymite form of silica melts at $1670{ }^{\circ} \mathrm{C}$, $\beta$ Crystobalite's melting point, $1713^{\circ} \mathrm{C}$, vitreous silica; lechatelierite is an unstable glass at all temperatures below $1713^{\circ} \mathrm{C}$.

${ }_{8} \quad$ Littleton, Harvey, Glassblowing-A Search for Form (New York, Ontario, Victoria, England, 1980), p 49. 
strengthens it, is called soda glass or 'crown'. When an alkaline silica glass figure 1 is compared with a silica glass figure 2 it is possible to see differences in the crystal structure and these dictate the behavioural specifications of the glass. Another glass type is known as Pyrex glass ${ }^{10}$. Due to the boric acid in this glass it is resistant to thermal shocks, and its expansion coefficient to heat is very small, therefore it is commonly used in the production of kitchenware/ ovenware.

In a glass batch broken and scrap glass pieces or cullet are added, this encourages speedier melting of the batch and is economical. Of course, every glass producer uses the materials and ratios suitable for their purposes in the mixture of their batch ${ }^{11}$.

The materials and components of the glass batch are important for glass as it goes from the liquid form to the solid form. Whenever its fluidity is changing and solidifying, the structure of the glass must adapt to these changes. Whilst the hot glass is cooling to room temperature, it is necessary to maintain a certain temperature to prevent tension and stresses within the structure of the glass. This is called annealing. Each glass composition has different annealing temperatures and times.

\footnotetext{
$9 \quad$ Littleton, p 49.

10 Trade name for the Corning Glass Works, Corning, New York.

11 These limits, expressed by Henry Halem, for the formulation of glass batches give an idea for the ratios of the mixtures:

$\mathrm{SiO}_{2}$ $63-73 \%$

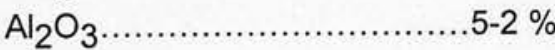

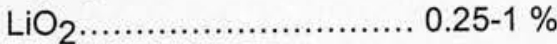

$\mathrm{Na}_{2} \mathrm{O}, \mathrm{K}_{2} \mathrm{O} \ldots \ldots \ldots \ldots \ldots \ldots . . . . .17 .5 \%$ or less

$\mathrm{MgO}, \mathrm{CaO}, \mathrm{BaO}, \mathrm{ZnO} \ldots \ldots \ldots \ldots . . .8 \%$ total of all.

Halem, Henry, Glass Notes-A Reference for the Glass Artist (Kent, Ohio, 1996), p 14.
} 
On the subject of the colouring of glass, certain metallic oxides need to be added. Any such oxide added to a glass composition will interact with it in relation to the batch and the furnace atmosphere. For these reasons the ratios of the additions and the specifications of the batch must be known exactly. Generally, the most commonly used oxides are, copper, cobalt, iron, manganese, nickel and titanium. These oxides can be added to the batch either separately or mixed with others.

In reality from its beginnings until the present day, both in terms of glass batch and general principals of production little has changed. Nowadays in industrial and scientific studies the smallest fluctuation in factors will have a substantial effect, however for the use of glass as an art material these fluctuations are perceived to be negligent and capricious. The most important point in the use of glass as an art material is to find the quality of glass which will best serve the artist's purpose. The physical and chemical qualities of glass will direct the artist to develop the notions of rhythm and wise use of time. The natural physiognomy of man is driven by instinct from birth, the initial instinct to suckle and the development of the holding and grasping reflex, turns the co-ordination of brain and hand into an automatic reaction. This chain of involuntary activity and the instinct to touch is interrupted in man's relationship with glass by the necessity of tools; this is a vital point in the competition between man and glass. From this point on the materials progression depends on the artist. Likely as not, the most charming quality of glass for the artist rises from the very challenge of its physical structure. 


\subsection{THE DEVELOPMENT OF GLASS}

There is no conclusive evidence of how glass was discovered; there is not a foolproof explanation which does not leave some questions unanswered. There are only inconclusive theories, such as its formation in the ashes of a fire started on a beach by sailors ${ }^{12}$; thus its discovery was more than likely a coincidence. The most watertight collusion of this theory comes from the Roman historian, Pliny (AD 23/24-79), and is supported simply because all the environmental factors necessary for the formation of glass were present. This theory includes all the ingredients: silica, the most important material in glass, obtained from crushed flint, quartz or sand, the melting point of which must be lowered with alkaline oxides in order for it to melt at lower temperatures ${ }^{13}$; happily, this alkalinity was present in the natron blocks ${ }^{14}$ which were placed on the fire for a pot to stand on. This theory throws up a number of seemingly inconsequential questions such as was the log fire hot enough to attain a suitable temperature, and how did the silica mix with the alkaline sufficiently? Practically and theoretically the most logical assertion to make is that, materialwise, the discovery of glass came as a ceramic glaze, and was formed with the development of some of the silica based mixtures used in glaze making.

The beginnings of its history lie too far back in the mists of time and unfortunately there is insubstantial evidence and knowledge of the material, thus making definitive conclusions virtually impossible. For 5000 years mankind 
has formed glass, the earliest evidence at hand belonging to the start of this era are examples of amulets and glass beads from Mesopotamia ${ }^{15}$, dated around 2500 years BC. The discovery of fire and the development of worked metal tools ushered in a new dawn for the human race and the seeds of the discovery and application of glass were sown.

Bead making utilises the most simple of tools and is easily controlled due to the small size of the objects. Intense technical knowledge and skill was not required for their production and this caused the increase in their popularity. Efforts were concentrated in the changing of shapes and the dimensions of beads and the range of their colour, as well as making jewellery, ornaments and amulets, the manufacture of more functional objects was emphasised, following its development. Thus the core moulding method was born.

The period, which displayed great abundance in the core moulding method, was $15^{\text {th }}$ to $11^{\text {th }}$ centuries $B C^{16}$. In this technique the glassmaker coats a metal rod with a dough mixture of clay, sand and dung in the shape of the end glass product. Afterwards he dips this form into melted opaque glass or drapes it with coils of glass. For decoration the glassmaker trails thin strands of coloured glass onto the form, smoothes them into the glass using the marver and then drags a pin through them to create a marbled effect. (Figure 3) This wavy and lacy style of motif and the coloured spirals, which are placed on the neck or between the motifs, are the general characteristics of glass made by core moulding methods. The decoration is followed by the addition of a foot and handle. When the form is complete and following its cooling, the clay mixture is 


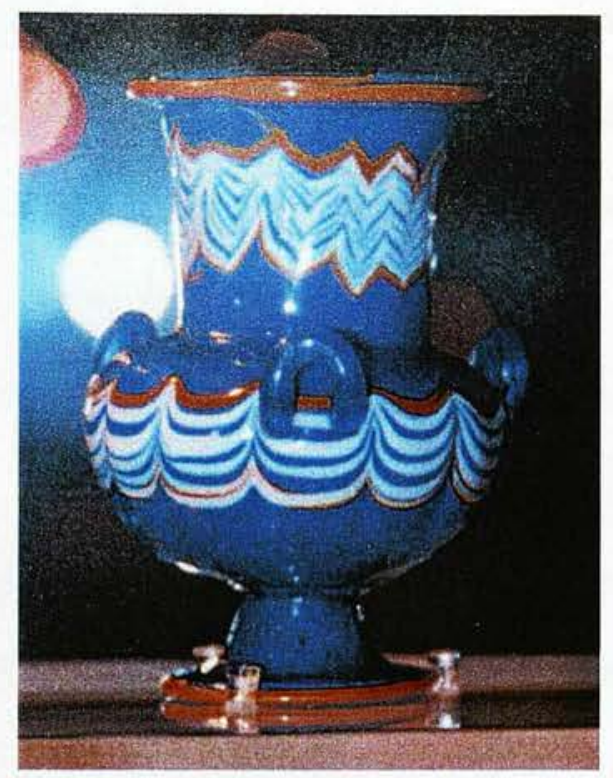

Figure 3

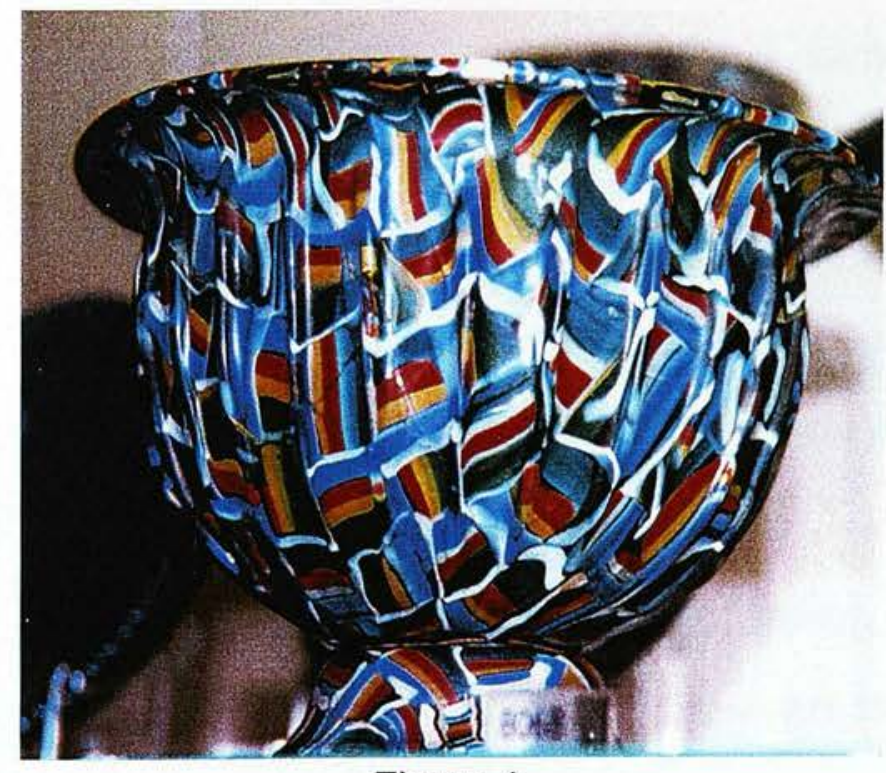

Figure 4

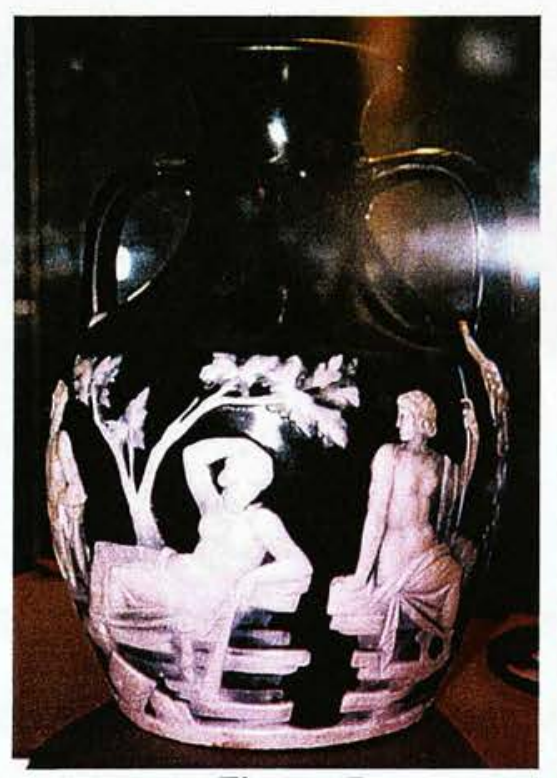

Figure 5

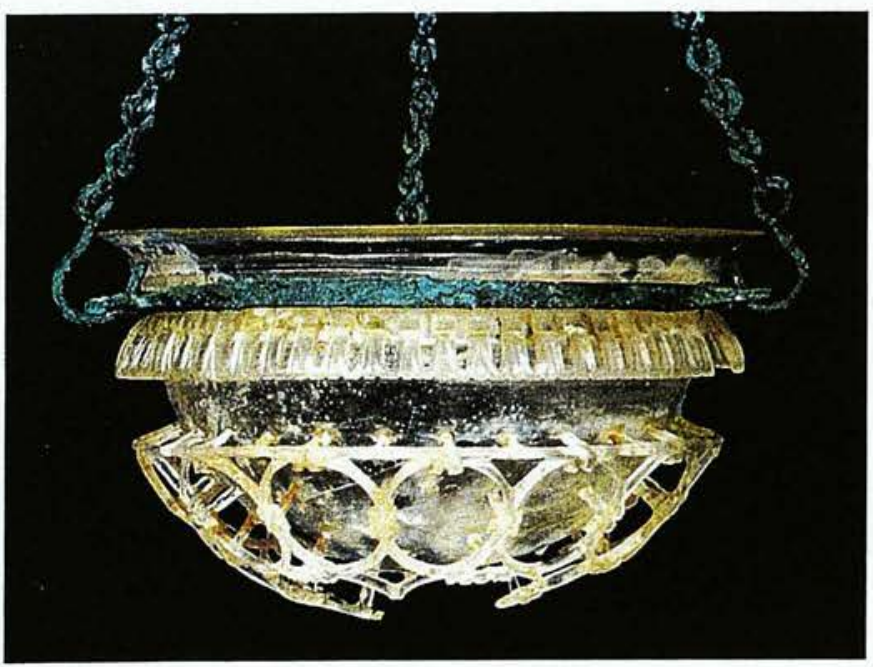

Figure 6 
taken out and the glass is cleaned. Small perfume containers, bottles and vases were all made using this technique. During this period the use of multicoloured and twisted canes for decoration inspired development and later, especially in $3^{\text {rd }}$ century BC, luxurious and sophisticated wares, made using the mosaic technique, were produced ${ }^{17}$.

The heyday of mosaic glass making was directly after Alexander the Great conquered Egypt ${ }^{18}$. During this period the use of mosaic in glassmaking created some of the most complicated decorations, enchantingly beautiful compositions and a harmony in the application of colour and form. (Figure 4) Together with the difficulties in the application of the technique, which require improved knowledge and skill, and the length of time it takes to be completed, these objects inhabit a special place out of the ordinary. Glass pieces found in excavations show that most came from palaces or temples. This suggests that glass was especially addressed to the higher echelons of society.

Alongside the production of glass through the aforementioned techniques, moulding practices also played a significant role. Smearing glass into the mould or pouring in hot glass heralded the beginning of various forms and decoration techniques. Naturally, in this technique maintaining the working temperature of the glass when pouring it was difficult, as was encouraging the glass to diffuse throughout the mould ${ }^{19}$. However, Roman glassmakers developed techniques in order to solve these problems, and the way was cleared for new discoveries in glass. Carving the solid lump of glass and shaping it was one of the burgeoning

\footnotetext{
$17 \quad$ Whitehouse, David, Glass of the Roman Empire (New York, 1988), p 14.

18 Bruhn, Jutta-Annette, Designs in Miniature: The Story of Mosaic Glass (New York, 1995), p 10.

19 Whitehouse, $\mathrm{p} 10$.
} 
techniques in this period. Around $75-50$ years BC, in the Syro-Palestinian region $^{20}$, with the discovery of the glass blowing technique, glassmaking went into a new phase.

The blowing method brought simplicity to production, allowing many pieces to be made in a short time. This caused the price of glass to fall and as such it was attainable to every level of the public. Although free glass blowing provided plentiful production, blowing into moulds became the nucleus of serial production. The principal of the blowing technique seems straight forward enough, a rod with glass on which is blown to make a bubble, in actual fact acquiring the skill to master the technique is a time consuming business. The glass is melted at $1300-1500^{\circ} \mathrm{C}$, when the temperature is decreased to $1100^{\circ} \mathrm{C}$ the viscosity of the glass increases. At this consistency the required amount of glass is gathered onto a blowing iron, this is the initial action, but after this a series of applications interact to create the final product: glass, heat, tool and the individual are the four contributing factors which effect the outcome. Glass making by blowing is not however restricted to the blowing iron. For different parameters and dimensions punty, bit and gathering irons, jacks, tweezers, wooden blocks and shears are amongst the other main tools used in blowing.

From the beginning Egypt, Mesopotamia, Palestine and Syria have brought new techniques, forms and novelties to glass art. Their contribution in this field has caused them to remain for hundreds of years as the main players in the area of glass, however through wars and immigration the techniques of glass art spread. The development and novelties were carried by Jewish, Syrian and

20 Yokohama Museum of Art, Yokohama, Treasures from The Corning Museum of Glass (1992), p 184. 
Egyptian immigrants throughout Europe and helped to encourage European glass into a new period of development. Following the discovery of the blowing technique, a particular zeal for glass blowing started in Italy, France, Belgium, Germany and England.

During the period of the Roman Empire (27 BC - $395 A D$ ), a special importance was given to glass making and in all the techniques used in production, two attract particular attention. One of these was Cameo glass, which is formed by the application of two different coloured glasses, one on top of the other. In this technique the glass underneath is a dark colour, whilst the top layer is white. For decoration the top white layer is cut, carved and polished to reveal the motif, and this naturally gives it a relief, creating three dimensional scenes and a deep contrast with the layer underneath. Although there are occasional examples of more than two layers, the most popular combination is white on dark blue. This production was difficult, requiring great knowledge and skill, but this technique became one of the most esteemed amongst the nobility. The cameo glasses made in Italy between $25 \mathrm{BC}$ and 50-60 AD were very popular ${ }^{21}$. (Figure 5) The most well known example of this technique is the Portland vase currently in the British Museum in London. The other technique is the Cage cup technique, it was also called diatreton ${ }^{22}$. (Figure 6) The first examples to come to light caused lengthy discussion on the techniques used to create these glasses, their delicate three dimensional decoration envelop very simple and modest glass forms in a particularly striking manner. Initially it was presumed that the decoration must be welded to the forms as it could not possibly be cut away, however it was later discovered that they were whole forms which had in fact 
been very skilfully cut $^{23}$. The diatreta glasses from the later period of the Roman Empire, from $250 \mathrm{AD}$ until the mid $4^{\text {th }}$ century, were mostly made in Cologne (Koln), Athens and Strasbourg. Nowadays, the examples gained from excavations are not entirely complete, but there are nineteen diatreta examples. As these pieces were cut from one piece of glass, their manufacture required great skill and much patience and they were considered, in their time, as very valuable and unique pieces. As deciphered from the writing on the works, they were made specifically for nobles of the Roman Empire ${ }^{24}$.

The development of glass until the $7^{\text {th }}$ century, formed through the interaction between the east and west and grew out of the give and taken shown in the political, social and commercial exchanges of countries. With the decline of the Roman Empire and the birth and swift spread of Islam, the cultural changes in the Near East and North African countries, resulted in the dominance of Islamic decorative art in glass. In the $10^{\text {th }}$ century, both Egypt and Syria became the centres of glass making and the main focus for glass exportation. Glass became an abundant and cheap material; it is recognised that traders from this period were selling goods in glass vessels without charging extra for the glass ${ }^{25}$. In the $12^{\text {th }}$ century lamps made from various metals and porcelain, were also produced in glass, thus creating a new avenue for the use of glass in Islamic glassware. Especially during the late $13^{\text {th }}$ and $14^{\text {th }}$ centuries glass was used as a vessel for lighting, in the form of oil lamps. From the point of view of shape,

\footnotetext{
23 Kämpfer, Fritz and Beyer, Klaus G., Glass-A World History, trans. Edmund Launert (London, 1966), figures 41-42.

Whitehouse, p 50. An example found in Strasbourg in 1826 bears the name of Emperor Maximiane Avgvste.

${ }_{25}$ Büyüktunçay, Attilâ, "Ortaçağ Islam Dünyasında Camcılık”, Şişe Cam (Nov.-Dec. 1979), No. $105, \mathrm{p} 20$.
} 
decoration and colour they gained and maintained a special position for them, even in later periods ${ }^{26}$.

In Islamic glass, forms as important as glass lamps were Islamic enamelled beakers. It has been discovered that these vessels were produced in the Ayyubid (1169-1260) and early Mamluk (1250-1517) periods. Investigations into these show that the beakers were used for various purposes, but mainly for drinking. Summer S. Kenesson, who has researched into the use of Islamic glass beakers states that:

"Some could have been intended for ceremonial use, others as gifts or awards, some for export and sale on an open market; it has even been suggested that some were used for lamps. ${ }^{27,}$

The evolution throughout time of the form and decoration of these beakers, depending on their purpose and use, has been a result of commerce and other interaction between countries and has been remarkable. A piece, from the mid $13^{\text {th }}$ century, called The Luck of Edenhall, possibly from Aleppo in Syria, became the subject of a ballad ${ }^{28}$. (Figure $7 \mathrm{a} / \mathbf{b}$ ) The vessel is shaped thus, its rim extends out from the neck, it sits comfortably and its body rises ergonomically. The composition of the decoration is a typical Islamic example which was much appreciated and copied by the Frankish invaders ${ }^{29}$. The existence of beakers of the same form and decoration in Syria and Egypt shows that they dated

\footnotetext{
26 See Chapter 2. 1. History of Turkish Glass / Glass in Turkish Architecture, p 40.

27 Kenesson, Summer S., "Islamic Enameled Beakers: A New Chronology, Ward, Rachel, Ed., Gilded and Enamelled Glass from the Middle East (London, 1998), p 45.

${ }_{28}$ Charleston, R. J., "The Luck of Edenhall-A Notable Acquisition for the Nation", The Connoisseur (1959), Vol. 143, p 35.

29 Ettinghausen, Richard and Grabar, Oleg, The Art and Architecture of Islam 650-1250 (Middlesex, 1987), pp 374-375.
} 

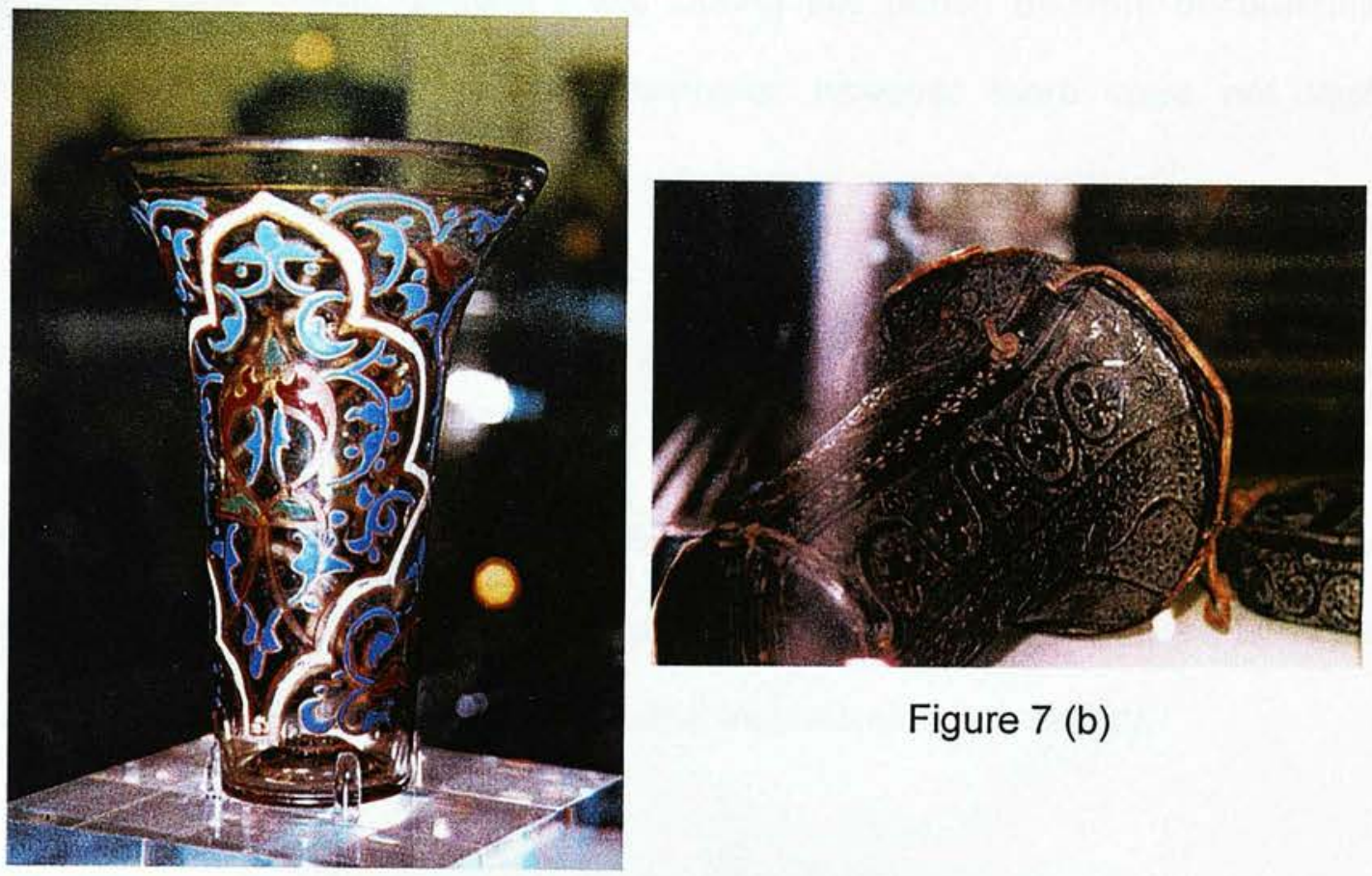

Figure 7 (b)

Figure 7 (a)
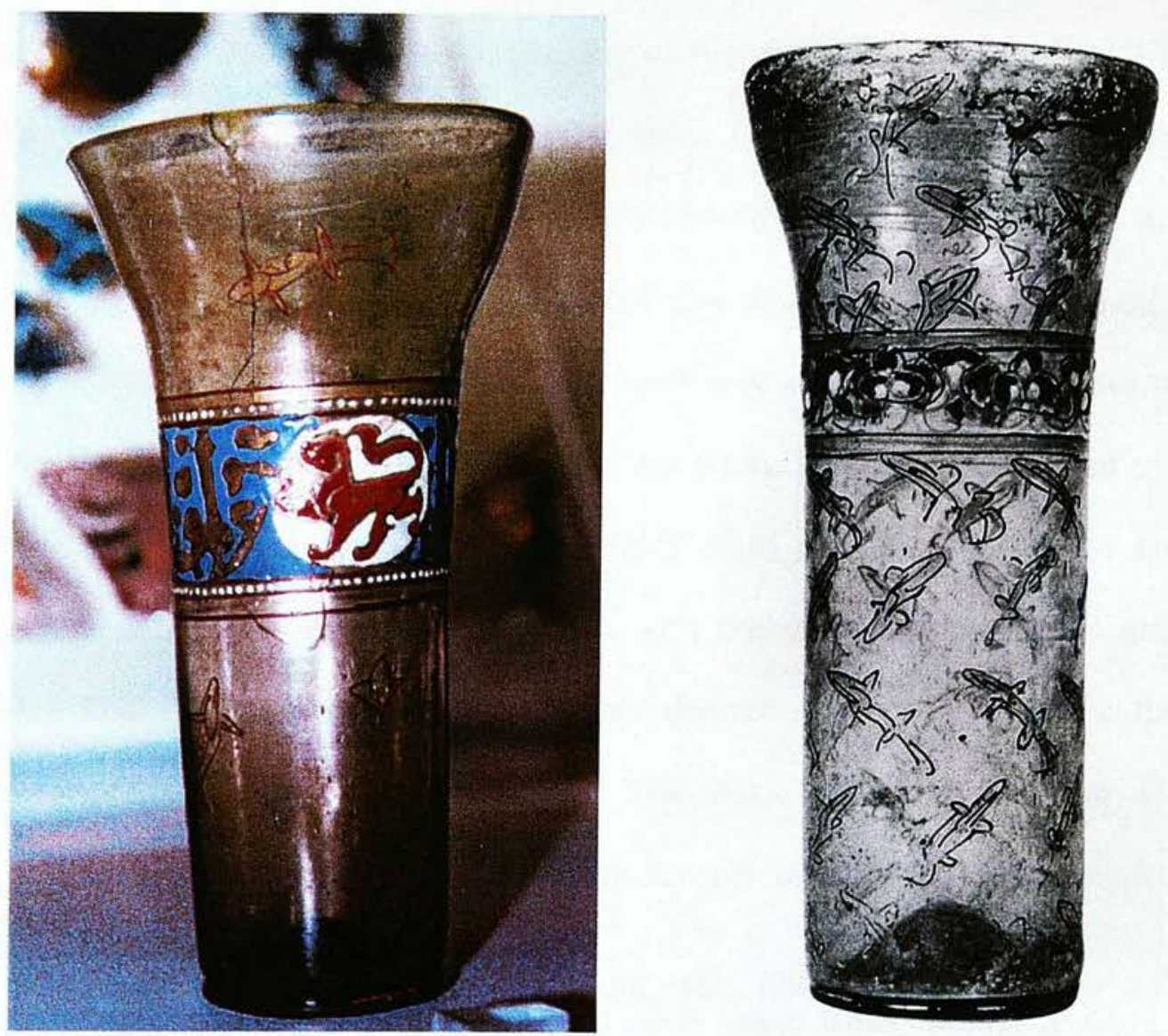

Figure 8 (a)

Figure 8 (b) 
from the same period. (Figures 8 a/b) During this period different decorations have been applied for different purposes, however there were not vast differences between the forms and decorations of Islamic countries ${ }^{30}$.

In regards to Islamic glass one of the most important sources of information was the excavation of a shipwreck in the Bay of Serçe Limanı in Turkey found in 1977-79. Glass products and material dated from $11^{\text {th }}$ century were found on the ship. The archaeological dives made to this commercial ship have become an important point of reference for studies into Islamic glass history.

Serçe Limanı is a small bay between the Island of Rhodes and the mainland on the South West Coast of Turkey. (Map 1) A sponge diver made the discovery alongside other shipwrecks. The contents found in this commercial ship make it an important discovery. Archaeologists have given the ship's date ${ }^{31}$ at 1025 and have assumed that it was coming from the Black Sea or a port near Constantinople, it was carrying a load of amphoras which it delivered to Israel, on the return journey with its new load it was caught by a storm and sunk ${ }^{32}$. In the cargo, alongside ceramic bowls, gold money and jewellery there were found two tons of raw glass and one ton of scrap glass. Eighty Islamic glass pieces in good condition and sixteen glass weights were also found. Figure 9 shows a chunk of glass, which was congealed with broken glass fragments and mud. The findings from this ship were too diverse to signify whether the ship belonged to Fatimids or Byzantium. Therefore, questions such as what the purpose was of the cullet in the load remain unanswered. However, it was

\footnotetext{
30 Dolez, Albane, Glass Animals (New York, 1988), pp 43-44.

31 Bass, George F., "The Nature of the Serçe Limanı Glass", Journal of Glass Studies (1984), Vol. 26, p 64. Its date is fixed by Byzantine coins of Basil II and the three latest Fatimid glass weights carried on the ship.
} 

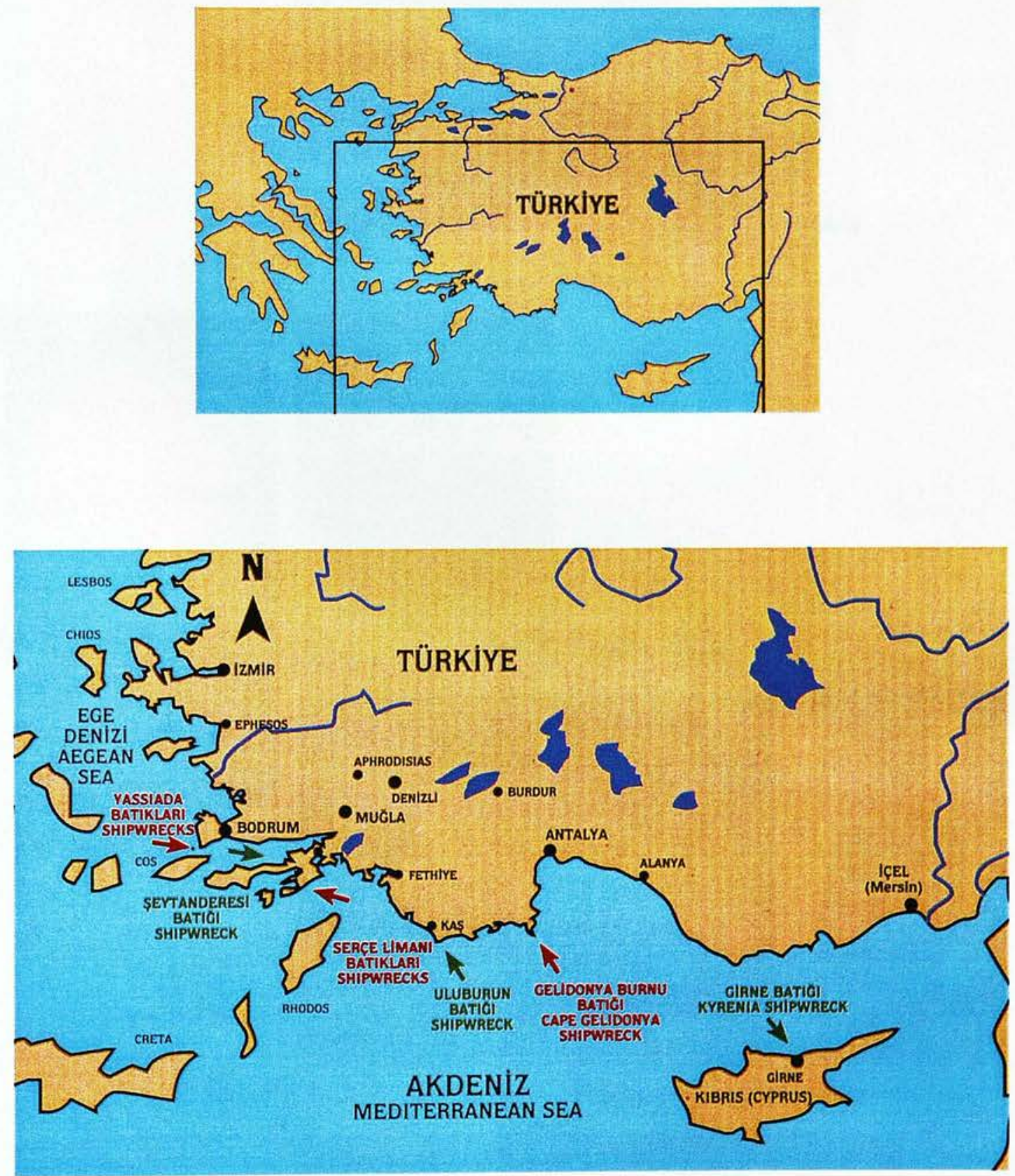

\section{Map 1}

Serçe Limanı 


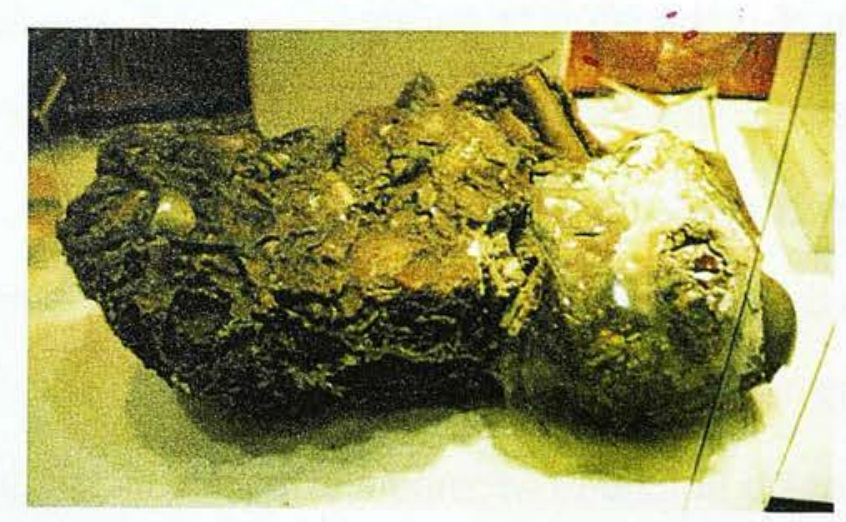

Figure 9

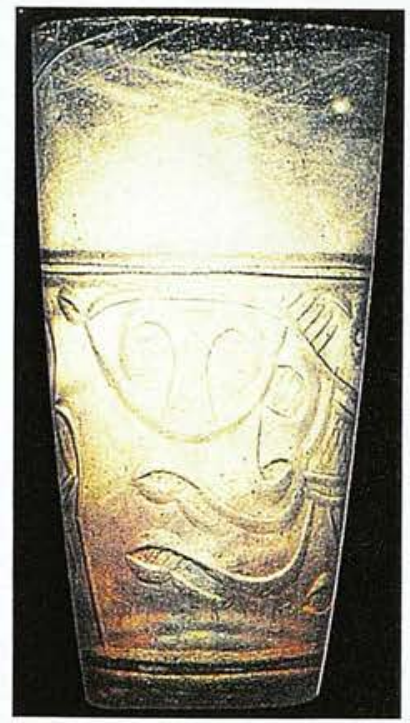

Figure $10(b)$

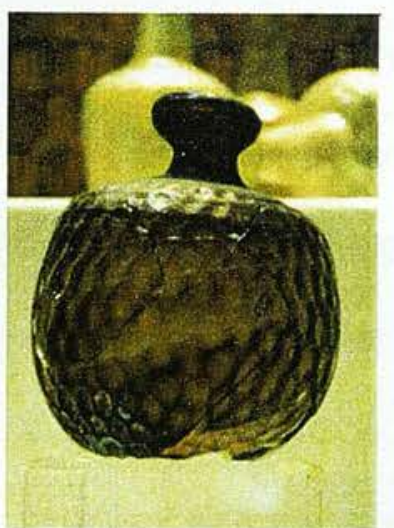

Figure 10 (a)
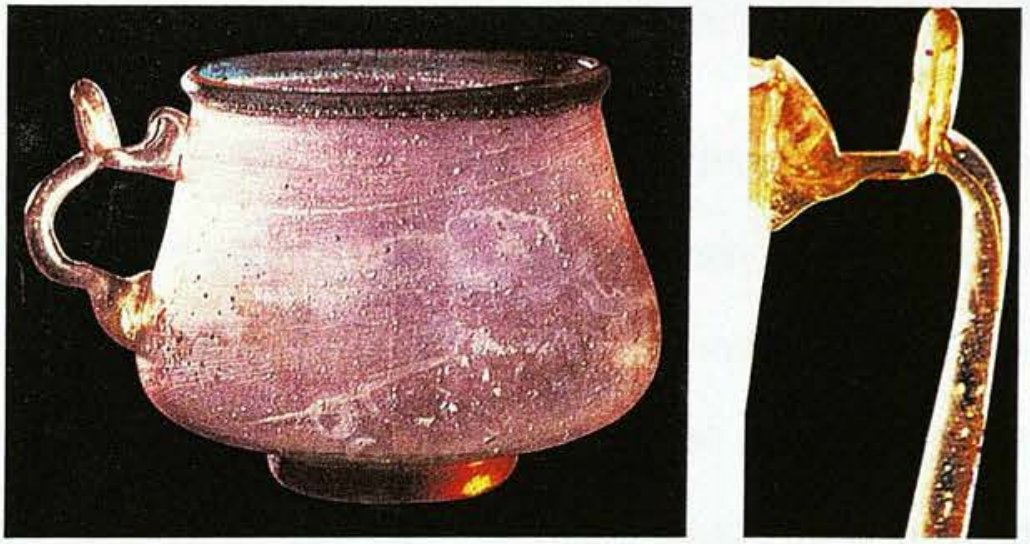

Figure 11 and detail of a handle

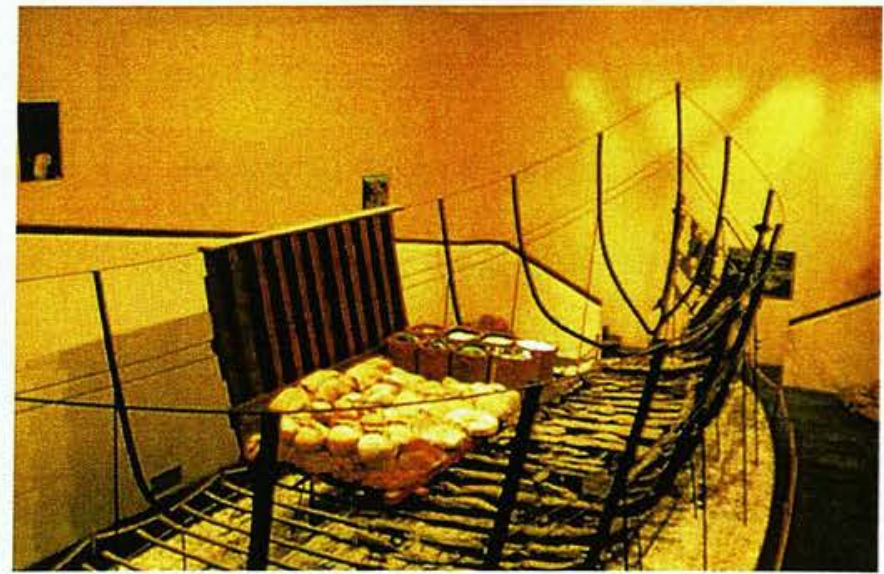

Figure 12 
suggested that it may have been a Byzantium ship departing from a harbour belonging to the Fatimids and was carrying glass chunks and scraps to be used in glass production ${ }^{33}$. The light which this wreck has spread onto Islamic glass art makes its collection one of the most important to be found in museums. As a result of many years of work and the painstaking assembly of thousands of glass pieces, it shows the existence of around two hundred different kinds of glass items. Amongst these pieces the visual aesthetics of decoration were clearly at the forefront. Etching, relief work, botanical, geometric and animal motifs decorated the works. Likewise some very modest and simple vessels, whose beauty is concealed behind their function and detail, were also found. As with figure 10a, figure 10b showing a beaker with a lion motif is a fine example, which shows the fussiness of decoration, the success of the balance and stylisation of the motif, together with the added dimension given to the motif by the skilful use of line. Amongst the other findings are jugs and cups, these are especially valuable and beautiful due to their attention to detail, such as the small extension on the handle to place the thumb against when pouring. (Figure 11 and detail) Each individual piece of the ship was reconstructed, and after being chemically treated was exhibited. It provides one of the oldest examples of modern ship making techniques ${ }^{34}$. (Figure 12) The product range is from tableware to ink containers. Although, it provides information about the period's production and decoration techniques, it also is a valuable source of information on the lifestyles of the period. As the author of Islamic Glass, Marilyn Jenkins points out; at the end of the day, this find has allowed the glass art of the early mediaeval period to be discussed with renewed confidence ${ }^{35}$. 
During the heydays of Islamic glass movements began in Venetian glass. The first written source in relation to Venetian glass making dates from the $11^{\text {th }}$ century $^{36}$. The production of this century was restricted to the manufacture of bottle making. The deepest interest in glass making came from the monasteries and created the seed for the development of glass making in this region. The inhabitants of monasteries admired the many different kinds of glass making that they witnessed from the East and they made efforts to transfer techniques and skills in this area, these efforts turned out to be the spark for the beginnings of Venetian glassmaking. Author, Karel Hetteš, speaks in relation to this subject:

"That the interest of the Monte Cassino Monastery was not merely theoretical can be supported by a report that in 1066 the monks there invited glassmakers from the Orient to introduce or improve the production of glass in their own monastery. ${ }^{37,}$

Even though Venetian glassmaking started by importing materials and employing glassmakers from the Orient, it improved in a short period of time and they soon developed their own style and techniques. Due to the possible threat of fire in the glass workshops in Venice, they moved to Murano Island and the glassmakers were banned from leaving the country in order to keep trade secrets safe. They went as far as calling Murano Island a "gilded cage"38. These are indications of the importance of glass and its dominant role in the economy of the region. Venetian glassmakers created extraordinary products

Hetteš, Karel, Old Venetian Glass, trans. Ota Vojtišek (London, 1960), p 12. Hetteš, p 13. 
belonging to a fantasy world, including dragons, unicorn and serpents, and produced goblets, vases and ewers for an almost fairytale landscape. (Figure 13)

Today, in glass literature, some glass making techniques are known by their Italian names, such as, filigrana glasses made by cane compositions like vetro a fili, vetro a retorti, vetro a reticello and millefiori, and mosaic glassmaking. Between 1400 and 1700, with the eye catching colours, forms and themes that they utilised, Venetian glass became dominant in world glassmaking. However, even though they were pressured to stay in the country, they left and spread their secrets of glassmaking to others, thus Venetian glass began to lose its popularity. At the end of the $16^{\text {th }}$ century, this spread was responsible for the introduction of Venetian style glassmaking (à la façon de Venise) in Austria, South Germany, Bohemia, The Netherlands, Belgium and Great Britain ${ }^{39}$. Author, Keith Middlemas, goes into detail about this dispersion and also mentions that over 150 years centres of glass production had formed in Antwerp, Liege, Nuremberg, Barcelona and Hall in Tyrol ${ }^{40}$. There is a fine example of façon de Venise production, seen here in figure 14 a horse and figured goblet made in Germany. As time passed, each country, using its own materials, brought about variations in the quality of the glass and as each country developed its own production in accordance with its own culture and tastes, the popularity of Venetian glass dwindled. When glass suitable for cutting and engraving was developed with the use of potassium obtained from forest plants ${ }^{41}$, Venetian glass, which had dominated the market for hundreds of years, was relegated to second place and Bohemian glass became the most

\footnotetext{
39 Dodsworth, Roger, Glass and Glassmaking (Great Britain, 1993), p 7.

40 Middlemas, Keith, Continental Coloured Glass (London, 1971), pp 30-31.

41 Mentasti, Rosa Barovier, Venetian Glass 1890-1990, trans. Matthew McParland (Verona, 1992), pp 8-9.
} 


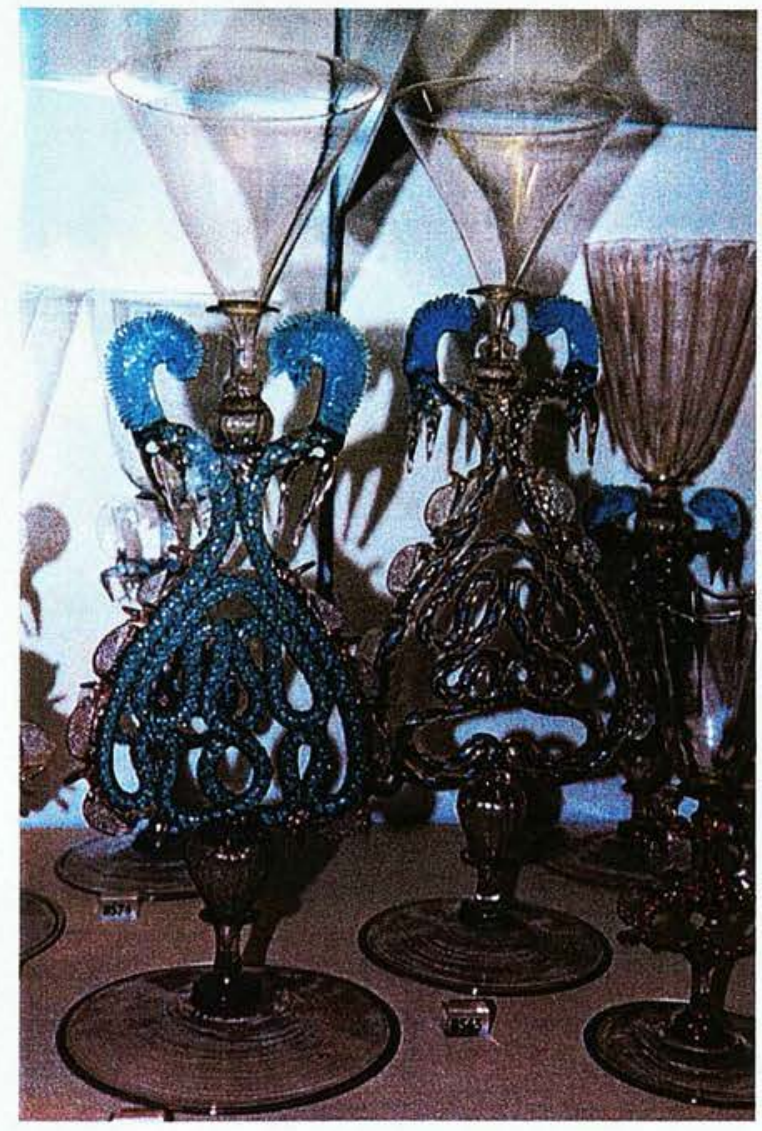

Figure 13

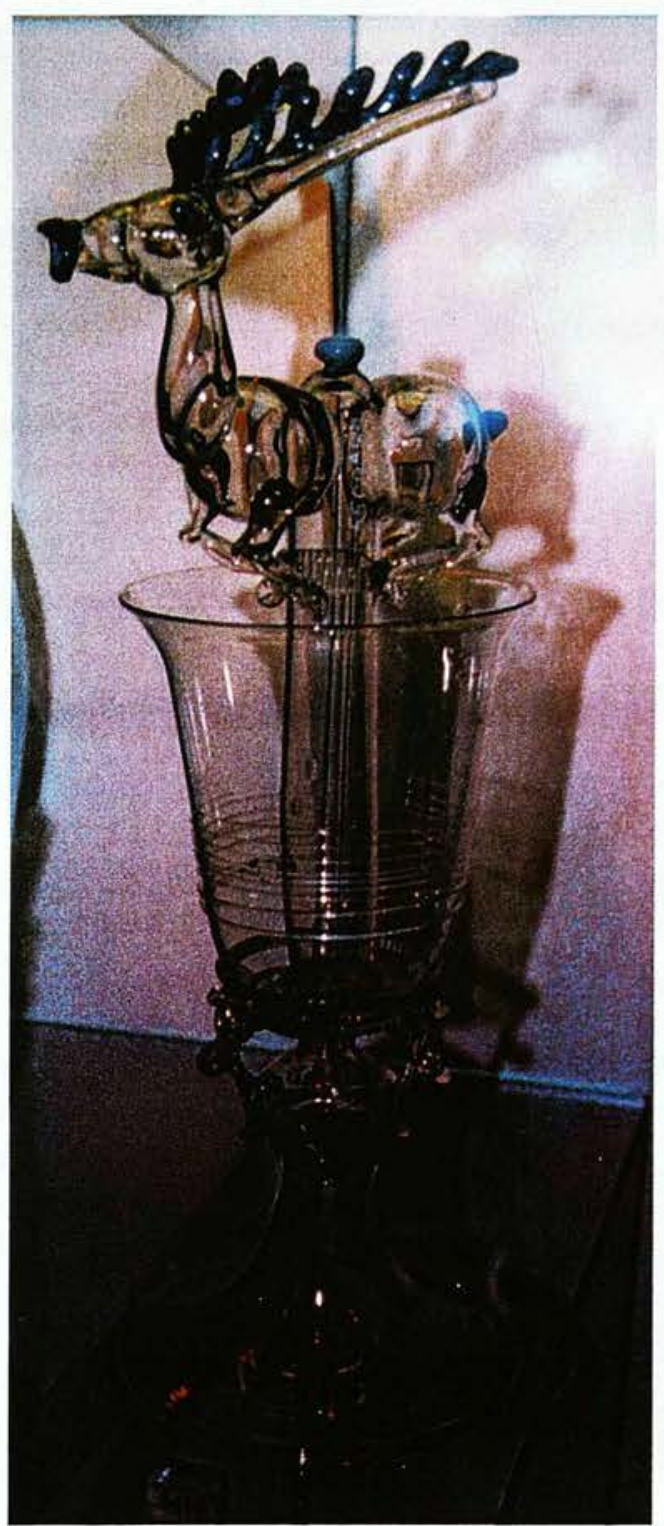

Figure 14 
prevalent. Potassium glass has a stronger structure and is also known as forest glass $^{42}$.

As Bohemian glass was felt to be more suitable for Baroque tastes it was preferred and this required the Venetian glassmakers to make an effort to save their techniques. Ironically, a studio established by a glass master, who worked in the glass studios in Prague, aimed to produce à la façon de Bohemia in Murano in 1730 . However, it was soon found to be unsuccessful and was closed down ${ }^{43}$. The supremacy of Bohemian glass on the world glass market increased over time and Bohemian glassmakers exported their products throughout the world. In the $18^{\text {th }}$ century, the demand in Turkey for Western style products increased, and Turkey also joined the number of countries importing from Bohemia. Likewise, for many years, similarly to Venice, Bohemian glassmakers produced Turkish style goods for export ${ }^{44}$.

The change which occurred in British glass in the $17^{\text {th }}$ century affected the world market, as Bohemian glass had previously. Leaded glass, suitable for cutting and known for its brilliancy was invented by George Ravenscroft (1618-1681) in 1676 , becoming a popular type of glass for glassmakers and consumers alike. The unusual brilliancy of this glass when etched with diamond tools or without any decoration, also the deep cutting methods, which produced a prismatic play of light, made British glass popular on the international market.

\footnotetext{
$42 \quad$ Cooke, Frederick, Glass (London, 1986), p 8.

43 Hetteš, p 30.

$44 \quad$ See Chapter 2. 4. The Unique Properties of Turkish Glass, p 97.
} 
Whilst glass in Europe and the East was changing and developing, and following the colonisation of America, German emigrants started glassmaking in New Jersey at the beginning of the $17^{\text {th }}$ century. Throughout the $18^{\text {th }}$ century they more or less monopolised glassmaking, and have continued to produce bottle and window glass. It was at the start of the $19^{\text {th }}$ century that glassmakers started to produce tableware out of their normal working hours and then proceeded to add this production to their regular commercial production. For speed of production mould blowing became a popular technique, however, the development of mechanical pressing machines in the 1820 s opened the way for American tableware to enter an era of true mass production ${ }^{45}$.

The industrial developments which occurred swiftly throughout the whole world during this period, allowed for large scale mechanisation and automation, likewise in the second half of the $19^{\text {th }}$ century art glass and glass design concepts began to form. Beginning with Emile Gallé (1846-1904), the glass designs created by designers for production by craftsmen in factories or studios, enabled the creation of a new understanding in glassmaking. Author, Chloe Zerwick, mentions that this new understanding had a big effect on glass art; it is as important as the discovery of glass blowing ${ }^{46}$. In Galle's art he believes the power of nature and its beauty is a reflection of God and the value given to every individual element, which exists in it, is placed at the forefront of his work. The shades of colour and his excellent use of soft lines are sometimes realistic, sometimes romantic and frequently enchanting, these underpin the main philosophies of his work. As he wrote on his studio door: 
"Our roots are in the depth of the woods-on the banks of streams, among the mosses. $^{47 "}$

The influence of Gallé was evident on both sides of the Atlantic, on the one side in the breathtaking works of Louis Comfort Tiffany (1848-1933), and on the other in the works of Rene Lalique (1860-1945). Lalique began with jewellery designing, before progressing to perfume bottles, until eventually his beautiful designs became influential on the world stage. In a similar vein many other artists have been affected by these changes and developments.

\section{CONCLUSION}

In our lives glass has the appearance of always having existed and naturally enough it seems it will continue to always be there. With hindsight, the adventure clearly started with a rock mineral converted into a functional object, showing that in every step of this journey the efforts of mankind have been to produce the best and the most beautiful. As a tiny spot in the universe, and relatively experiencing only a second's worth of living, glass and the interaction it has with other materials forms an inconspicuous part of daily life. This incredible material will continue to develop in the future with the respect that it has been shown in the past. It will inspire both industry and artists and will continue to serve the human race in varying forms. 


\section{TURKISH GLASSMAKING}

\section{PREFACE}

Turkish glassmaking is solidly rooted in history, it is supported by traditional and cultural elements and has developed over a period spanning hundreds of years. This chapter, in conjunction with analysing Turkish glass art history over various periods, Seljuk, Ottoman and Bosphorus, aims to consider the defining qualities of Turkish glass. The production methods which are made in accordance with tradition, modern glass making in Turkey, contemporary glass art and glass art education in institutions of higher learning will be discussed together with examples from my personal experience. 
2. 1.

GLASS IN TURKISH ARCHITECTURE

2. 2.

GLASSMAKING IN ANATOLIA

2. 2. 1. SELJUK GLASS (1038-1308)

2. 2. 2. OTTOMAN GLASS (1281-1923)

2. 2. 3. BOSPHORUS GLASS / BEYKOZWARE

2. 3. THE CULTURAL ASPECTS OF TRADITIONAL TURKISH GLASSMAKING

2. 3. 1. GLASS BEAD MAKING

80

2. 3. 2. PRAYER BEADS (TESPIH)

2. 3. 3. REVERSE PAINTING ON GLASS

2. 4. THE UNIQUE PROPERTIES OF TURKISH GLASS

2. 5. NEW DIRECTIONS IN GLASSMAKING AFTER THE FORMATION OF TURKISH REPUBLIC

THE FIRST TURKISH GLASS WORKS “ TÜRK ŞiŞE VE CAM

FABRIKALARI A. Ş. / PAŞABAHÇE"

2. 6. TURKISH CONTEMPORARY GLASS ART AND

2. 6. 1. TURKISH GLASS ART EDUCATION: THE BACKGROUND

2. 6. 2. LOOKING AT GLASS DESIGN AND DESIGNER

THE INFLUENCE OF 'ÖNDER KÜÇÜKERMAN' ON GLASS ART IN TURKEY 


\section{1. HISTORY OF TURKISH GLASS}

The history of glass workmanship amongst Turkish crafts goes back to the XII and XIII centuries and unlike other traditional crafts such as bookbinding, cotton printing, bow making ${ }^{48}$, sadlery and woodcarving which have been lost over the years, glassmaking has continued to exist and maintained an important position throughout its production in Turkey. Due to glass being a fragile material, its resistance to the influences of time is reduced. The process of melting and therefore the recycling properties of glass have prevented many objects from reaching the present day. In spite of these handicaps, those works which have survived from the Seljuk and Ottoman periods give us enough information about Turkish glass art, how they were used and the methods of production. The method of manufacturing used in both Seljuk and Ottoman glassware is the technique of blowing. By this method of blowing hot glass by a blowing iron, both tableware and window glass were produced.

Research into the history of the Ottoman Empire makes it is possible to follow the continuous development of glass art. The existence of glass workshops at, Eğrikapı, Balat, Bakırköy and Ayvansaray in the 1600s, the interest of the monarchy in glass production, the protection of the rights of those involved in the glass business, regulations regarding glass importation, limitations on glass raw material exportation and the interest shown in quality are all remarkable. Sultan Mahmoud I (reign 1730-1754) $)^{49}$ brought crystal masters from France ${ }^{50}$ in

\footnotetext{
$48 \quad$ Pallis, Alexander, In The Days of The Janissararies (London, 1951), p 154.

49 For the chronological list of Turkish Seljuk rulers and Ottoman Sultans, see Appendix F.

50 Şentürk, Şennur and Istanbulluoğlu, Ari, Beykoz Camları/Beykoz Glass, A catalogue to accompany the exhibition "Beykoz Glass" at Yapı Kredi Vedat Nedim Tör Museum (Istanbul, 1997), p 8.
} 
the mid $18^{\text {th }}$ century and by the end of this century the glass workshops were moved to surround the Eğrikapı/Tekfur Palace by Sultan Mustafa III (reign 1757-1774) who also reintroduced some regulations for glass making. These are valuable indicators of the interest of the Ottoman Empire in glass production. Afterwards, the visit of Derviş Mehmed Dede to Italy and his subsequent visit to the workshops at Beykoz, Paşabahçe, Çubuklu and Incirliköy contributed a different taste and style to Turkish glass art. During this period the Ottoman Empire used Beykoz products as a reflection of the level of development of the Empire and sent these products to international industry exhibitions to represent the Palace. The most important of these exhibitions was "The Great Exhibition of the Works of Industry of All Nations ${ }^{51 "}$. (Figures 15, 16 and 17) On the first of May 1851, Queen Victoria opened the Exhibition in the Crystal Palace in London in which The Ottoman Empire displayed 3300 objects. ${ }^{52}$ This Exhibition displayed the latest developments in the production of many nations and was important for Turkey as it showed that it possessed both the raw materials to use in its domestic production and the capability to utilise the necessary production methods. All the goods which Turkey displayed ${ }^{53}$ in the exhibition, silk, cotton, raw materials, metal goods and glass were produced and developed with the support of the Sultan. The most popular glass objects of

\footnotetext{
51 Spillman, Jane Shadel, Glass from World's Fairs 1851-1904, The Corning Museum of Glass (Corning; New York, 1986), p 9.

52 Official Descriptive and Illustrated Catalogue of Great Exhibition of the Works of Industry of All Nations 1851, Spicer Brothers (London, 1851), Vol. III, p 1387.

$53 \quad$ Illustrated London News, Supplement (Gratis) to the Illustrated London News (Saturday, March 8, 1851), Allotments of space to Foreign Countries;The goods displayed in the Exhibition by Turkey were on the north side of the central avenue, with a frontage thereto of 24 feet, and extending back to the refreshment court at the north end of transept; having an area of 7488 feet, with 1344 feet in the gallery above; total 8832 feet.
} 


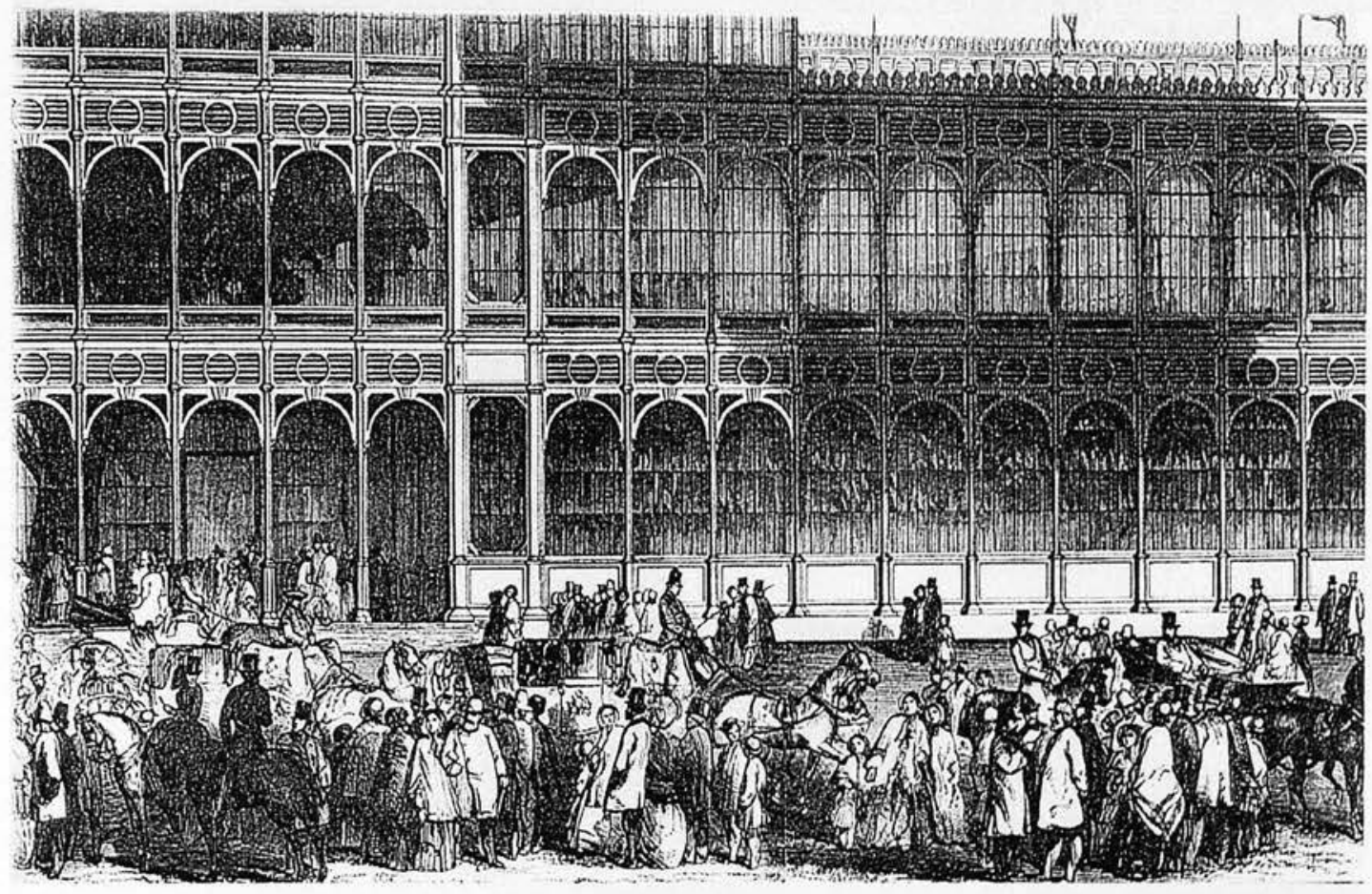

Figure 15

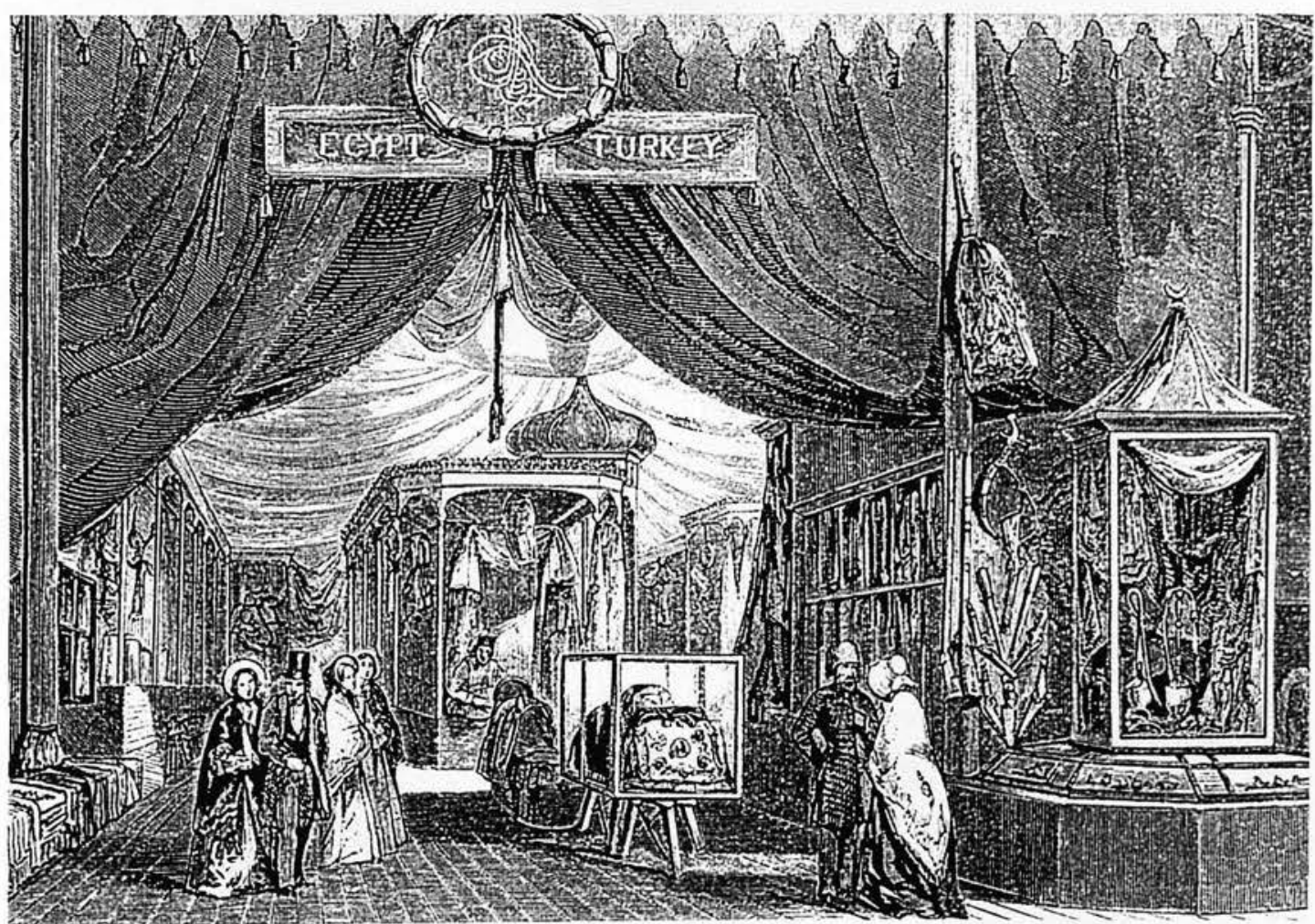

Figure 16 


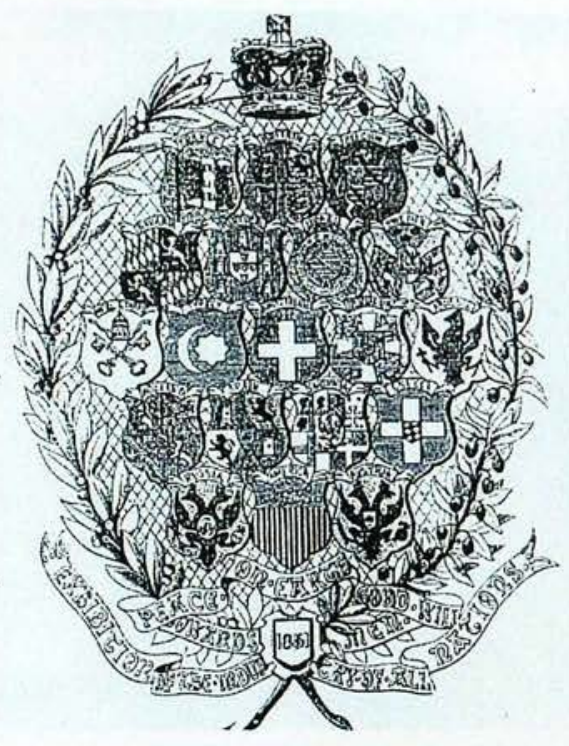

Figure 17

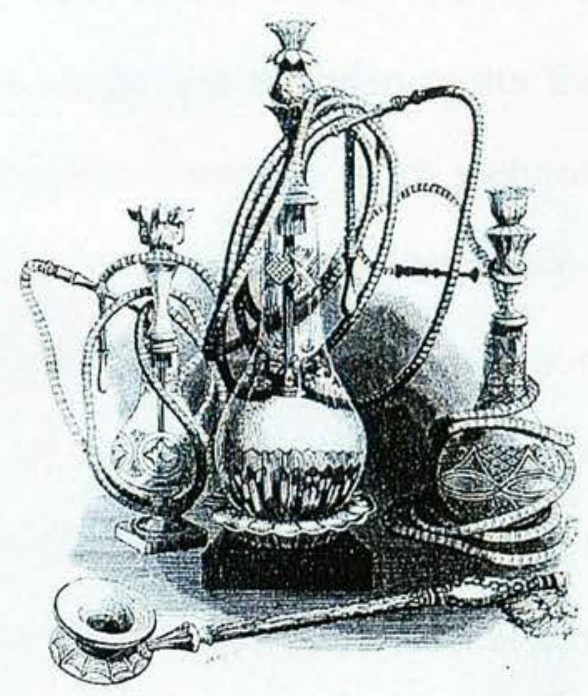

Figure 18

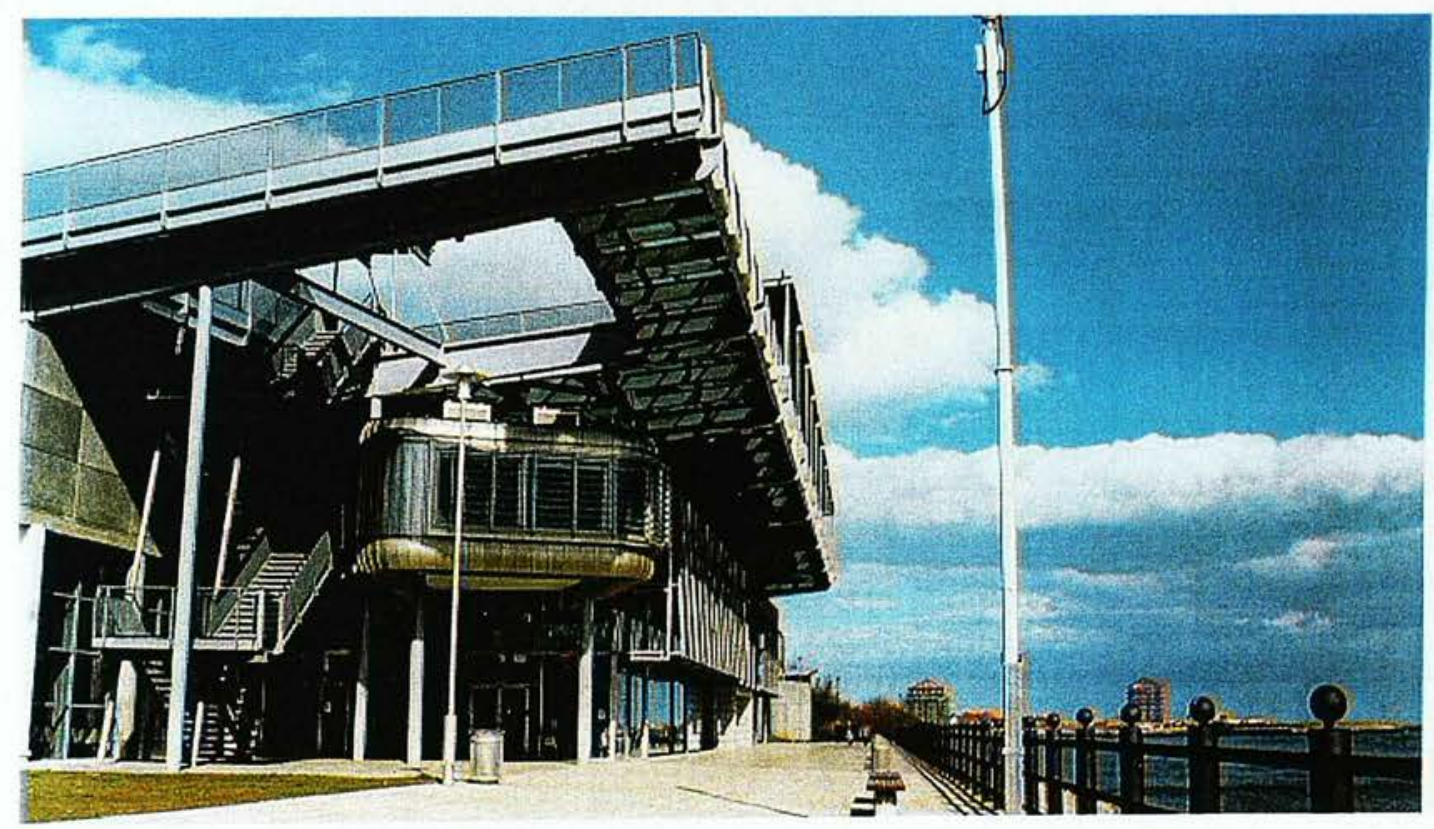

Figure 19 (a)

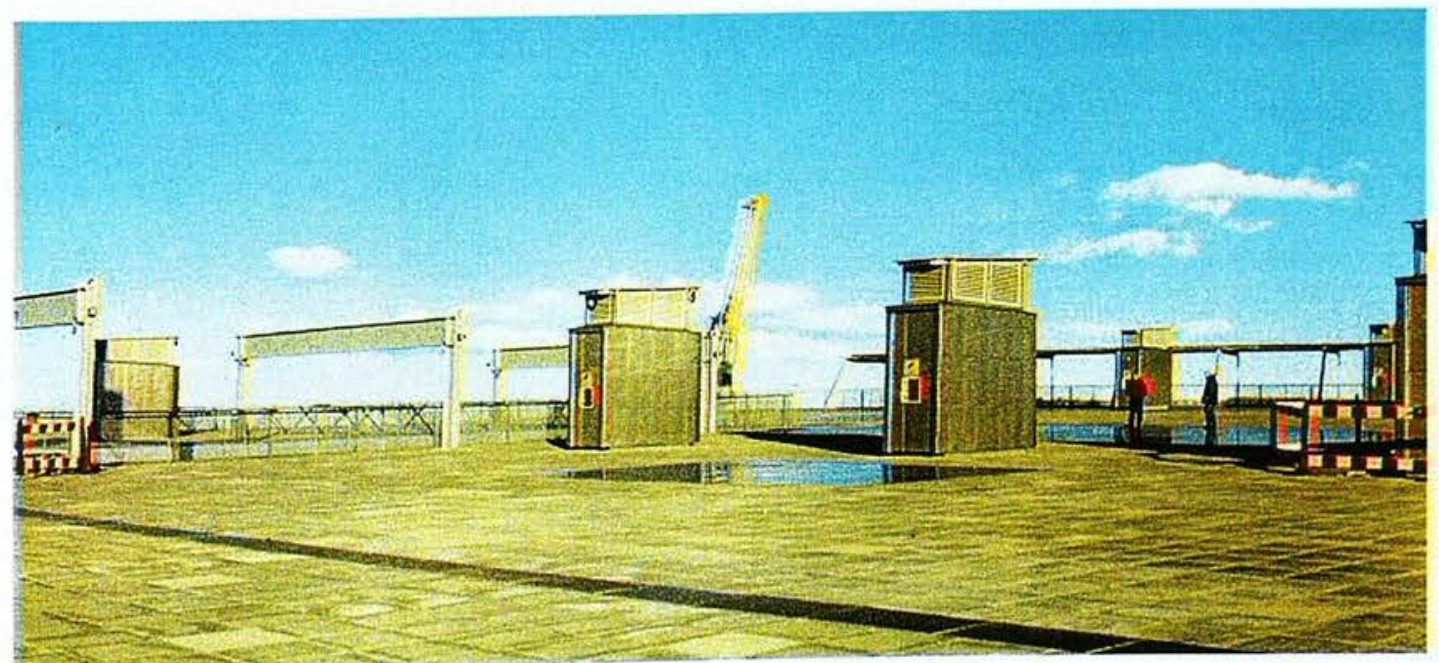

Figure $19(b)$ 
that time were nargiles ${ }^{54}$, hoşaf $f^{55}$ and şerbet bowls ${ }^{56}$, saucers and jugs of which about twenty were displayed. These caught the attention of the Exhibition organisers who chose them out of thousands of exhibits to be pictured in the Exhibition Catalogue. (Figure 18) At the same time, the Exhibition Committee gave a medal to the management of the factory in respect of their success ${ }^{57}$. (Details are given in Appendix A, for a list of glassware sent for this Exhibition by the Central Committee of Constantinople, on the instructions of the Ministry of Commerce ${ }^{58}$ ). During this period, objects produced by traditional production methods, which reflected the cultural structure of a nation, were not as popular as they had been and were supposed not to be the sign of a developed country. However the objects which Turkey displayed at the Exhibition skilfully and beautifully reflected cultural characteristics i.e. nargiles, hoşaf and şerbet bowls and as such they stood out from the rest.

The production of glass is inextricably connected with tradition and this tradition is amalgamated with society's creativeness, this results in glass finding a niche for itself in many places and fields. Turkish glass art, in a wheel of development and change, has found itself a position in every period. From Seljuks to the Ottomans, from the Ottomans until it arrives at present day production and all its developments indicate how well Turkish glass constantly pushes boundaries of endeavour in glass making.

\footnotetext{
$54 \quad$ English: Hookah, smoking-pipe.

55 Hoşaf - khushaf. Literally: Pleasant Water. Hoşaf is similar to şerbet but less sweeter and less condensed than şerbet.

56 Pallis, p 140, "Rest to the soul and blood to the body".

57 Bayraktar, Nedret, 'Osmanlı Devri Cam Sanatı', Paşabahçe (March 1985), Year 1, No. $3, \mathrm{p} 3$.

Official Descriptive and Illustrated Catalogue of Great Exhibition of the Works of Industry of All Nations 1851, p 1390.
} 


\section{GLASS IN TURKISH ARCHITECTURE}

For the Ottomans, as for the Seljuks, architecture was of great importance. This dynasty was celebrated in and adorned by Mimar Sinan's (1491-1588) magnificent works, which were an ostentatious symbol of the living dynamism of each period. In Ottoman architecture, in particular, ideals of vastness and splendour were at the forefront, they combined fine decorative detail with greatness of scale. In their buildings there is no denying that they used glass to great effect, giving the appearance of space and size and creating great depth. Often the best results glass provides are when it is used to expand the interior space until it takes on the airy qualities of the outside world. Andrew Moor describes the role of glass in architecture in relation to this subject:

"A glass window can powerfully change the external appearance of a building, particularly at night. It can obscure ugly external views from inside a building or separate internal spaces physically but not visually. It can enclose a space or soften the glare of sunlight. ${ }^{59 "}$

Glass used in architecture can add a breath taking quality to a building, although changes in design understanding and technical developments have added extra value to the glass nowadays, the effect on contemporary architecture is not ostensibly different to that of the past. For example at Sunderland Glass Centre the glass roof plays an important role in the architectural design of the building and as one of its many attractions it supplies

$59 \quad$ Moor, Andrew, Architectural Glass Art - Form and technique in contemporary glass (London, 1997), p 9. 
an interaction between the individual and the building. From both inside and out it declares the concept of expansion through its volume. (Figures $19 \mathrm{a} / \mathrm{b}$ ) Thus, they have followed in the footsteps of King Solomon ${ }^{60}$.

In Ottoman architecture the lightness produced by glass is in stark contrast with the buildings' strong and thick walls. The side windows invite fresh air $^{61}$ in as they open and close and provide a different light altogether with their various textures and forms. Likewise the upper windows provide another kind of atmosphere through an expansion of the building into the heavens and infinity. This direct acceptance of light fills the space with the natural play of light and shade and the Ottomans frequently made beautiful use of the richness of this quality.

The poetry in the description of light in architecture can be seen in the Ottomans' attentive and detailed approach to every aspect of life. Its consequences can also be seen in Islam. Taking pleasure from life and living every moment to the full was the philosophy of the Ottomans for the majority of their dynasty. Likewise when it comes to design and decoration they were careful to attempt to fulfil all the human senses. Even in the decoration of gravestones, prepared following the end of an earthly life and going to an unknown period, they created incredibly poetic works with symbols and forms ${ }^{62}$. (Figure 20) This kind of attention to detail and the importance placed on its

60 Zerwick, p 18. "It has been said that when the Queen of Sheba visited King Solomon, she saw in the courtyard of his palace what she believed to be a pool of water. Accordingly, she tucked up her skirts so as not to wet them when she crossed, thereby revealing her regal limbs. Solomon then enlightened her by saying; This is the palace evenly floored with glass"

61 Goodwin, Godfrey, Sinan: Ottoman Architecture and Its Values Today (London, 1993), p 66 .

Inman, Nick, Ed., Istanbul (London, 1998), p 121. "The gravestones within it were often lavishly symbolic: from their decoration you can tell the sex, occupation, rank and even the number of children of the deceased." 

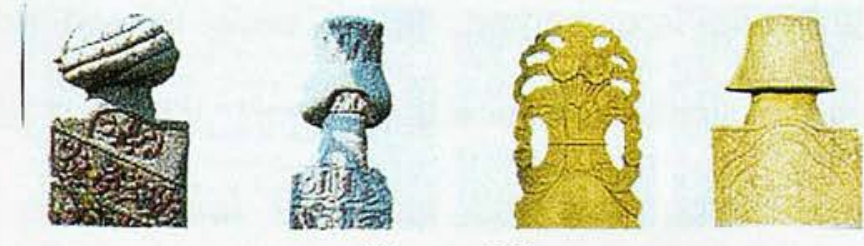

Figure 20

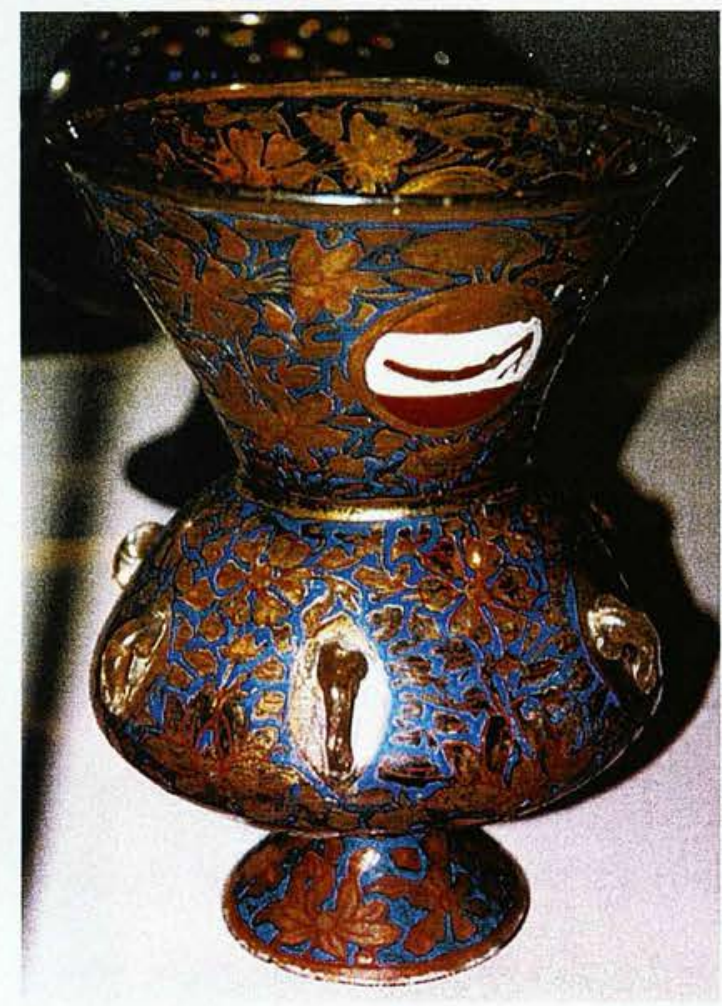

Figure 21 (a)

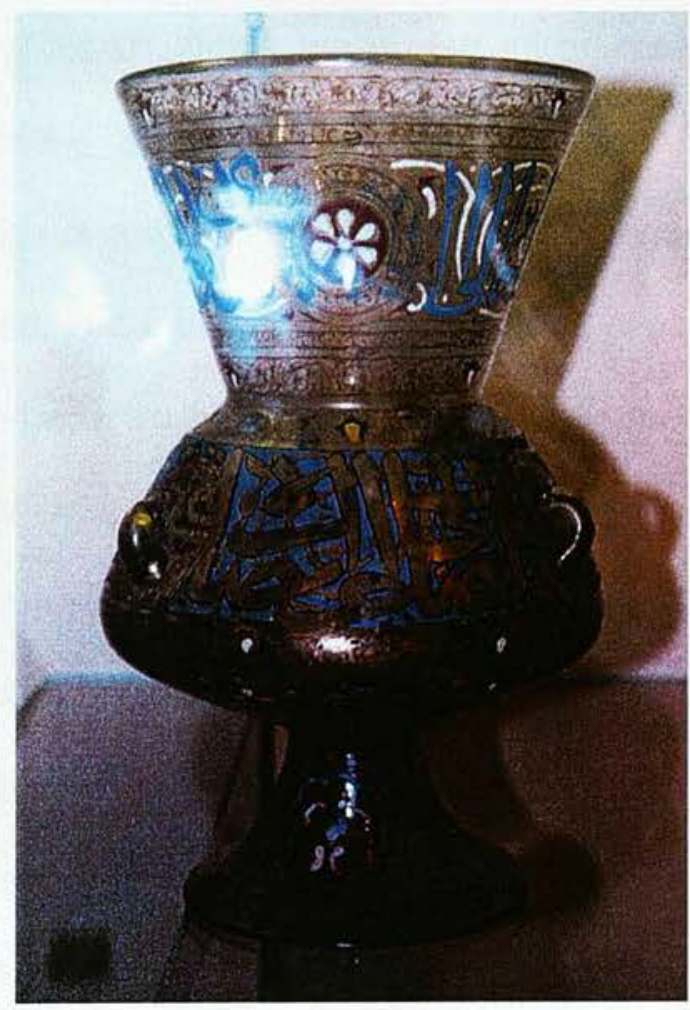

Figure $21(b)$

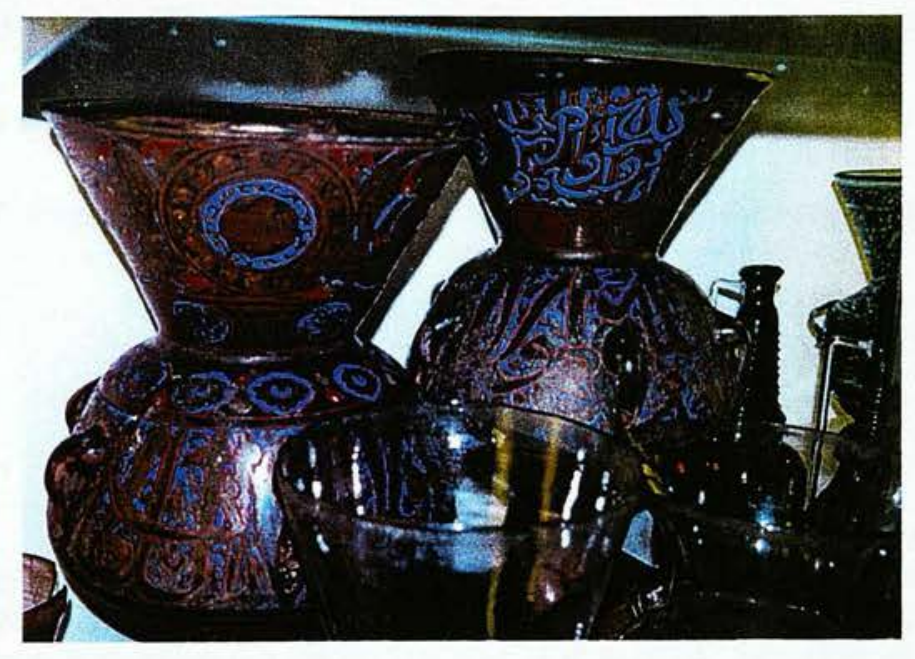

Figure 21 (c)

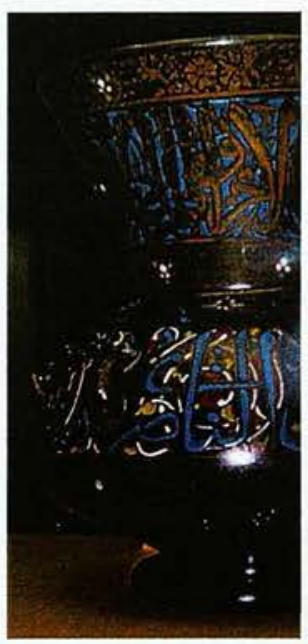

Figure 21 (d) 
application, coupled with their creative, aesthetic and mellifluous imaginations meant that the use of glass as an architectural element in buildings was accepted quite naturally. However the use of glass in architecture was not restricted to architectural elements but was primarily involved with the introduction and spread of light through buildings. For instance alongside the use of ceramic and metal oil lamps, glass oil lamps were also introduced in mosques. The best examples of these are from the $14^{\text {th }}$ century. Set comfortably on a wide and bulbous body is a thick neck with a broad opening, underneath, and balancing both of these, is an amazingly delicate foot. (Figures $21 \mathrm{a} / \mathrm{b} / \mathrm{c} / \mathrm{d})$ The combination of these parts came about without the use of contemporary design rules but is still, nevertheless, beautifully well proportioned. The restrictions on the reproduction of the human figure in Islam have entailed the application of plant and geometric motifs on glass oil lamps. The colours are mostly translucent with hues of green or blue, slightly "dirty" in shade. Gilt and enamel are the main sources of decoration. Rich, harmonious and rhythmic decorations adorn them alongside quotations from the Koran. The amalgamation of the calligraphy and the motifs gives these pieces their distinct harmony. The glass loops that delicately pour down from the main body are used to suspend the lamp. Although these lamps are functional, they make a far greater contribution to the mosque by enhancing its spiritual ambience ${ }^{63}$.

\footnotetext{
63 Taqî-ud-Dîn Al-Hilâlî, Muhammad and Khân, Muhammad Muhsin, Translation of the meanings of The Noble Qur'an in the English language (Madinah, K. S. A., ND), p 472.

"Allah is the Light of the heavens and the earth. The parable of His Light is as (if there were) a niche and within it a lamp: the lamp is in a glass, the glass as it were a brilliant star, lit from a blessed tree, an olive, neither of the east (i. e. neither it gets sun rays only in the morning) nor of the west (i. e. nor it gets sun-rays only in the afternoon, but it is exposed to the sun all day long), whose oil would almost glow forth (of itself), though no fire touched it. Light upon Light! Allah guides to His Light whom He wills. And Allah sets forth parables for mankind, and Allah is AllKnower of everything." Sûrah An-Nûr, 24:35.
} 
The first example of the use of glass in Islamic architecture was found with the production of "filgözü 64 " in the Seljuk period. As in every part of the world during the 16th century the Ottomans had difficulties in producing window glass, although they had not yet perfected the skills, this did not deter them from producing glass. On the contrary they pushed their capabilities to the limits in the production of glass and one solution they found had been previously discovered centuries ago by European glassmakers producing stained glass windows and they learned to appreciate each and every small glass piece. An enchanting example of this type of combination of glass in stained glass windows is to be found in Paris, France in Notre Dame Cathedral. (Figures 22 a/b/c) These very colourful and figurative rose windows made in the $13^{\text {th }}$ century, project colourful shafts of light across the Cathedral making the outwardly domineering walls of the building seem less dense and commanding. Without using lead, the Ottoman glassmakers used blowing methods to produce small window glass pieces and placed them in plaster constructions. These windows can be viewed $d^{65}$ to best effect from an angle of $45^{\circ}$. By combining small shards of glass together they covered large areas successfully. However, as well as making their own glass, they also imported glass from Venice ${ }^{66}$ especially when they needed to cover large areas. It is possible to find beautiful examples of this application in some buildings belonging to this period, for example, in 1580 Mimar Sinan built Şemsi Paşa Mosque for Şemsi Ahmed Paşa, and again in 1547-48 he built Iskele Mosque for Mihrimah Sultan both of which provide examples of this technique which are visible today. (Figures $23 \mathrm{a} / \mathrm{b}, 24 \mathrm{a} / \mathrm{b}$ and 25 a/b)

\footnotetext{
$64 \quad$ See Chapter 2. 2. 1. Seljuk Glass, p 49.

65 Goodwin, Godfrey, Islamic Architecture: Ottoman Turkey (London, 1977), p 108.

66 Goodwin, Godfrey, A History of Ottoman Architecture (London, 1971), p 113.
} 


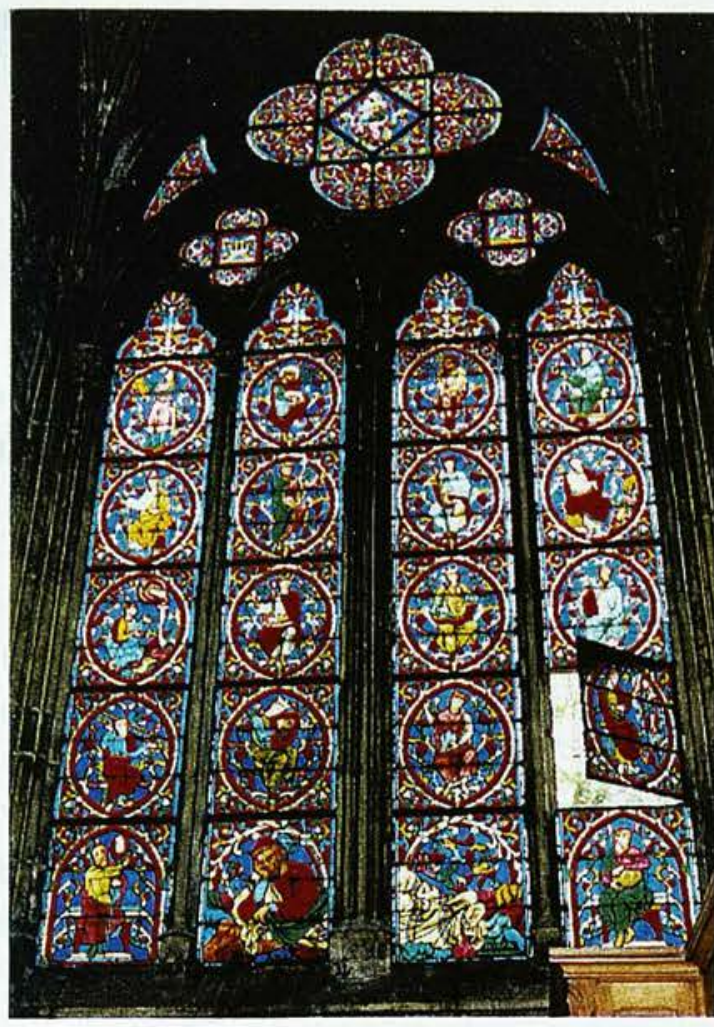

Figure 22 (a)

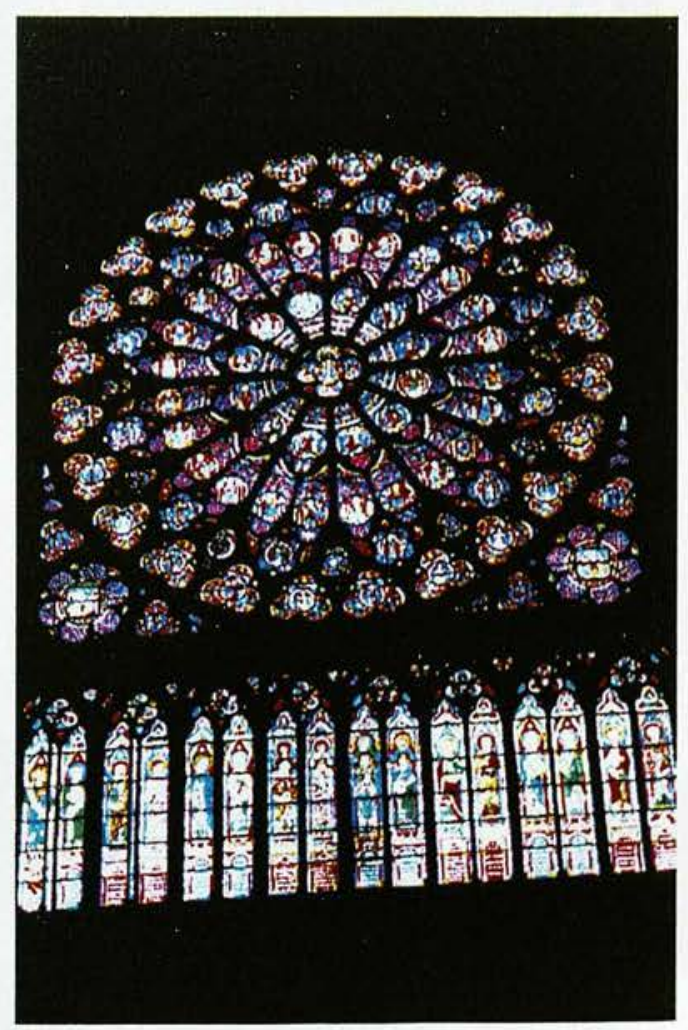

Figure 22 (b)

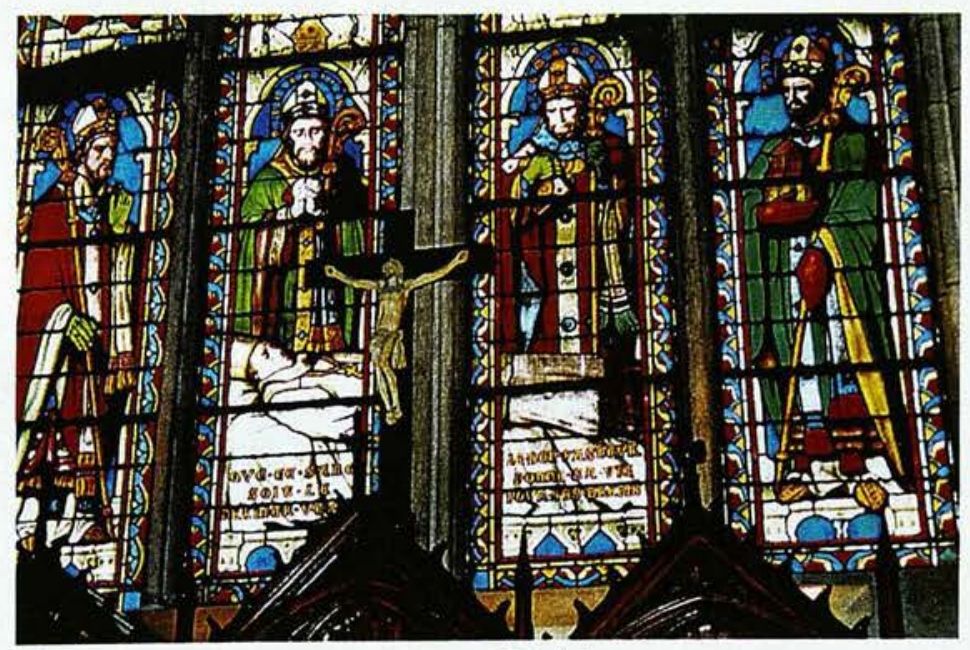

Figure 22 (c) 


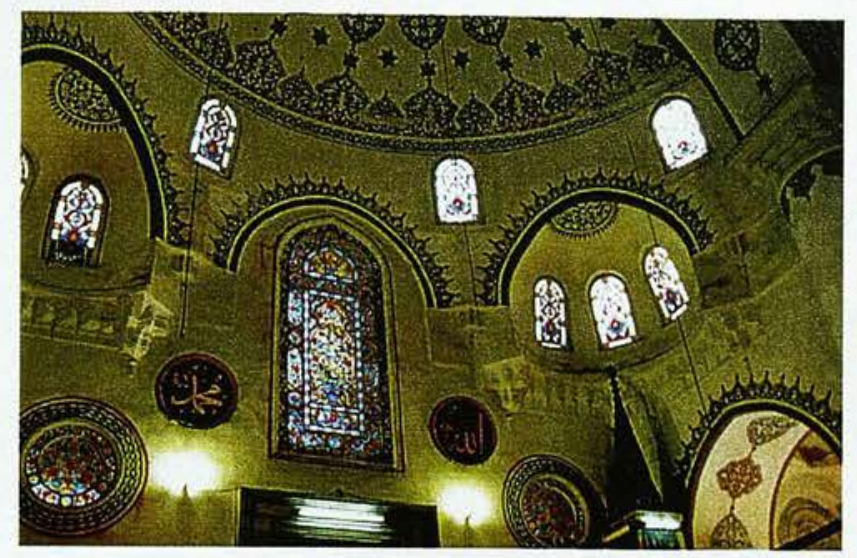

Figure 23 (a)

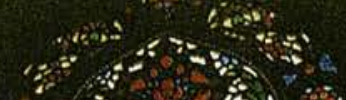

h.s.

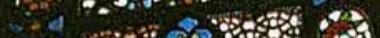

स\%

isi \&

D) 1 of

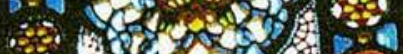

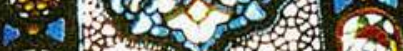

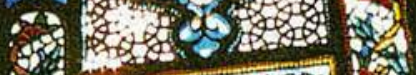

Tef

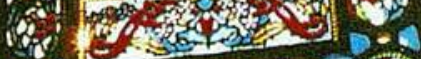

D. 1 (5)

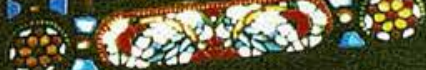

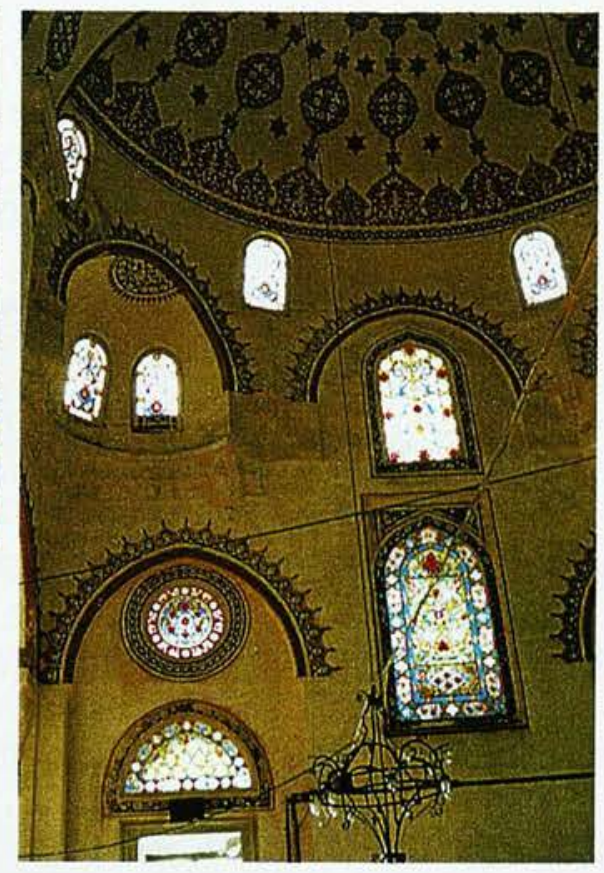

Figure 23 (b)

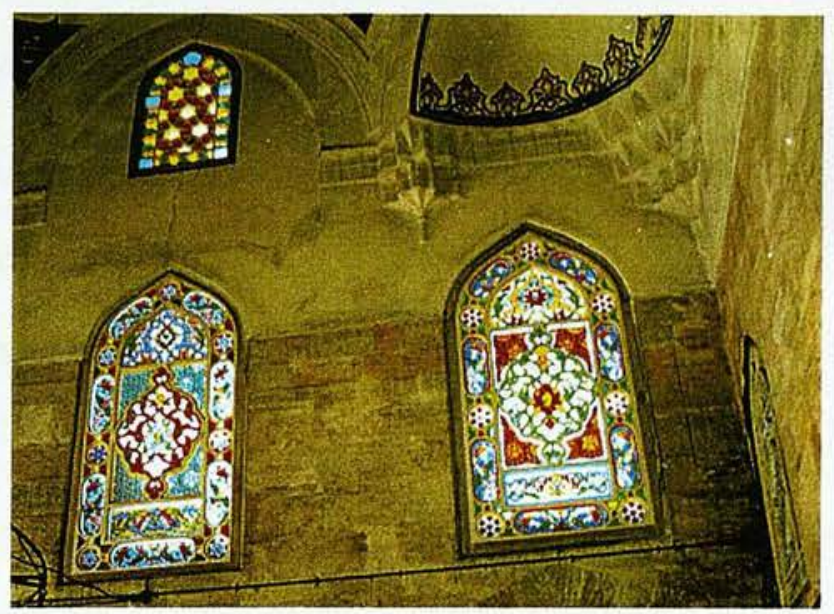

Figure 24 (b)

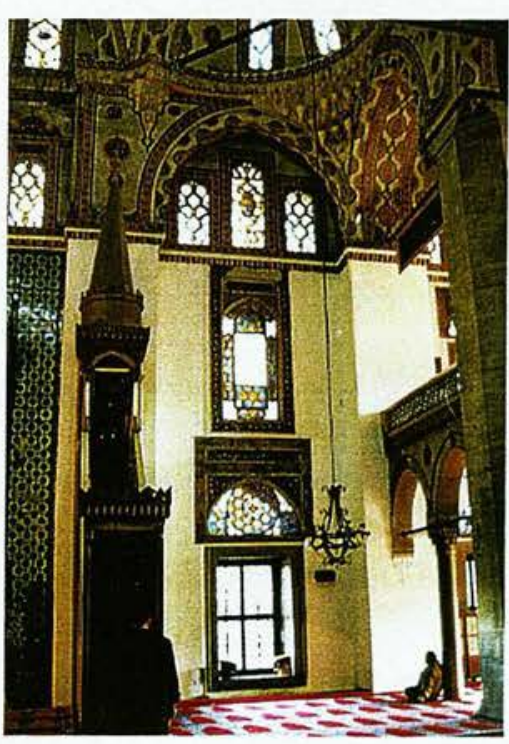

Figure 25 (b)

Figure 25 (a) 
At the same time, glass masters wanting to show off their skills and success at every occasion, as can be seen in the miniatures depicted in Surname-i Hümayun ${ }^{67} c 1585$, where they were parading their skills to the Sultan Murad III, and like all craftsmen they were very proud and held their works in high esteem. (Figure 26)

Window glassmaking, especially in the Ottoman period, was given great importance and the makers took great care and attention of this aspect for the best part of 600 years. Likewise, they protected their upper windows with a second layer of glass to provide durability. Following the Industrial Revolution they could not ensure protection for traditional glass making as more transparent and durable glass became widely available, such as different varieties of window glass. The developments in European glassmaking directly changed the use of glass in architecture and brought to end a tradition whilst at the same time directing glassmaking towards new styles.

In Turkish architecture the use of glass was not restricted to windows, regardless of window glass dominating production, in the last period of the Ottoman Empire in particular, one can see a working towards a different use of glass in architecture. It is possible to come across the most beautiful example of this different use in Dolmabahçe Palace which stands in one of the most important sites on the Bosphorus in Istanbul. In its construction it used some of the most advanced techniques and materials available in the $1850 \mathrm{~s}$. The mentality of the Ottomans, to be fond of detail and exceptional features, can be observed in the construction of the Palace. The glass used in the decoration of 

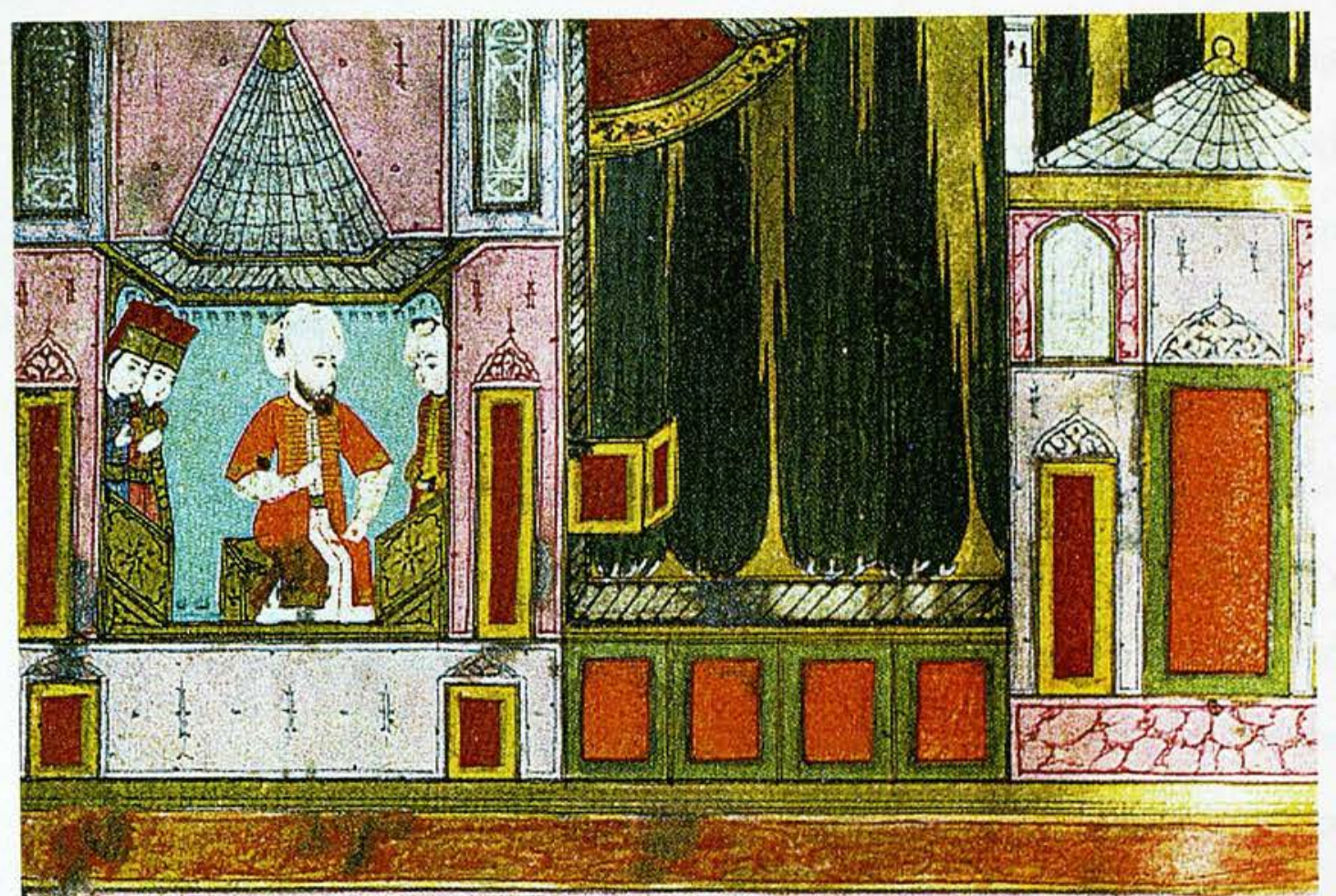

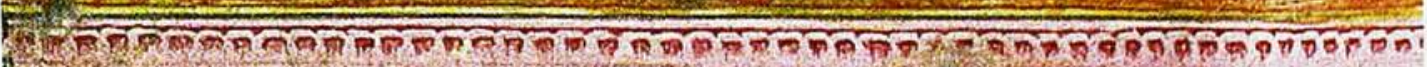

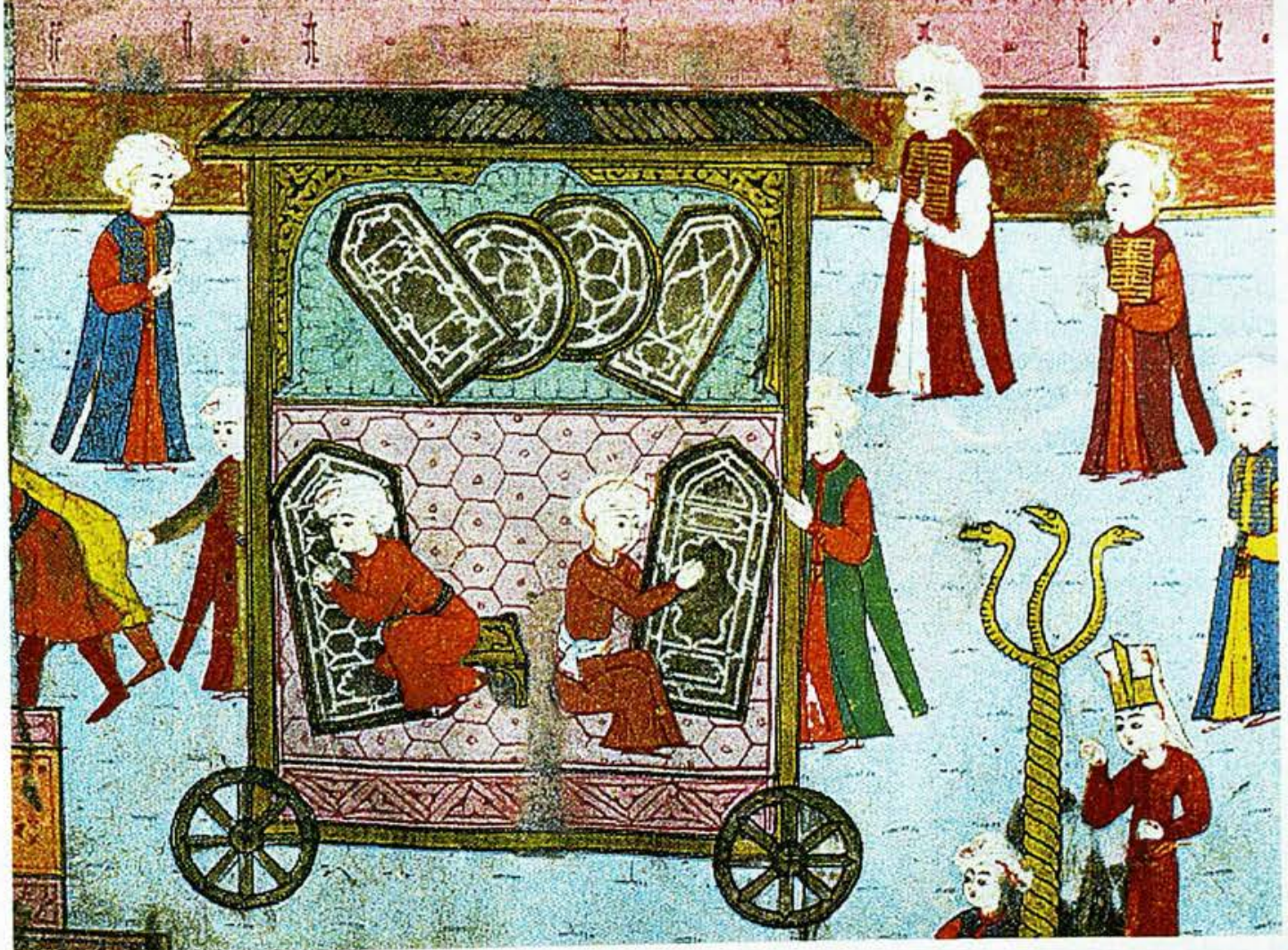

Figure 26 
the Palace bears the names of some of the most famous producers in the world: A Baccarat Crystal staircase (Figures 27 a/b/c), a giant Frederick Rixon, designed chandelier, from London, weighing 4.5 tons, a Gaveau, Paris-made crystal piano and chair (Figure 28), together with many other chandeliers and hundreds of candelabras ${ }^{68}$. (Figures $29 \mathrm{a} / \mathrm{b} / \mathrm{c} / \mathrm{d}$ ) Considering the importance given to the construction and decoration of the Palace, the hundreds of glorious works of art it contained had to be the most distinguished examples of their craft. It was built for the Sultan to live in, in order to replace the Topkapı Palace in position and was to be the centre for the imperial residence ${ }^{69}$. Therefore, every individual work of art reflected the might of their period from both an artistic and technical angle. This is displayed by the crystal cut staircase which combines the technical achievements of this time with the visually decorative qualities of glass. Regarding this subject, in an article by Önder Küçükerman, he states that:

"The staircase is an outstanding manifestation of the combined power of art and technology, because although it was not technically difficult to produce the glass components themselves, to conceive such a new application in the architectural context was a spectacular design achievement. ${ }^{70,}$

As a matter of fact, the use of materials in various different contexts is a common occurrence today. For example, the staircase in the Victoria and Albert

$68 \quad$ Küçükerman, Önder, "Glass Galore at Dolmabahçe Palace-Dolmabahçe Sarayı ve Ünlü Kristalleri", Skylife, (Turkish/English) (November 1997), p 49 and 58. "Apart from this giant, the palace was lit by 82 chandeliers-52 crystal and 30 bronze, 142 pendant ceiling lights, and nearly four hundred standard candelabra - 60 of crystal and 334 of other materials."

$69 \quad$ Freely, John, Inside the Seraglio/Private Lives of the Sultans in Istanbul (London, New York, Victoria, Ontario, Auckland, 1999), p 258.

Küçükerman, p 57. 


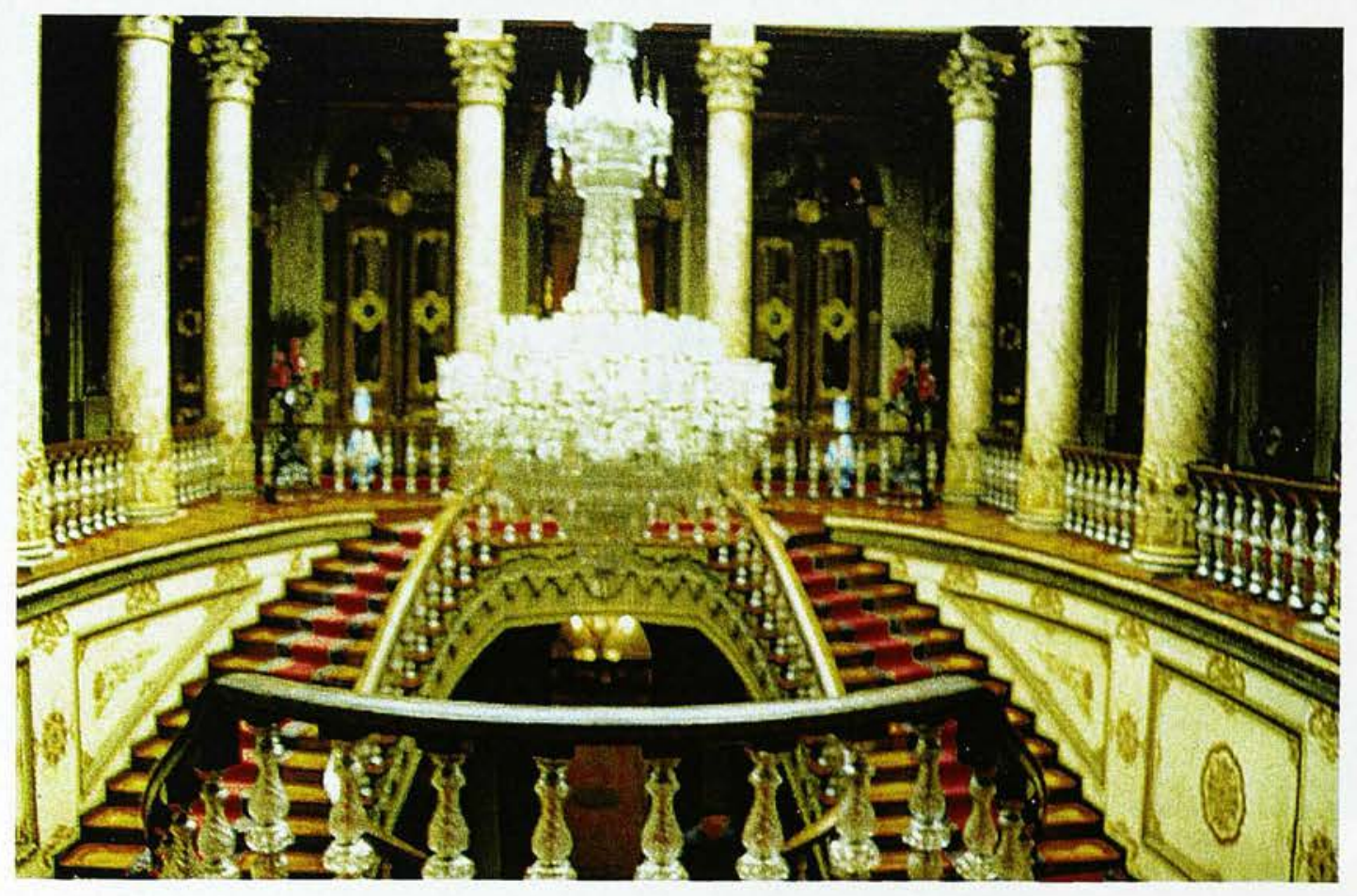

Figure 27 (a)

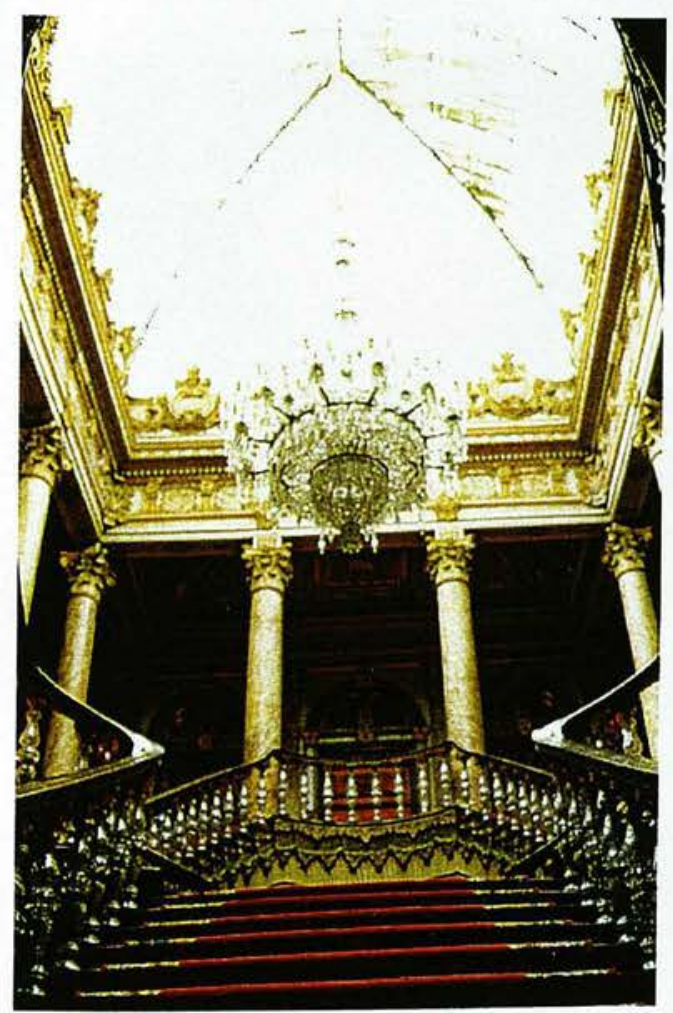

Figure 27 (b)

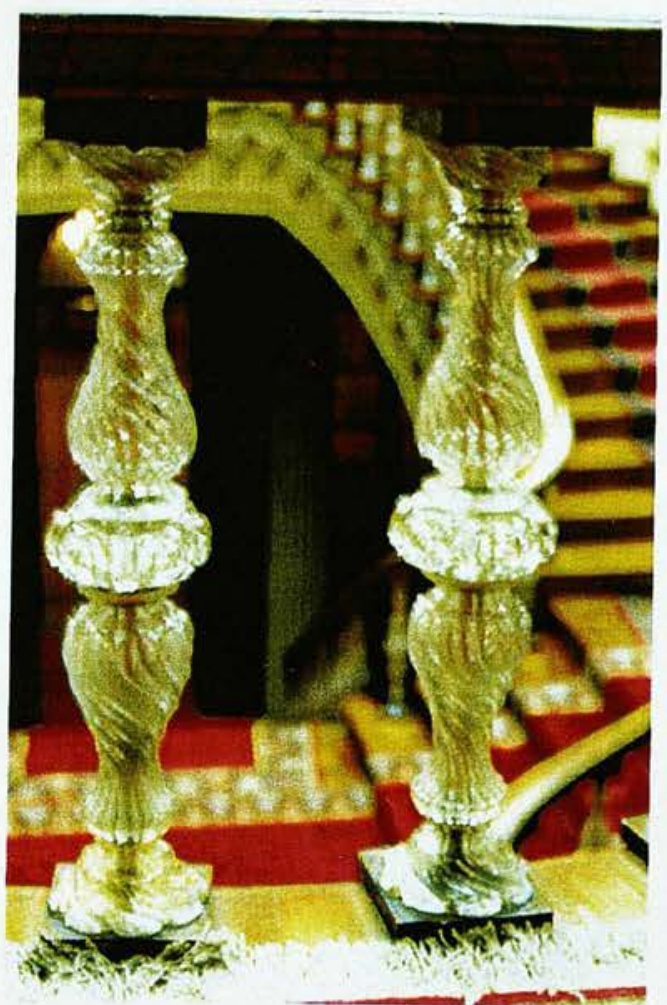

Figure 27 (c) 


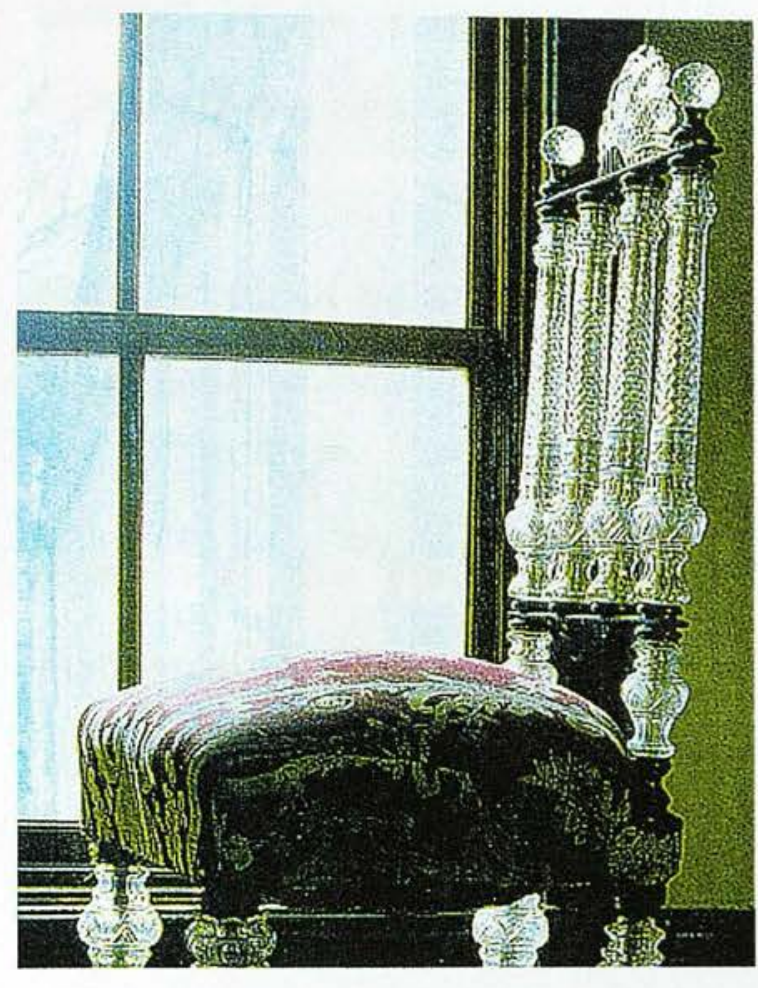

Figure 28

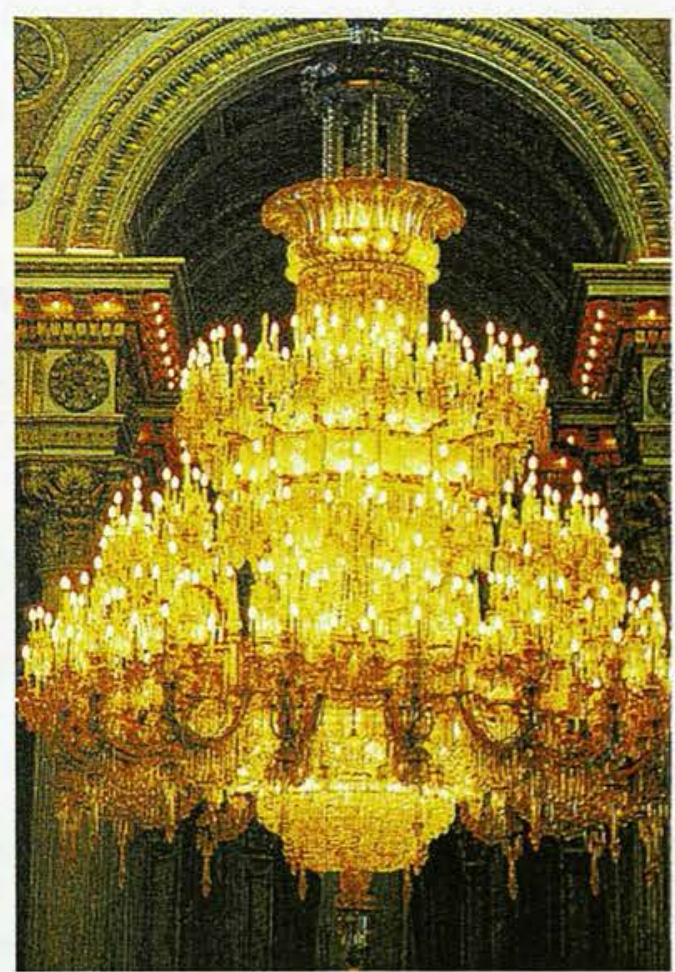

Figure 29 (a)

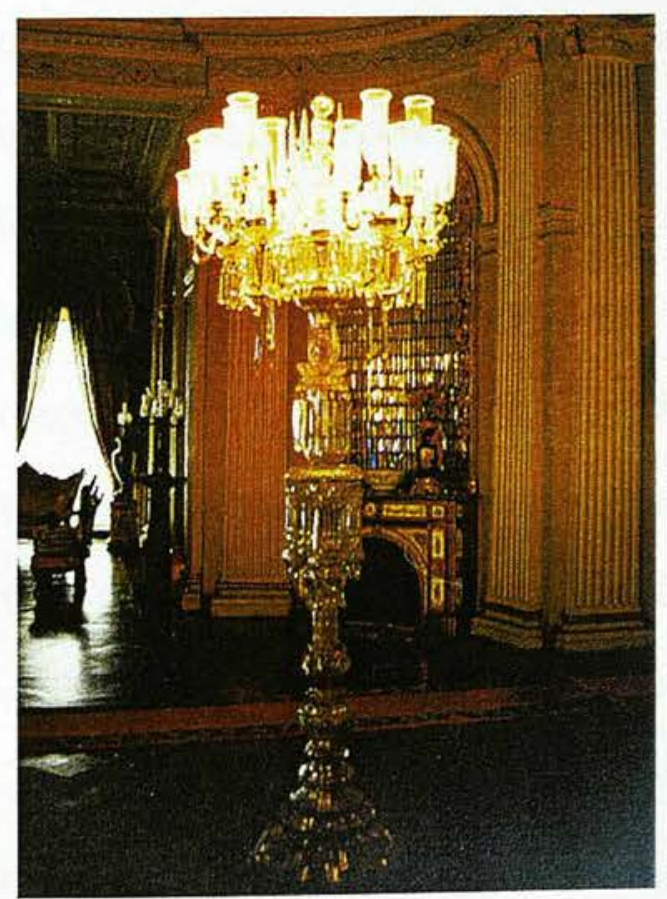

Figure 29 (b)
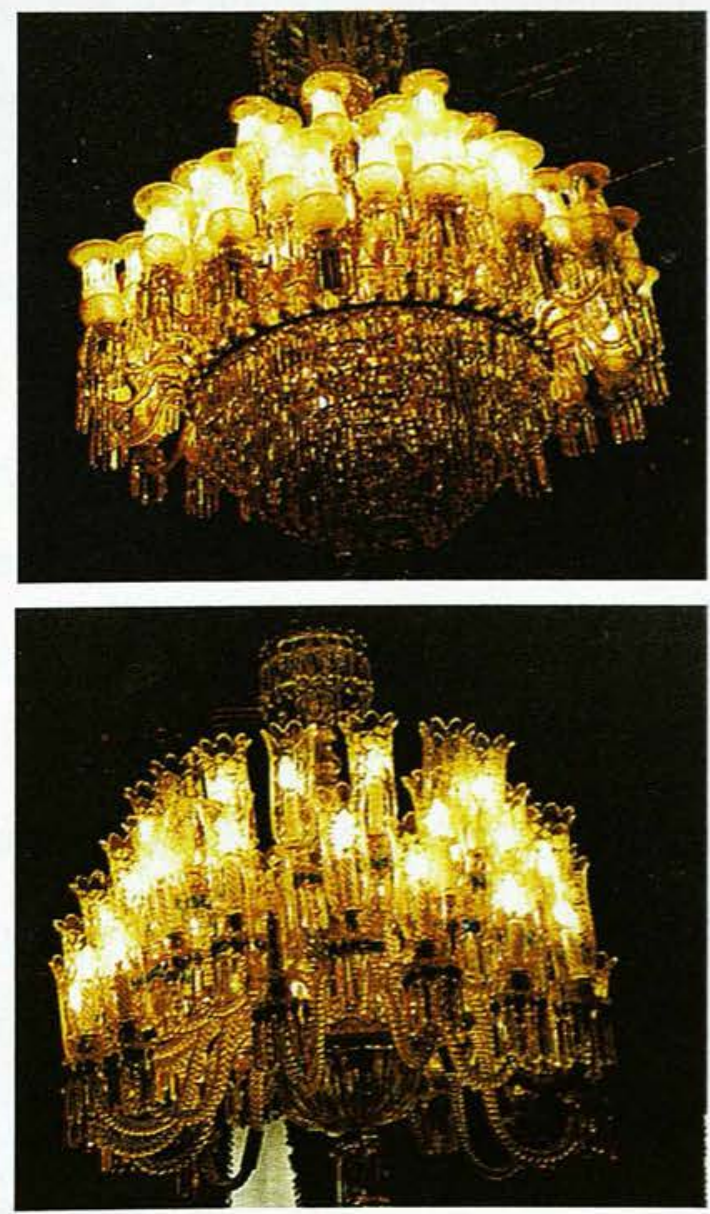

Figures 29 (c) and (d) 
Museum, London designed in 1994 by Danny Lane has applied the reflective qualities of glass very successfully. (Figures $30 \mathrm{a} / \mathrm{b}$ ) The essence of the design is in the rhythm made by the repetitive use of the material combined with the natural colour of the cut glass. It displayed an ostentatious image and came to the forefront of contemporary design as a rare visual feast.

It is known that the majority of glass used in Dolmabahçe Palace was purchased ${ }^{71}$ at "The Great Exhibition of the Work of Industry of All Nations ${ }^{72 " ~ i n ~}$ London in 1851. However, an important point which is overlooked is that whilst the Palace was under construction, the exhibition in London also took place and the display of glass in this exhibition effected the architectural understanding of the Ottomans. In 1839, at the beginning of Abdulmecid l's reign (1839-1861) and following the Tanzimat Reforms an effort was made towards Westernisation in an attempt ${ }^{73}$ to change the architectural look of the city and the door was opened to the application of cultural interaction. Undoubtedly the Turkish delegation at the exhibition and the committee in charge of purchasing goods for Dolmabahçe Palace reflected the impressions which they gained at this extraordinary exhibition into the construction and decoration of the Palace. The glass kiosk (Figure 31) on the first floor of the palace is an example of the impressions gained and reflected from the exhibition. It provides a contrast with the solid and contained structure of the Palace. This kiosk is an application which had not previously been seen in Turkish glass tradition, it can be considered as a small-scale model of the Crystal Palace which itself was constructed specially for the exhibition. It was clearly in discord with the outer

\footnotetext{
71 Küçükerman, p 50.

72 See Chapter 2. 1. History of Turkish Glass, p 37.

73 Barillari, Diana and Godoli, Ezio, Istanbul 1900-Art Nouveau Architecture and Interiors (Florance, 1996), p 11.
} 


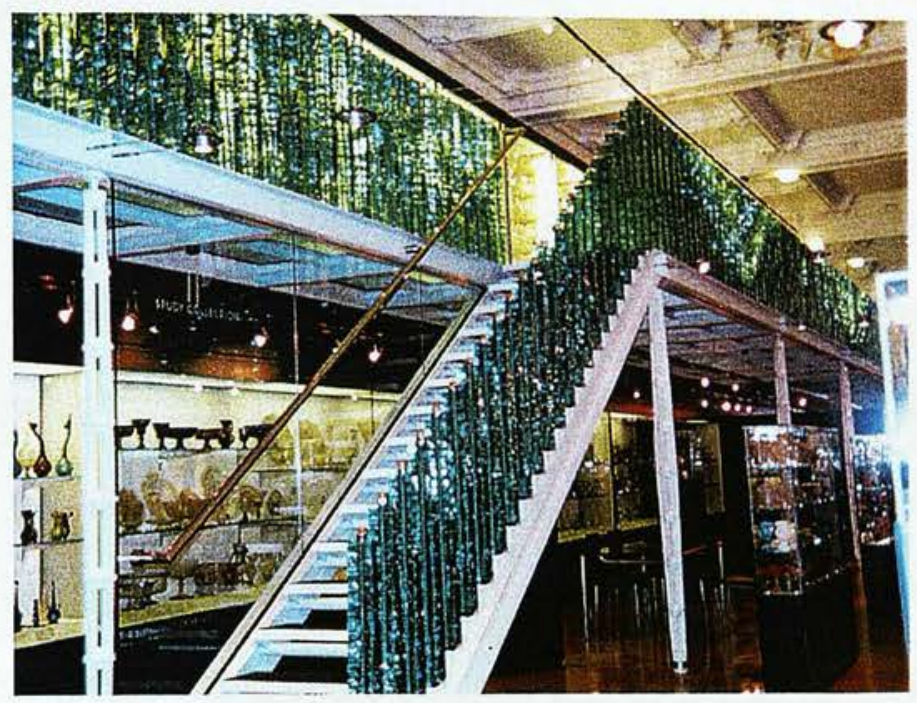

Figure 30 (a)

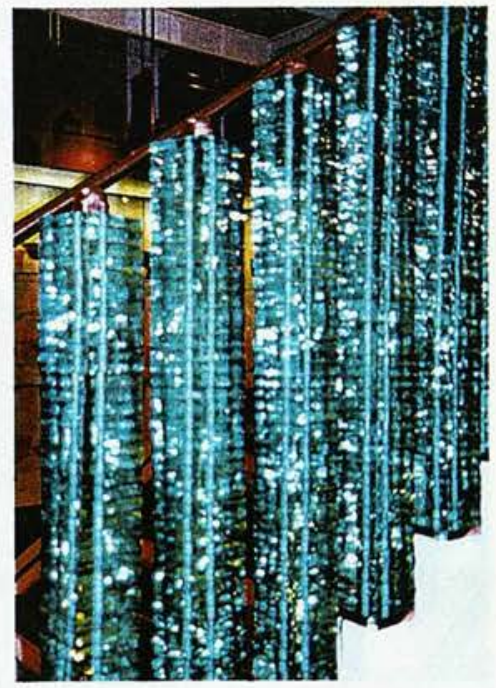

Figure 30 (b)

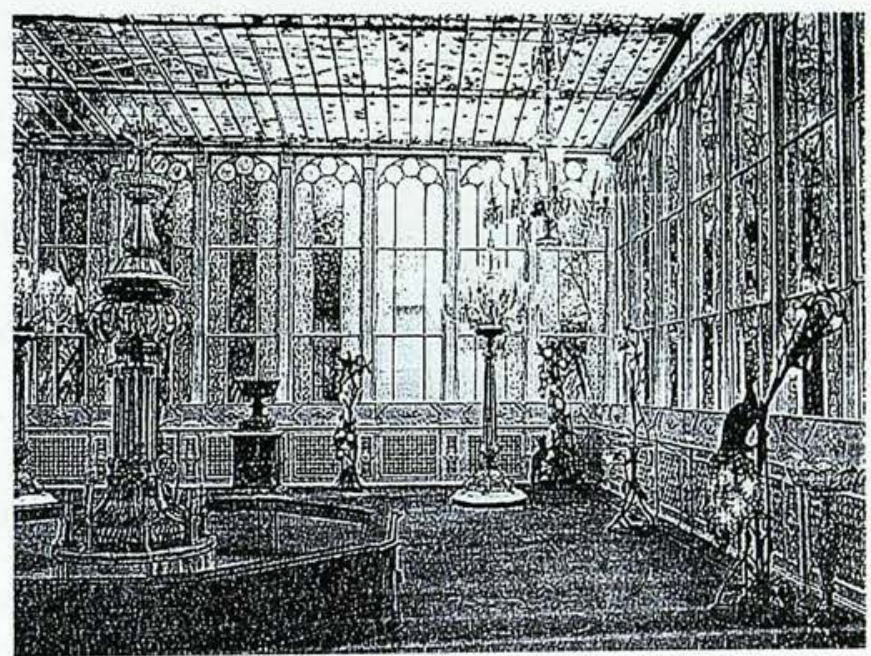

Figure 31

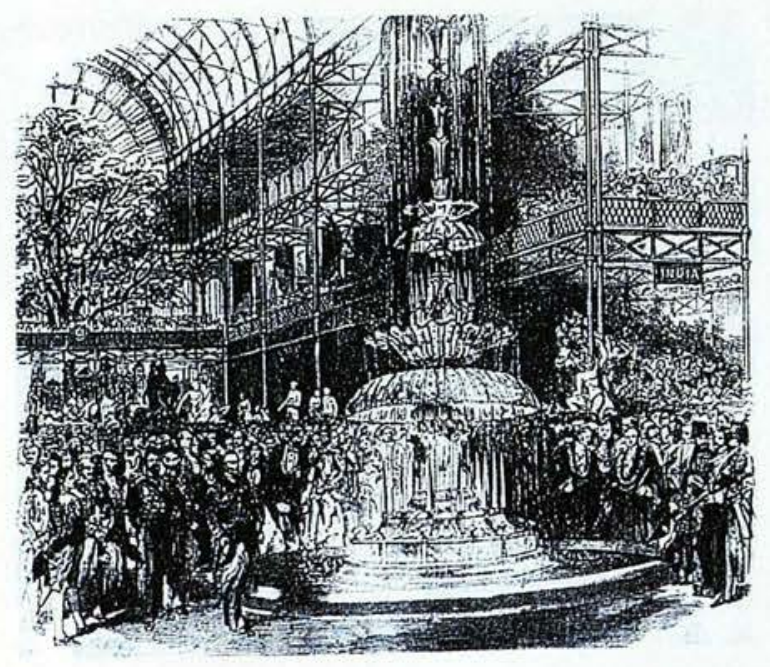

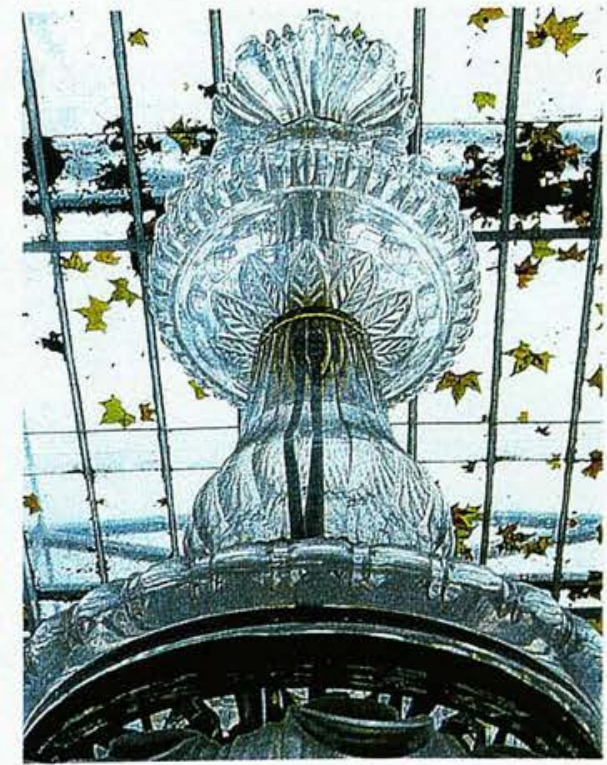

Figure 33 
structure and architectural design of Dolmabahçe Palace and this supports the idea that it was built after the experience of the Crystal Palace. In addition to this, the glass fountain at the centre of the kiosk bears strong similarities both in location, form and meaning to one of the most discussed works at the exhibition which was a glass fountain at the very centre of the Crystal Palace. (Figures 32 and 33) The glass used in Dolmabahçe Palace as well as in Beylerbeyi and Çırağan Palaces in this period was a prominent indication of a new understanding of architecture and the stepping into a new design phase.

Over hundreds of years in Ottoman architecture, the tradition of using glass has changed as it has followed the development of the technological advancements in the subject of glass. This demonstrates the structure of Turkish society, which is open to change, and development. At this time it was not a conservative society and as such was ready to accept novelty, however, in this adaptation they did not break completely from their established, ample, life style. This concept was reflected onto glass in architecture and provided an optimistic indication in regards to the future of glass. Unfortunately the continuation of this attitude did not endure due to revolutionary changes in life and politics. The current generation has witnessed the uncompromising blend of Medieval, Classical, Islamic and Modern architecture which has tragically transformed this vision into the domineering construction of insipid and hostile architecture. 


\section{2. GLASSMAKING IN ANATOLIA}

In light of archaeological excavations, it is apparent that whenever the Turks settled in a region, they became engaged in glass making ${ }^{74}$. Research carried out into glass pieces from Anatolia (Map 2) shows without doubt the existence of glass making as well as other handcrafts in the region. Although there is comprehensive evidence for the existence of other handcrafts, for glass production, on the other hand, there is only limited evidence. The earliest glass pieces found in Anatolia date ${ }^{75}$ from $8 \mathrm{BC}$ and there is also evidence of glass making in Sart in 6 BC. Likewise in Porsuk and Anamur ${ }^{76}$ signs of glass furnaces have been discovered which is proof of glass making in this period. Glass samples belonging to this period were also found in Finike and Bigadiç ${ }^{77}$ made by core moulding technique. (Figure 34)

In each region, following the invention of glassblowing, glass was used commonly in different forms and quantities, this naturally effected Anatolian glass making. In the years 1 and $2 \mathrm{AD}$ the most commonly produced glassware were small bottles made by freehand and mould blowing techniques. They consisted of various colours and forms, with a globular body onto which was set the neck, the lip of which was turned over and outwards often joining again with the neck. (Figures 35 and 36) In addition to these there were vases with handles, decorative bird shaped vessels, pitchers and other bottles among the excellent

Turner, W. E. S., Prof., "Glassmaking in Turkey", Journal of the Society of Glass Technology (Suffolk, 1950), Vol. 34, p 91.

$75 \quad$ Lightfoot, C. S. -Arslan, M., "Anadolu Antik Camları" (Ankara, ND), p 8.

$76 \quad$ Lightfoot -Arslan, p 9.

77 Canav, Üzlifat, TŞCFAŞ Cam Eserler Koleksiyonu (Istanbul, 1985), p 30. 


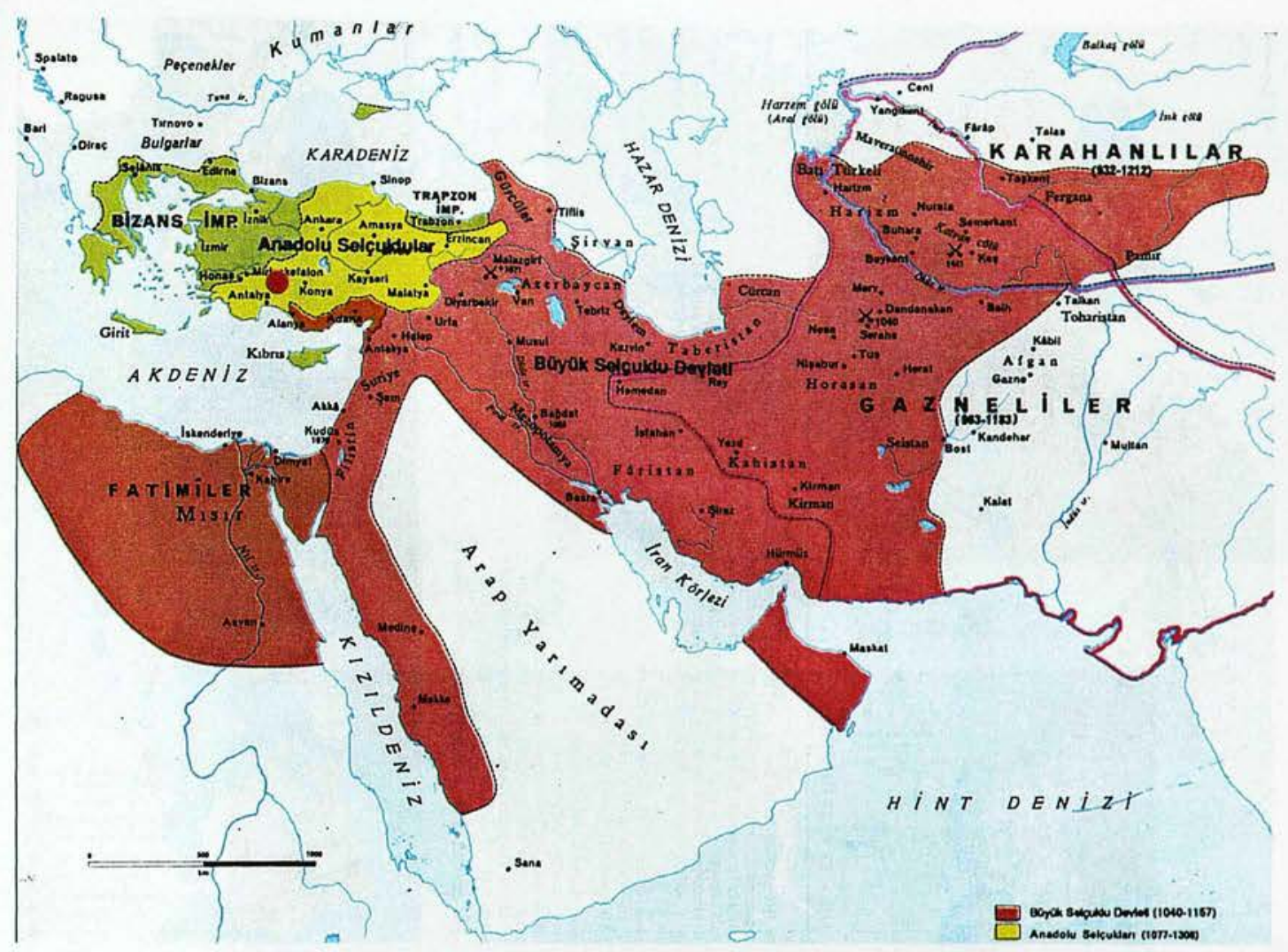

Map 2

\section{- Beyşehir Lake/Konya}

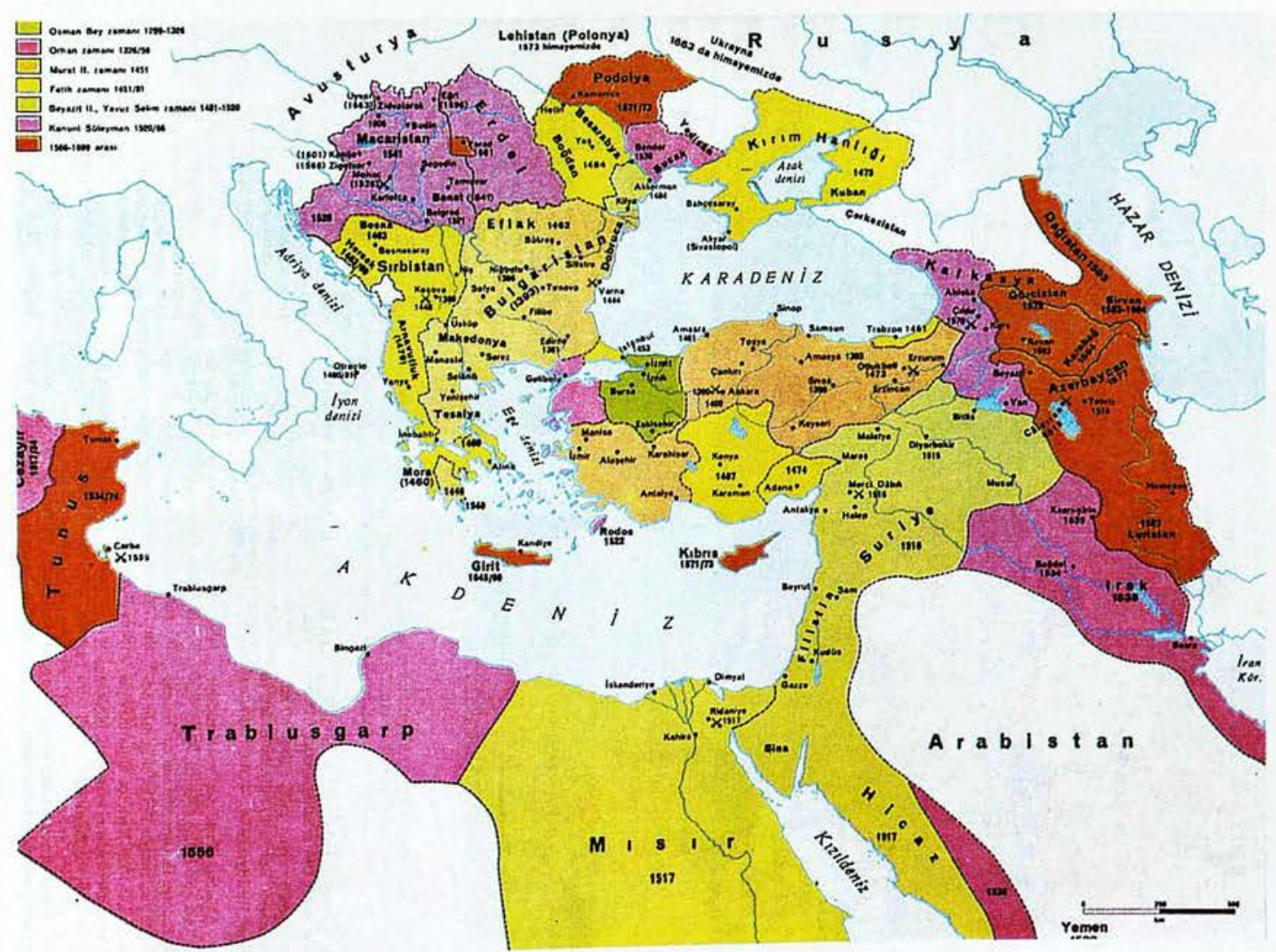




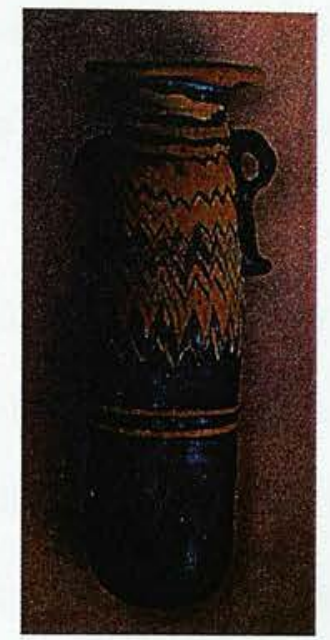

Figure 34

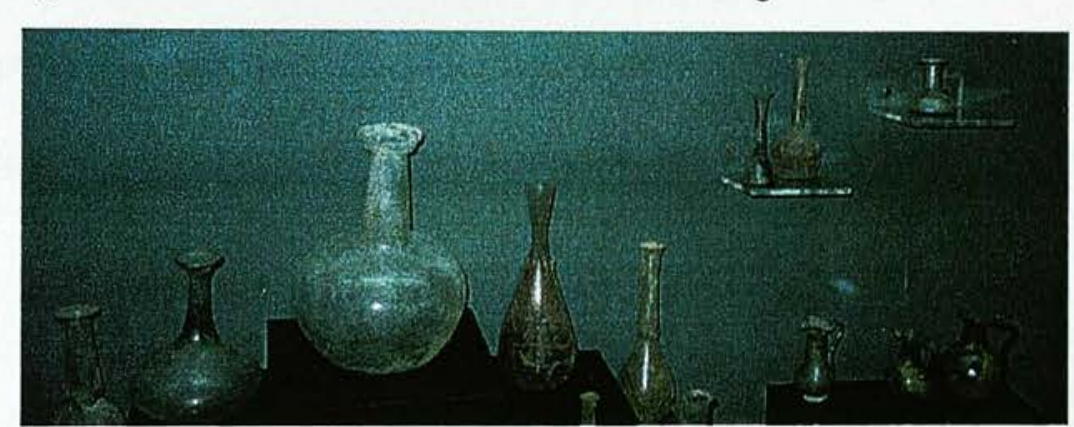

Figure 36

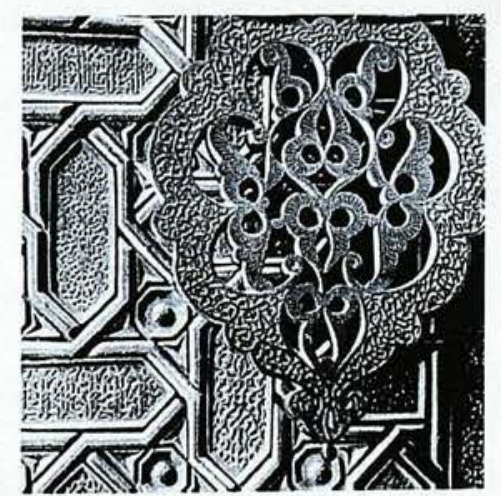

Figure 37(a)

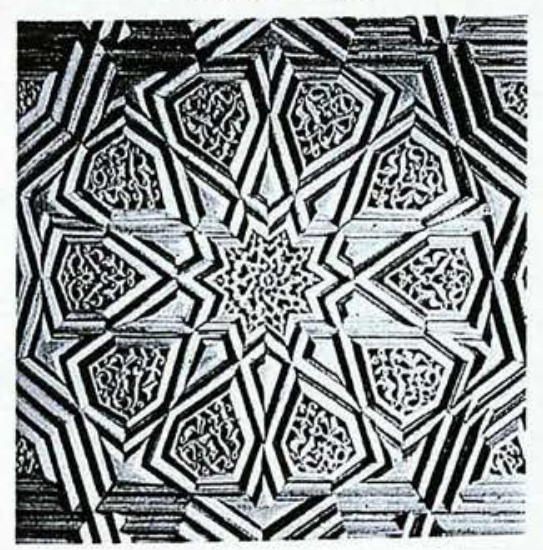

Figure 37 (b)

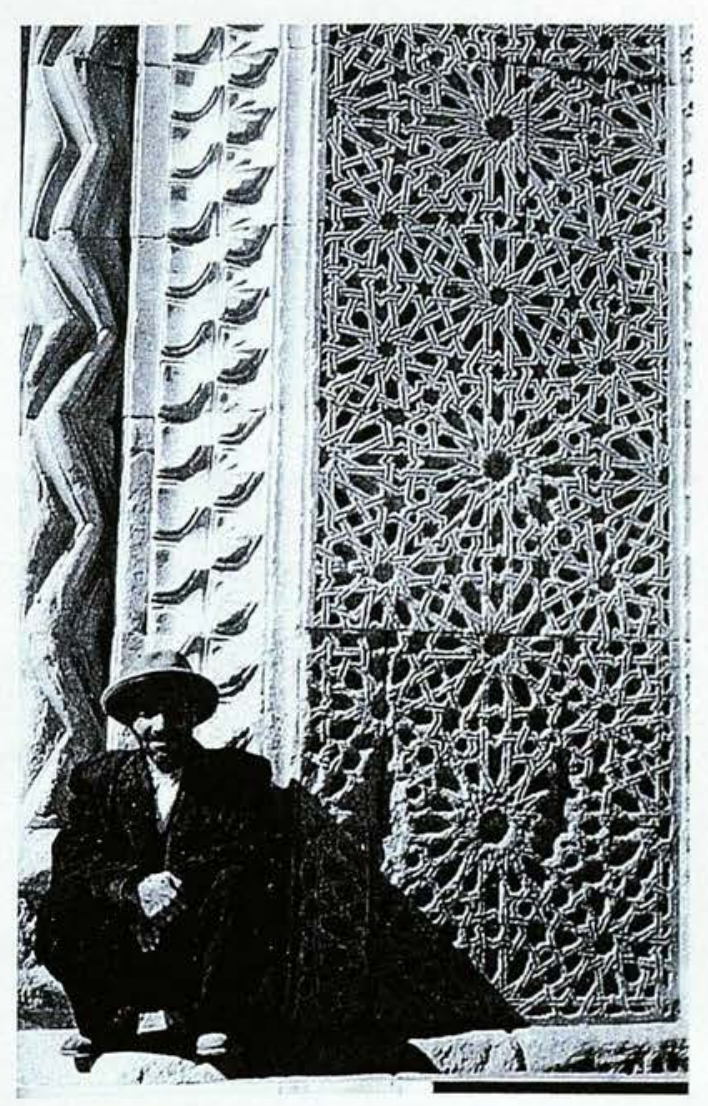

Figure 37 (c) 
examples of glass from Anatolia. Generally, glassmaking in Anatolia, especially in the Seljuk period, possessed qualities of vivacity and vibrancy.

The migration of Turks into Anatolia availed a huge development of the arts. In both architecture and crafts they left some very splendid works. The liveliness that they provoked within the arts was shown in the colourful motifs, gilt and enamels, and intricate examples of calligraphy, which gave birth to the assimilation of the characteristics found within Turkish glass art. The creative and prospective understanding of art by the Anatolian Seljuks did not only build the foundations of Turkish glass art but made a great contribution to its future.

\section{2. 1. SELJUK GLASS (1038-1308)}

Seljuks, the Turkish Dynasty who were dominant over the Muslim Near East (Map 2) between the $11^{\text {th }}$ and $14^{\text {th }}$ centuries (1038-1308), had a very important effect on Turkish history especially in their approach to the arts and in the creative development of other subjects. Their contribution ${ }^{78}$ to the rise of Anatolian culture was outstanding and today their art works are considered amongst the best remaining in the region. Towards the end of the $13^{\text {th }}$ century the Seljuk State was in decline, and following this, various Anatolian regional principalities, known as the Beyliks formed in the East and West of Anatolia under different names. The existence of these Beyliks was fairly short term and none left a distinctive mark in art like that of the Seljuk's. However, the most vigorous of these, which were the Ottomans in Western Anatolia were as

78 Akurgal, Ekrem, The Art and Architecture of Turkey (Oxford University Press, 1980), p 10. 
powerful in art and rule as Seljuks and later were responsible for initiating the Ottoman Dynasty (1281-1923).

Seljuk Turks were interested mainly in the area of architecture, and created their own peculiar style in the fields of stonework, coloured woodwork and the manufacture of mosaic wall tiles ${ }^{79}$. (Figures $37 \mathrm{a} / \mathrm{b} / \mathrm{c}$ ) Similarly many of their handcraft products went on to provide a strong base for Ottoman art. But information about the manufacture of Turkish glassware is very limited during the period of time between the Seljuk and the Ottoman sovereignties. This lack of information in various branches of art does not mean that glasswork was not produced, but rather that it has not survived in abundance to this day. Marvellous examples of art have been found from the Ottoman period which were produced over many years, they were in fact the continued synthesis of works by the previous Seljuk and Anatolian Turks.

Sometimes information about the development in many branches of art which were accomplished by Turks, especially in the manufacture of tiles, can be obtained from various sources. The limited information available about glass works has created a general impression that such material was necessarily imported from other countries ${ }^{80}$, like Syria, Palestine and Alexandria ${ }^{81}$.

Among the many kinds of products which were produced in the Seljuk period, we mostly observe a kind of window glass called şemsiye ${ }^{82}$ which was used in

\footnotetext{
79 Blair, Sheila S. and Bloom, Jonathan M., The Art and Architecture of Islam 1250-1800 (Yale University Press, 1994), p 132-146.

Bayramoğlu, Fuat, Türk Cam Sanatı ve Beykoz Işleri (Ankara, 1996), p 9.

81 Canav, p 19.

82 English: Umbrella. Also some Turkish sources call şemsiye glass as "Rovzen making".
} 
the construction of mosques and theological schools. Ekrem Akurgal describes the şemsiye glass as "locally made coloured glass, embedded in the stucco of window grills ${ }^{83}$. The excavations ${ }^{84}$ of Kubad-Abad Palace (1226-1236) (Figure 38), which was built under the patronage of Alaeddin Keykubad I, Sultan of Seljuks (reign 1219-1237) on the banks of Beyşehir Lake ${ }^{85}$ (Map 2) was the most important site for the discovery of this type of window glass used in architecture during this period. These remnants are coloured pieces of window glass, goblets, plates and coloured glassware, bottles, thin bodied and large mouthed glasses. The colours of these glasses ${ }^{86}$ are blue, dark blue, green, purple, yellow, brown and mostly brown fil gözü ${ }^{87}$. Glass known as fil gözü is window glass which is circular and swollen in shape ${ }^{88}$. In excavations evidence of plaster was found on the pieces of glass, it is believed that they were used as a vitrified ornamentation in windows by putting the glass pieces in frames of plaster which achieved a stained glass appearance ${ }^{89}$. Because of the porous structure of this glass which was produced with a thick rim and thin centre, it makes it impossible to see outside, but has an interesting capacity to illuminate its interior surroundings. A glass plate ${ }^{90}$ was also found in a small pool located on the terrace of the palace that faces the Lake of Beyşehir. It belonged to the time period determined by the researcher Mehmed Önder and is an important source of information ${ }^{91}$ about Seljuk glass. (Figures $39 \mathrm{a} / \mathrm{b}$ ) Being different from

\footnotetext{
$83 \quad$ Akurgal, p 206.

84 Önder, Mehmed, "Selçuklu Devrine Ait Bir Cam Tabak", Türk Sanat Tarihi Araştırma ve Incelemeleri II, Istanbul Devlet Güzel Sanatlar Akademisi (Istanbul, 1969), p 1.

85 Aslanapa, Oktay, Turkish Art and Architecture (London, 1971), p 163, "According to the historian, Ibn Bîbî, when Alâ al-Din Kayqubad was passing through the province of Konya on his way from Kayseri to Antalya he found an extraordinarily beautiful spot on the shores of the Lake of Beysehir and ordered that a town should immediately be built there".

86 Théma Larousse, Sanat ve Kültür: Türk-Islam (1994), Vol. 6, p 300.

$87 \quad$ English: Elephant eye.

88 Temel Britannica, Ana Yayıncılık and Britannica Corporation (1992), Vol. 4, p 111.

89 Önder, p 1.

90 A shallow plate with $30.5 \mathrm{~cm}$. diameter and the edge inclines up by $2.5 \mathrm{~cm}$.

91 Önder, p 1-5
} 


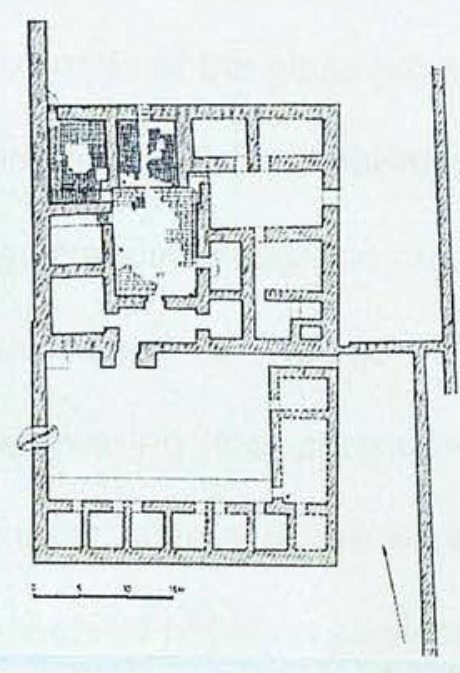

Figure 38

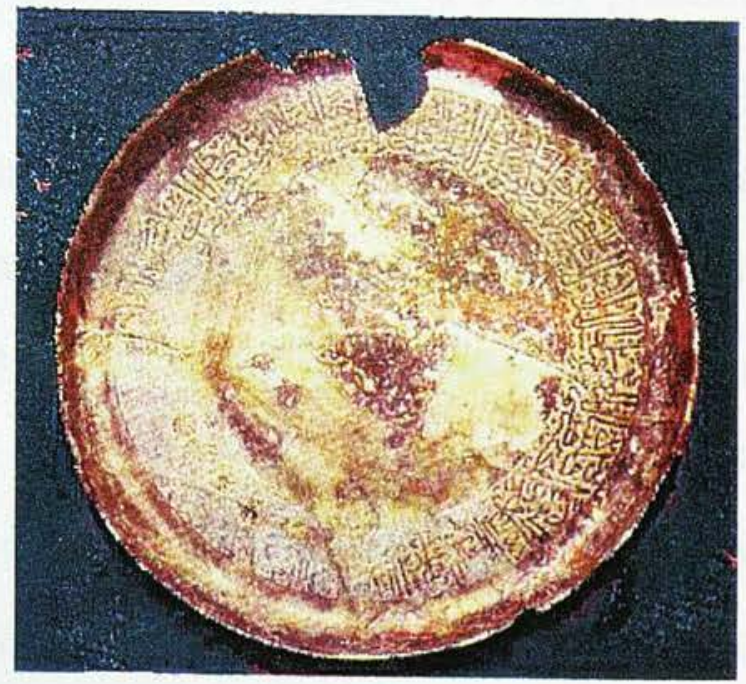

Figure 39 (a)

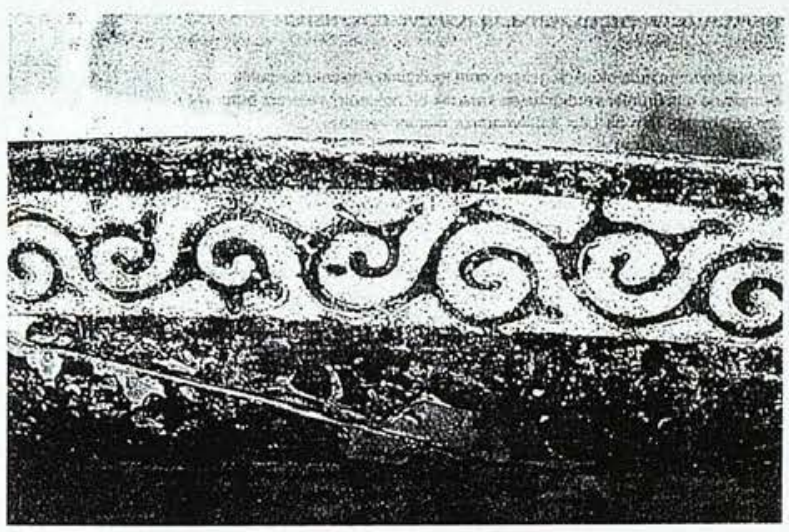

Figure 39 (b)

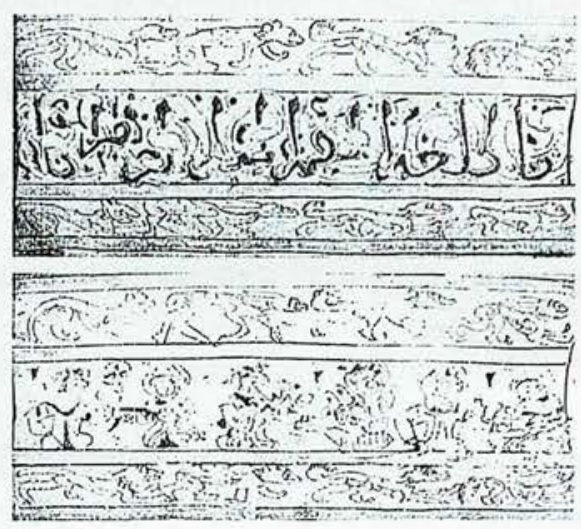

Figure 40 (a)

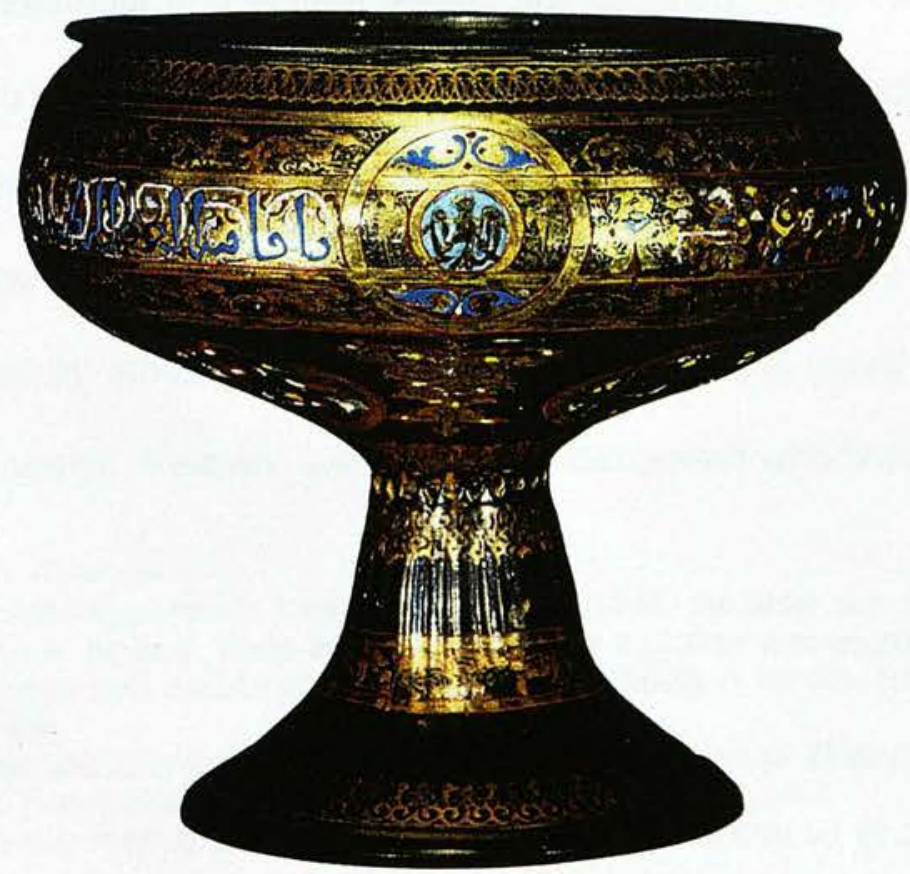

Figure 40 (b) 
the coloured window glass found in excavations, this plate is a very precious example of the glass production of Seljuk. On the other hand, an example which emphasises the importance and value of glass is the commissioning of a special dinner service produced in the name of the Sultan. It is amber coloured, enamelled and gilded. The epitaph on the border of the plate is a eulogy addressing the person who would use the plate ${ }^{92}$. It reflects the typical characteristics of the period. In this period of time close relationships can be observed between glassmaking in Anatolia, Syria, Middle East and glassmaking in Egypt $^{93}$. We do not have enough substantive information about glassmaking in Anatolia. However the style of calligraphy is similar to samples from Aleppo ${ }^{94}$ and this enforces the theory that work in Anatolia was commissioned from Syria. Although another possibility is that some glassmakers keeping alive the Syrian tradition, were producing work in Anatolia. Nowadays however, there is not enough evidence to support these theories. It is noticeable that at that time the distinct decorative horizontal bands on Anatolian pieces resemble those used by Ayyubids ${ }^{95}$. (Figures $40 \mathrm{a} / \mathrm{b}$ ) Samples of glass from this period have botanical, geometrical and animal motifs, but because of the rarity of samples which we have inherited, we are not able to collect sufficient information about authentic works of Seljuk glass. However, it is possible to make general assumptions by taking into account the similarities between the characteristics of objects used by other communities of this time. Seljuk glass is ornamented with gilt and enamel. Vessels are generally decorated with borders containing

\footnotetext{
92 In the epitaph Giyaseddin Keyhüsrev II's (1237-1246) the elder son of Sultan Alaeddin Keykubad I, name is praised. Parts of the epitaph were indistinct and could not be read and pieces of the broken part could not be found. See Appendix $F$ for the chronological list of Turkish Seljuk rulers.

${ }_{93} \quad$ The gilded and enamelled glass made in Egypt called Fustat. (Fustat is an old Islamic capital near Cairo between 642-969)

94 Öney, Gönül, Prof. Dr., Anadolu Selçuklu Mimari Süslemesi ve El Sanatları (Ankara, $1988), \mathrm{p} 138$.

95 Jenkins, Marilyn, Islamic Glass (The Metropolitan Museum of Art, 1986), p 38.
} 
laudatory writings and wishes of abundance for the person using the object. These are known as küfi writings (The characteristic Arabic script in this period). In addition to these fishes, birds, human figures and bosses are also used ${ }^{96}$.

(Figure 41) There is another excellent specimen from this period which is the bottom part of a bottle in the British Museum. Although some sources indicate the origin of this bottle as Syrian ${ }^{97}$, the calligraphy clearly is in the name of the Seljuk Sultan "Imad al-Din Zangi"." (Figure 42) This bottle is gold painted and decorated with pomegranates, trees, dancing female figures and an eagle. The sites where both this bottle and the plate that was found in the excavations of Kubad-Abad Palace were produced, are unknown ${ }^{99}$.

Due to the lack of surviving pieces from this period, it is difficult to arrive at a definitive conclusion in regard to their origin as the pieces that are available and are decorated in an appropriate style may yet have come from Syria. Seljuk glass had a close relationship with other centres of glass production during the period and the apparent similarities in style and decoration are important in order to reflect the history of Turkish glass art.

The work made from greenish translucent glass without decoration was intended for utility ware ${ }^{100}$, such as bottles, jars and vases. The shapes of these vessels are simple for general purpose. It is difficult to obtain reliable results on the extent of the influence of Seljuk glass on Ottoman glass due to the absence of material and information. The glass in the architecture of Seljuk is used either

\footnotetext{
$96 \quad$ University of Istanbul, Istanbul, $1^{\text {st }}$ International Anatolian Glass Symposium (April $26^{\text {th }}-$ $\left.27^{\text {th }} 1988\right), p 66$.

Ward, Rachel, Gilded and Enamelled Glass from the Middle East (London, 1998), Scanlon, George T., "Lamm's Classification and Archaeology", p 27.

$98 \quad$ Tait, Hugh, Five Thousand Years of Glass (London, 1991), p 130.

99 Thanks to Rachel Ward for sharing her knowledge and expertise. 


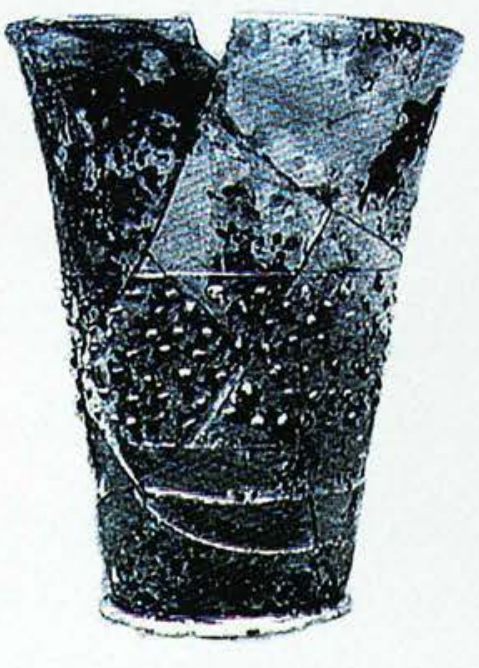

Figure 41

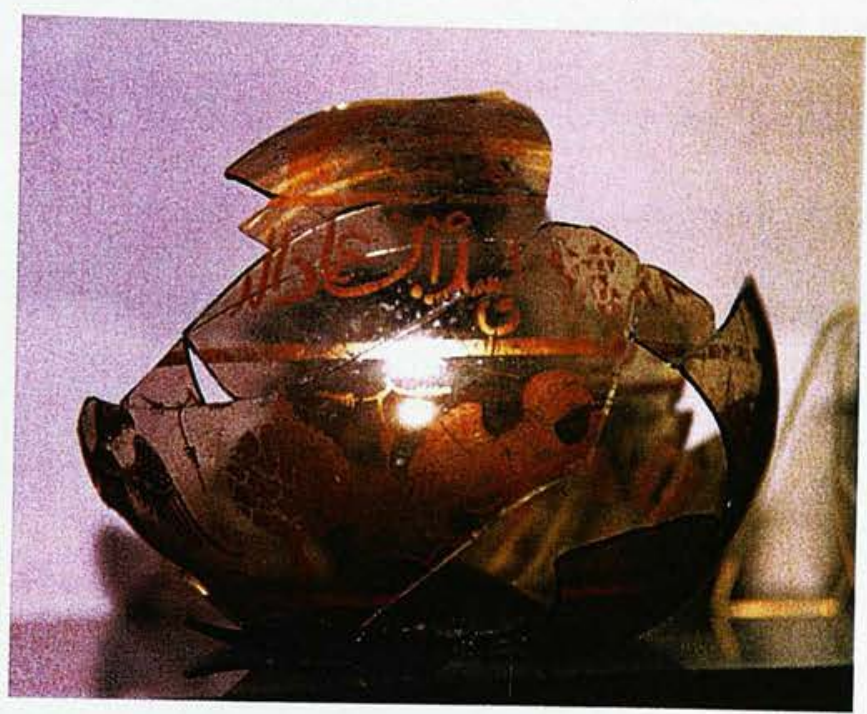

Figure 42

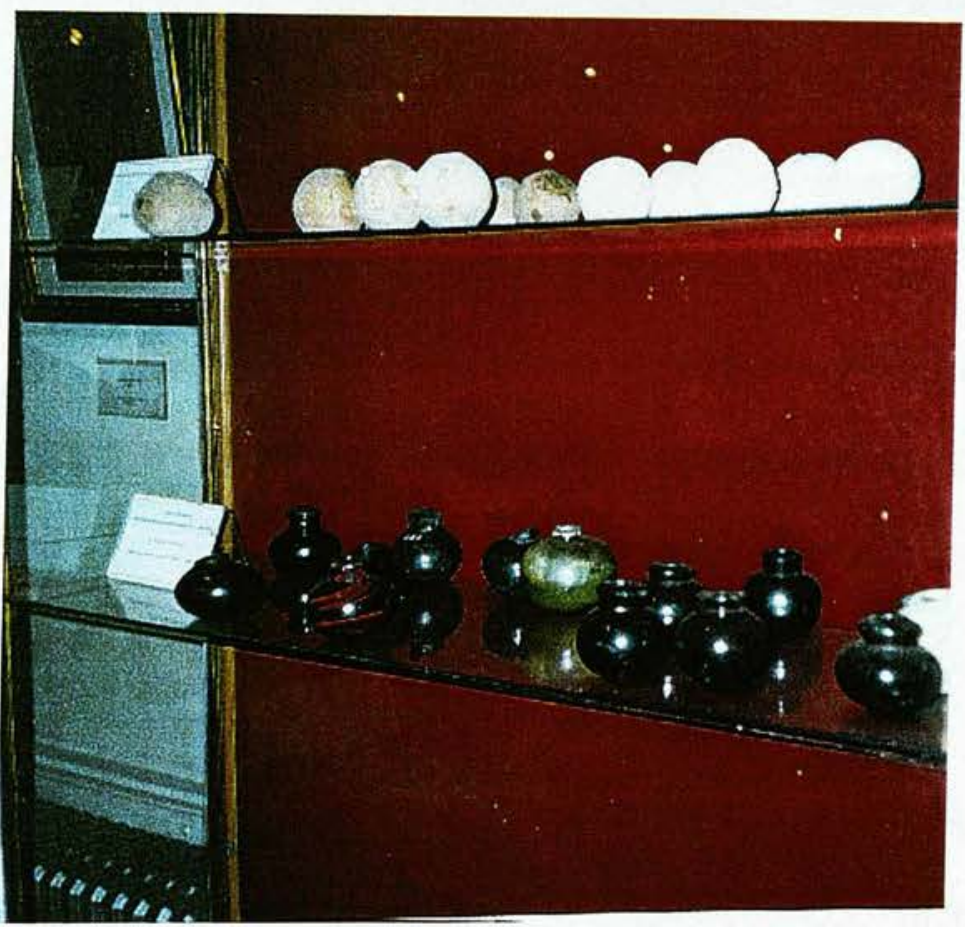

Figure 43 
as decoration or as building elements and we have ample evidence for this ${ }^{101}$. We do not have such evidence for ornamental and functional production, therefore perhaps this was a less developed branch of glass making which did not effect later periods. However the works of Seljuks must have influenced the works which followed especially those produced in the Ottoman period. Nevertheless, there is a gap of almost 500 years from which we have little information about glassmaking in the region. By the $18^{\text {th }}$ and $19^{\text {th }}$ centuries however, the Ottomans were making their own responses to changes in the fashion, living style and general cultural developments in the world, they developed their own forms, decorations and style of glassmaking.

\section{2. 2 . OTTOMAN GLASS (1281-1923)}

While the Ottoman dynasty was only one Beylik among tens which formed in different corners of Anatolia, it surpassed the Byzantine Empire and spread to different continents. (Map 3) During their 600 years of sovereignty the Ottoman dynasty made a significant contribution to Turkish and world art. The dynasty developed through placing importance on the arts and this included supporting various handcrafts and bringing new regulations regarding art into practice. The lengthier existence of architectural works is due to the durability and quality of the materials used in their construction and also their scale.

Today, the samples of glasswork, surviving from the Ottoman period, are only from the last century of the dynasty. The glass products, which we have inherited, consist of pieces in perfect, complete shape as well as reconstructed

101 Önder, Mehmed, p 1. 
objects that were found during excavations. As well as these products, some literary sources, old documents written for different purposes, accounts, notes, diaries of ambassadors or travellers and miniatures are also important and provide valuable sources of information about Turkish glassmaking.

One of the oldest sources found regarding Ottoman glassmaking is a manuscript (1503-4) which belongs to the reign of Sultan II. Bayezid (reign 1481-1512). This manuscript mentions the payments made to glassmaster Yusuf for his mirrors and glass lamps ${ }^{102}$. In addition to this, accounts and documents recorded during the construction of Süleymaniye Mosque and Complex (1550-1557) are of great importance regarding this subject ${ }^{103}$. These records mention glassmakers who worked for the construction of the mosque, and includes their salaries, even the numbers of days they worked in detail. They also show that 15 glassmakers out of 16 were Muslim and only one was Christian, and a glass master called Sarhoş Ibrahim (Ibrahim the Drunkard) who was a very skilful glassmaker ${ }^{104}$. Apart from these, another document lists the payments of the Sultan to the artisans who brought presents ${ }^{105}$ during the festive time (Bayram) and glassmaker Hasan's name was found on this list ${ }^{106}$. Regardless of the existence of these documents the paucity of objects today which could provide examples of Ottoman glass is acknowledged. At this point, any interpretation of the shape and quality of the glass products until the beginning of Beykozware production at the end of the $18^{\text {th }}$ century, remains only

\footnotetext{
102. Bayraktar, Nedret, Istanbul Cam ve Porselenleri (Istanbul, 1982), p 20.

103 Küçükerman, Önder, Prof., Cam Sanatı ve Geleneksel Türk Camcılığından Örnekler (Ankara, 1985), p 141.

104 Bayramoğlu, p 10.

105 Although these objects were presents, it was customary for Sultan to make some payment to the artisans, to show his interest, how much he liked the pieces and how much he cares for the artisans.

${ }_{106}$ Bayraktar, Nedret, “Osmanlı Devri Cam Sanatı", Paşabahçe (Feb. 1985), Year 1, No. 2, p 3.
} 
as an educated guess at functional or domestic ware production. Thus, the broken humbara ${ }^{107}$ pieces (Figure 43) found in the excavations of Rhodes proves that the period which they belong to is Kanuni Sultan Süleyman Period (reign 1520-1566) from the Battle of Rhodes involving the Ottoman Navy in $1522^{108}$.

The miniatures depicted in Surname-i Hümayun (c.1585), mentioned in section 2. 4. "The Unique Properties of Turkish Glass", provide valuable information concerning the existence of glassmaking during the Ottoman period. Surname-i Hümayun is of great importance in Ottoman glass art history. The purpose of making these miniatures ordered by Sultan Murad III (1574-1595) was to organise a huge festival for the occasion of his son Şehzade Mehmed's circumcision and by this means he wanted to show the strength and the richness of the Ottoman Empire. This festival, which was prepared over two years and lasted for fifty-two days and nights, was held on the Sultan Ahmed Meydanı (the old Hippodrome). Looking at it from a historical viewpoint, it is the first event that was completely recorded by writing and drawing ${ }^{109}$. Among all the miniatures in this book, which includes illustrations of glass art, one miniature attracts the most attention. This miniature depicts glassmakers on a mobile platform making glass from the furnace. (Figures 44 and 45) Sultan sits in the top left corner and watches the ceremony with his guests and members of the public. Meanwhile these miniatures provide an excellent example of Turkish miniature art. They reflect the characteristics of Turkish miniatures, showing scenes of daily life in a realistic manner. The expression given to the faces by

\footnotetext{
107 Grenades thrown by cannons, made from very thick glass and formed like coloured $\underset{108}{\text { balls. }}$

${ }_{108}$ Günalp, Reha, "TŞCFAŞ Cam Eserler Koleksiyonu", T. IŞ Bankası Kültür ve Sanat Dergisi (March 1990), Year 2, No. 5, p 82.

${ }_{109}$ Ettinghausen, Richard (Preface), Ipşiroğlu, M. S., Eyüboğlu, S. (Int.), Turkey-Ancient Miniatures/UNESCO (Italy, 1961), p 24.
} 


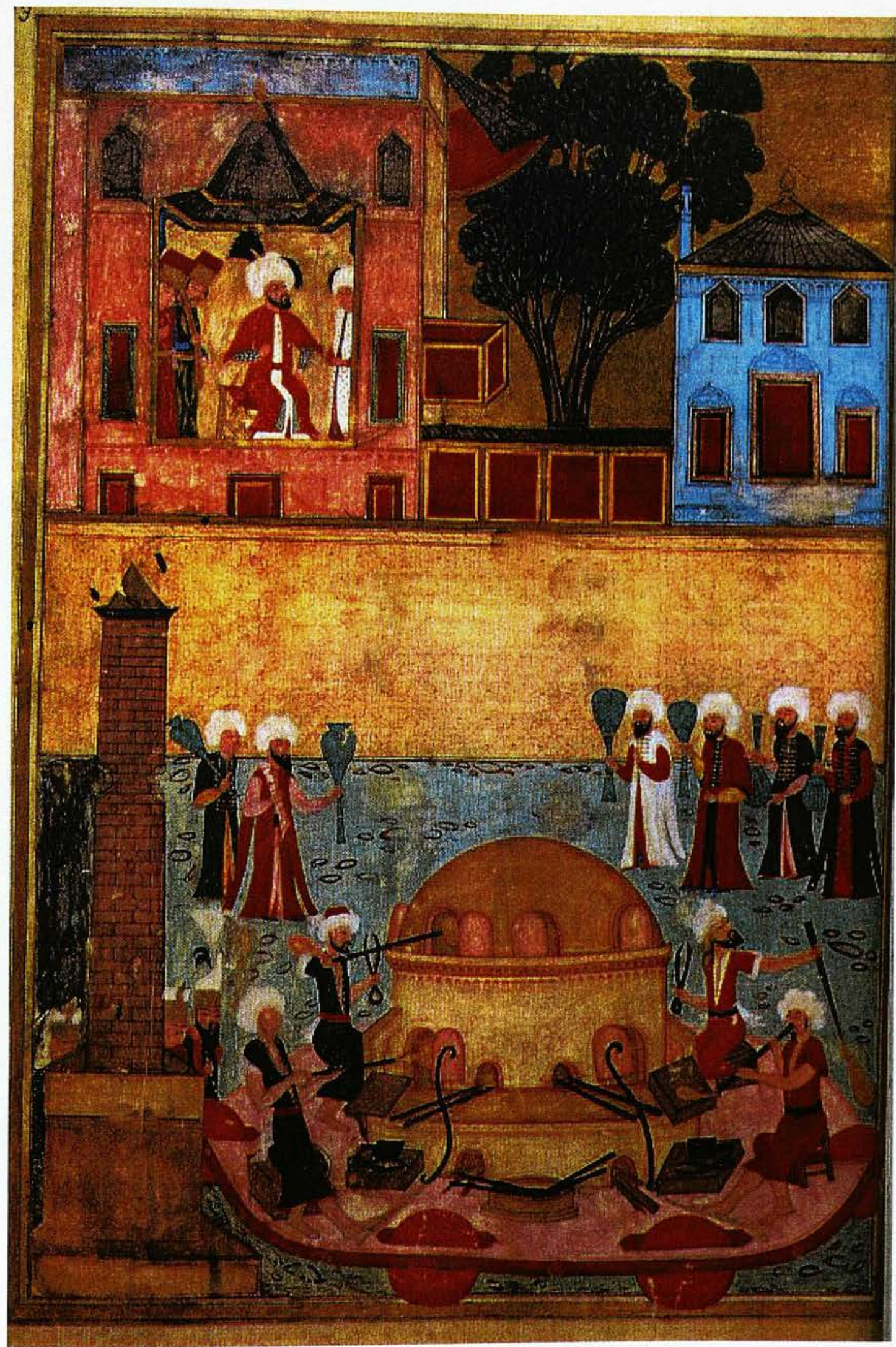

Figure 44 


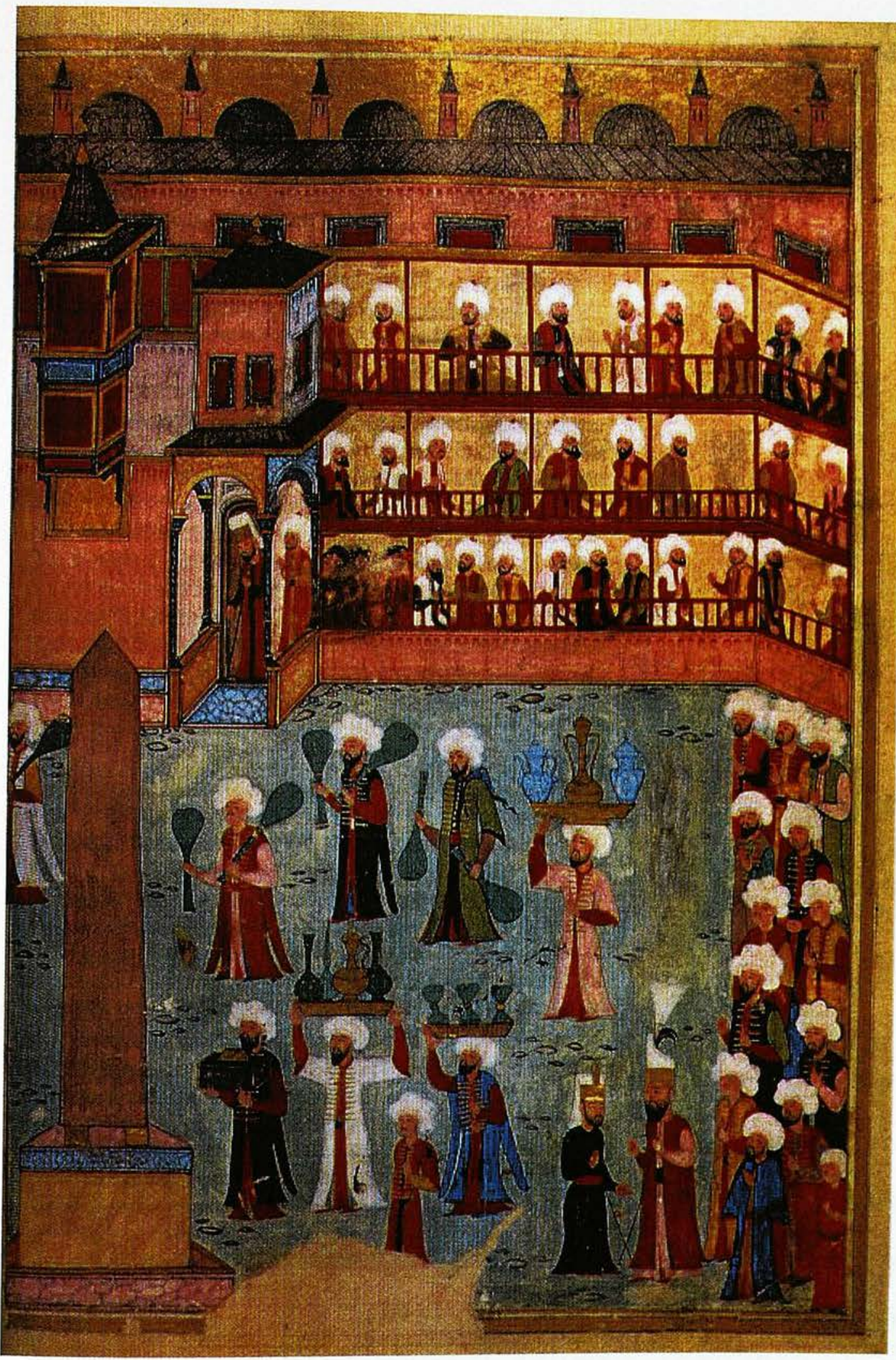

Figure 45 
eye movements and characterisation in the drawings attract special attention. (Figure 44a detail) Looking at this miniature with a critical eye, it is possible to collect many valuable clues concerning Ottoman glass and glassmaking in the $16^{\text {th }}$ century. In this drawing there is no huge difference in glass blowing compared to today's glassblowing techniques and tools. It lays out the whole process from the burning of wood to the melting of the glass, preheating of blowing irons, blowing glass, marvering, swinging, reheating and right up to the use of wooden blocks and jacks as a main tool. Apart from the group of four who are blowing in front of the furnace on the mobile platform, there are different groups of glassmakers parading and carrying glass in trays over their heads in the background. These glass forms in the miniature are decorated in different ways and they are blue, green and yellowish brown in colour. Two glassmakers, one with white, the other with pink caftans are carrying a green flask with yellow bosses and blue spouted jugs on their heads. (Figures $45 \mathrm{a} / \mathrm{b}$ detail) The outlines of these forms show a great resemblance to the same period of Iznik (Nicaea) pottery. (Figures 46 and 47) It strengthens the idea of the existence of popular glassmaking in the Ottoman dynasty as well as producing Iznik pottery.

It is worth mentioning that depicted in this miniature there are also some forms which bare resemblance to later examples of çeşm-i bülbül. (Figure 44b detail) Considering that the artist who has made the miniature, is not a glassmaker but a nakkaş (decorator), it is thus expedient to deem it his own interpretation and description of the event. One of the strongest clues is the similarity of çeşm-i bülbül to the famous Italian vetro a fili decoration technique both visually and 


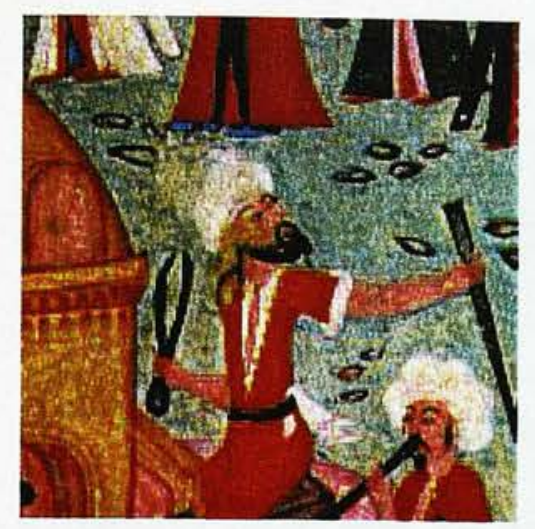

Figure 44 (a) detail

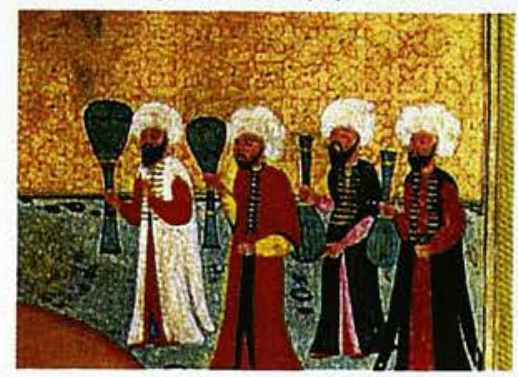

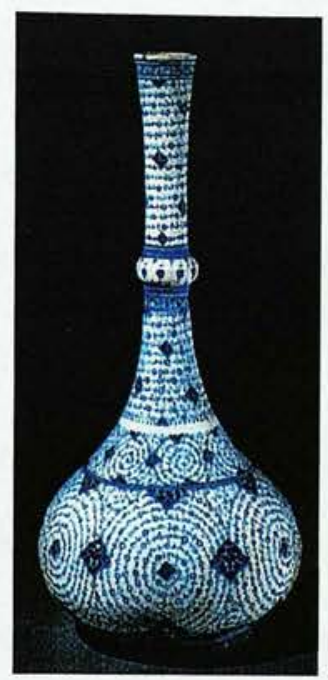

Figure 46

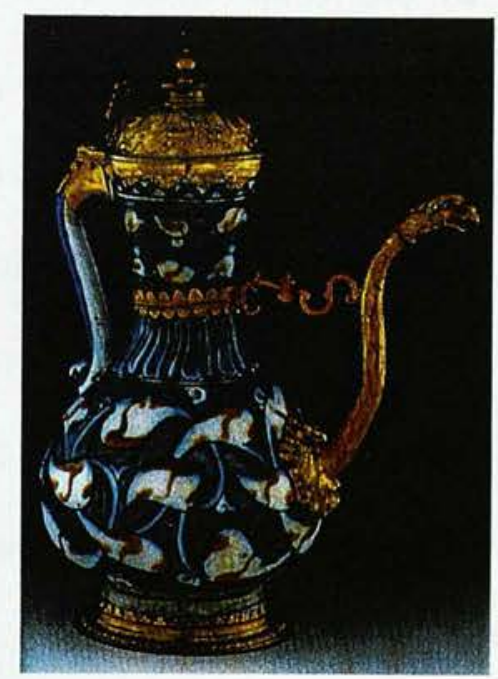

Figure 47
Figure 44 (b) detail

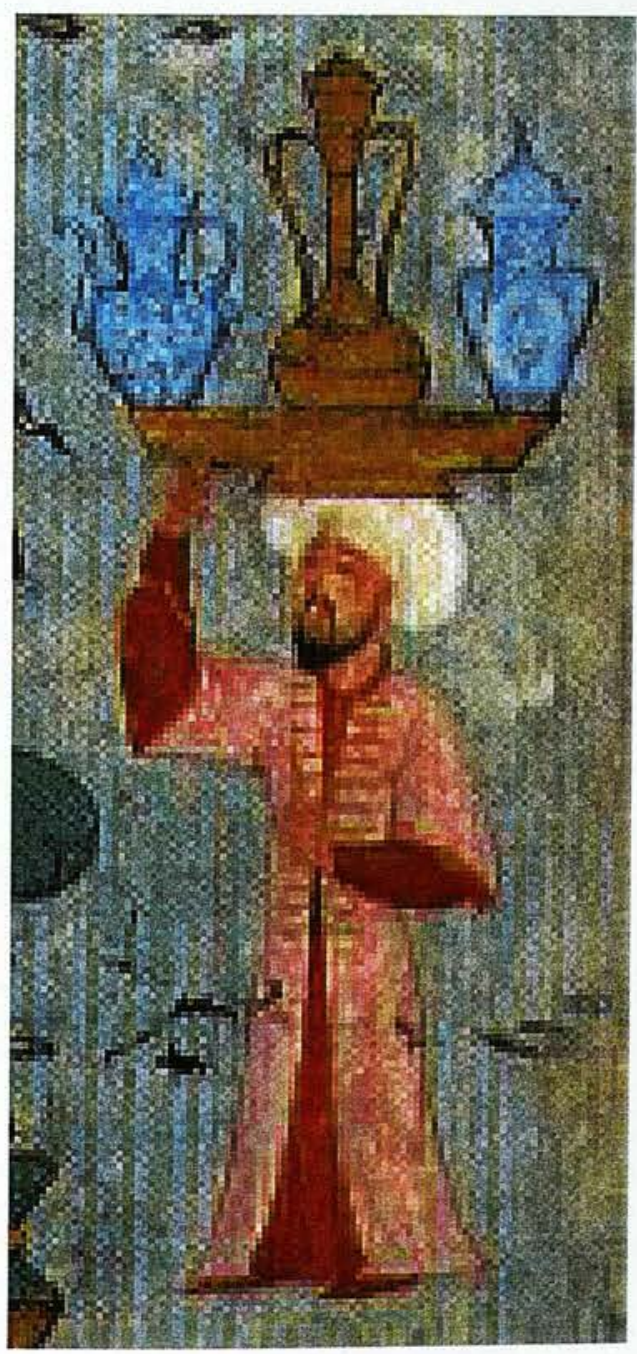

Figure 45 (a) detail

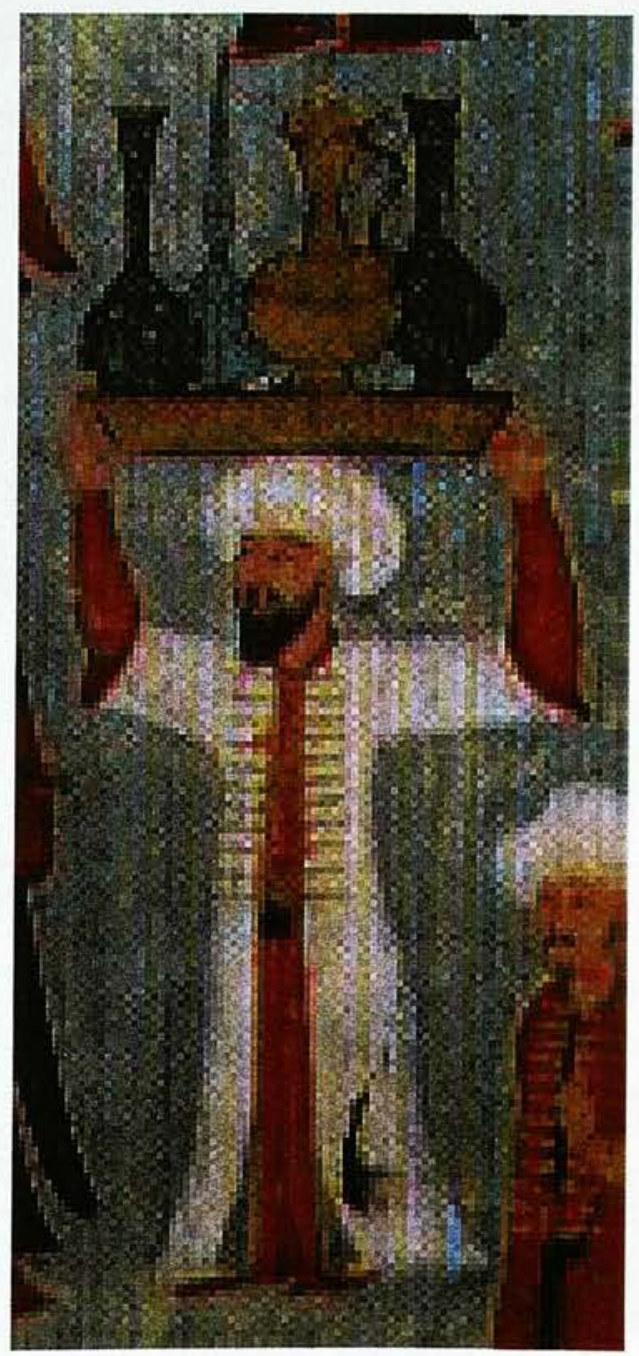

Figure 45 (b) detail 
technically. Thus, one of the latticinio ${ }^{110}$ decorated Venetian glass lamps has been surface decorated in Turkey and dates from the second half of the $16^{\text {th }}$ century and is now in the Topkapı Palace ${ }^{111}$. (Figure 48) This typical botanical stem, leaf and lotus flower ${ }^{112}$ decoration is very similar to the decoration on Iznik pottery as well as on textiles (Figures $49 \mathrm{a} / \mathrm{b} / \mathrm{c}$ ) from the same period. These similarities have also been noted by Charleston in his essay "The import of Western glass into Turkey: $16^{\text {th }}-18^{\text {th }}$ centuries". Also, the similarity between the decorated flasks, which are carried by the glassmakers, are remarkably close to the çeşm-i bülbüls. This likeness strengthens the debate that çeşm-i bülbül samples from the end of the $18^{\text {th }}$ century are the continuation of these types of decorated flasks. It is hard to say that vetro a fili decorated glasses, which were imported from Venice in c1569, did not affect these well equipped glassmakers in 1585 as they were already capable of using different techniques and producing various forms. It is not a fair reflection on the history of Turkish glass art to categorically say that çeşm-i bülbül production started following the return of Derviş Mehmed Dede from Italy. The glassmakers in Turkey were well aware of this technique for at least 200 years and did not have to wait for someone to go abroad to be trained in different techniques. It should be added that, in 1569, Grand Vizier Sokullu Mehmed Paşa (1505 -1579) commissioned from Venice 900 pieces, similar to this lamp:

\footnotetext{
110 An Italian expression used for the description of vetro a filigrana in the past. It includes three blowing techniques slightly different from each other using coloured and white canes, vetro a fili, vetro a retorti and vetro a reticello. See for more, Tait, Hugh, Five Thousand Years of Glass (London, 1991), pp 238-240 and 244.

111 Charleston, $\mathrm{p} 21$.

112 A Chinese motif which was appropriated and came to be considered as part of their own Mediterranean culture as a result of the commerce between the East and the Mediterranean countries by the middle of the $14^{\text {th }}$ century.
} 


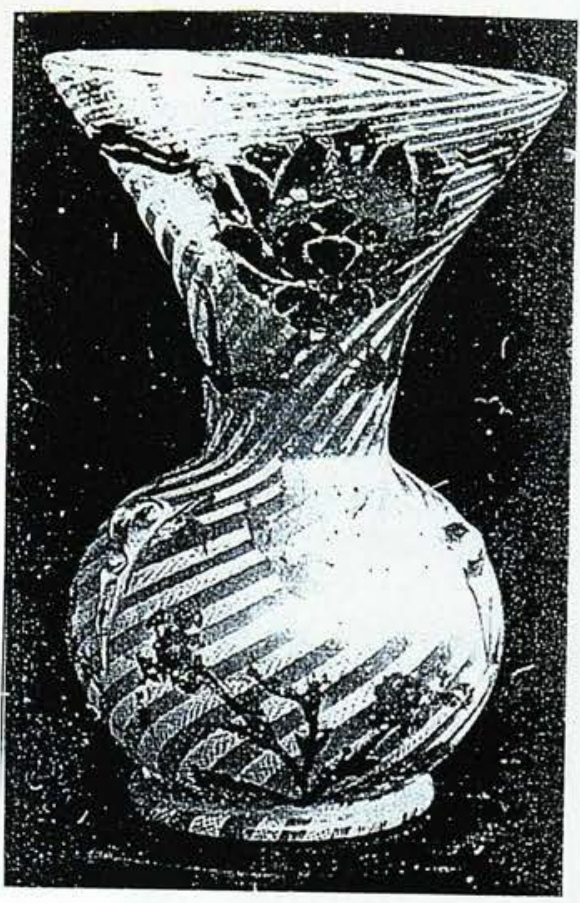

Figure 48

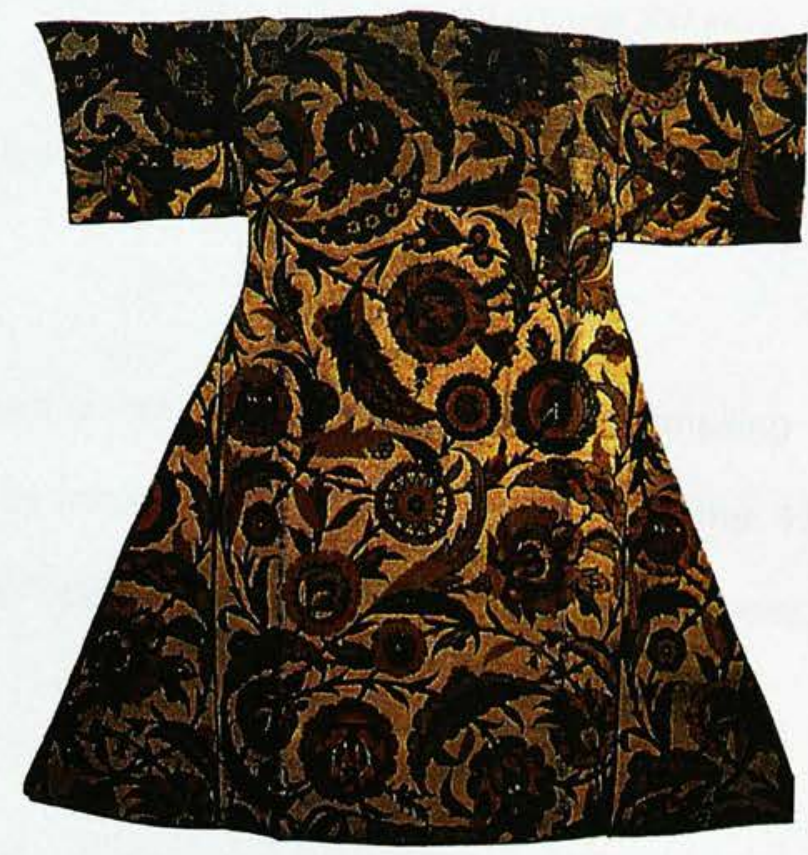

Figure 49 (a)

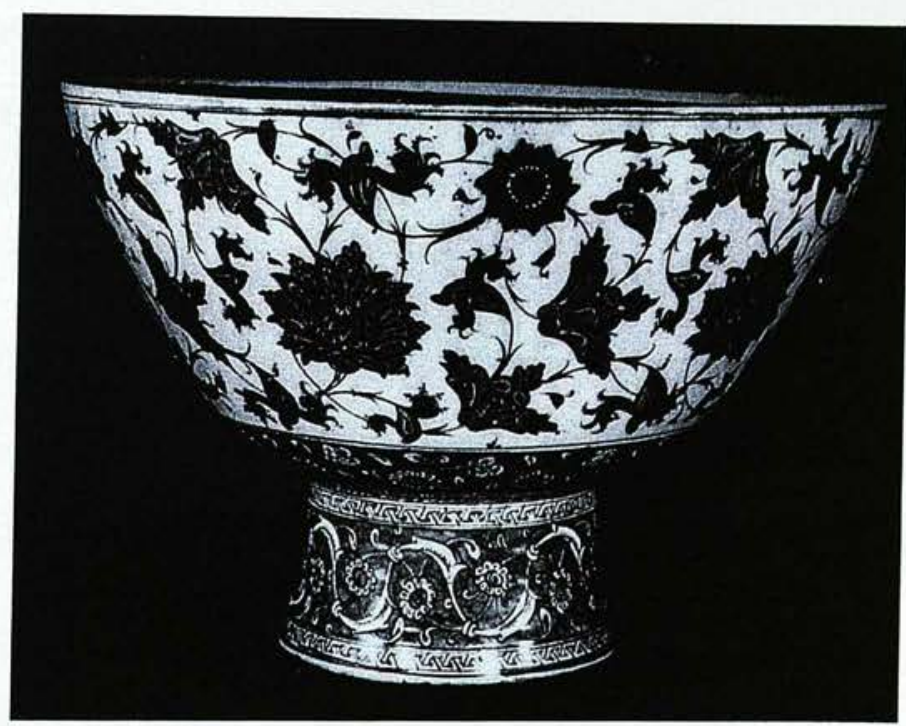

Figure 49 (b)

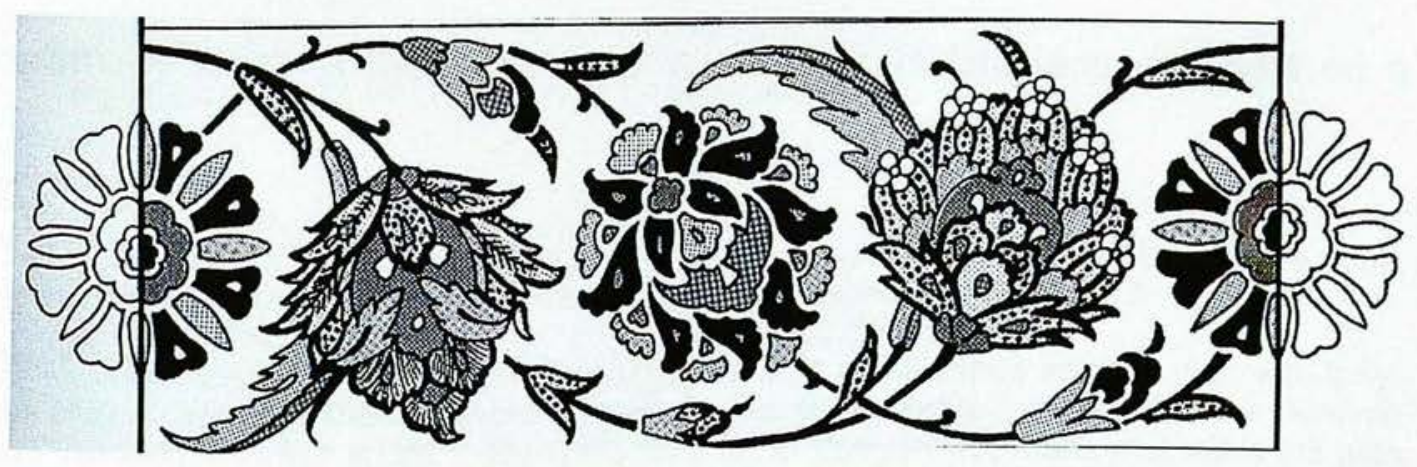

Figure 49 (c) 
"Of this shape they want 300 , of the long shape in the annexed drawing 300 more, and another 300 half as big again as the type of these long lamps, in all 900, part plain and part with latticinio decoration: and in addition, one of those lamps, or lanterns, for state rooms ${ }^{113 "}$.

In his essay Charleston reaches a conclusion that Turkish glassmaking is limited only to bottlemaking. His interpretation comes from one of the $17^{\text {th }}$ century traveller Evliya Çelebi's ${ }^{114}$ notes which describes a similar procession nearly one hundred years later:

"They are mentioned specifically as bottle-makers, and it seems from this fact and from the presentation in the miniature that in fact their craft was limited to this one branch of the industry, ...There seems little call to seek amongst these craftsmen the makers of the complicated latticinio glasses of sixteenth-century type which are somewhat vaguely attributed to the glasshouse of Beykoz ${ }^{115 n}$.

But, at the same time Charleston says that those forty-five firms working making glass dishes which are mentioned in Evliya Çelebi's notes ${ }^{116}$ are "inconceivable". And Charleston interprets Evliya Çelebi's description of glassdishes, as meaning window glassmaking. Here, there are two different ceremonies and covering a period of approximately one hundred years. Consequently it is a mistake to assume these explanations, with regards to a ceremony which is held about one hundred years later and comment on a

\footnotetext{
113

$114 \quad$ Charleston, $\mathrm{p} 18$.

Goodwin, p 151, "An indefatigable traveller, scholar and musician, he wrote a book, mingled with reportage, fantasy, political diatribes, and personal recollections."

${ }_{116}$ Charleston, p 21. five shops; they pass making dishes of glass on litters. The bottle-makers... are one hundred and five men, with four shops... The glass factories at Constantinople are, that within the gate of Jubbal, that before the gate of Eyub, and that within the gate of the potters, and at Khasskoi. There are none at any other place. They pass making bottles. Whoever wishes to see a specimen of the fire of hell, may look on the fire in these glass factories;... "
} 
different miniature, should be definitive. Unfortunately, therefore, in that particular period, it is not clear what the term 'bottle-making' extends to. It can easily be interpreted as a general classification of tall jugs, pitchers or vase-like forms which can hold various materials. In addition to this, whilst Charleston was writing his essay, he obviously only had the left page of the miniature. The scene in fact covers two facing pages. Consequently, he has drawn his conclusion from the glassmakers parading behind the furnace who are depicted only carrying bottles instead of those on the facing page carrying more complicated forms.

Throughout history, as seen in the previous example, artists have frequently represented the application of their art for different reasons. These kinds of depictions define the link between the individual and the formation of the object. The purpose of depicting the artist at work is to break down and demolish the routine of experiencing everyday and practical objects in a visual and tactile manner, but instead to gain an insight into and an appreciation of its form and decoration. Observations of the formation increase the observer's delight and expectations. At the same time, the feeling of permanence inspires the artist to expand the boundaries of his art.

Sometimes, these artists display their artistic personality and their works with pride, for example, in parades, and often they think to demonstrate their skills and show the difficulties of their art as a decoration on its form. It is possible to find many examples in other, different branches of art. One fine example of this perspective can be found on an antique Greek Hydria ${ }^{117}$ that reflects this

117 A pitcher used to carry water which has one vertical and two horizontal handles that help to support it whilst carrying on top of the head. 
unchanging attitude for centuries. (Figure 50) This painting indicates the interior of a pottery workshop and Athena crowns the potter with a tiara made by daphne leaves. Here, the description shows the precious nature of the artist and emphasises importance to this existence. A view throughout history suggests that there is not always a vast difference in mentality, just in time and place. The similarities of these samples in regards to their content are astonishing. Although in Lancashire, England the celebration of the guild of merchants ${ }^{118}$ goes back to 1329 , in 1842, engravers and glasscutters processed and presented their products with pride. (Figure 51) Also in 1888, "the Glassmakers and Cutters Tenth Grand Picnic" in Stourbridge is another artistic display of glassmakers $^{119}$

Today, in many branches of art, artists build some special demonstration areas in their work places to present their skills to the public. Also they delight in amazing their audience by theatrically showing their capabilities. As time goes by, demonstrating their skill becomes an integral part of their work and some of the best examples can be found in glassmaking. There are many examples of these demonstrations all over the world such as Uredale Glass, Sanders and Wallace, Gillies. Jones etc ${ }^{120}$. Of course, glass provides its audience with a more accessible spectacle because of its technical properties which allow it to

118 The Illustrated London News (London, 1842, Sept. 10), Vol. I, p 276.

119 Polak, Ada, Glass-Its Makers and Its Public (London, 1975), pp 182-184. “...the central event of the day was the grand procession of the members of the trade with an artistic display of flint and coloured glass. But added to the traditional forms of entertainment were others distinctly of the new age: the visitors could take rides on steam horses or make an ascent by balloon." Original documents from the British Friendly Societies' are preserved in the Central Library, Brierley Hill.

${ }_{120}$ More examples can be named such as Selkirk Glass, Caithness Glass, Millrace Glass, Edinburgh Crystal, Stuart Crystal, Gleneagles Crystal, Corning Glass Centre, Pilchuck Glass School. 


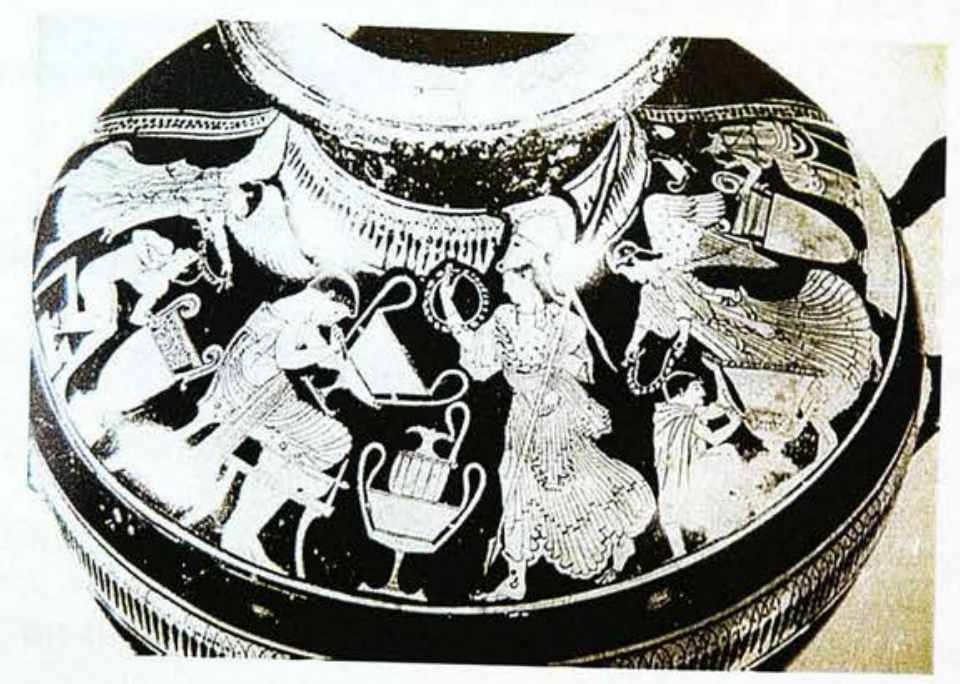

Figure 50

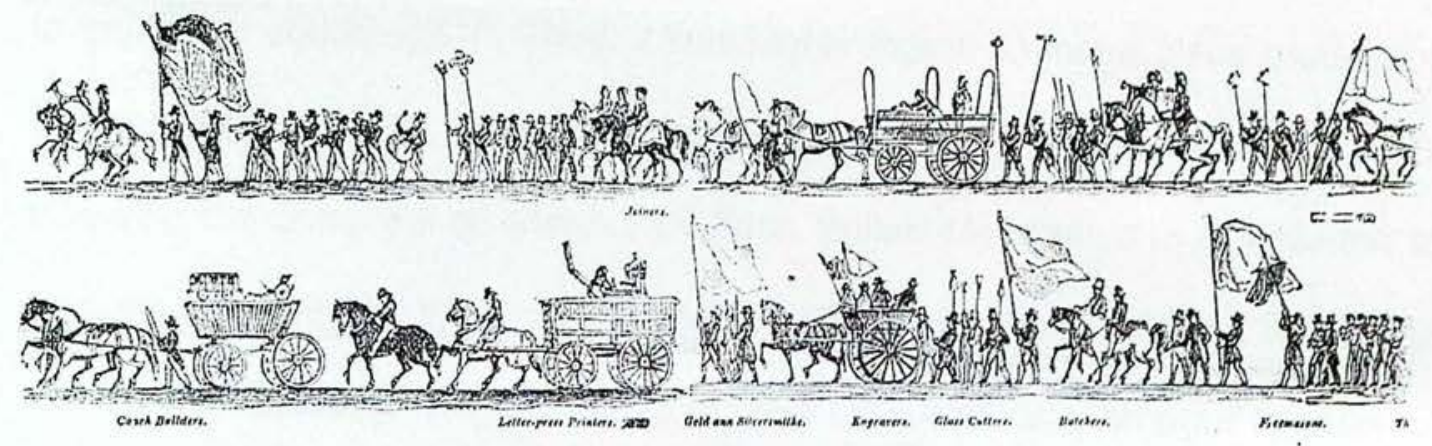

Figure 51
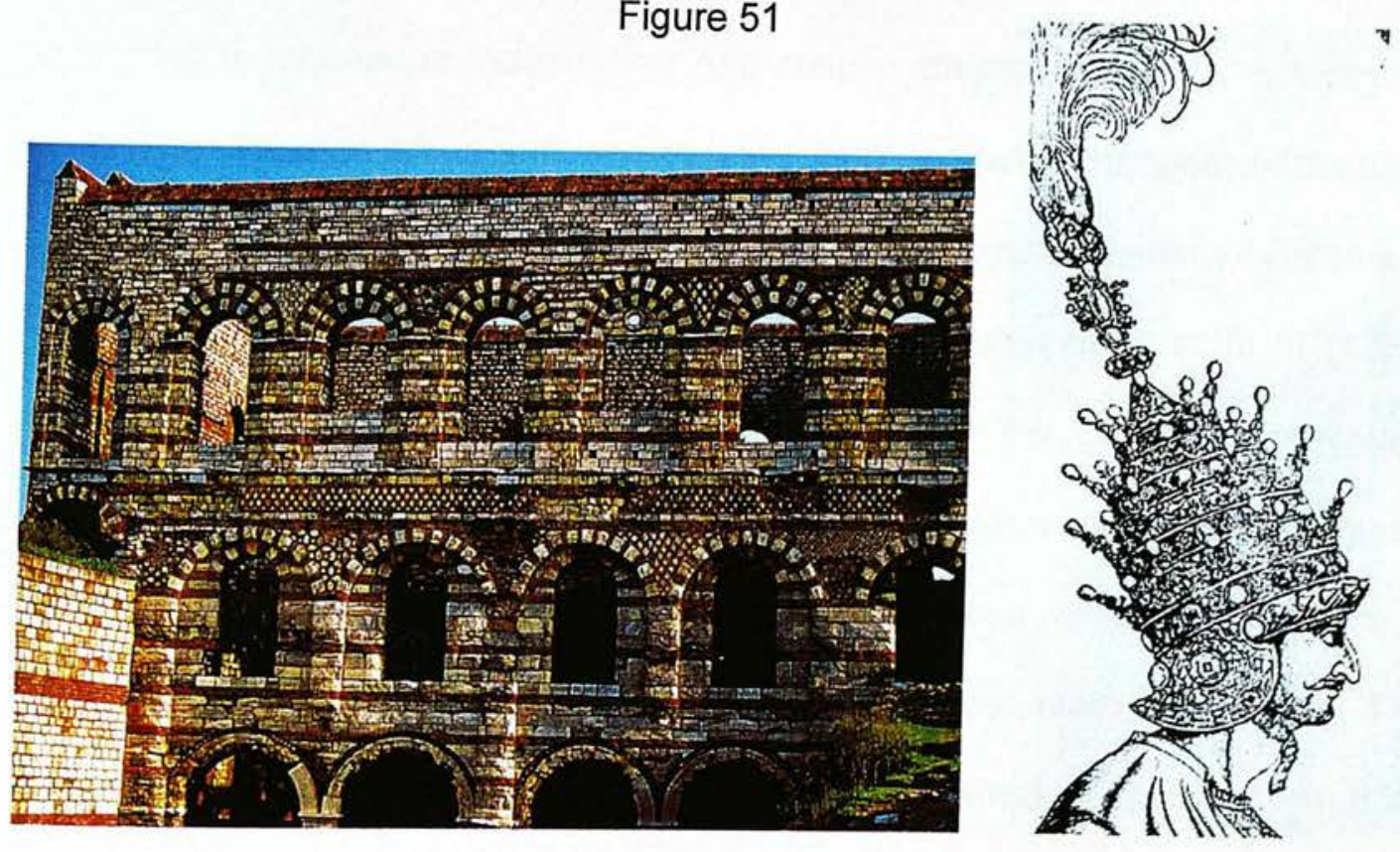

Figure 52

Figure 53 
be processed quickly and there is also usually only a short time from the beginning to the end of its production.

In the Middle Ages, Syria had positioned itself at the centre of Islamic glassmaking. The most brilliant time of Syrian gilded and enamelled glass was in $13^{\text {th }}$ and $14^{\text {th }}$ centuries and came to an end in $15^{\text {th }}$ century due to Timur's (known as Timurlane) (reign 1370-1405) raids in the country. Following Timur's invasion the skilled artisans were forced to move to Samarkand ${ }^{121}$. In the meantime, it is convenient to remember that glass of this period of time was considered to be a very precious material and was presented to the Sultans and to important statesmen ${ }^{122}$. Thus, it was highly logical to move glass production centres close to the centres of administration and government. In 1453, following the conquest of Istanbul by Fatih Sultan Mehmed, the city started to become the centre of the Empire. Later on, after the invasion of Syria and Egypt in 1516, by Sultan Selim I (1512-1520), the Caliphate was brought to Istanbul and the city became the heart of the whole Islamic world. The changes occurring in Istanbul in industry, art and culture affected the glass industry as well. The Ottoman glass industry adapted itself to these changes, centralised itself in Istanbul and produced activity around Eğrikapı, Bakırköy, Balat and Ayvansaray in c1600s. (Map 4) Furthermore, in the reign of Mustafa III (17571774) new regulations were established. As a result of this, glassmakers moved their workshops to a particular area around Tekfur Palace (Figure 52) (Map 4) and paid rent for these workshops. Hereupon, the close relationship between glassmaking by the Ottomans and the government was quite remarkable. The regulations brought by Sultan Mustafa III for glassmaking progressed from

122 See Chapter 2. 2. 1. Seljuk Glass, Imad al-Din Zangi, p 49. 


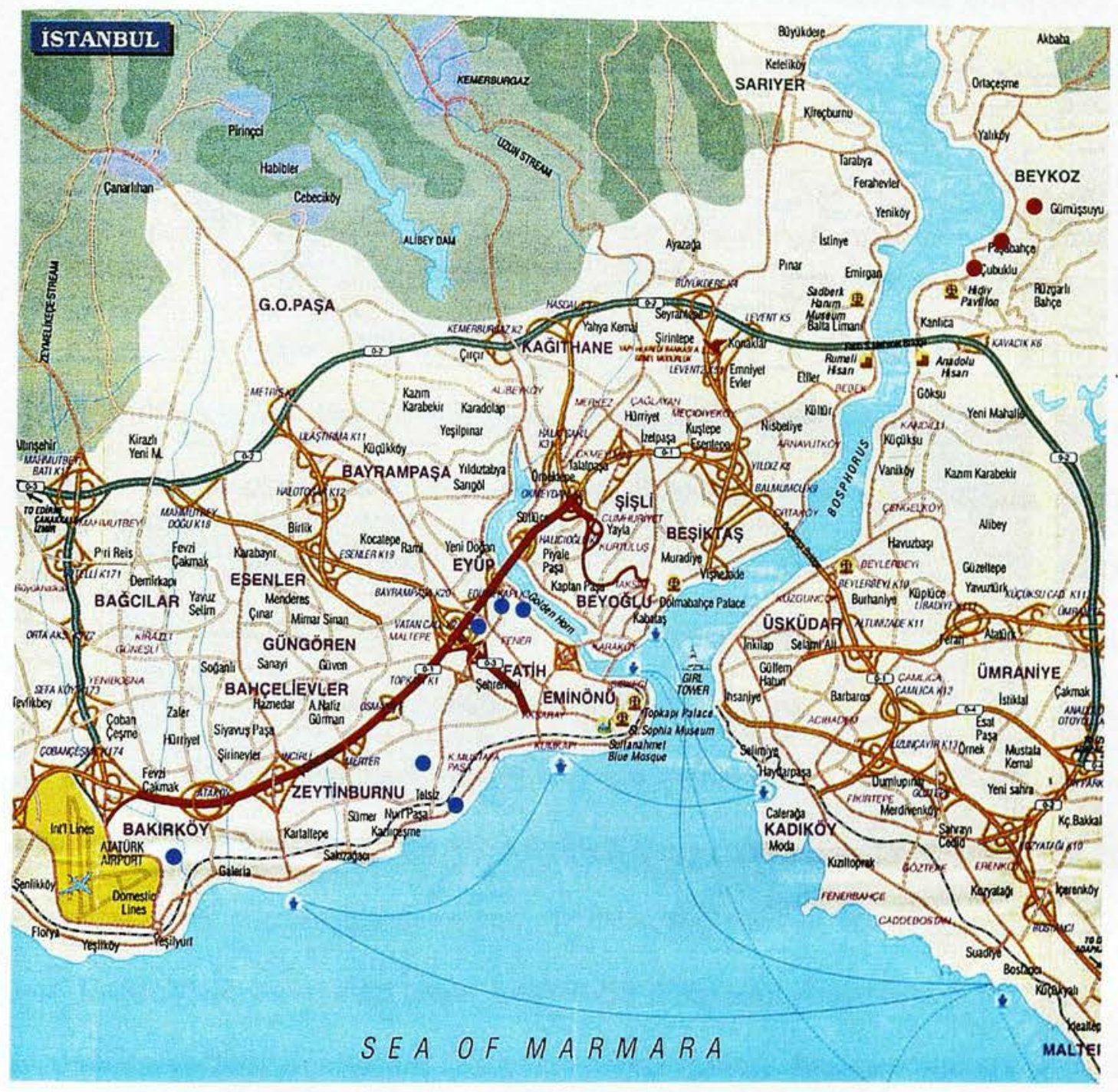

Map 4

- Ayvansaray, Balat, Bakırköy, Yedikule, Kumboğazı, Tekfur Palace

- Beykoz, Çubuklu, Paşabahçe 
merely moving the workshops around the Palace and the income from these workshops was transferred to a trust. Regulations have also paid great care to protect the rights of the glassmakers and make regular payments to the elderly and disabled from this fund ${ }^{123}$.

Henceforth, instead of looking into the glassmaker's wages and the number of their working days, one should focus on the reasons for this branch of art to be discontinued as it had gained great attention from the Ottoman Empire. The main reason observed is the beginning of liberal commercial politics, which allowed the import of glass products from abroad. The government's ruling strategy paid great sensitivity to the subject of exporting, for instance fine-white sand from the shores of Kumboğazı near Yedikule ${ }^{124}$ (Map 4) which was used for glassmaking and was strictly monitored in regards to exportation. It is therefore puzzling that they should have tolerated the import of glass objects, an act which nearly caused the cessation of Ottoman glass art. For example, in 1899 in Paşabahçe an entrepreneur named Saul Mediano established the factory "Fabrica Vetrami Di Modiano"125. It was a large factory and, depending on which source one regards; it had 500 or 900 workers, but was unable to compete due to the number of products imported from abroad and went into decline in 1902. The reign of Sultan Mahmud II (1808-1839) marks the beginning of the reforms to adapt the country to European culture. Every kind of product was popular, if it came from abroad in this period of time. However, a couple of centuries previously, the Ottomans witnessed the importation of glass from Venice by

Türk Camcılığı Sergisi (Ankara, 1947), p 2.

Türk Camcılığı Sergisi, p 1.
Kuzudişli, Zeynep, “Geleneksel Türk Camcılığı - Yaşayan Camcılığımız”, 4. Boyut (April 125 Kuzudişli, Zeynep,
$1990)$, Year 1, No. 2, p 21. 
Sokullu Mehmed Pasha (1505-1579) in mid $16^{\text {th }}$ century. Michael Levey summarises this matter in his book "The World of Ottoman Art":

"Of course, imports from the West were as old as Mehmed the Conqueror-who had positively imported Gentile Bellini. For Suleyman 'the Magnificent' Venetian goldsmiths had created that specially sumptuous helmet. (Figure 53) Ahmet I had begged for Venetian glass ${ }^{126}$ for his new mosque... ${ }^{127}$."

In the heyday of the Ottoman Empire, no one thought that it would collapse but, every small mistake and weaknesses in different aspects created the base for its decline.

In the time of the Ottomans, especially in the reign of Magnificent Suleyman, the balanced relationship between art and the social structure started to change due to the pressure of European capitalism. However, both in its heyday and also during the decline of the Ottoman dynasty the administration had not changed in its approach to the arts and likewise to glass. Glass art and production were important to the Sultan and his court and were always dealt with in a sensitive manner. In glass production, the finest examples of Beykozware were produced in the $18^{\text {th }}$ century and were encouraged and supported by Sultan as a part of his personal special interest.

\footnotetext{
126 Carswell, John, Iznik Pottery (London, 1998), p 106. "The Sultan managed to cajole the Venetians into providing the coloured glass for the windows."

127 Levey, Michael, The World of Ottoman Art (Norwich, G. B., 1975), p 130.
} 


\section{2. 3. BOSPHORUS GLASS "BEYKOZWARE"}

At the end of the $18^{\text {th }}$ century, glass production started with the establishment of a glass studio in Istanbul on the Anatolian side of the Bosphorus, a district called Beykoz. Later, these products became known as Beykozware, following the establishment of other studios in the same district, such as Paşabahçe, Çubuklu and Incirköy. (Map 4)

In the $18^{\text {th }}$ and $19^{\text {th }}$ centuries, Beykozware products could be identified by being transparent crystal cut glass and gilt-decorated ware, opalinnes, and coloured glasses together with çeşm-i bülbül products.

The Beykozware products have inclined towards a particular meaning and this is the main theme that forms the identity of Beykozware. These products have never been mere tableware and as a consequence of this quality, they have existed as decorative objects without being restricted by such considerations. Beykozware originates from some exceptional ware which do not exist in any other cultures such as gülabdan (rose-water sprinklers), aşurelik (oriental pudding bowls), karlik (This is a form of jug that cools its contents with snow which has been placed in a little pouch near the handles ${ }^{128}$ ), lâledan (a single tulip vase). The identity of Beykozware is hidden in its forms, its purpose and its decorations. In spite of the fact that similar decoration appears on glassware made in a few European countries, especially Bohemia, the most widely known decoration on Beykozware is the parsley motif drawn on transparent glass by 
gilt. These products are named maydanozlu $u^{129}$. (Figure 54) They are transparent cut glasses and in addition to a parsley leaf, they are decorated with other leaf motifs, stylised flowers, hearts, moon and stars, lines in harmony with the shape of the product and also some geometric drawings. (Figure 55) Though the common features of these decorations are similar, the same element is never repeated. What is attractive here is that the artist performing the decoration has reflected his own feelings and creative skill on the product at that particular moment. Many varied cutting combinations have provided the opportunity to perform very different gilt decorations. Though the motifs on the products with the same purposes are similar, noticeable differences have certainly been found. (Figure 56) It is widely believed that cut and gilt decorations on such transparent glasses are the products of the initial period ${ }^{130}$.

In addition to the other motifs the knob on the lid of some covered bowls has been transformed into a Mevlevi turban which is another unique characteristic of Beykozware. (Figures 57 a/b) Many sources give the same interpretation regarding the creation of this shape. This turban shaped knob design belongs to Mevlevi Derviş Mehmed Dede who trained in Italy and established a glass studio following his return to Beykoz $z^{131}$. At the end of the $18^{\text {th }}$ century, it appears that the glassmasters were capable of creating assorted designs, relying on technical knowledge; creativity, and the ability to use their own skills. The interesting point is that these glassmasters have not endeavoured to create any other original forms beyond this one. Thus, with their unusual shapes, the eyecatching pistols were made by copying the pistol-shaped bottles of $18^{\text {th }}$ century 


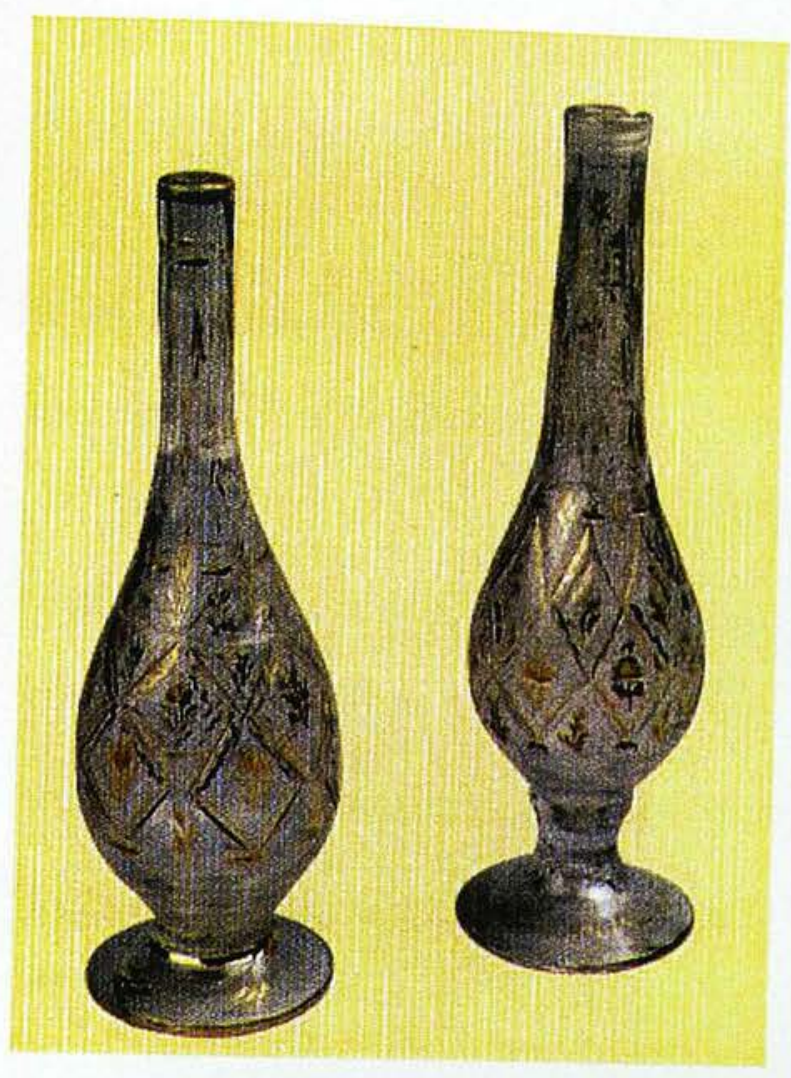

Figure 54

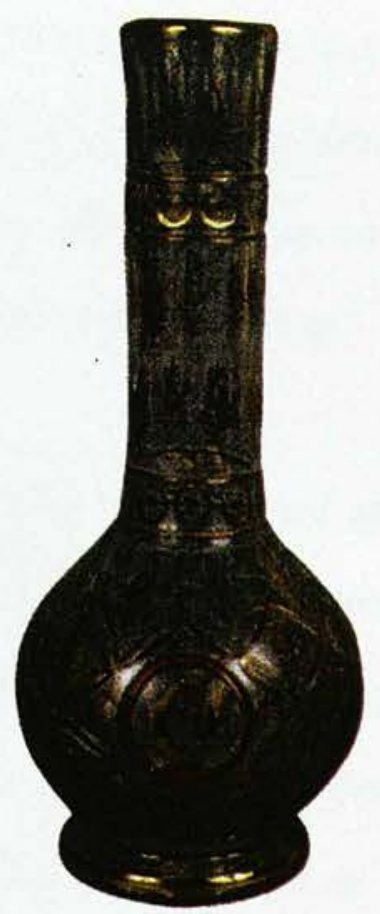

Figure 55

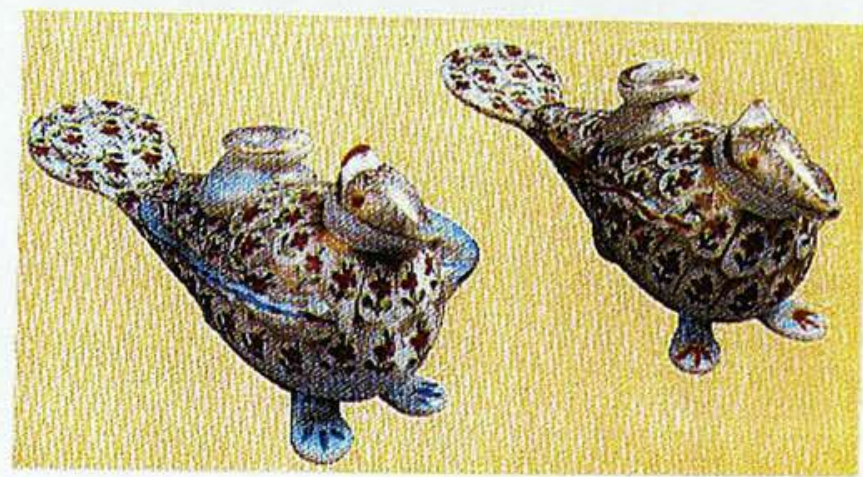

Figure 56

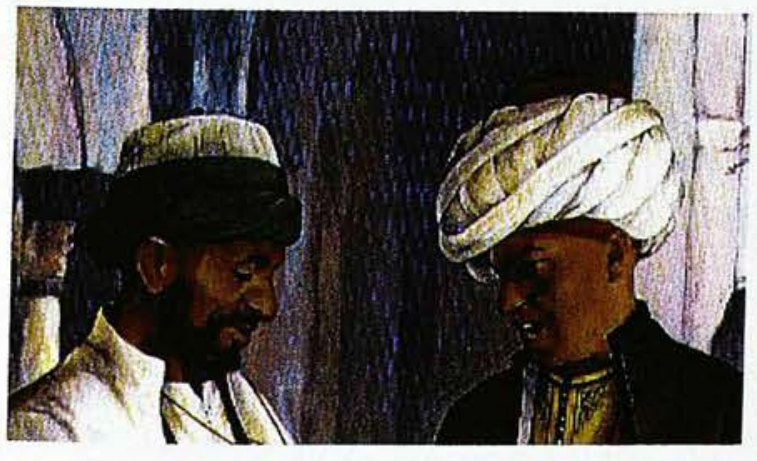

Figure 57 (a)

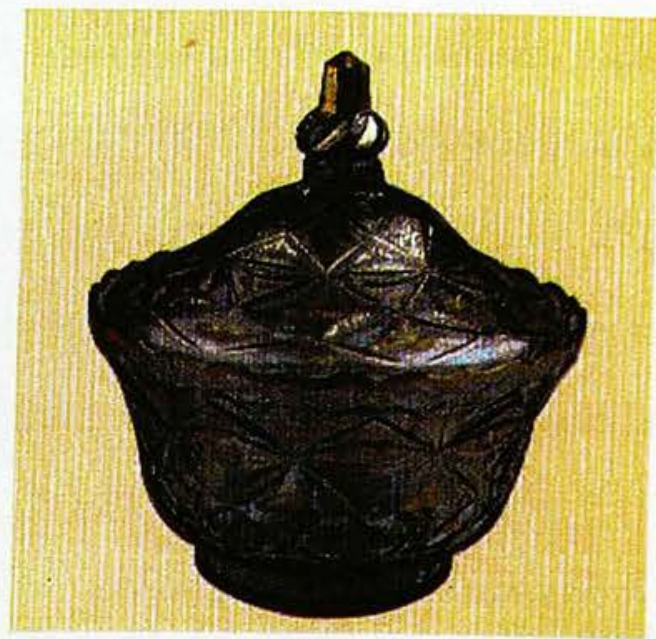

Figure 57 (b) 
Venetian glassware. (Figures $58 \mathrm{a} / \mathrm{b}$ ) This limited creation of forms is an indication that Turkish glass art has primarily been based on decoration rather than form. Here, it is possible to monitor whether the Turkish glass art culture is relevant to its manipulation and that formalisation is secondary, as it attaches so much importance to the application of various decoration, painting and cutting.

When mentioning Beykozware, one of the products that is associated with the forefront of production is lâledan. There are some distinguishing points that separate lâledan's identity from other Beykozware products. As a cultural heritage lâledan stood out with its unique specification of being a form that was attributed to a particular flower. Lâledan is not any ordinary vessel or vase. They reflect the Turk-Ottoman culture of decorative objects. It is the power of tradition which has dictated the form and has found a special usage for it. The purpose of its manufacture is to present a single, excellent depiction of a tulip. One of the oldest examples of its use is seen in Figure 59, this etching from 1787 depicts Sultan Abdülhamit I (reign 1774-1789) standing over a tray of lâledans, each containing a single tulip.

The tulip motif became very popular at the time of the Ottomans and has been translated into several decorative applications such as textile, miniatures, rugs, calligraphy and especially pottery/tiles which signified an incredible importance to the history of a simple wild flower which grows freely on the mountains. The abundant use of the tulip motif started in the Ottoman period and even gave its name to this time, "Tulip Era" ${ }^{132}(1718-1730)$ in the reign of Sultan Ahmed III

\footnotetext{
132 Turkish: Lâle Devri, In this period of time, Sultan and the Statesmen were captivated by a festive atmosphere. As a consequence of this ambience, this period has created great achievements in art for the Ottomans, especially in literature, music and poetry, as well as painting and calligraphy.
} 


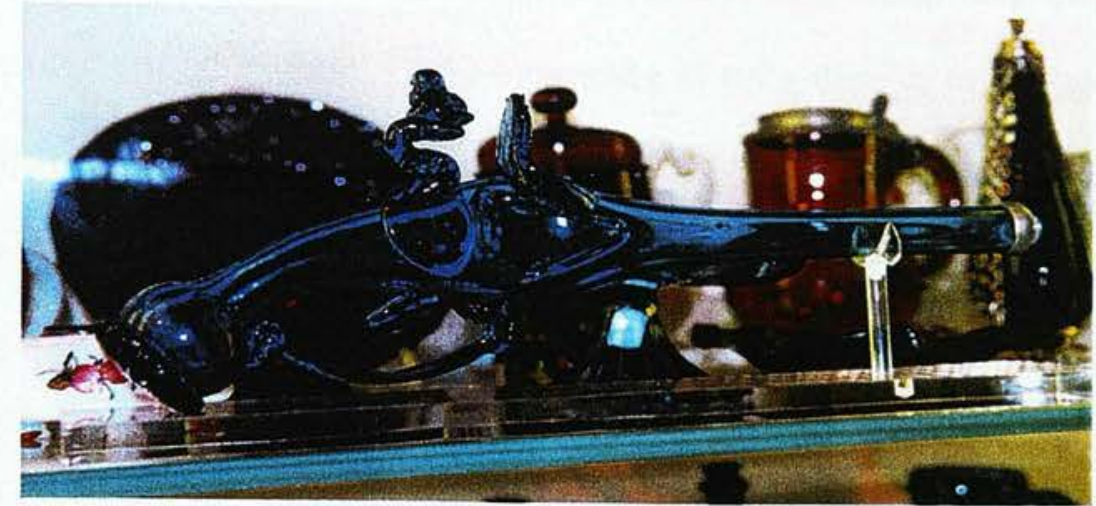

Figure 58 (a)

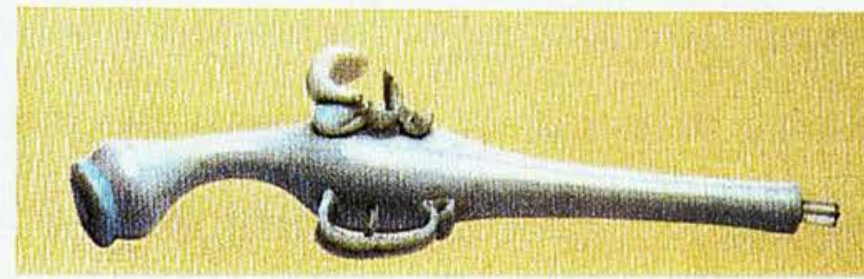

Figure 58 (b)

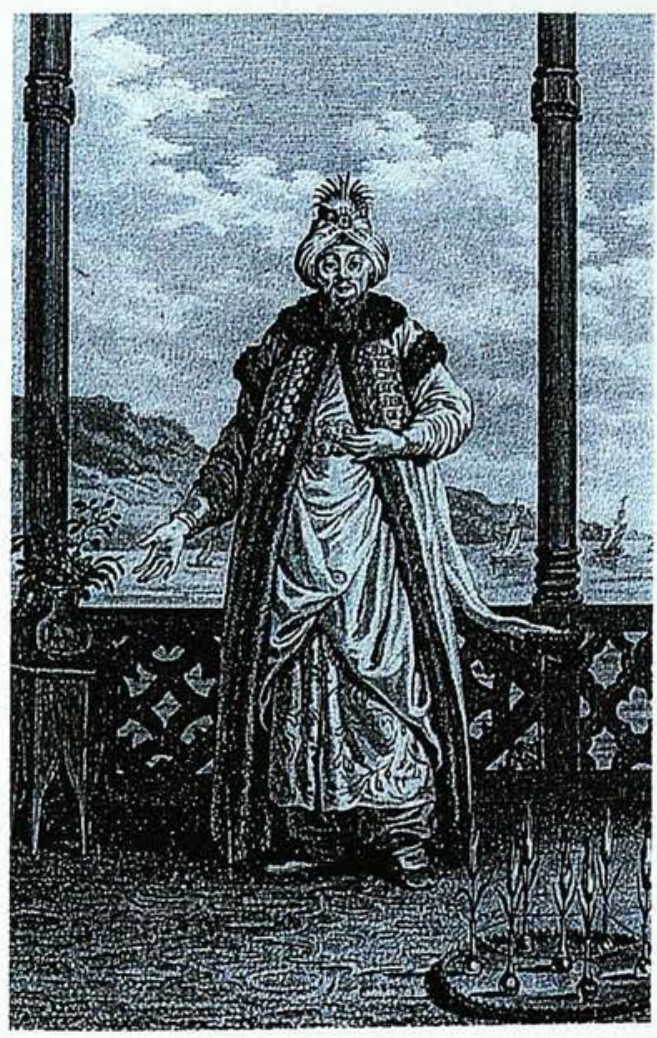

Figure 59

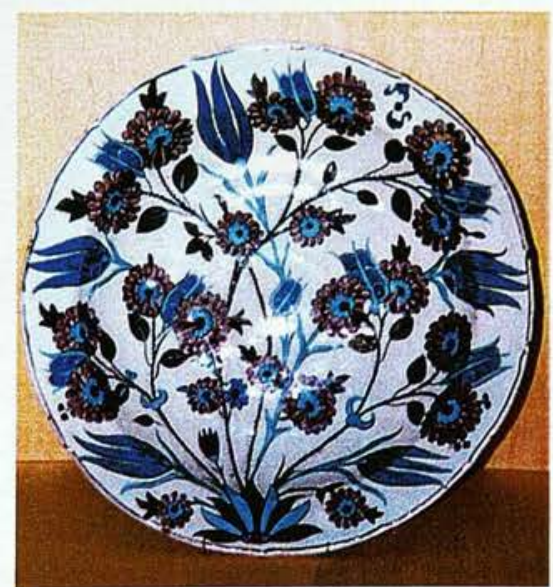

Figure 60 (a)

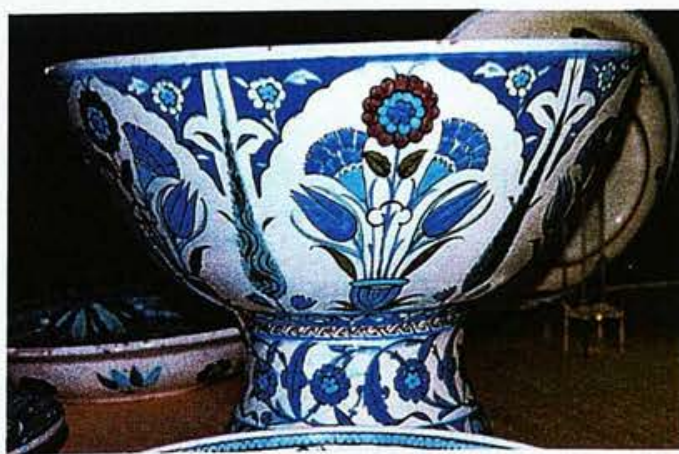

Figure 60 (b) 
(1703-1730). However, this does not mean that the use of the tulip originated in this particular period of time. Early examples of tulip design in Seljuks can be seen in tulip decorated tiles, found in the excavations of Kubad-Abad Palace, Beyşehir Lake, Konya. In fact the popularity of the tulip motif goes back centuries and derives from the Turks addiction to flowers and their special love of tulips. For example, there are beautiful samples of tulip designs and other flowers such as stylised carnations, spring blossoms and lotus flowers which are frequently witnessed on mid $16^{\text {th }}$ century Iznik tiles. (Figures $60 \mathrm{a} / \mathrm{b}$ ) Likewise, the appearance of such flowers on textiles is a result of the vanity of sultans who desired to look their best and adorned themselves with the tulip motif. (Figures 61 a/b) Certainly the tulip was the symbolic emblem of the Ottoman court in the period of Sultan Suleyman I (reign 1494-1566) which naturally was one of the main foundations of its application.

In Istanbul, between 1681 and 1726 the existence of 1108 tulips under different names and characteristics has been recorded ${ }^{133}$. In addition to the rules governing the buying and selling of tulip bulbs, it was decreed that there be heavy penalties for the misappropriation of the tulip. For one period the tulip was more important and valuable than a human life ${ }^{134}$. Even Sultan's poet Nedim described the indulgence and depravity of their world:

"Let us laugh, let us play, let us enjoy the world to the full"135

\footnotetext{
$133 \quad$ Pavord, Anna, The Tulip (London, 1999), p 54.

$134 \quad$ Lodewijk, Tom, The Book of Tulips (London, Sydney, Auckland,Toronto, Johennesburg, 1979), p 37.

${ }_{135}$ Atıl, Esin, Turkish Art (Washington and New York, 1980), p 35.
} 


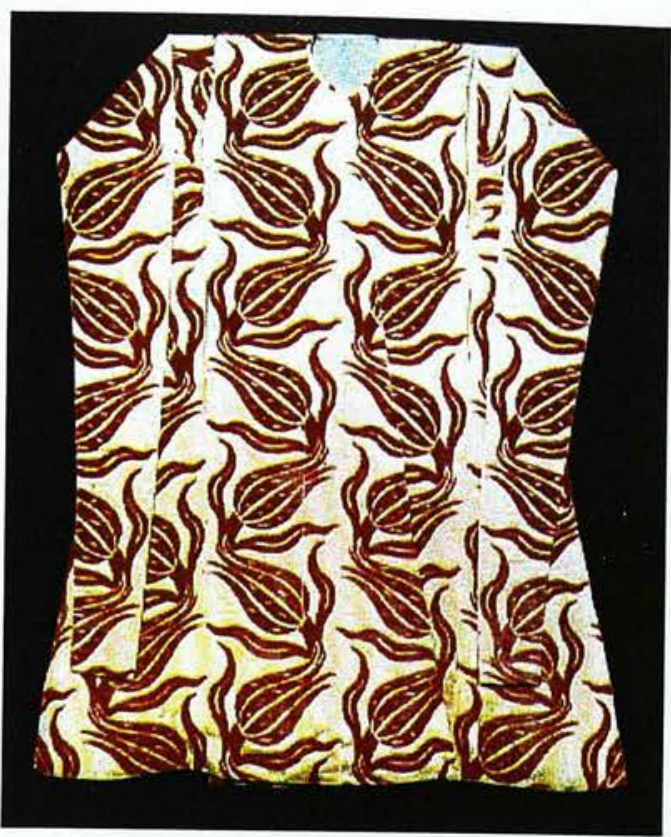

Figure 61 (a)

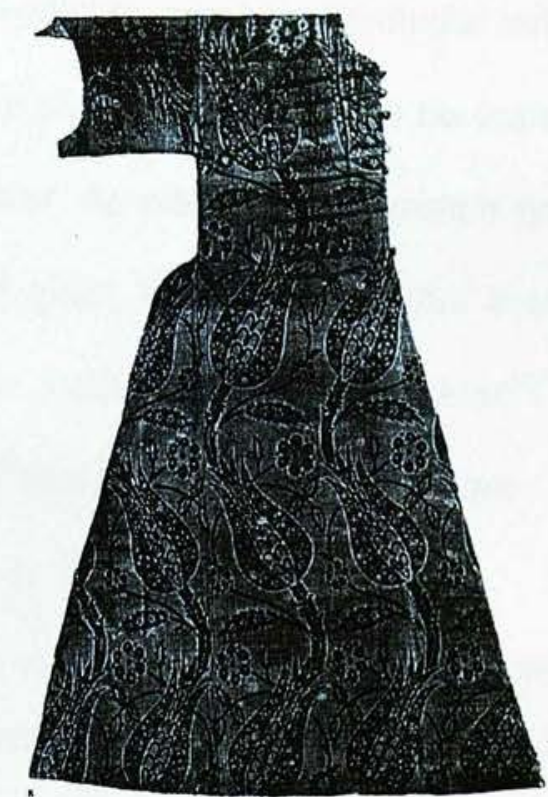

Figure 61 (b)

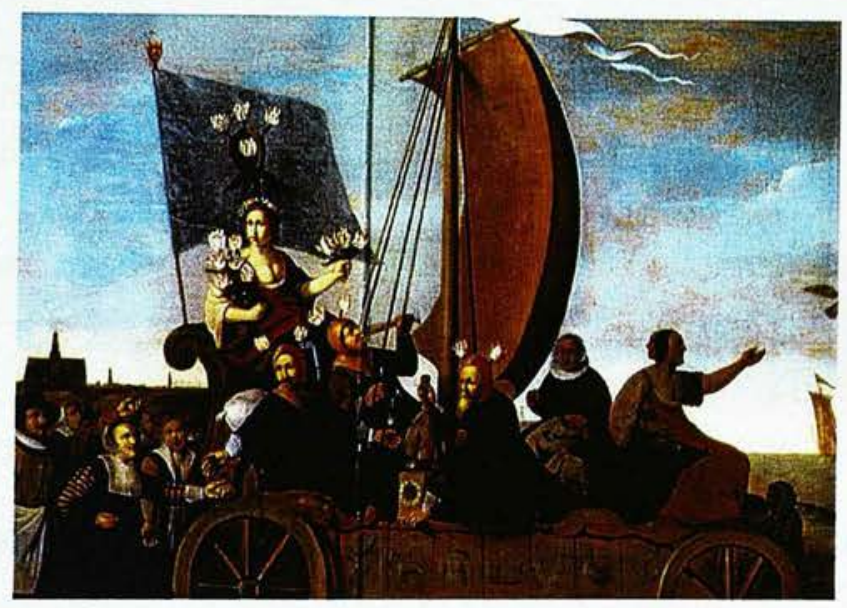

Figure 62

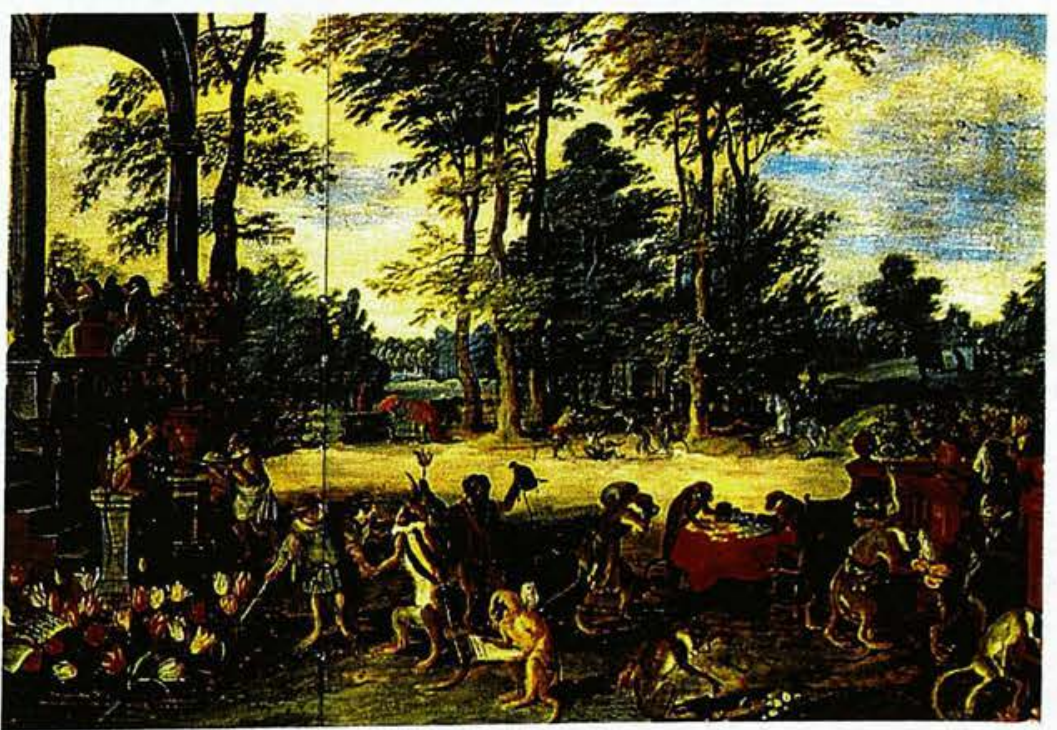

Figure 63 
It is hardly surprising that the scale of this addiction combined with the influence of the Sultan and the desire of the people to please him $^{136}$ should be expressed in the production of a vase for a single flower. As well as the common types of lâledan such as crystal, opaline, coloured glass and çeşm-i bülbül there are more unusual examples in existence, for instance, gold and silver ${ }^{137}$. The Author Anna Pavord in her book "The Tulip" makes reference to lâledan:

"...sometimes as single blooms displayed in single vases. European travellers had already noted this particularly Turkish custom: to present a single, perfect bloom in a narrow-necked container or Lâledan. ${ }^{138,}$

Lâledan is also known as Şukufedan. The reason for this comes from the time of Sultan Ahmed III when his Grand Vizier Mehmed was called Lâlezari, 'lover of tulips'; or Şukufe Perveran, 'lover of flowers'139.

Its soft oriental outline, wide-open mouth, narrow sinuous neck, plump body and elegant stem identify lâledanware. They are generally decorated with gilt or small wild flower motifs in distinct geometrical patterns. The dimensions of the motifs and the order of their application form a harmonious synthesis with their pear-shaped bodies. Occasionally it appears that decoration may have

\footnotetext{
136 Goodwin, p 260, "When the tulips are in flower, and the Grand Vizier wishes to show them to the sultan, care is taken to fill the gaps where the tulips have come up blind, by flowers taken from other gardens and placed in bottles. Beside every forth flower is stood a candle, level with the bloom, and along the alleys are hung cages filled with all kind of birds. The trellises are all decorated with an enormous quantity of flowers of every sort, placed in bottles and lit by an infinite number of glass lamps of different colours. These lamps are also hung on the green branches of shrubs which are specially transplanted for the fete from neighbouring woods and placed behind the trellises. The effect of all these varied colours, and of the lights which are reflected by countless mirrors, is said to be magnificent...."

${ }_{137}$ Bayramoğlu, Fuat, "Glass Distinction", Turquoise/The International Magazine of the Turkish World (Spring, 1990), p 20.

138 Pavord, p 35.

$139 \quad$ Lodewijk, p 37.
} 
taken a secondary role to the production of these beautiful and practical forms. They are produced by blowing, with the stem and the foot being attached later.

During the reign of Sultan Suleyman I much importance was placed on the tulip flower and when the Belgian Ambassador Busbecq visited, he was enchanted by the flower's beauty. And so during the latter half of the $16^{\text {th }}$ century he took tulip bulbs to Vienna and as such opened the way for the growth of the tulip across Europe ${ }^{140}$. Following this, the craze for the flower spread quickly throughout Europe. It was common during this time for a miller to exchange part of his mill for a single bulb or for a bride to present rare bulbs as her dowry ${ }^{141}$. In the $17^{\text {th }}$ century "Tulipomania" overtook Europe and painters were even inspired to describe this madness in their work. One of the most eye-catching examples of this period is a very amusing painting by Hendrik Gerritszoon Pot (15851657), entitled "Flora's Wagon of ldiots". (Figure 62) Also a painting by Jan Brueghel (1601-1678) which depicts unscrupulous and unmannerly Tulip Merchants dressed up as monkeys. (Figure 63)

Of course, the Tulipomania in Europe produced an effect on the production of decorative arts which was a development to be seen later on in the Ottoman Empire. In Holland, where the Tulipomania was most striking and an important artistic output was pottery, they made "Tulip Pagodas". (Figures 64 a/b) However, until the Head of the Royal National Tulip Society, the florist Barlow, designed ${ }^{142}$

\footnotetext{
$140 \quad$ Blunt, Wilfrid, Tulipomania (Middlesex and Melbourne, 1950), p 8.

141 Blunt, $p 12$.

142 Pavord, $p 250$.
} 


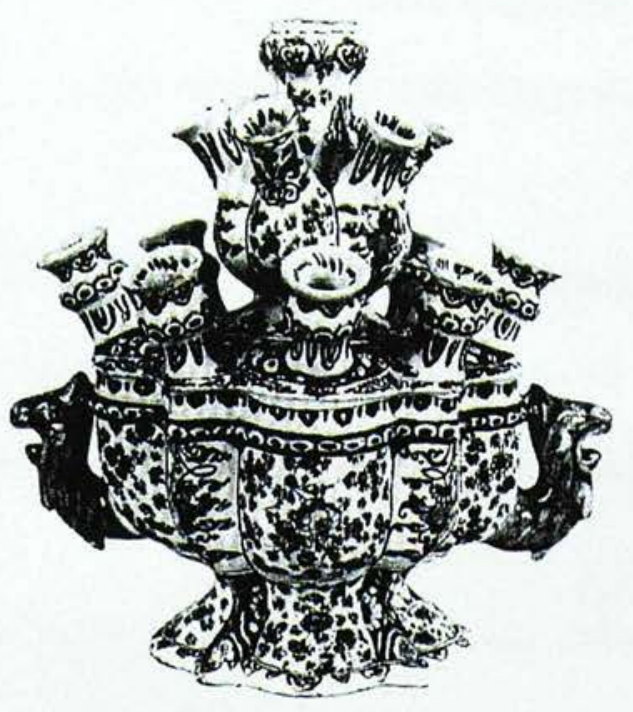

Figure 64 (a)

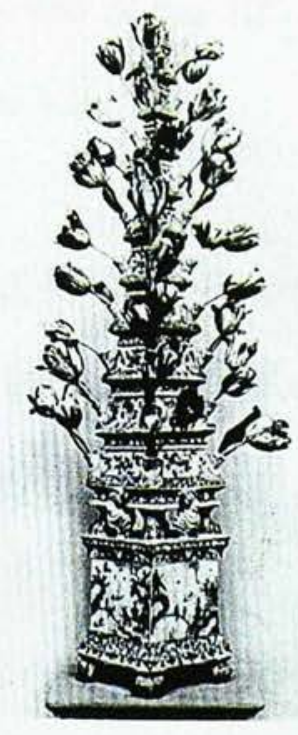

Figure 64 (b)

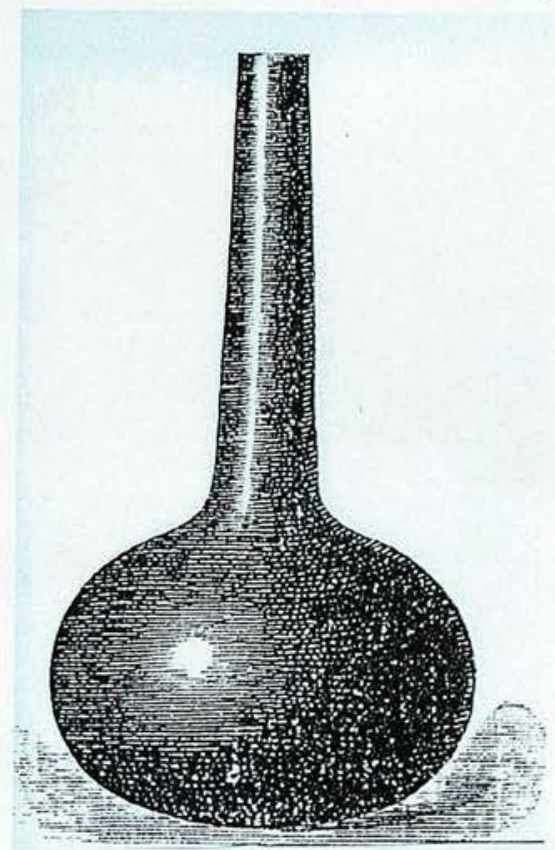

Figure 65

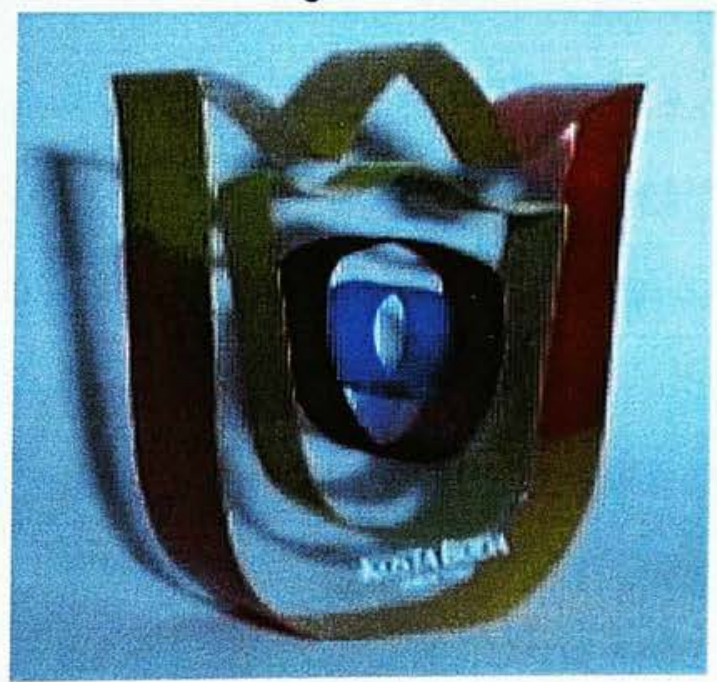

Figure 66 
a hideous black glass tulip vase (Figure 65) at the end of the $19^{\text {th }}$ century, there had been no specific form of vase designed for the tulip.

Today "Tulipomania" and "Tulip Era" has declined, nevertheless the tulip is still loved and desired throughout the world and its image and design is still represented on many contemporary forms. (Figure 66)

It is possible to put Beykozware in four categories:

1) Crystal-colourless glass

2) Coloured glass

3) Opaline glass

4) Çeşm-i bülbül

1) Crystal-colourless glass

Both during the production and after its cessation at Beykoz, Beykozware was continually held in high esteem by the public. Naturally enough Beykozware was started by one form or another but it is difficult to say which was the seed of growth. There is however speculation that crystal and colourless glass were the defining forms, but this theory is as yet unsubstantiated ${ }^{143}$. A broad look at Beykozware shows that almost every form was produced using crystal glass and the majority of pieces displayed a combination of gilt and/or cutting techniques. The gilt decoration applied on this type of glass has been fired at 
low temperatures and through everyday use the gilt may be partially removed, however there is generally a residual trace of the original lines and this is a particular quality of Beykozware which distinguish it from its imitators ${ }^{144}$.

Crystal and colourless glass makes use of decoration which is far removed from any excessively elaborate adornments. It utilises the clarity of the glass and occasionally gilt or cut edges, this produces beautiful reflections of light and gives an elegant and exquisite look; a characteristic which makes it distinct from other Beykozware.

2) Coloured glass

Beykozware produced with coloured glass maintains no particular distinction in form from the other products. The most commonly used colours are blue, red, green and their varying hues. (Figures 67 and 68 ) The surface decoration consists of gilt, enamel and cut decoration. In this decoration there is no difference in either technique or motifs from those found on the other Beykozware products.

\section{3) Opaline glass}

Opaline glass has a special place in Beykozware, not in form but from a technical angle and due to its distinct colour and methods of decoration. They are rich and varied enoughto create a category of their own. 


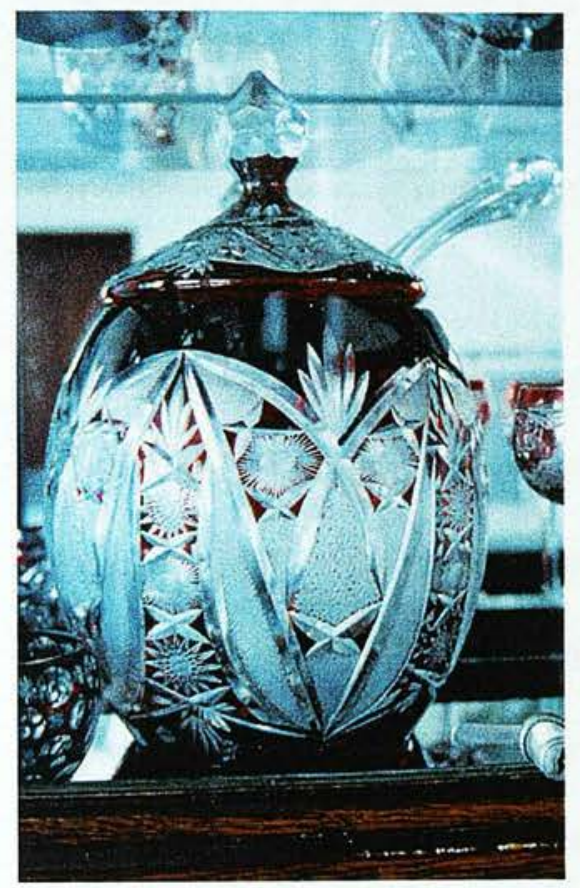

Figure 68

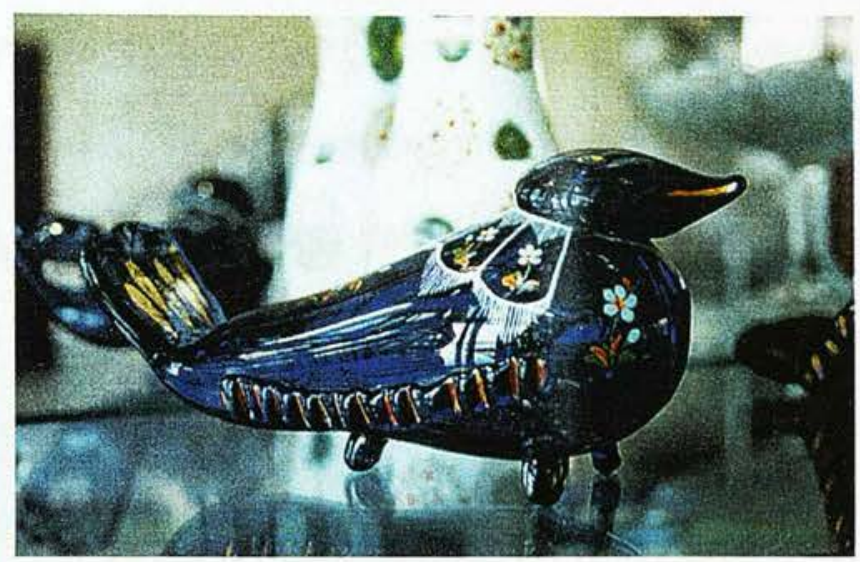

Figure 67

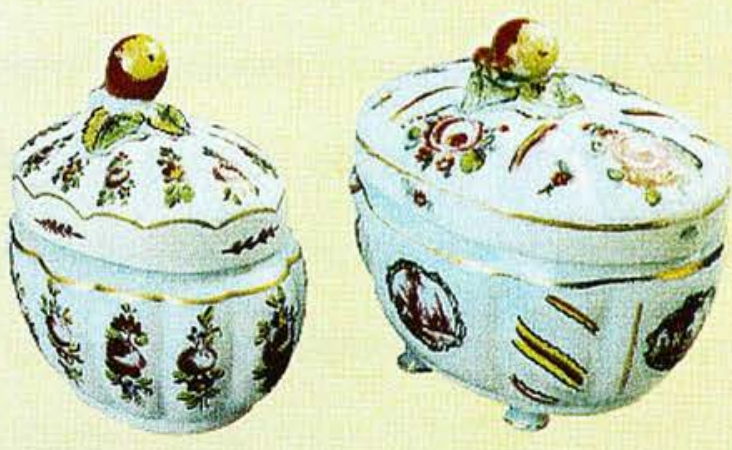

Figure 69

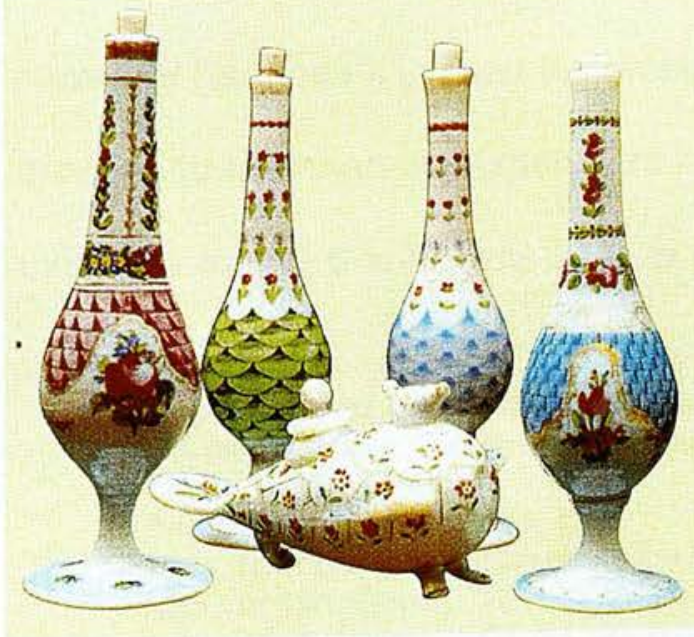

Figure 70

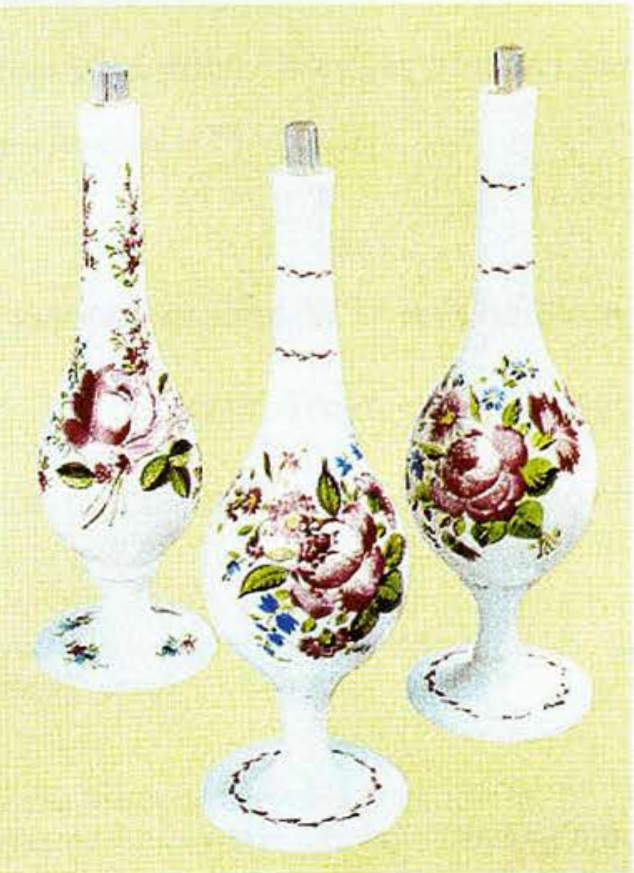

Figure 71 
Opacity is the result of light interference ${ }^{145}$ inside and at the surface of a glaze and glass. The transparency of this glass is changed by the addition of various materials. To make the glass opaline, into the batch must be added tin oxide $\left(\mathrm{SnO}_{2}\right)$, bone ash ${ }^{146}\left[\mathrm{Ca}_{3}\left(\mathrm{PO}_{4}\right)_{2}\right]$ and zinc phosphate ${ }^{147}\left[\mathrm{Zn}_{3}\left(\mathrm{PO}_{4}\right)_{2}\right]$ and other opacifiers $^{148}$. For the desired colour metal oxides will be added. The most common opaline example is milk-white; turquoise, blue, green, purple and their hues form the rest of the colour scale.

There are various different interpretations regarding the first invention of opaline glass. One of these comes from Önder Küçükerman, who states that Venetian glass masters developed ${ }^{149}$ special formulas and produced for the first time opaline glass which looked very much like porcelain. On the other hand Fuat Bayramoğlu in his article "Beykoz Işi Cam Eşya" points to the French physicist Réaumur (1683-1757) as inventing opaline glass:

"The French physicist Réaumur wanted to make a porcelain as it was very popular in Europe at that time, he produced a dough from glass which looked like porcelain and it became known as Réaumur porcelain or glass porcelain. ${ }^{150 "}$

However Réaumur's interest in porcelain developed around 1717 and he did not proceed further than the experimental stage with his work. There is no definitive evidence to say that he was able to produce porcelain ${ }^{151}$. Notwithstanding the

\footnotetext{
145 Thanks to Prof. Zeliha Mete, for sharing her knowledge. Correspondence on 21. 02. 2000, Dept. of Chemistry, Dokuz Eylul University, Izmir, Turkey.

$146 \quad$ Canav, p 98.

147 Sentürk and Istanbulluoğlu, p 15.

148 Mete, for more information about the opacity and the opacifiers see Appendix B.

149 Küçükerman, Önder, "19. Yüzyıldaki Sanayileşme Hareketinin Sembolü Olarak Beykoz Issi Camlar", Antik \& Dekor (1997), No. 40, p 102.

$150 \quad$ Bayramoğlu, "Beykoz lşi Cam Eşya", p 4. (Translation from Turkish)

151 Haggar, Reginald G., The Concise Encyclopaedia of Continental Pottery and Porcelain, (Netherlands, 1960), p 377.
} 
creation of the first true hard-paste porcelain has been credited to Etienne Mignol de Montigny and Pierre-Joseph Macquer ${ }^{152}$ after 1766 . When viewing both Önder Küçükerman's and Fuat Bayramoğlu's interpretations from a historical stance it becomes evident that there is a chronological discord with Fuat Bayramoğlu's idea which is more supportive of Önder Küçükerman's i. e. during the $16^{\text {th }}$ century in Venice, $17^{\text {th }}$ century in Germany and $18^{\text {th }}$ century in the whole of Europe ${ }^{153}$ opaline glass was commonly used.

Again, in Fuat Bayramoğlu's opinion, Turkish opalines reflect a reddish colour when it is held up to the light and because this does not occur in European made opalines but is a quality peculiar to Turkish opaline ware. This may be due to the sand which is used in the production of the ware ${ }^{154}$. On the one hand this sand is said to come from Paşabahçe ${ }^{155}$, on the other from a totally different region, Kumboğazı ${ }^{156}$. These antagonistic speculations indicate that there is no definitive knowledge of where the source of the sand lies. Under these conditions, presuming that this reddish colour is a specific qualification of the production region is no more than speculation. In addition to this the reddish colour is in fact a common trait amongst all opalines ${ }^{157}$.

Opaline glass takes the form of bowls, cups, shakers, covered boxes, vases, ewers, jugs, gülabdans ${ }^{158}$, and sweet bowls all of which are functional objects however there are also pieces which put function to the rear and are primarily

\footnotetext{
152 Eriksen, Svend and de Bellaigue, Geoffrey, Sèvres Porcelain (London, 1987), pp 43-44.

153 Günalp, p 83.

154 Bayramoğlu, 1996, p 26.

155 Bayramoğlu, "Beykoz Işi Cam Eşya", p 4.

156 Adar, Ali Gökçen, "Koleksiyoncu Gözü ile Cam Dünyasında Opalinler', Antik \& Dekor, No. 24, Istanbul, 1994, p 30.

157 Şentürk and Istanbulluoğlu, p 15.

158 Gülabdan is a generic name for any form which holds rose water even if technically it refers specifically to one shape.
} 
decorative objects, such as birds and pistols. Covered boxes made from opaline glass differ from those made from coloured glass in the shape of their handles; as well as having Mevlevi dervish turban shaped knobs ${ }^{159}$, they also utilise fruit shapes. (Figure 69)

In the early mediaeval period, rose water sprinklers were in common production, however they only maintained their popularity for a couple of generations before starting to decline ${ }^{160}$. This can be established from examples which survive today.

In practically all these pieces we can clearly see a reflection of Turkish culture and traditions, for example, rose water plays an important religious role for a Muslim family in their daily lives and especially on religious days like Ramazan $^{161}$ and festivals such as Kandil, gülabdans, bird and pistol forms are used to hold rose water, finding function in highly decorative objects. In traditional structures an important value is being hospitable and showing great care to serve guests. This is a custom which is exhibited on many of the Beykozware. Both opalines and other glass applications of Beykozware are predominantly directed towards serving. Some beautiful examples of this application are Turkish delight/sweet boxes, bowls and many other forms including ewers used for sprinkling and storing the rose water.

\footnotetext{
$159 \quad$ See Chapter 2. 3. 3. Bosphorus Glass/Beykozware, p 65.

160 Jenkins, p 32.

161 Ramazan is the Islamic time for fasting from food, water, sex and other pleasures and desires. Rejecting evil thoughts, dishonesty, lies, etc. It is a time to wholly feel the existence of God, purify the body and cleanse the soul. According to the Islamic Year Calendar which is based on the lunar cycle, it continues for 30 days.
} 
Noticeably, the forms in Beykozware are all reasonably similar to one another. Under scrutiny it is quite clear that, although the glassmakers were capable of producing more complex forms, on the whole they restricted themselves to the repetition of only a few. Lâledans, gülabdans and ewers are examples of the reproduction of a simple form, barring only a few differences. Similarly to lâledans, gülabdans also sit on a round foot and have a plump body, but differ towards the neck which is a simple, narrow, cylindrical tube as opposed to the open mouth of lâledans. (Figure 70) The ewers also display their differences on the spout and handle. Each form also has its own individual stopper. Gülabdans' stoppers are generally transparent but occasionally are made from opaline glass, however they are all extremely plain and modest in adornment, being for purely functional purposes. (Figure 71)

The natural colour of opaline glass which makes up the background provides distinct advantages for the decoration, allowing for the application of very colourful motifs. Likewise with crystal cut glass, gilt decoration is very popular on opaline glass. Along with freehand botanical drawings and moon and star motifs there are also many repetitive designs such as fish scale and geometric patterns. Red, green, blue and yellow are the most frequent colours used in the decoration of opaline glass.

Whether it is opaline glass or crystal, colourless and coloured glass, they share a common denominator. The forms are all unpretentious, they are far removed from technical and formative ostentation, and they always tend towards a functional purpose. Apart from handles, feet and spouts they did not strive to create differences in form but required that the pieces were kept far from 
complexity. From this point of view the only pieces of Beykozware which show differences are çeşm-i bülbüls.

4) Çeşm-i bülbül

When the production of çeşm-i bülbül is compared to other glassmaking techniques within Beykozware it is exceptional from a technical angle. The word itself comes from Persian and means "nightingale's eye". There are varying interpretations for describing this style of decorative glass as çeşm-i bülbül. For instance, when this type of glass is held up to the light, rotated and moved back and forth it gives the impression of a nightingale's eye ${ }^{162}$. On the other hand, in 1885 a glass factory was established in an area of Çubuklu/Incirköy called Çeşm-i bülbül ${ }^{163}$. Çeşm-i bülbül does not describe a certain type of object, rather it is an elegant and lyrical description. Çeşm-i bülbül is a wide range of production formed by a specific technique. This technique arranges white and coloured glass rods in sequence. (Figure 72) Then the object is shaped and the distinctive swirling pattern produced. Like a very famous Italian glass blowing techniques called vetri a fili. This technique requires special skill and experience. (There are a number of ways of producing the same effects of this technique. The choice is down to the preference of the glass blower. One of these is described in Appendix C) There are particular specifications which differentiate Turkish çeşm-i bülbül from those produced in other countries. Prof. W. E. S. Turner highlights some of these differences: 


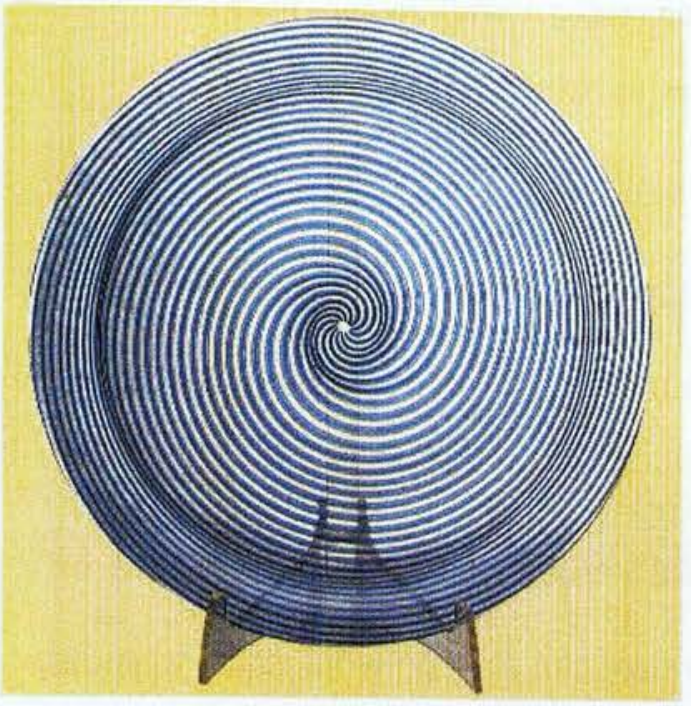

Figure 73

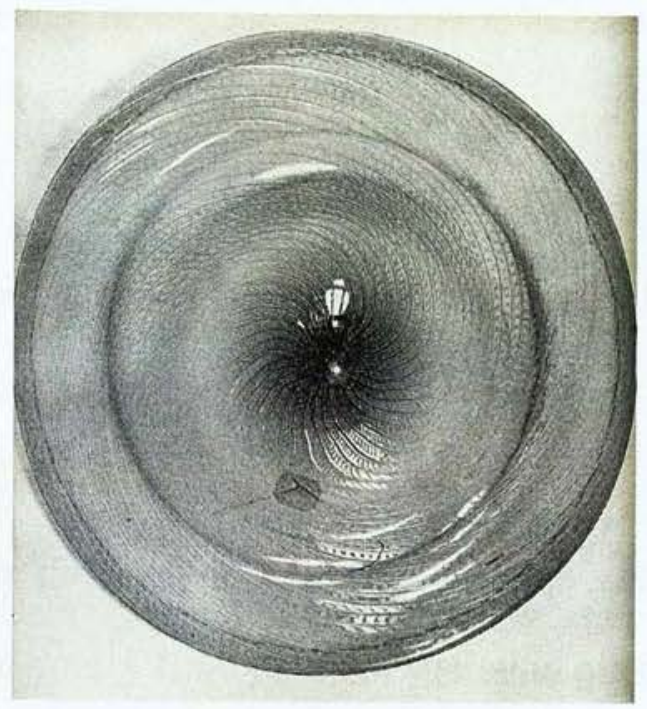

Figure 74

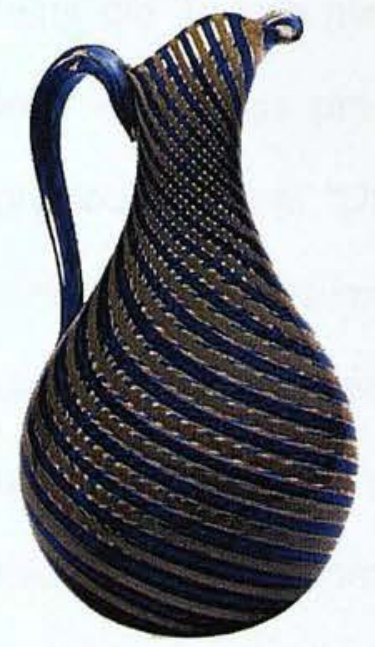

Figure 72

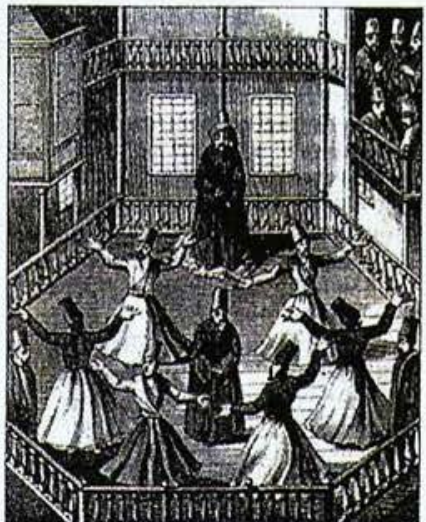

Figure 75

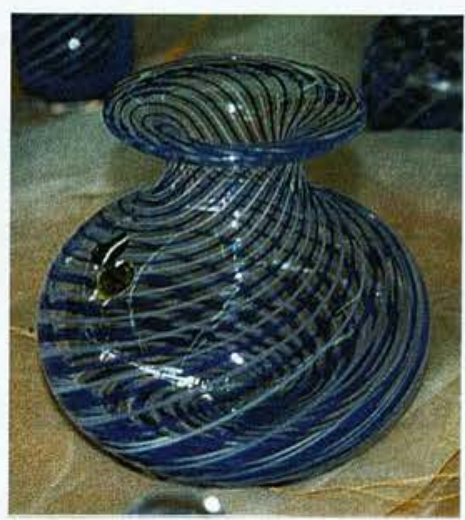

Figure 76 (a)

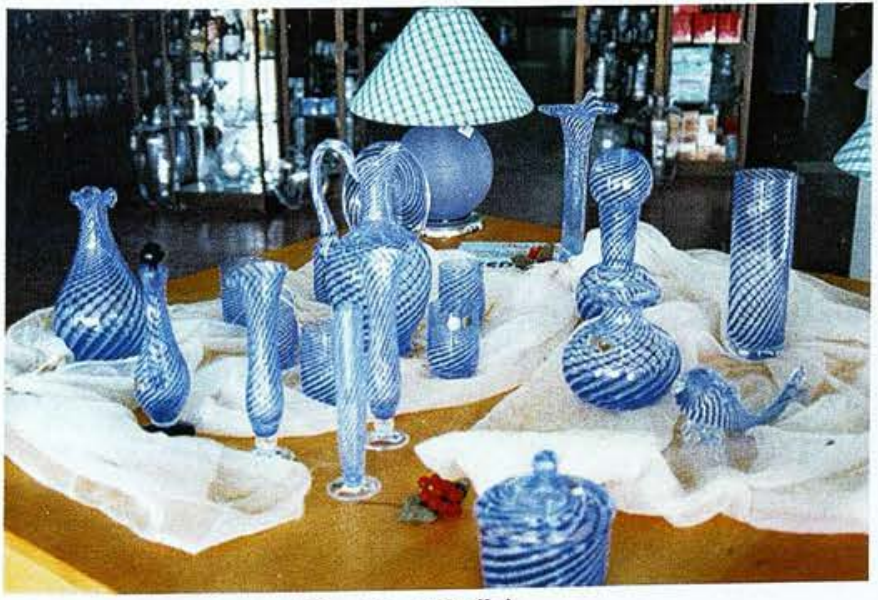

Figure 76 (b)

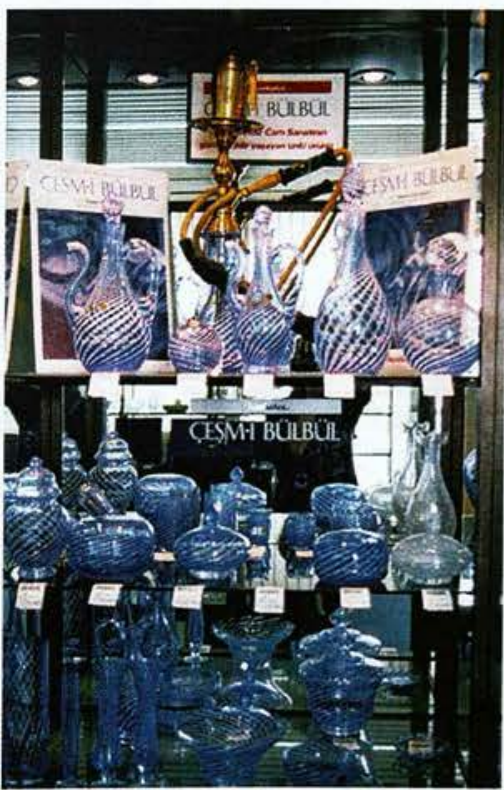

Figure 76 (c) 
"The thick lines on Turkish çeşm-i bülbül contain slimmer lines placed next to each one. This is the speciality of Turkish çeşm-i bülbül making ${ }^{164}$." (Figure 73)

In addition to this, although it is quite rare, the use of pistachio nut green is specific to Turkish çeşm-i bülbül and not found in those of other countries ${ }^{165}$.

The swirling movement in çeşm-i bülbül is definitely in harmony with the very nature of glass blowing. It is interesting that during 1000 years of Venetian glass blowing history and the creation of many styles and techniques only this one in particular has been chosen by Turkish glassmakers. (Figure 74) The question of "why did Turkish glassmakers acquire this specific technique and apply it to their own glass production?" leads to some interesting conclusions. In the previous section, "Ottoman Glass", the existence of latticinio decorated glass lamps which were imported from Venice in mid $16^{\text {th }}$ century was mentioned. It is clear that during that period Ottoman glassmakers were influenced by this technique and appropriated it. By the time they had developed the technique it had earned the appreciation and admiration from the public and took its place in traditional production. This acceptance may be in part due to the colours used. The peculiar Turkish fondness for blue and the proximity of this hue to that used in Iznik pottery played an important role in defining the tastes of that period.

The origin of this swirling pattern found on çeşm-i bülbüls is not especially important as the pattern has close connections with a very common, traditional Anatolian pattern which would have been familiar, thus the style was easily accepted. In addition to this, the pattern carries connotations of whirling 
dervishes at the ceremony of Sema ${ }^{166}$. (Figure 75) Here the social and cultural elements are related to the form and decoration and symbolise their power of sanction over design and taste. Today, Paşabahçe Glassworks brings this traditional and inherent pattern from its tranquil place on the museum shelves to be a pleasurable part of public consumption. (Figures $76 \mathrm{a} / \mathrm{b} / \mathrm{c}$ )

166 Inalcık, Halil, The Ottoman Empire-The Classical Age 1300-1600 (London, 1973), pp 200, 201. "The patron saint of the Mevlevî order of dervishes was Maulânâ Jalâl al-Dîn Rûmî (1207-73), one of the world's greatest mystical writers. ...he recognised music and dance Semâ, as the most effective means to attain mystic ecstasy, the highest degree of sufi experience. Semâ was the chief ceremony of the Mevlevîs, who became known as the "whirling dervishes", from their whirling dances in their special dress." 


\section{3. \\ TRADITIONAL TURKISH GLASSMAKING}

\section{3. 1. GLASS BEAD MAKING}

Bead making has its roots far back before the birth of Christ ${ }^{167}$ it arrived in our time with specific qualities and, from a design point of view, it retains the value of design, giving it a special place and importance. Countless forms, motifs, textures, colours, materials and their combinations have been used in the creation of beads. Whatever the materials used in making the beads there is a common denominator in all of them. This is that which makes a bead a bead: a hole in the middle. From time to time the position of the hole has changed to accommodate use and purpose, however the one constant is the existence of the hole. A single bead cannot be of monumental size but when it is united with others its dimensions may take on more grand proportions. Its size allows it to be conveniently carried as both a functional and decorative object, bringing the bead into daily life, as such it has also played a positive role in becoming an object connected to beliefs and cultures. In contrast to the other materials used, glass has a special place in the mixture. Bead making with glass has brought different meanings to its concept, due mainly to the rich and varied qualities of glass, the principal aspects of which are malleability and the variety of colour which can be obtained. From time to time it has transformed the bead into a sculpture in its own right. Interestingly, when beads are made from glass the most predominantly represented motif is that of an eye or face. (Figure 77) 


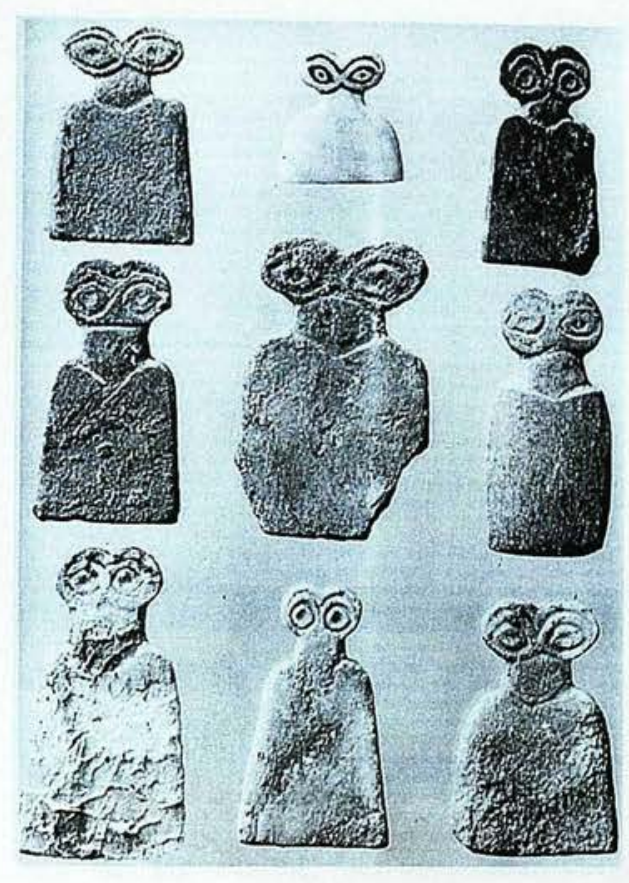

Figure 78

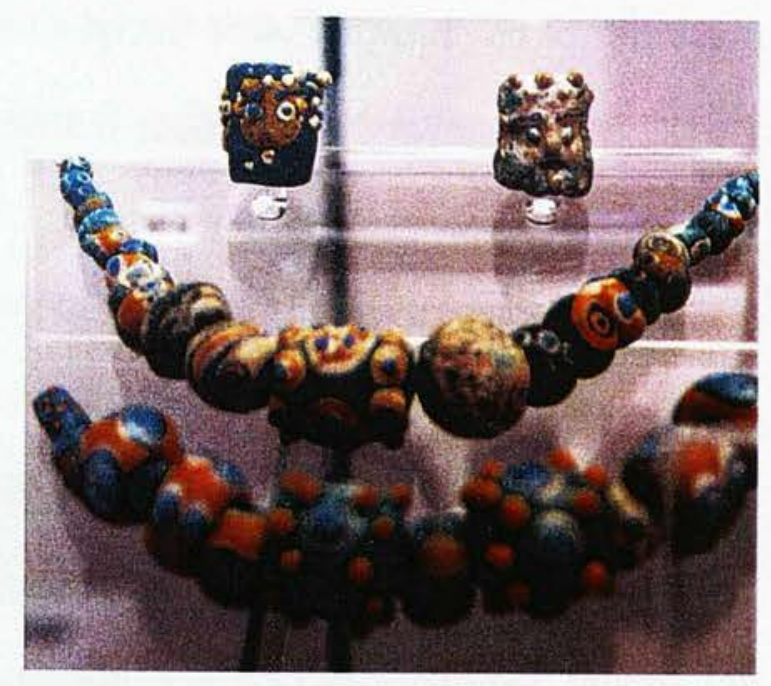

Figure 77

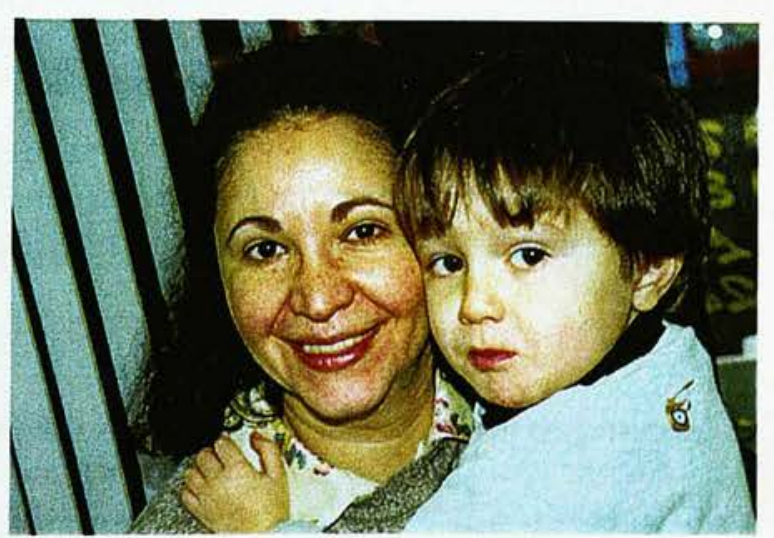

Figure 79

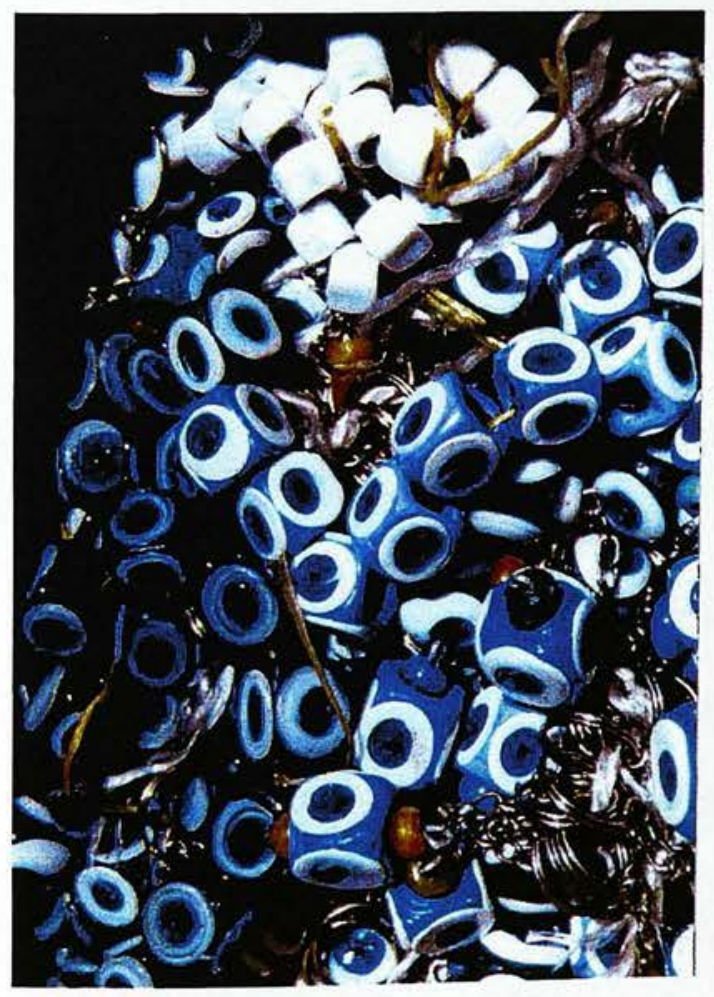

Figure 80 (a)

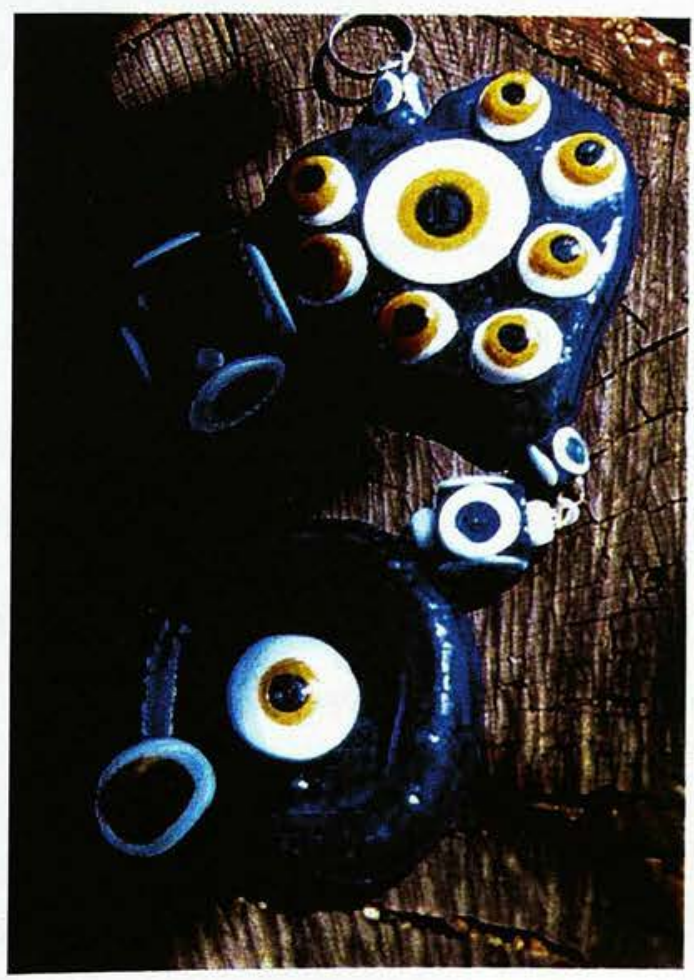

Figure 80 (b) 
This product born from beliefs has, throughout time, shown itself to represent the different adaptations and applications of various cultures.

In the thousands of years of the history of glass art and the traditions of Turkish glass art, the technique, design, colour and purpose of the unique eye beads have also changed very little. Living in Anatolia, and being Anatolian is reflected strongly in the character and provides a settled, well-defined cultural identity. Over hundreds of years this identity has not changed even though the system of the family structure has changed with a shift from matriarchal to patriarchal society. Belief and behaviour were not changed by this, but rather they merely harmonised with the passing of time. Characteristics such as hospitality, dignity, honour and respect for one's elders did not diminish but came to contemporary times alongside a deep bond with tradition. The established fears and superstitions within Anatolian society are all expressed in different ways. This tradition and belief structure arrived in the present time alongside the remarkable phenomena, "Nazar ${ }^{168 "}$, which has had a dominanting effect on people, imbuing them with a confidence in their safety.

The civilisations of the world have created different belief systems with their developed cultures and traditions. In the global context as well as on a continental scale there is a wide spread of behavioural differences, likewise when focussing on a smaller scale, such as regional or local communities one can also find astonishing variety. During the formation of the Turk, Anatolian and Ottoman ideologies, it was strongly believed that the evil eye or malicious look could inflict harm onto belongings and lives. The roots of these beliefs go

168 Nazar: malicious look or thought directed at one's belongings or loved ones. Speculative superstition. 
far back in time to the Palaeolithic Period ${ }^{169}$. It could be open to misinterpretation if one were to limit these beliefs to specific regions and peoples. These beliefs can be considered universal ${ }^{170}$, they are, for instance, present in the foundations of Christianity. During the short time that man is on earth he has a set of rules to follow and the index of these rules stems from beliefs present in the time of their formation. Uncontrollable temptation and desire are the seeds of jealousy, being akin to the evil eye it brings harm to people's belongings and their loved ones and therefore the desire to covet is strongly disapproved of. In The Ten Commandments in The Book of Exodus, 20 , it says:

"Thou shalt not covet thy neighbour's house, thou shalt not covet neighbour's wife, nor his manservant, nor his maidservant, nor his ox, nor his ass, nor any thing that is thy neighbour's. ${ }^{171 "}$

The symbol of the eye, throughout most periods and cultures, was believed to possess protective qualities. In relation to this subject in his book, Magical Ancient Beads, Jamey D. Allen writes:

"In many places, the belief in the "evil eye" persists, as does the wearing of beads with eye patterns to protect an individual or valued commodity from such harm. Eye beads, then, are considered to be powerful amulets. ${ }^{172 n}$

169 Dubin, Lois Sherr, The History of Beads - from 30000 B. C. to the Present (Great Britain, 1987), p 307.

${ }_{170}$ So universal, there are all sorts of ideas, vigorously propounded around the subject on the world-wide web: "....Now envy is universal. But some societies attempt to keep it under control, while in others it is unleashed by being turned into a social principle. We have no defence against the Evil Eye because our entire social ethic is rooted in Envy. At least the benighted Asians have their amulets and prophylactic gestures..." by Hakim Bey, The Evil Eye, Alta Vista, Evil_eye.html.

171 The Holy Bible, containing the old and new testaments (Cambridge, New York, Melbourne, Sydney, London, New Rochelle, ND), p 103.

$172 \quad$ Allen, $\mathrm{p} 87$. 
Both the decoration and supernatural powers of the eye were thought to provide protection for its owner, small sculptural idols and jewellery emblazoned with the eye motif never went out of favour. Excavations in Northeast Syria ${ }^{173}$ have produced the most beautiful examples of these idols from the late Uruk Period.

(Figure 78)

In all corners of the world, various cultures have deeply held beliefs surrounding the evil eye. In Turkish it is known as "kem göz" and in other cultures it is referred to by a multitude of different names ${ }^{174}$. The same belief provides supernatural powers of protection especially to children, innocents, animals and people who are not able to protect themselves. In every society there is an onus on the child deriving from the instinct to protect from visible or invisible powers which may cause harm, either physically or spiritually. In this context, the malice imposed by either thought or sight can be mitigated only by an object with similar super natural or mystic powers. For the Turks the practice of attaching eye beads to baby clothes or bed heads demonstrates the continuation of these beliefs. (Figure 79) Evidently they were not slow to extend these beliefs and adapt them to daily modern life. The relationship between consumer culture and developing technologies resulted most prominently in the demonstration of wealth through the acquisition of material goods. When earnings are directed towards consumerism and great importance is placed on material goods e. $\mathrm{g}$.

\footnotetext{
173 Black, Jeremy and Green, Anthony, Gods, Demons and Symbols of Ancient Mesopotamia / An Illustrated Dictionary (London, 1992), p 79.

174 The evil eye is known as "ayin horeh" in Hebrew, "ayin harsha" in Arabic, "droch shuil" in Scotland, "mauvais oeil" in France, "böse Blick" in Germany, "mal occhio" in Italy and was known as "oculus malus" among the classical Romans. Anonymous, Evil Eye Protector/lt is not polite to stare, Alta Vista, stare.html.
} 
televisions and hi-fis, the most advanced and expensive models are put under the protection of eye beads, with the aim of being protected by Nazar. Likewise, the first addition to a new car is to hang an eye bead from the rear view mirror and often a sticker bearing the eye bead motif is placed in a prominent position on the car to protect against accidents. The idea of protecting advanced technologies and high-tech electronic and computerised equipment with eye beads demonstrates the dilemma societies experience when adapting and amalgamating two different cultures. In this dilemma, the eye beads symbolise the clash experienced when Eastern societies desire to adapt a Western life style to their arabic traditions. This chaos is not only present in Anatolian culture but is also displayed when other eastern societies attempt to assume Western practices. In Pakistan, for instance their political system is that of an Islamic Republic and as the use of items such as CDs have become more widespread in some cases people have taken to writing blessings from the Koran on them, placing them in their cars and expecting to be protected from a possible accident; this is a qualified indication of active cultural chaos.

The evil of the unknown has an inexplicable power, yet its antidote, which is the eye bead, also has unexplained powers. The evil eye is mostly considered to be female due to its connections with witches ${ }^{175}$. However, the eye beads also reflect uncomfortable feelings towards unfamiliar things. The Dictionary of Folklore, Mythology and Legend describes it like this:

175 Walker, Barbara G., The Woman's Dictionary of Symbols and Sacred Objects (USA and Canada-Toronto, 1988), p 309. 
"Probably it arose from the belief that people whose eyes somehow looked different (Pliny cites Phylarchus on people with two pupils in one eye and the image of a horse in the other) were capable of doing magic: this is a specialised form of the fear of strangers common among many peoples. ${ }^{176,}$

Interestingly, there is no huge difference when the Ottomans interpret such phenomena. Since the majority of their society's eye colour is brown or of a dark hue, there is a strange, unwelcome feeling towards those with "glass blue" eyes. They interpreted the presence of people with eyes of a light hue as being of possible harm to them. As the Ottomans spread across the continents they formed a conglomeration of tens of nations which became mighty and would apparently never decline, it is therefore remarkable that they upheld this peculiar belief in the super-natural dangers brought about by the vagaries of human physiognomy. In regards to this subject, historian and journalist Jason Goodwin makes this observation:

"They avoided straight compliments at all costs, as carrying the Jettatura, the Evil Eye. Praise a thing, as often as not it would be pressed into your hands: for the Eye was on it, and it would only bring bad luck to the owner if it was kept. ${ }^{177 "}$

Since the beginnings of the use of eye beads the materials used in their production have not changed, they vary from bone, stone, agate and gem stones to the most commonly produced glass. Glass bead production started with the decoration of camel or horse harnesses, and today in Anatolia,

$176 \quad$ Leach, Maria, Ed., Funk and Wagnalls Standard Dictionary of Folklore, Mythology and Legend (London, 1972), p 837.

Goodwin, p 133. 
particularly around Izmir, manufacture continues in small scale glass bead studios. (Figures $80 \mathrm{a} / \mathrm{b}$ )

When one compares glass bead making with other glass production methods, the technology can be considered a very simple process, however it still requires talented and knowledgeable hands to create the most beautiful artefacts. Glass bead makers in Anatolia are becoming scarce, they continue their production by passing down knowledge from father to son, but their numbers are dwindling. As in many crafts, glass bead making is on the verge of becoming a lost technique, due to social and economic pressures the younger generation is less enamoured to following in the footsteps of their forebears.

During a field trip to Izmir/Cumaovası, Görece Municipality in August 1999, three generations of a single family of glass bead makers were interviewed. (Figures 81 and 82) Between them they were producing almost the entire Aegean Region's demand for beads. The workshop they use is at the far end of the village, facing onto fields. The building itself is without standard windows or doors, in fact there are no specifications other than it has four walls and a roof. (Figure 83) In this hut with its dust-covered floor and in unhygienic and primitive conditions bead production was observed. In addition to the conditions of the production site, the main material in the manufacture of beads is provided by empty Rakl ${ }^{178}$ bottles. (Figure 84) The materials used as colorants are coloured glass cullets and commonly found colouring oxides. The tools used in making the beads are simple iron rods and a couple of flat metal instruments. (Figure 85) These tools are of different lengths and widths, even with their varied 


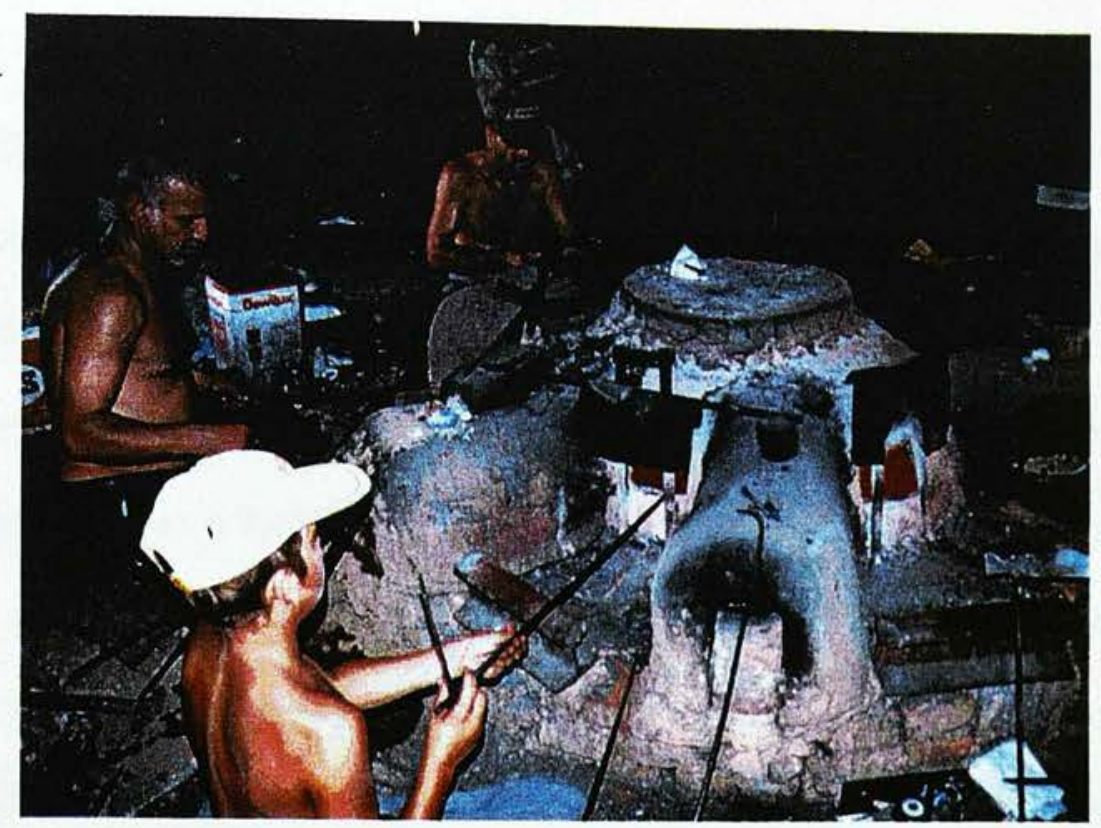

Figure 81

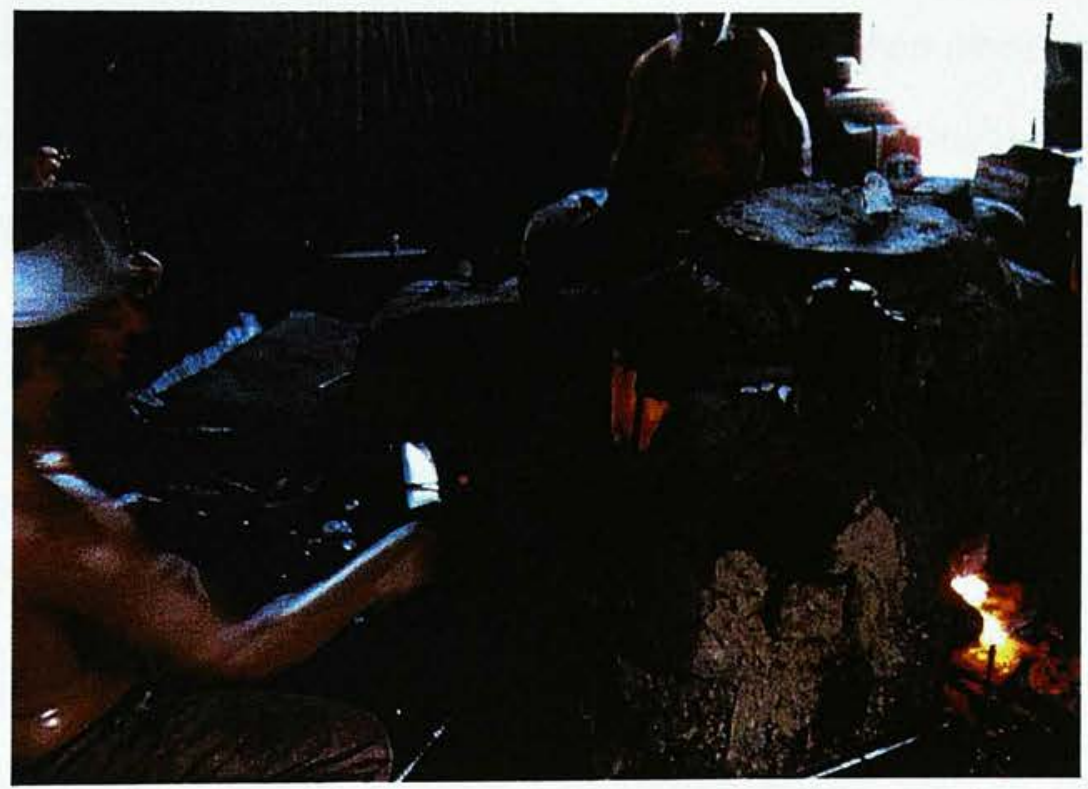

Figure 82
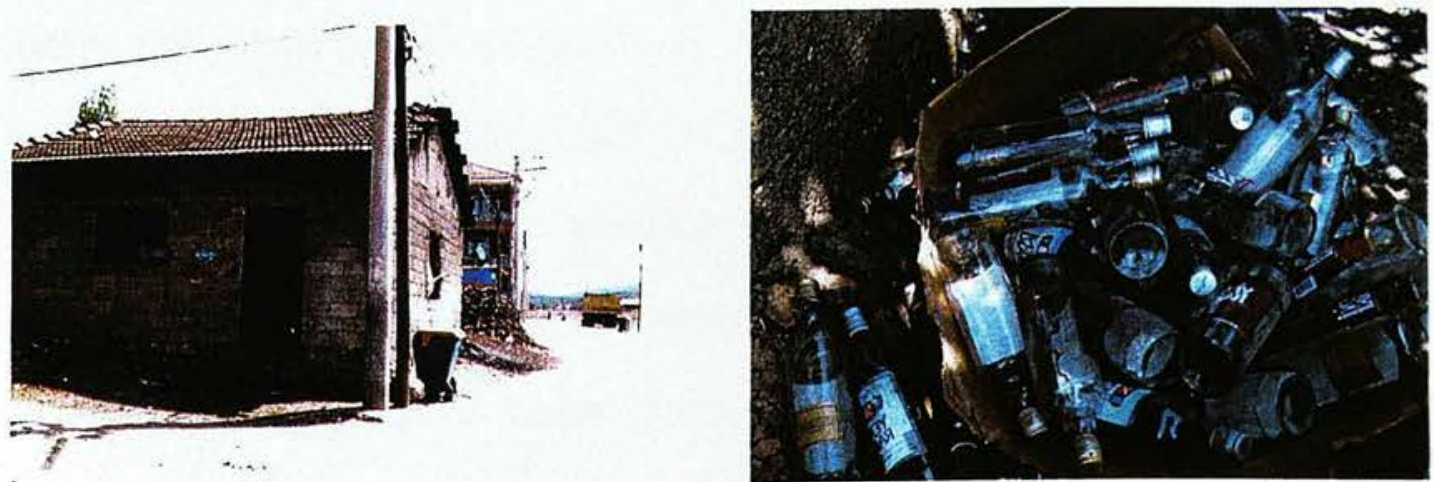

Figure 83

Figure 84 
dimensions there are not more than a dozen types. For each different application of bead there are different tools, but the standard bead with a hole in the middle is produced mainly with two specific tools. One of these is a sharpended iron rod, its dimensions dictate the dimension of the hole and its length varies between 75 and $100 \mathrm{~cm}$. The other tool is a flat metal piece with a nick in one edge, used as a template and marver. It is approximately $25 \times 4 \mathrm{~cm}$., it is of minimal thickness. After the desired amount of glass is gathered onto the rod from the furnace it is moved back and forth with a turning motion supported on a metal block. This action gives the glass its spiral shape. Whilst the glass takes shape the flat metal tool is used to cool and aid the formation of the piece. (Figures $\mathbf{8 6}$ and $\mathbf{8 7}$ ) In accordance with the beads' specification other decorations are added and this produces a variety of application. Once the bead is considered to be finished it is placed into small annealing rooms besides the melting pots. This is done to relieve the strain on the glass whilst cooling. This process developed over many years of observation, tests and experiences and has now become part of daily life.

In the country as a whole, with regard to living handcrafts, this family firm has an important role to play in ensuring their preservation. Without financial or technical support this establishment has little chance of surviving alongside or being part of current development. In the later part of the $18^{\text {th }}$ century and during the $19^{\text {th }}$ the developments of the Industrial Revolution spread from Europe around the globe. At this time some glass industries were unable to utilise the developing new technologies and therefore declined; for the small business making glass beads nowadays a similar result is probably inescapable. Already the producers perceive that they cannot improve on their 


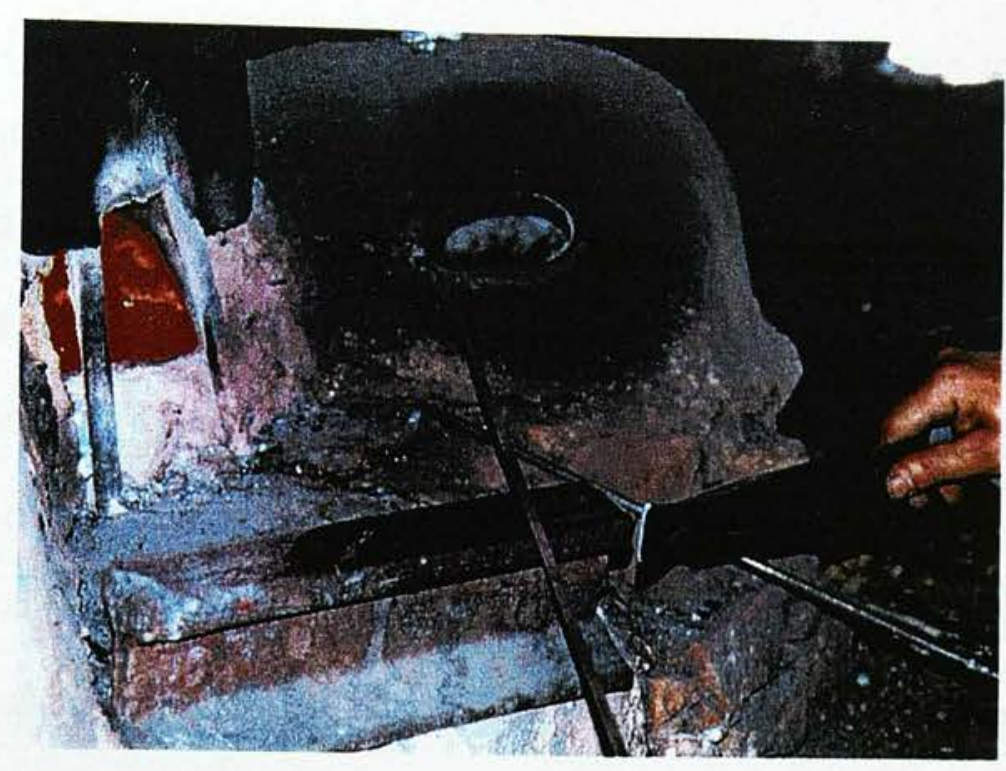

Figure 85

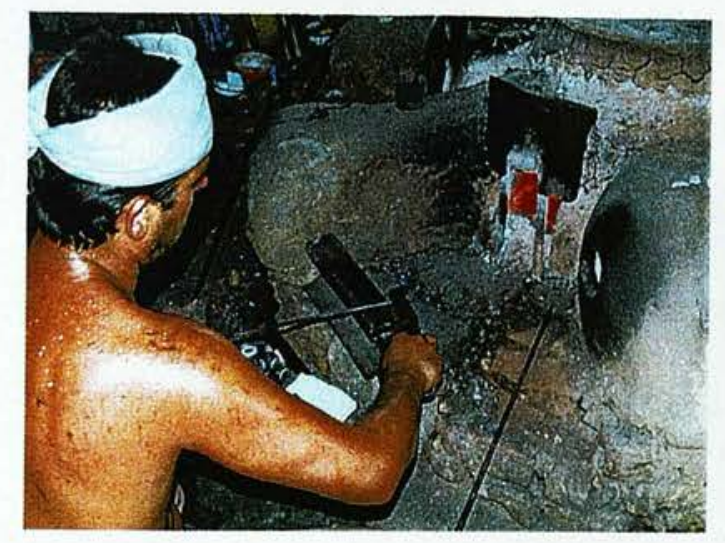

Figure 86

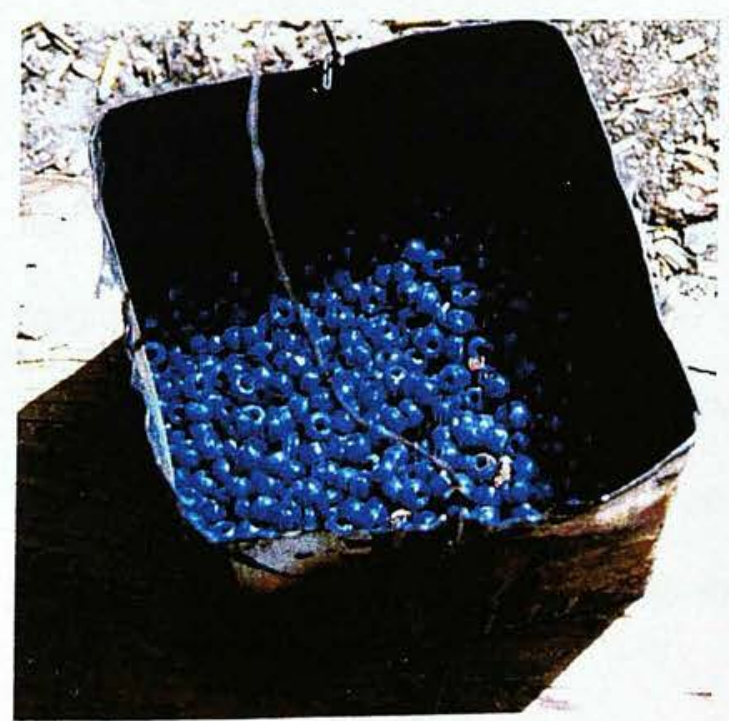

Figure 88 (a)

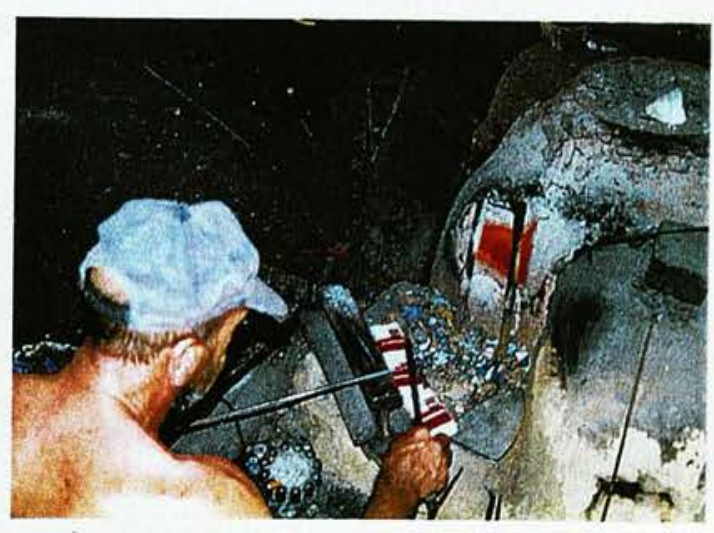

Figure 87

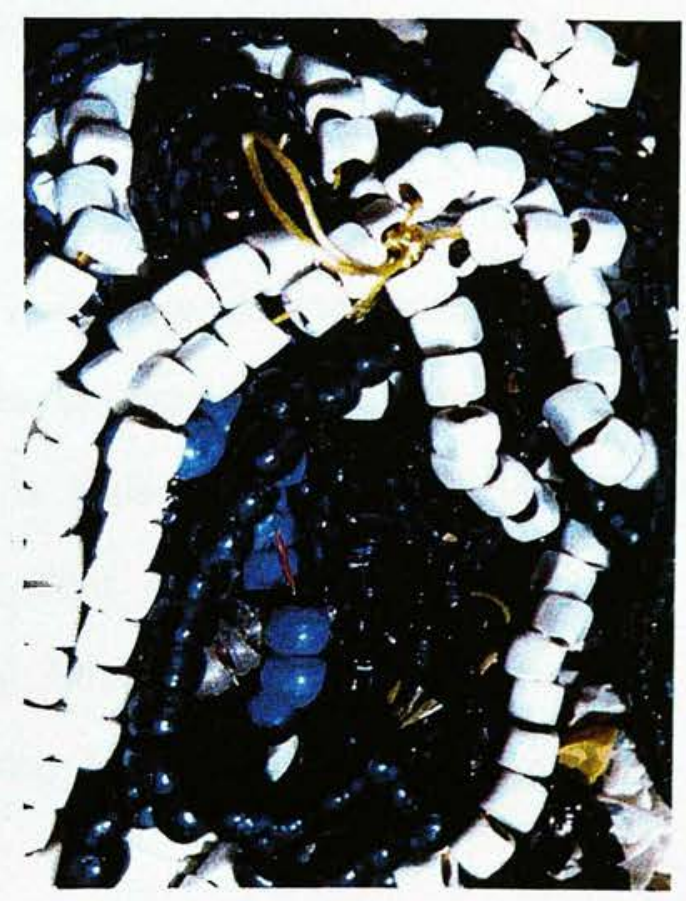

Figure 88 (b) 
product and they feel dejected and helpless. This could be seen to signify the beginning of decline in their production. The existence of societies' widely held beliefs in the symbolic protection of the eye bead, fed its popularity and engendered its wide scale production thus ensuring a reasonable price and allowing for carefree consumption. These were the main reasons for the divergence of glass bead making from other crafts, which helped it to survive until today. A common point between all cultures in their manufacture of beads is that they are used for decoration, and not solely for protection. (Figures $88 \mathrm{a} / \mathrm{b}$ ) In a couple of decades it will be virtually impossible to meet the demands for beads due to the lack of enthusiastic family members continuing their traditions. The new generations do not want to emulate a grandfather who lost his sight in middle age due to poor working conditions; if these problems are not tackled, younger family members will naturally direct themselves towards other businesses.

Simply solving some of the problems connected with the raw material will make life a little easier for glass bead makers. In a visit to the same family in 1992 the problems which were found to exist are those which are still causing difficulties today, this is a universal tragedy which is sad and unjust. If small businesses were to receive support and constructive advice it would undoubtedly bear fruit for those struggling handcrafts which are striving to maintain not just their traditions but their entire existence. It is imperative to encourage private companies and individuals to make contributions. In 1988 a book was published on Anatolian glass bead making in Turkey. Although this book is dominated by the technical side of the glass bead making it also shows the conditions and 
problems of bead makers in Turkey. Those who are aware of this book ${ }^{179}$ are, by reason of their knowledge, aware of the problems which exist within the industry, however they have not made any visible attempts at constructive reform.

In Denmark in 1992 they purposely set about a project attempting to revitalise the old technologies in Lejre Archaeological Research and Application Centre. During this project ${ }^{180}$ the Anatolian glass bead making methods were on the agenda. In relation to this, the almost impossible to describe series of tunnels and holes which make up the traditional glass bead furnace, with its octopuslike asymmetry and dome-shaped mixture of brick and clay, ${ }^{181}$ found an opportunity to be reconsidered. (Figure 89 ) When using advanced technologies in the production of glass beads i.e. in the materials and fuel, there is a significant difference in the final product both visually and tactually compared to the output of traditional production methods. If beads are manufactured using advanced technologies they should be produced in such a way as to ensure that they retain the qualities of beads manufactured by traditional methods. This is the only way to secure the future of bead making. Önder Küçükerman refers to this point in one of his articles:

179 Küçükerman,Önder, Glass Beads (Istanbul, 1988), p 6. Like the General Manager of Istanbul Porcelain Industry Ltd., the Vice President Manager of "Türkiye Şişe ve Cam Fabrikaları A. Ş." (Turkish Bottle and Glass Works Inc.), the Research Manager of the TŞCF Project and Technical Services, TŞCF Research Centre and the General Director of the Turkish Touring and Automobile Association.

${ }_{180}$ Küçükerman, Önder, "Anadolu'nun 3000 Yıllık Kimlik Ürünü Göz Boncuğu Üzerine Danimarka'da Bir Seminer ve Bir Geliştirme Projesi Önerisi”, Sanat (November 1993), No.3, p 14.

181 For more detailed information about the structure of glass bead furnaces in Anatolia, see Küçükerman, 1988, p 44-56. 


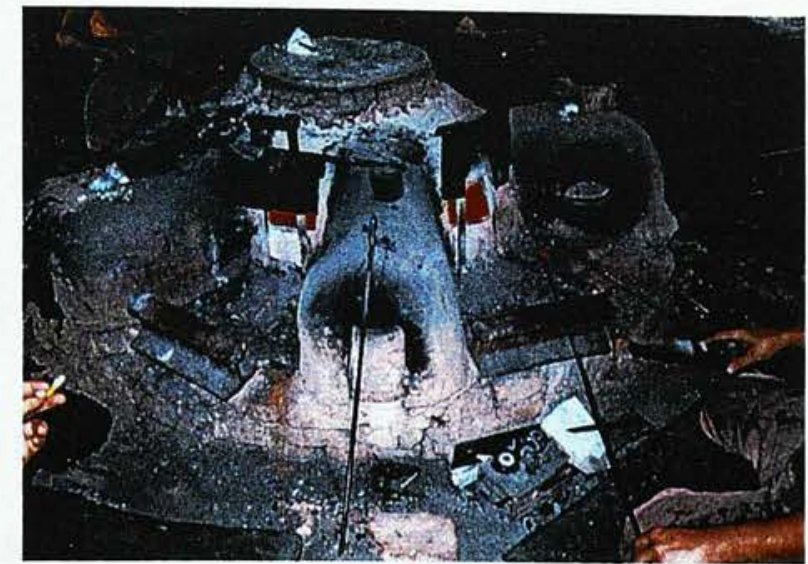

Figure 89

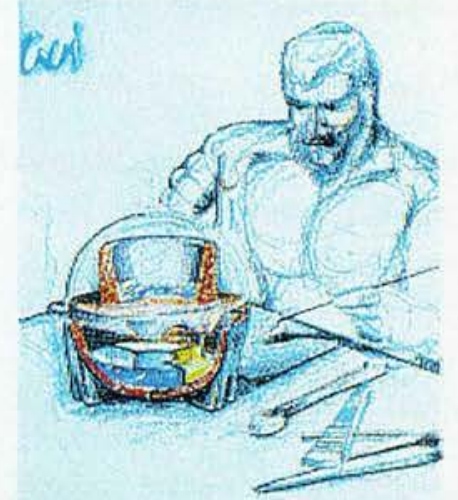

Figure 90 (a)
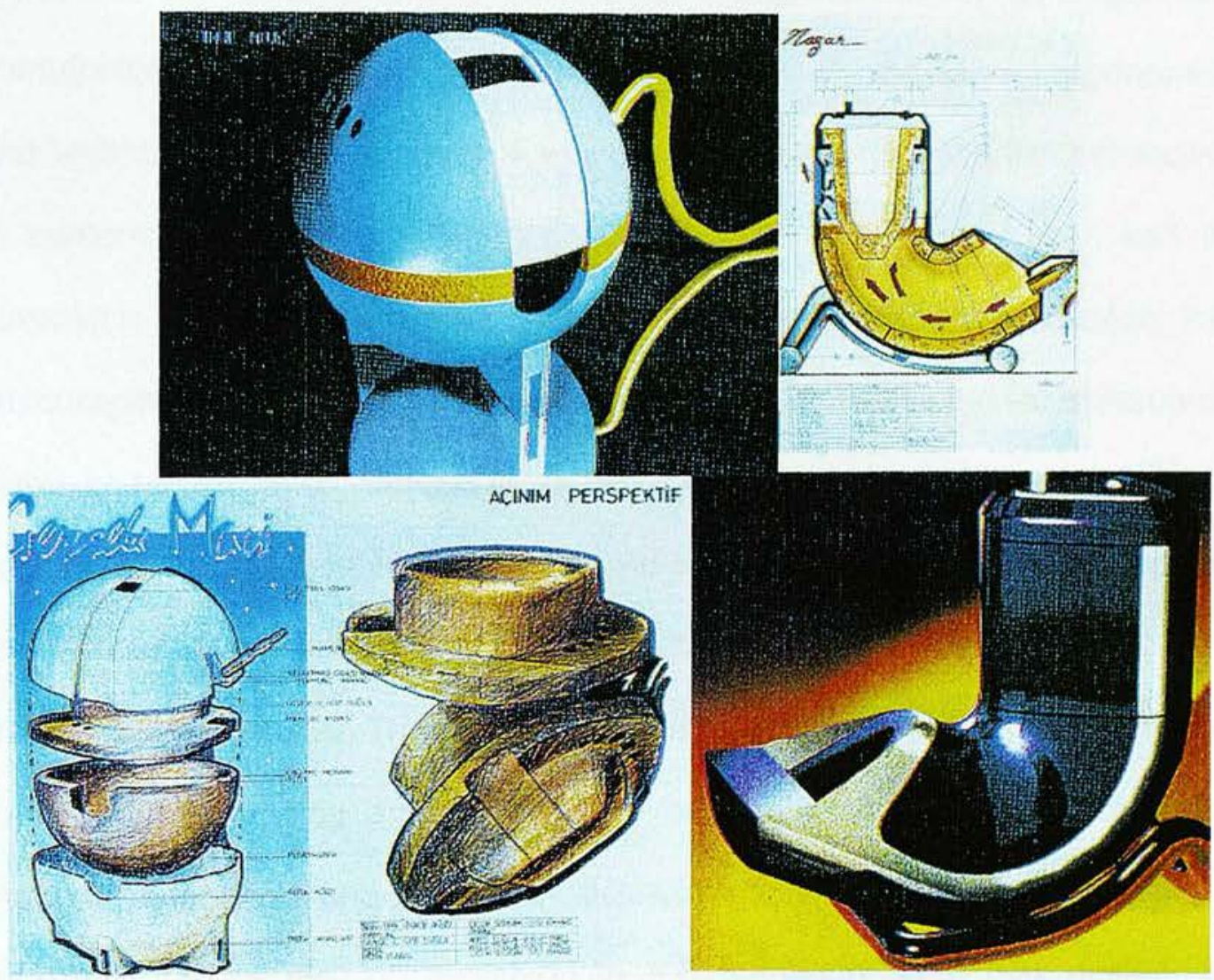

Figure 90 (b)

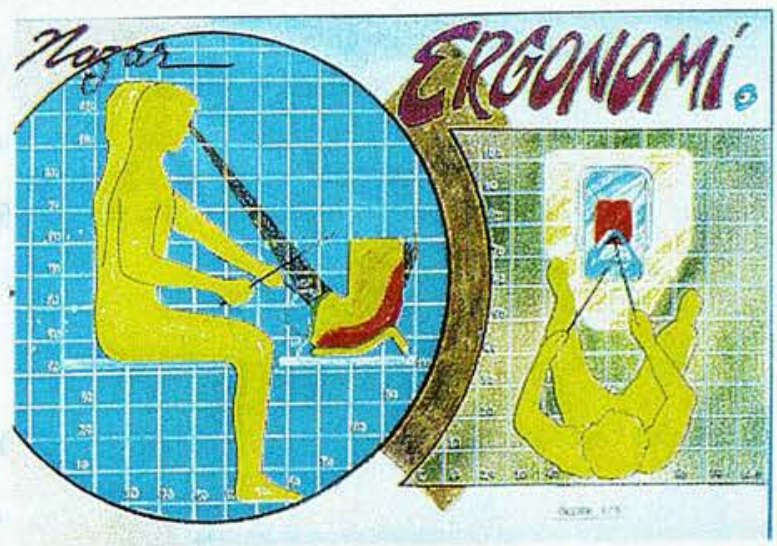

Figure 90 (c) 
"As a result, the glass beads produced at traditional furnaces today are almost identical with those produced 3000 years ago. Because of the great technical advantages they possess, these furnaces have survived and retained their economic value in spite of their simplicity. ${ }^{182 "}$

In light of these ideas, a research study has been undertaken to assess whether it is possible to use traditional methods in the production of glass beads and cope with the increase in demand without losing the identity of traditionally manufactured beads. From the point of view of health and safety, ergonomics and technological developments it has been attempted to tailor the production to contemporary practice. This research is done at university level and its purpose is to bring a new vision and interpretation to glass bead production. It is encouraging that this kind of design subject has been selected as a research study in Mimar Sinan University, in the Industrial Design Department ${ }^{183}$. In addition to this, to design a glass furnace by purely changing the technology and without losing the principles of production is a huge step forward in this subject. (Figures $90 \mathrm{a} / \mathrm{b} / \mathrm{c}$ ) The atmosphere of our technologically advanced age is continuously changing and improving through various popular sectors, for example automotive and computing technologies. These sectors have both a high demand and high consumer quota and constantly need new designs to fulfil them. Although such sectors are generally given priority, the choice of a glass bead-making furnace as a subject for further design and development is indicative of a movement towards the revitalisation of traditional handcrafts.

182 Küçükerman, (November 1993), p 15.

183 Küçükerman, (November 1993), p 12 and Küçükerman, Önder, "Gerçek Mavi Göz Boncuğu", Tasarım (March, 1993), No. 32, p 109-113. 
Glass bead making is a beautiful example of the continuity between past and present. It helps society to perceive glass as an art object and, due to this persuasion, it builds a foundation and forms a link between glass and society. A perpetual interaction between society and glass, brings them face to face, even though it is also connected to beliefs, it is both functional and decorative.

\section{3. 2. PRAYER BEADS (TESPIH)}

In Islam there is a common use of tespih due to the influence of Sufi philosophy ${ }^{184}$. Its origins go back to India and Hindu ${ }^{185}$. It is also found in Buddhism and Christianity; in the latter it is used especially in Roman Catholicism. Whatever the religious differences, the purpose of use is the same $^{186}$. The functionality of tespih is dominant over its appearance as a decorative object. Despite everything else tespih is a tool, as it helps the worshipper to keep track of the number of the prayers without interfering with his concentration and rhythm and provides a record without necessarily engaging the mind.

Throughout history tespih has developed from the primitive form of a string with regular knots in it, to being made from a wide variety of materials and has found a niche in a broad consumer group. The materials used in tespih's manufacture

$184 \quad$ Chebel, Malek, Symbols of Islam (Paris, 1997), p 102.

$185185 \mathrm{BC}-\mathrm{AD} 320$. Dubin, $\mathrm{p} 80$.

186 Muslim prayer beads are strung in 33-or 99-bead strands. Prayer of the tasbih (tespih):33 times: "subhana-llah" (Glory be to Allah), 33 times: "Alhamdu-li-llah" (praise be to Allah), 33 times: "Allahu akhbar" (Allah is great). Or pray the 99 names of Allah. Anonymous, Alta Vista, Anglican Prayer Beads.html.

"The rosary, which can be found in any Catholic's hands..., it consists of five sets of ten beads, seperated by an individual bead, which are an invitation to fifty recitations of "Hail Mary", five of "Our father", and five of "Glory be to the Father". Le Gall, Dom Robert, Symbols of Catholicism (Paris, 1996), p 110. 
show a wide variety, from bone and stone to precious or semi-precious stones.

(Figure 91) In Islam great importance is given to being personally clean and not being ostentatiously wealthy. The most important thing is to be modest. Glass has a smooth and clean surface, it is clear and pure in its transparency and this makes it one of the most desired materials for making tespih. In Islam it is deemed necessary to ignore the material possessions of this life and to show an unwillingness to acquire such items, this attitude has put glass to the forefront with its low intrinsic value for consumers and its captivating qualities which reflect the importance of prayer and faith.

As glass was used for making tespih it became a familiar part of every day life and thus it maintained a symbiotic relationship with the culture and the individual. From another point of view, it produced an awareness of glass within the populace; they felt and considered it their own.

\section{3. 3. REVERSE PAINTING ON GLASS}

There has been a constant interest in reverse painting on glass for glassmakers in the East and Mediterranean ${ }^{187}$. The purpose of reverse painting was to add extra value and increase the decorative appeal of glass. Occasionally the reason was simply to protect the painting against weathering from the elements, also, the physical qualities of glass gave an extra shine to a painting. From time

187 . This application is also called "Tinsel painting" and "Glass Gilding" but, the term "Verre Eglomise" has been introduced for this technique by French artist and picture framer Jean Baptiste Glomy in $18^{\text {th }}$ century. Anonymous, History of Glass Gilding-From Roman times to the present, www. Eagle-nest-design.com/verra eglomise.htm. 


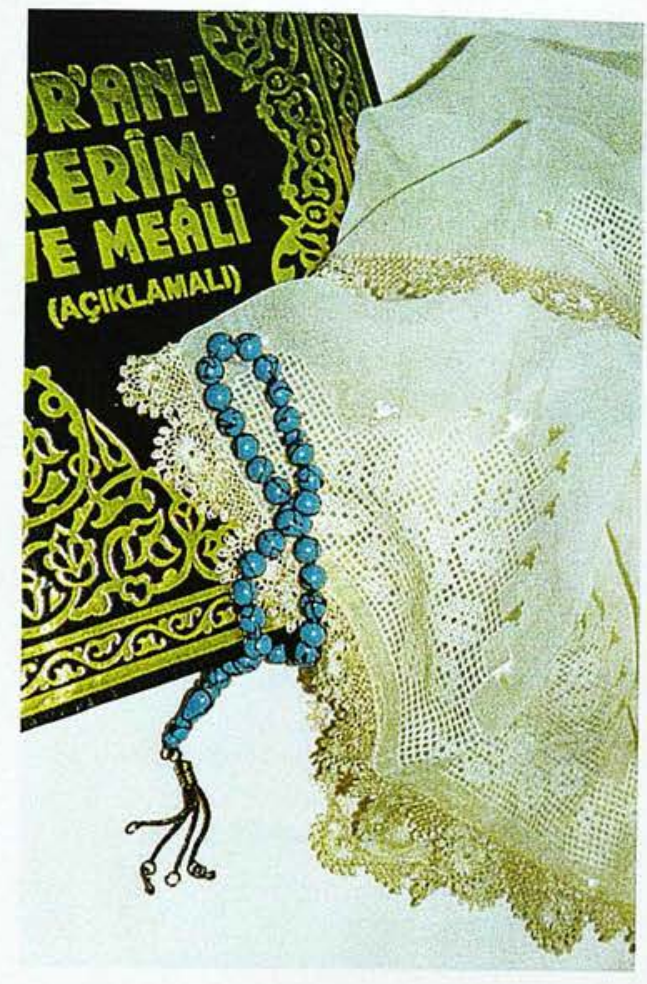

Figure 91

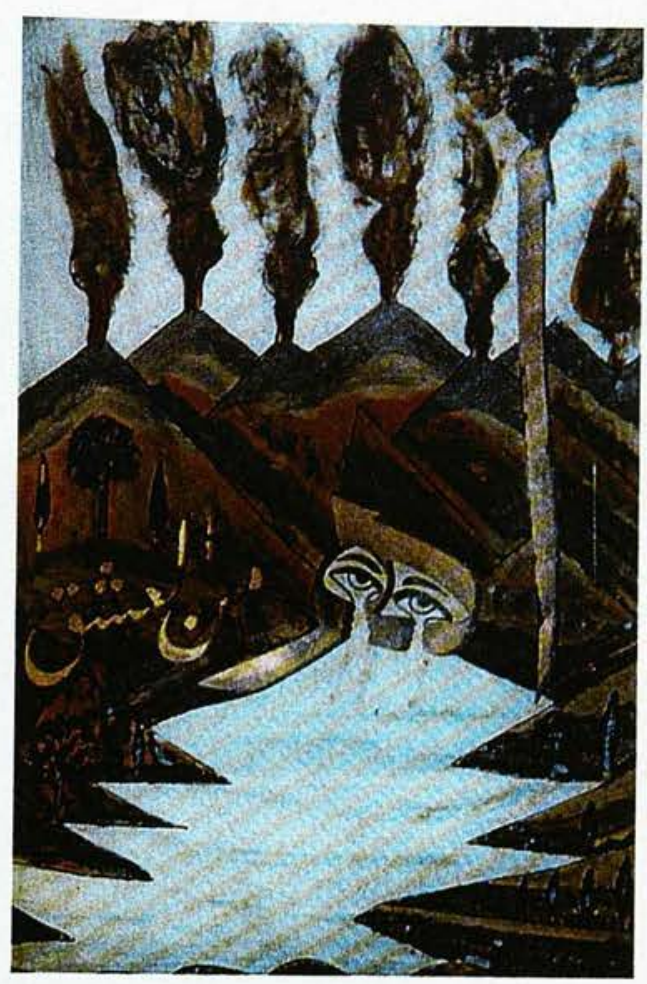

Figure 92

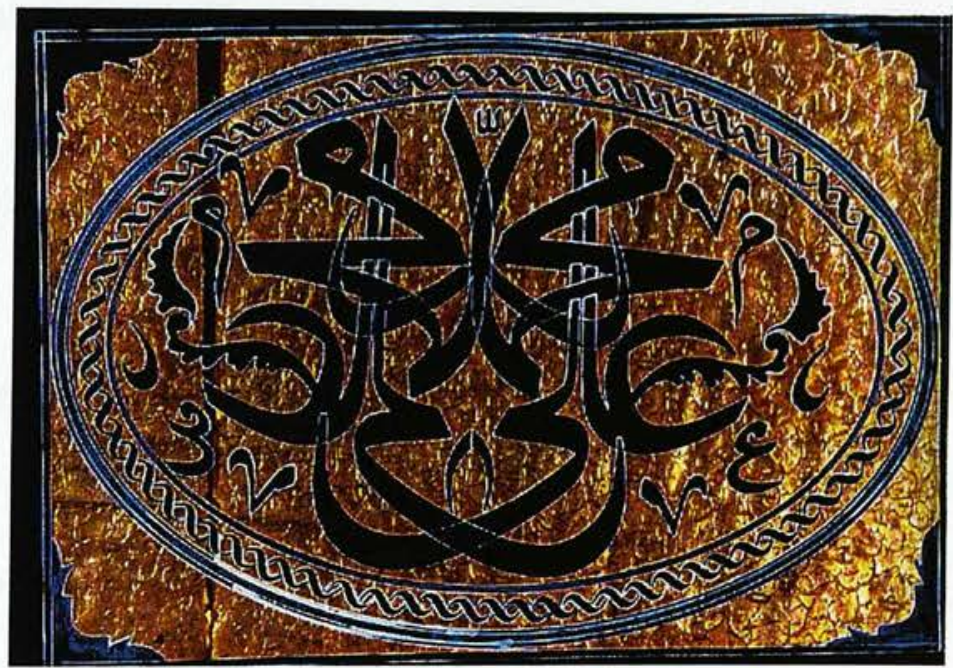

Figure 93

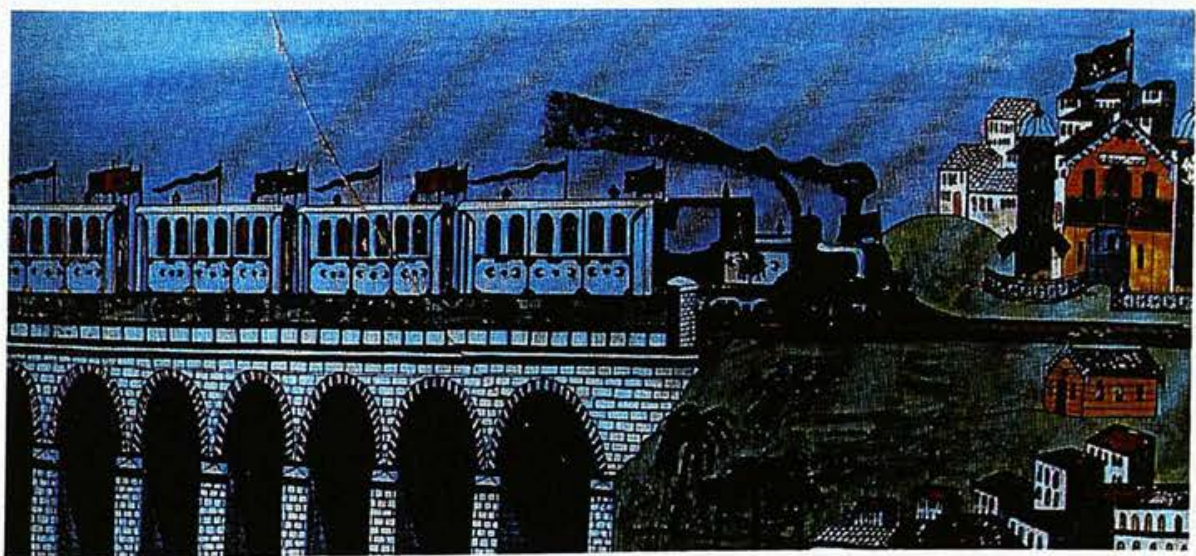

Figure 94 
to time reverse painting was used to copy engravings as the medium made them more affordable. Although this technique is not as widespread as stained glass it was mentioned in Cennino Cennini's $14^{\text {th }}$ century book, The Book of the Art of Cennino Cennini, on the application techniques of the arts. This proves that as one of the oldest techniques in glass art its roots are far back in history. Cennini describes this technique in his book. He writes:

"There is another way of working in glass, charming, lovely, and rare as can be imagined, which is a branch of art in devout use for the adornments of holy reliquaries, and it demands sure and ready design. ${ }^{188,}$

Qualities specific to glass such as reflection and transparency gave these artists' paintings additional values in the depiction of their chosen subjects, therefore glass became their preferred material. Interestingly the purpose of reverse paintings was not to decorate glass but to make a picture on glass. Therefore in this application the artist was not seeking to use the transparency of glass as an integral part of the painting, nor was it to be held against light but against a solid background. The glass was only used for protection and to add shine to the painting.

The oldest examples of traditional Turkish reverse paintings are dated from the first half of the $19^{\text {th }}$ century ${ }^{189}$. Its popularity during this period was very high and

188 Cennini, Cennino, The Book of the Art of Cennino Cennini - A Contemporary Practical Treatise on Quattrocento Painting, translated from the Italian, with Notes on Mediaeval Art Methods by Christina J. Herringham (London, 1899), chapter 172, p 154. 
this was maintained until the middle of the $20^{\text {th }}$ century. Nowadays it has gone the way of most other traditional handcrafts and fallen into decline.

These paintings are sometimes realistic, sometimes surreal and sometimes expressive; they are two dimensional, simple, colourful and produced by the folk artist for the pleasure of the viewer. For these artists the honest depiction of nature and truth to the definition of the object was at the forefront. Most importantly for the artists, their paintings were to be legible and accessible to their audience. The message within the painting should be easily understood. The most common scenes for the display of these paintings are cafes, barbers, greengrocers and sometimes newsagents. Reverse painting takes its place in everyday life, existing hand in hand with the public, its women, children and elderly. Because the audience for reverse painting is mostly the general public it is necessary for the artists to portray themes which are recognisable and acceptable to them and reflect their feelings.

The most frequent subjects of these paintings are fears, beliefs, legends and everyday tales. Important components in the artists' depictions are signs and symbols. With the use of these symbols, fairytales, poems and myths can be illustrated. The more dominant depictions in reverse paintings, however, are religious and composed of figurative symbols. A beautiful example of this can be seen in figure 92. In this painting Adam is shown banished from Eden in tears and his tears form rivers and lakes. These paintings interact with their living surroundings and are knit with both everyday and outlandish tales; they are presented simply, are naïve and humble yet direct. They carry no other meanings than their simple depiction as can be seen in figure 93. In this painting 
symmetry has been applied in calligraphy and reads "Muhammad Ali". This writing intricately decorates the mirrored glass with great ornamentation because it is believed that this painting will bring sustenance, abundance, tranquillity and protection.

These aspects can be considered as general characteristics of Turkish reverse glass painting. During the early years of the $20^{\text {th }}$ century, these paintings were produced predominantly by self-taught folk artists. They were naturally affected by current events and as such their paintings brought a different perspective to historical events. At this time, the artists who were depicting an imaginary world began to discover exciting new meanings through the everyday objects linked to their lives. Within the process of Westernisation, the machinery connected with everyday life was chosen as a subject worthy of depiction in their paintings. This was an indication of the cultural consciousness of the folk artist. Figure 94 depicts Hicaz railway. At the beginning of the $20^{\text {th }}$ century, Sultan Abdulhamid II (reign 1876-1909) celebrated the $25^{\text {th }}$ year of his reign and the Islamic world united to contribute in the building of the railway ${ }^{190}$. This act was held with great prestige and made the Turkish people proud. In the painting the artist has depicted the moon and star symbol many times to show his pride and love for his country and government which has performed the act of building the railway in accordance with religious beliefs. The symbols used to describe the flora and the architecture draws a clear picture for the audience showing the region the event took place in. As is the general character of reverse paintings, it invites the audience into its subject matter. 
Similarly to bead making, reverse painting on glass can enhance a society's visual appreciation of glass. These paintings are an ostentatious example of naïve art. Due to the physical interaction of glass it provided a suitable material for transformation into an art object and has continued society's attitude towards an admiration for glass. 


\section{4. THE UNIQUE PROPERTIES OF TURKISH}

\section{GLASS}

It is apparent within Turkish glass art that more emphasis is placed on decoration than on form. The limited range of forms used does not depend solely on functionality but are chosen to cater for the public's taste and also their suitability for the application of decoration. Instead of striving for the production of clear and flawless glass, the existence of formal and technical freedom in the production of glass meant that manufacturing problems such as bubbles or cloudiness in the glass were solved by simply adding colour. This is typical of the relaxed attitude and the tendency towards comfort present in many Mediterranean countries, caused by the structure of the community ${ }^{191}$. To produce a harmony between the form, decoration and functionality was not considered to be unimaginative, just realistic in response to the needs and demands of the public. The unvarying reproduction of forms and simplicity of line does not reflect any insufficiency either in the imagination or the practices of the artist. He is purely responding to the demands of the market. ${ }^{192}$ Forms have been developed and filtered over many generations until a simple well-liked

\footnotetext{
Porter, James Sir, Observations on the Religion, Law, Government and Manners of the Turks (London, 1771), Chap. XIV, Miscellaneous Observations on the Manners of the Turks, $p$ 254-314. See also; Bart, George L. Sir, Turkey; Its History and Progress: From the Journals and correspondence of Sir James Porter, Continued to the Present Time (London, 1854), p 313339.

We can see a similar approach to mosaic art throughout the ages. The source of the power of sanction in mosaics was not the public's demand, instead it was considered the orders of the Church. The necessity to reflect the figures clearly and make religious ideas readable put constrains upon the artists. Although they had the skill to use all kinds of techniques the requirement places upon them by the Church limited their freedom of expression in this medium.
} 
piece was developed and they continued to produce this rather than foisting radical innovations onto the public.

In Islam, creating figurative drawings and objects are very strictly prohibited ${ }^{193}$ according to the Koran (5:92):

"O believers, wine and arrow-shuffling, lidols [taswir] and divining-arrows are on abomination, /some of Satan's work; then avoid it. ${ }^{194,}$

Due to this ban, multi-coloured and intricately patterned Islamic Art has developed. Today, these very well balanced colour compositions gain much admiration from various sectors of society. These colour arrangements together with the form and motifs reflect the power of the artist's fantasy world formed inevitably from living in a dream world instead of reality. In Turkish glass art, the main reason for the motifs, which are usually botanical elements or repeating units, (Figure 95) progress from the necessity of living in a dream world and have been assimilated into absolute tradition.

In $15^{\text {th }}$ Century, Mehmed II $(1430-1481)^{195}$, who was brave, open-minded, intellectual $^{196}$ and a master of five languages ${ }^{197}$ developed some very close relationships abroad and ordered his portrait painted by the Renaissance

193 Irwin, Robert, Islamic Art (London, 1997), p 79, It is also specified in one of the Prophet Mohammed's hadiths: "An angel will not enter a house in which there is a dog or a painting".

194 Irwin.

195 The Conqueror, Turkish known as Fatih Sultan Mehmed, (reign 1444-1481).

196 See for more, Freeman, Edward A., Ottoman Power in Europe, Its Nature, Its Growth, and Its Decline (London, 1877), p 114.

197 Finlay, George K. S. G., Observations on the causes of the rapid conquests of the Ottoman Turks in Europe (Royal Society of Literature of U. K., 1856), Second series, Vol. 5, p 90 . 

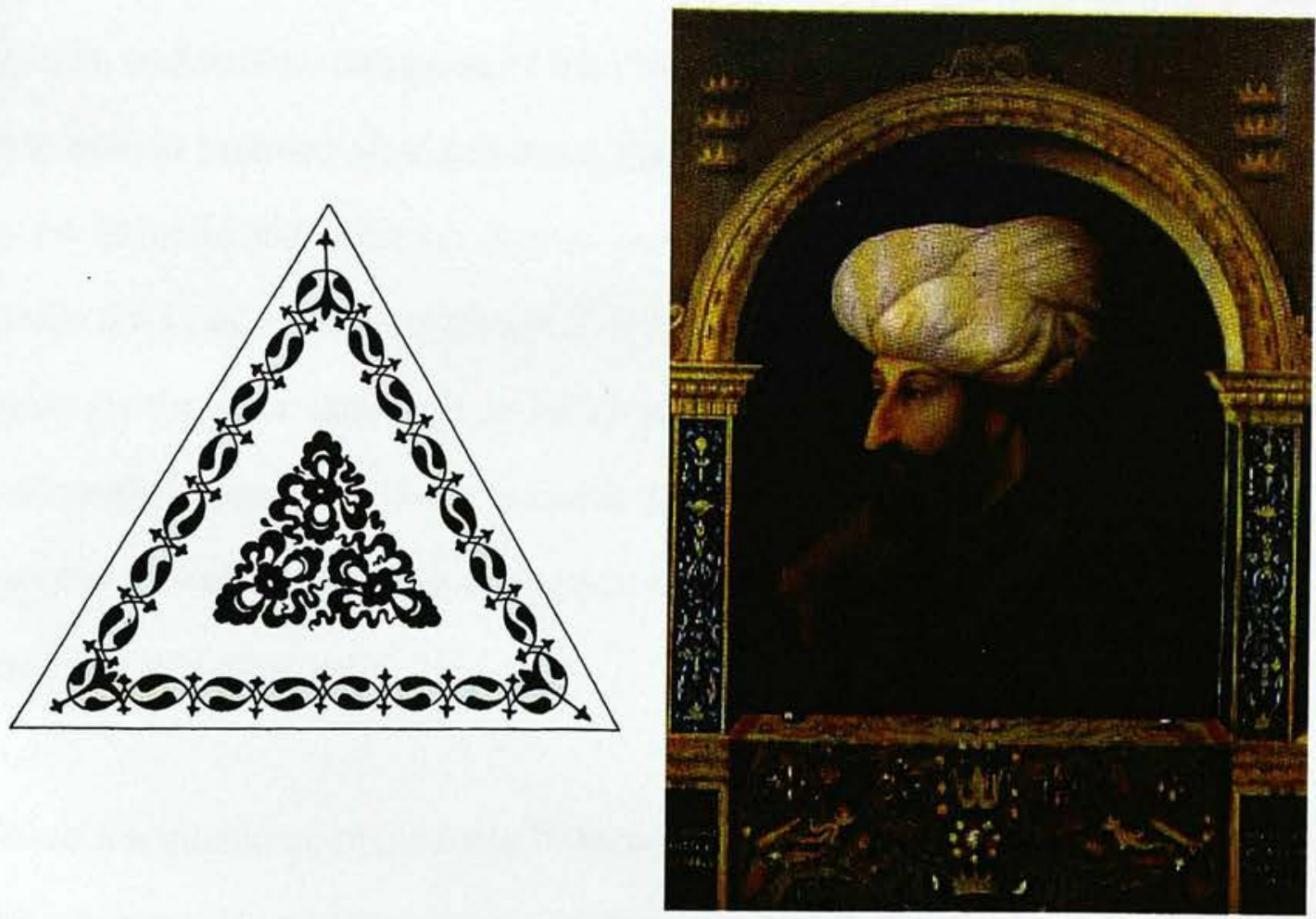

Figure 95

Figure 96

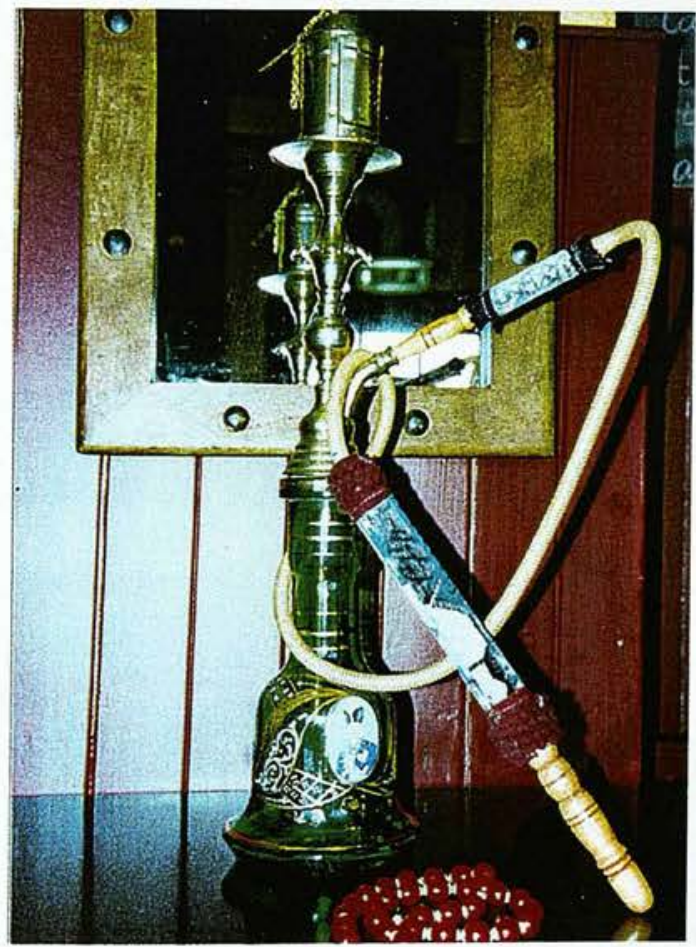

Figure 97 (a)

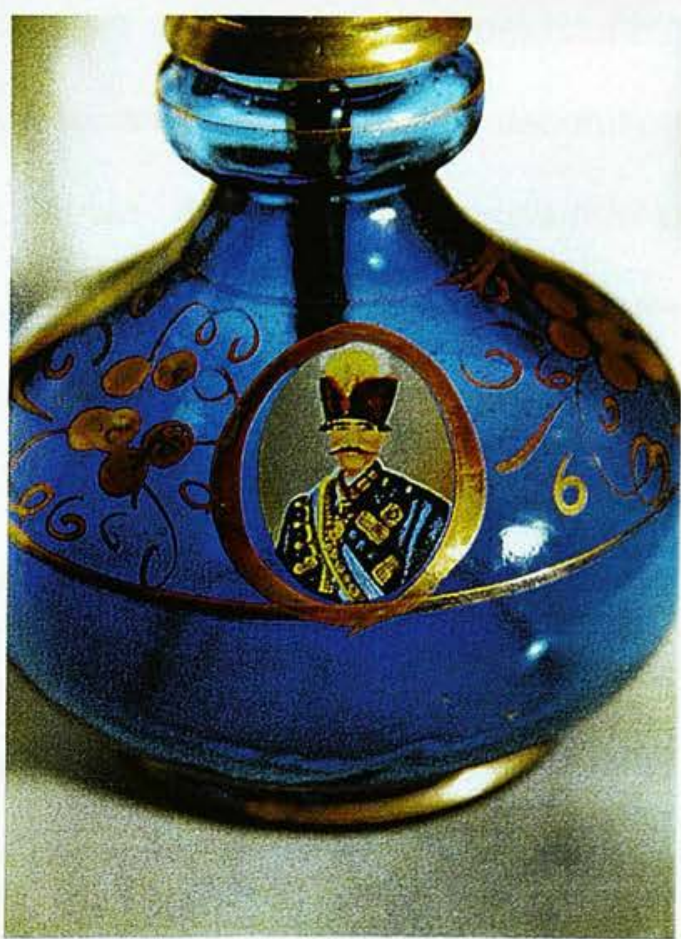

Figure 97 (b) 
artist $^{198}$ Gentile Bellini (1429-1507) and the decoration of the Palace walls with frescoes in the Italian style ${ }^{199}$. (Figure 96) This departure revolutionised the cultural and political structures of the Ottomans and demolished the chauvinism that existed between East and West. He also pioneered the building of bridges in art between the Ottoman Empire and Western Europe. The transformation which took place under Mehmed II in Islamic Ideology transpired to create a more harmonious approach to Islam rather than the more formal structures previously adhered to. This represents the initial demolition of long established taboos. Nevertheless, these early beginnings have taken a long time to actually progress into glass art.

There are examples of products ${ }^{200}$ from the $19^{\text {th }}$ century which were born out of the intense trading and commerce between Bohemia and the Near East. These show that pieces from Bohemia were designed with the Near East market in mind. Depicted on some of these pieces was either a typical view from Istanbul or the seal of the Sultan. Today there exists some transfer decoration examples, which depict portraits of Ottoman Sultans and commanders, especially on water-pipe glasses, which are not observed on Beykoz glassware and the commencement of which is not known precisely. (Figures $97 \mathrm{a} / \mathrm{b}$ ). Nowadays it is surprising that most of the water-pipe glasses are Iranian products and these water pipes covering older Turkish motifs and pictures, imported from Iran are being sold at Turkish tourist markets as Turkish products. In addition to carpet-kilim, ceramics, porcelain, jewellery and bead

$198 \quad$ See for more, Brown, Patricia F., Venetian Narrative Painting in the Age of Carpaccio (London, 1988), p 55. "Gentile Bellini has given this monument to his country, having been called to the Ottoman, and made a knight as a reward" and also Turkish Decorative Arts, An Exhibition presented by the Scottish Committee of the Arts Council in the Huntly House Museum (Canongate, Edinburgh, $21^{\text {st }}$ Aug.-14 ${ }^{\text {th }}$ Sept. 1958), p 7.

199 Inalcık, p 181.

200 Bayramoğlu, Fuat, Türk Cam Sanatı ve Beykoz Işleri (Istanbul, 1974), p 24. 
shops, the existence of a shop selling only contemporary studio glass products imported from Iran is noteworthy. This is in a building named Kızlarağası Hanı, in Kemeralt//zmir established specifically for this purpose in an area where tourist shopping is very intensive.

The existence of glass art which is documented and the miniatures seen at Surname-i Hümayun ${ }^{201}$ made by Nakkaş ${ }^{202}$ Osman circa $1585^{203}$ at Istanbul indicate an extensive production and the use of advanced techniques. It is known that in the beginning of the $13^{\text {th }}$ century, a number of glassmakers, especially mosaic makers moved from Constantinople to Venice and contributed to the development of glass with their particular skills and technical knowledge ${ }^{204}$. Even though we have no glass samples from the $15^{\text {th }}$ to $18^{\text {th }}$ centuries there are written sources from the $17^{\text {th }}$ century which bolster the case for the existence of early glass workshops in Istanbu| ${ }^{205}$. Evliya Çelebi mentions some bottle and mirror makers in Istanbul in his famous book about his journeys, called "Seyahatname",206. It is not however possible to speak about any characteristics of the glass products until Mevlevi Derviş Mehmed Dede, who was sent to Italy during the period of Sultan Selim III Period $(1789-1807)$ and had glass training there, returned and established a workshop at Beykoz I Çubuklu in $1795^{207}$. The production of Beykoz products, which commenced with Mehmed Dede, started to gain a special identity during his years.

\footnotetext{
201 The Surname of Murad III or Festival Book of Murad III.

202 Meredith-Owens, G. M., Turkish Miniatures (London, 1969), p 7. "Meaning a nakkaş who specialised in the painting of intricate floral designs on the margins of manuscripts".

203 Günalp, $\mathrm{p} 82$.

204 Hetteš, Karel, Old Venetian Glass, trans. Ota Vojtišek (London, 1960), p 14.

205 Sotheby's Concise Encyclopaedia of Glass (London, 1991), p 45.

206 Günalp, p 82.

207 Arıbal, Rıfat, "Türklerde Camcılık”, Şişe ve Cam (July 1967), No. 31, p 14.
} 
The current chaos in the identification of Beykozware should have been solved by reading the seals and the writings on the products, but unfortunately they were rarely stamped. Glasses were also commissioned by the Palace to be made outwith Turkey, especially in Bohemia and Venice, but according to Turkish taste and as per the preferences of the Palace. However, a definite identifiction regarding the production sites for these products have not been reached. An inventory from Murano, Italy, dated 1714 , mentions glass products made specifically for export to Turkey. These were called "alla Turchescha" and "per Constantinopoli"208. The Turkish market was very important for Italy, England and Holland in $18^{\text {th }}$ century. In regards to this subject, there is an article by Charleston entitled "The Import of Western Glass into Turkey" in it he mentions a book by Elias Habesci, published in 1784, called "The Present State of the Ottoman Empire". A chapter of this is called "Of the Commerce of England and Holland with the Turks", and it indicates this commerce as follows:

"The chief articles of their trade are, lead, tin, watches, all sorts of clock-work, hardware, woollen clothes of different qualities, spices and glass-ware ${ }^{209 "}$.

Unfortunately many were not stamped and were very similar to the domestic products and this added to the confusion of identification. Secondly, foreign makers brought from abroad or living in Istanbul made some of the products produced at Beykoz ${ }^{210}$. Therefore serial numbers which have not been used in Turkish may be observed on these products. When the Ottomans invaded other countries they wanted to leave their individual cultures and methods intact and

\footnotetext{
208 Boesen, Gudmund, Venetian Glass at Rosenborg Castle (Copenhagen, 1960), p 79.

209 Charleston, R. J., "The Import of Western Glass into Turkey: Sixteenth-Eighteenth Centuries", Reprinted from the Connoisseur (May-August 1966), Vol. 162, p 24.

$210 \quad$ Bayramoğılu, p 23.
} 
endeavoured to rule over them with equanimity. Jason Goodwin describes this melting pot of cultures thus;

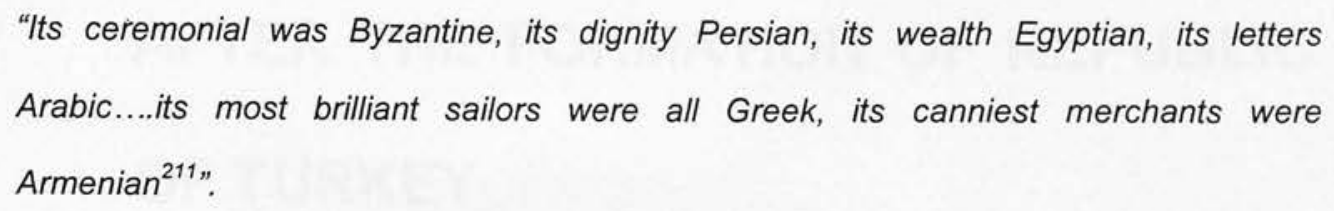

Whether or not it was the Turks who made these glass objects is unimportant, in the end they were designed for Turkish tastes. With the development of Beykozware culture, started by Derviş Mehmed Dede after his visit to Italy, a specific identity was established for Turkish glass which created a stepping stone for the future. He therefore played an integral role in the high activity of Ottoman glass making which itself is evident from the examples we have remaining. 


\section{5. NEW DIRECTIONS IN GLASSMAKING AFTER THE FORMATION OF REPUBLIC OF TURKEY}

For many centuries the Turks held glass art in a very esteemed position, the Palace also paid great attention to the production of glass, these facts, combined with the skill and creativity of craftsmen, produced the unique Beykozware at the end of the $18^{\text {th }}$ century. With the establishment of Beykozware a large market for glass developed in the Beykoz, Paşabahçe area. Developments during this period played an important role in the foundation of Paşabahçe Glass Factories (1934) following the establishment of the Republic of Turkey. Turkish glass art, which has continued for centuries as a handicraft as well as functional ware, reflects both Turkish tradition and culture. Its roots have helped to create its stylistic identification which is displayed by Turkish craftsmen, these have successfully converted traditional functional objects into decorative forms by the addition of artistic elements to their function.

From the beginning of the Republic of Turkey until the establishment of Paşabahçe there has not been any detailed evidence of glass-producing enterprises found. This is due to a shortage of documentation, but it seems in this ten-year period there was no significant attempt to establish any such workshop. Following the end of the war and the declaration of the Republic of 
Turkey on $29^{\text {th }}$ October 1923 the country suffered great economic deterioration. Time and money was needed to regulate government business, to set up a new system and to instigate Atatürk's intended reforms. During this period there was an attempt to restore industry and Ziya Üçüncü established ${ }^{212}$ a glass-producing workshop around Tekfur Palace in 1933. Its primary function was to produce tea and water glasses, however it fairly quickly closed down.

The glass industry at this time was an important section of the government's development plans and Paşabahçe was to be the starting point ${ }^{213}$. The first Industrial development plan covered the establishment of glass factories. The responsibility for their foundation lay with Türkiye Iş Bankası and the new factory started production in Paşabahçe under the management of the French Stain Company ${ }^{214}$. On $15^{\text {th }}$ August 1934 they laid the foundation of Paşabahçe factory $^{215}$ (Figures $98 \mathrm{a} / \mathrm{b}$ ) and on $3^{\text {rd }}$ July 1935 they began partial production ${ }^{216}$.

Ismet Paşa ${ }^{217}$ (1884-1973) laid the first foundations of the factory (Figure 99) and Mustafa Kemal Atatürk (1881-1938) sent a telegraph (Figure 100) of congratulations to the inauguration ceremony. He mentioned that the establishment of this factory was important as it was a major step in the first five-year period of the national industrial programme.

212 Demir, Çiğdem E., “Camın Öyküsü”, THY (April 1996), Istanbul, p 37.

213 Bayburt, Sinan R., "Gümrük Birliğinde Türk Cam Sanayii” MA Thesis, Unpublished, Ist. Univ. Sos. Bil. Enst. Maliye Ana Bilim Dalı (Istanbul, 1994), p 3.

$214 \quad$ Demir, p 37.

215 Anonymous, Paşabahçe, Year 1, No. 8, August 1985, Istanbul, cover.

216 Anonymous, Paşabahçe, Year 1, No. 7, July 1985, Istanbul, cover.

217 A Turkish commander and statesman, comrade in arms with Atatürk, first Prime Minister and after the death of Atatürk, second President of the Republic of Turkey. For the chronological list of Turkish Republic Presidents see Appendix F. 


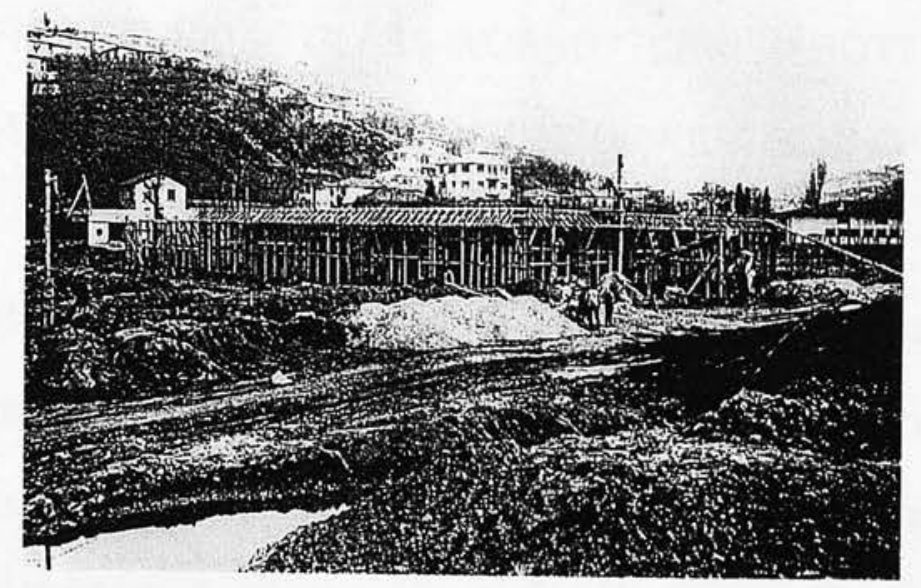

Figure 98 (a)

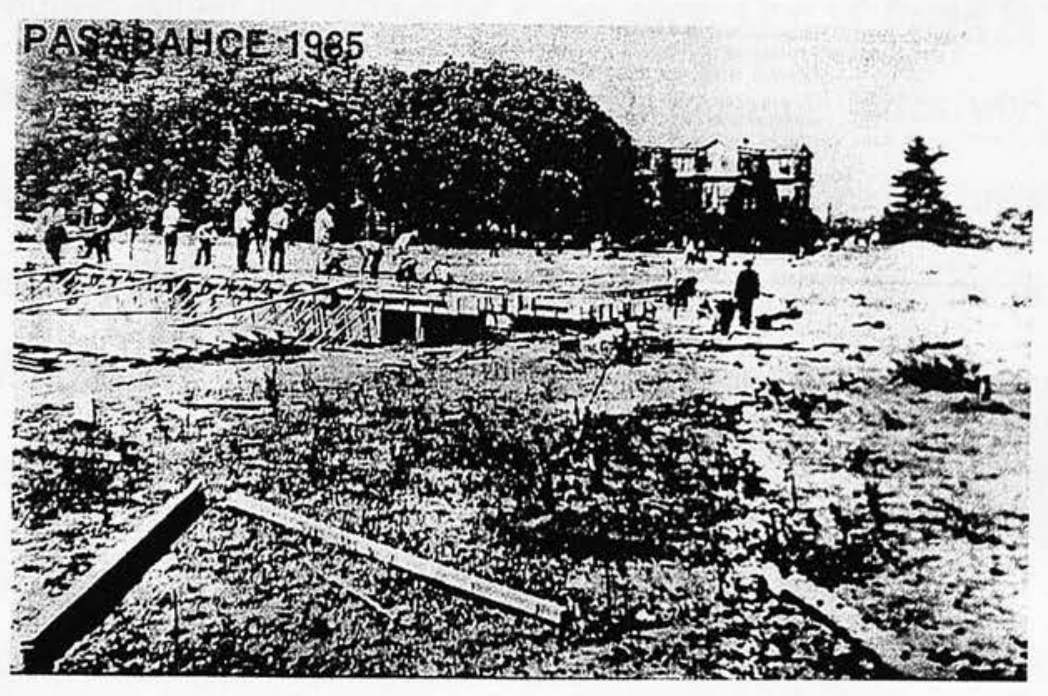

Figure 98 (b)

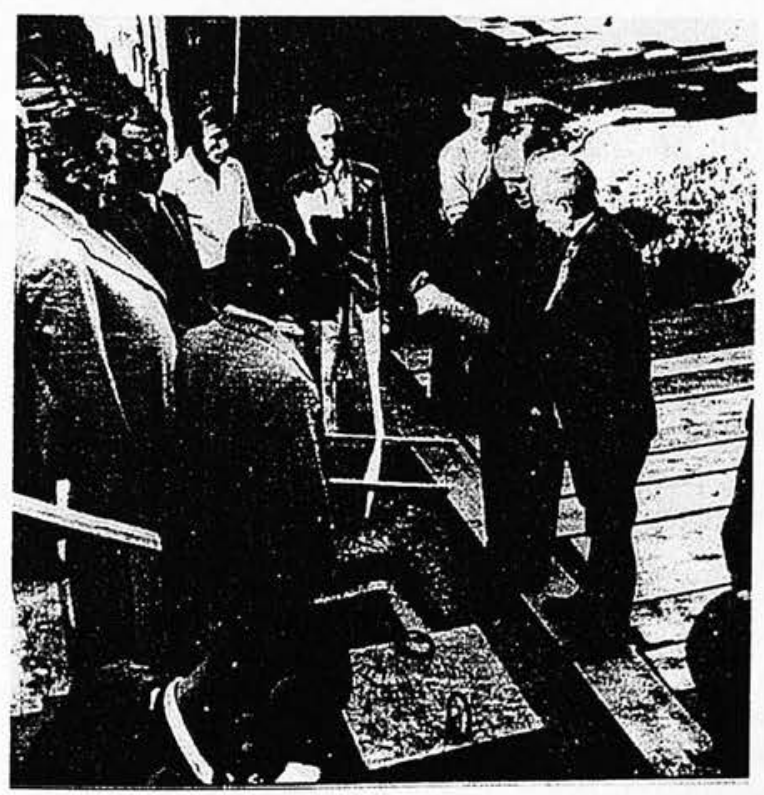

Figure 99

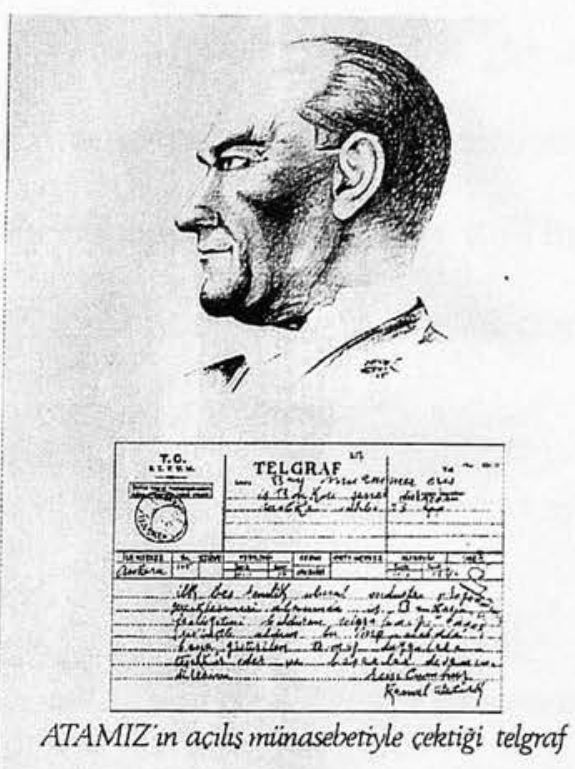

Figure 100 


\section{THE FIRST TURKISH GLASS WORKS "TURKISH BOTTLE AND}

GLASS WORKS INC. (PAŞABAHÇE)" OF REPUBLIC OF TURKEY

Today, Paşabahçe (Figures $101 \mathrm{a} / \mathrm{b}$ ) is one of the leading industrial organisations of Turkey with its 65 year long history and is still the leading name in the national glass industry. The production of Paşabahçe is indicated in tons. ${ }^{218}$ In routine daily production, barring automated production, there are two other kinds of output within the scope of Paşabahçe. One of these is the style of former Ottoman decorations applied to contemporary forms with the aim of supporting the presentation of original works of traditional Turkish glass art.

(Figures 102 a/b) The other is the multi-coloured original, one-off product, each different from the other and created with the intuition of the glassmaker. (Figure 103) Though the output of the Ottoman Period products (Beykozware) continues today, the hand production workshop at Paşabahçe/Beykoz ceased operating in 09 July 1999, and the factory is now in fully automated production. However, manual production has continued at the Denizli Glass Factory of Turkish Bottle and Glass Works Inc. (TBGWI / Turkish: TŞCFAŞ) since $1994 .{ }^{219}$ The most important aspect at this point is that a workshop of the importance of Paşabahçe, which provided a contemporary vision and approach to Turkish glass art and in which the glassmakers had the opportunity to create original works, closed when the master glassblower Yusuf Görmüş ${ }^{220}$ retired. The extraordinary location of Paşabahçe at Beykoz, its modern industrial

$218 \quad$ Total production is now one million tons per year. Focus on Paşabahçe, The Founding of Paşabahçe. http://focusmm.com.au/paşabahçe/co_id.htm

${ }_{219}$ Interview with Bilsen, Engin, Production Manager at Turkish Bottle and Glass Works Inc., Paşabahçe/Beykoz on 22.07.1999.

220., See Chapter 2. 6. Turkish Contemporary Glass Art and Education p 113. 


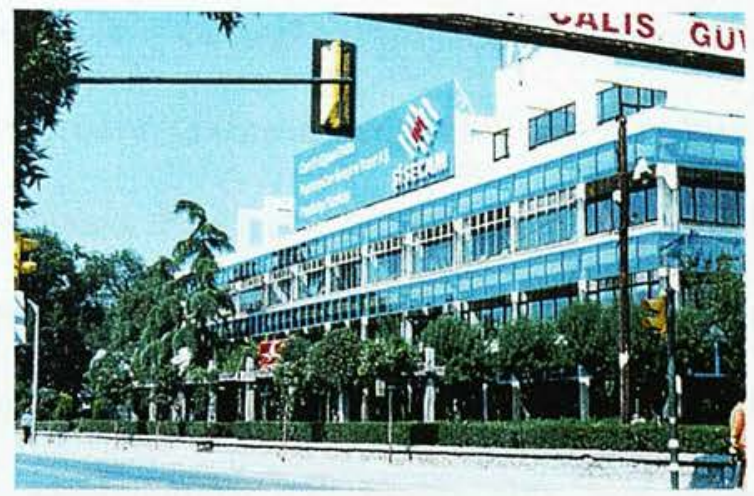

Figure 101 (a)

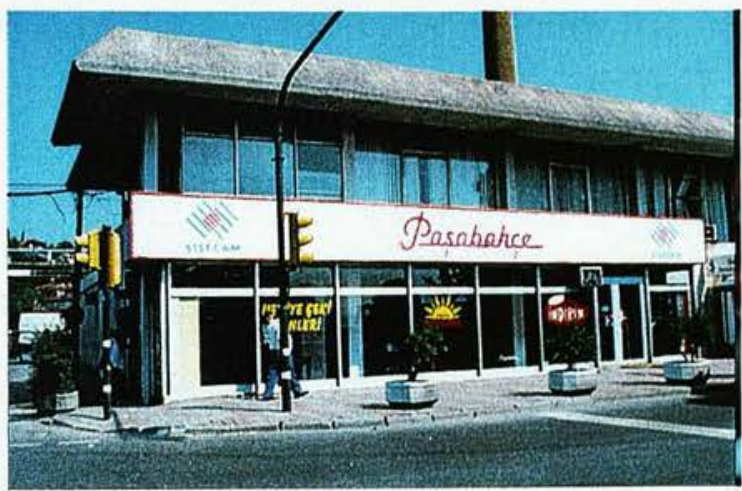

Figure 101 (b)

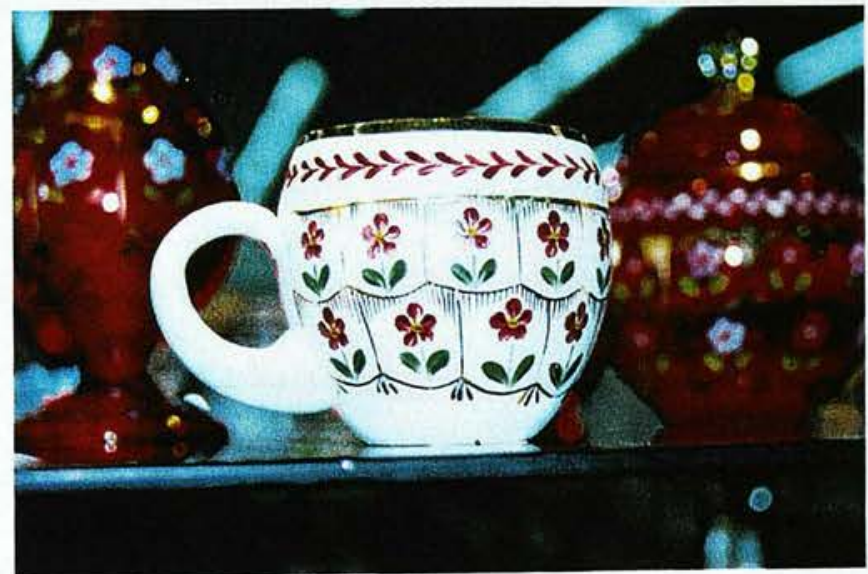

Figure 102 (a)
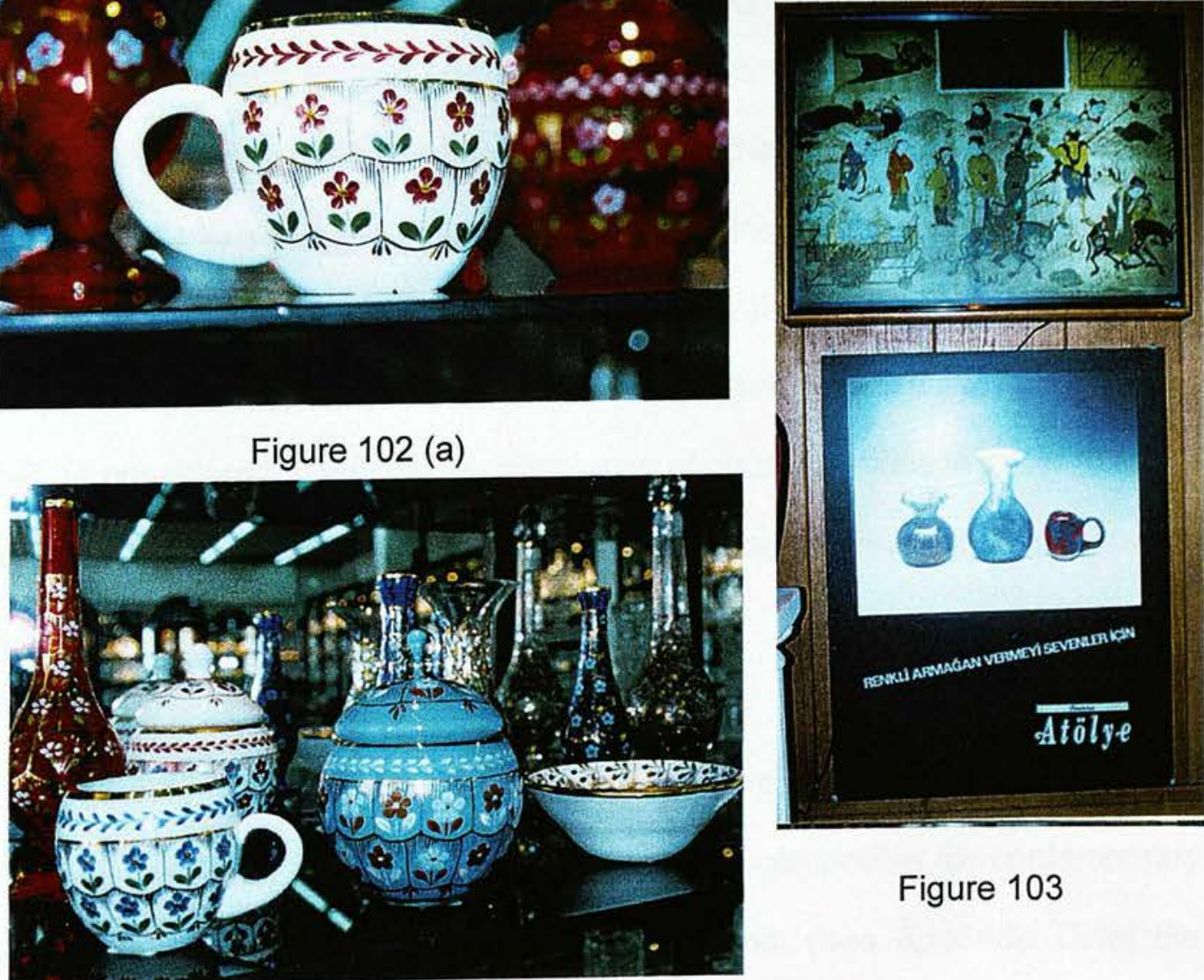

Figure 103

Figure 102 (b) 
infrastructure constructed with skill and experience gained over long years and its technological development, today serves only for the bulk production of glassware and glass vessels. However, contributions from such an important and large organisation to contemporary Turkish glass art, should result in a positive boost to prestige without causing any important detrimental change to the economy of the organisation. By taking this into consideration, the organisation surely considers this support to be a worthwhile expense in terms of promotional value.

After Paşabahçe had been established as a fully automated glass factory for many years, they were anxious to catch the spirit of the automated age through introducing modernisation, mechanisation and technical knowledge. They applied themselves therefore to large-scale production which monopolised the market. However, they limited themselves to decorated objects, which were produced due to the introverted politics of production within the company. They did not evaluate the changing fashions, tastes and art movements which spread through and affected other countries. There is a linear relationship between the general cultural structure of a nation and what they will accept in art. This relationship must not only be understood with regard to ones own country, but also be considered alongside the production of other countries in order to make works which are acceptable to public taste as either everyday functional objects or works of art.

There is no doubt that Paşabahçe is going down the right track as regards using glass commercially, its machinery and plants are compatible for contemporary times and its investments are economically sound. (See Appendix D for the 
detailed list of the plants and the companies of Turkish Bottle and Glass Works Inc.) This is evident from simple mathematical equations and looking at production capacity. The most important aspect is the approach to fine art from such an industry-orientated company.

On $20^{\text {th }}$ September 1999 , in my interview with Dr. Baha Kuban and Reha Akçakaya, working at TBGWI Research and Development Department as Business Development Experts, a number of valuable and expansive ideas which may be very useful in the development of Turkish studio glass art, were expressed. The possibilities of an artistic approach to glass in this highly industrialised environment constructed with the benefits of modern technologies, have been considered and are being evaluated by these skilled young men who intend to develop and improve their ideas towards this approach. They naturally believe that, the continuously increasing rate of automation in the production of such a great organisation will minimise the human contribution, this contribution will then be used in design and in the solution to confronting problems. The features of the personnel needed here will undoubtedly be very different from a small sized glass workshop or a university department approaching the matter from an artistic aspect. The comments were encouraging and constructive and in his report Dr. Kuban suggests the theory that a glass design department should be present within the organisation. Some of his most productive ideas are shown below: 
"...the relation may be considered as historical and respect to artistic heritage. This is what is generally observed world-wide. Leading glass companies, as a respect to their origin, are supporting small glass production, are continuing glass art activities within their structures or supporting these, and are performing these with interest in historical consciousness or for advertisement. ${ }^{221 "}$

The trends here are based on the close relationship to be formed between the artistic glass and glass production industry. These are the indicators of preparation for some changes in Turkey on this matter. Similarly, the opinions that positive relations between the fine arts and architecture departments of the universities may be developed are very constructive. What is dreamed of here, is to find a wide audience and market, which respond positively to the objects, created in the current atmosphere of forming traditions.

Today, TBGWI is about 65 years old. In 1963, when it was half as old, it had already recognised its failures and mistakes. This year is important as it signifies the period when the studio glass movement started in America. In his essay of 1963 Remzi Ormancı, The Chief of Technical Support at Paşabahçe, searched for the answer to the question, "what is the secret of directing this business towards fine arts?"222. He also wrote enthusiastically about plans for a new design centre which was hoped would contribute to creativity and found a movement towards art which would provide the perfect environment for glass makers to exhibit their skills. Only a few progressionists held these innovative views and today, when we look back, it is clear that these ideas were

$221 \quad$ Kuban, Baha, Dr., In his unpublished paper entitled "Cam sanatı bölümü üzerine notlar" (Istanbul, ND).

222 Ormancı, Remzi, “Güzel Sanatlar ve Goblecilik”, Şişe ve Cam, No. 10, Sept. 1963, p 5. 
not shared by enough people to create a large difference in the production of the company.

An industrial designer who works within the triangle of his drawing table, his ruler and his pens and possibly never sees a hot furnace with melted glass in it, and therefore has no idea of the characteristics of the glass in its production phase, can of course design glass in a glass factory. But even if this design is perfect from the technical angle, however one can easily see that something is missing in the context of the fine arts. (Figure 104) Today, even if this organisation believes that its action towards fine art is sufficient, it is only sufficient for the technique and the internal politics of the company. On $22^{\text {nd }}$ of July 1999, in an interview with Engin Bilsen, the Product Manager at Paşabahçe, he continuously mentioned the necessity of automation due to economic reasons, relative concepts such as quantity and beauty are not as important as economic facts as the factory is a business and not an experimental laboratory. Saying:

"...In an automated factory, a team of ten on a bench producing studio type glass is very inconvenient. ${ }^{223 "}$

This is an interesting indicator of Mr. Bilsen's prejudiced approach to technical ideas and is a restrained and inflexible point of view. A company of such scale and economic power of production must strike a balance between producing a ton of drinking glasses to the public's tastes and manufacturing a unique object suitable for an individual. 


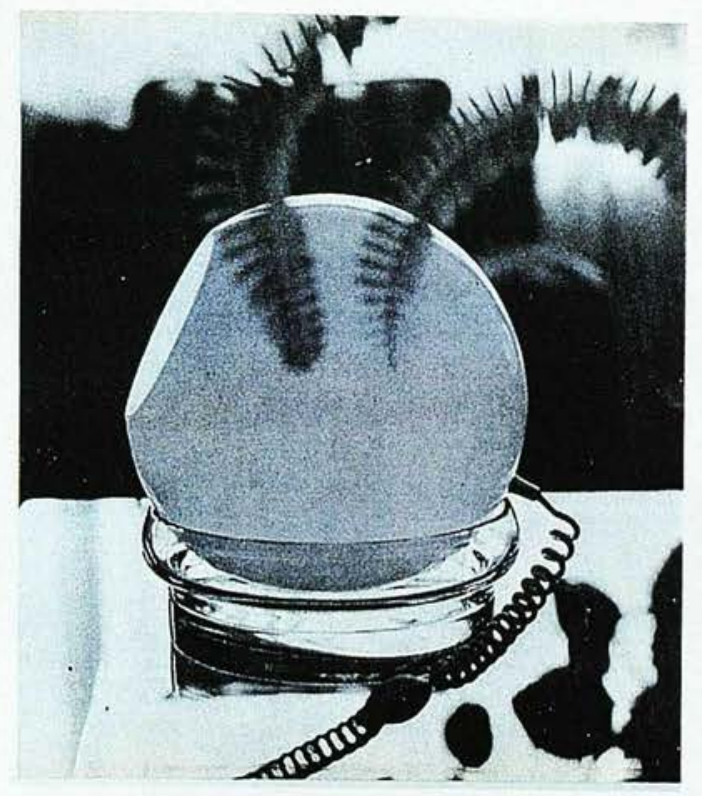

Figure 104

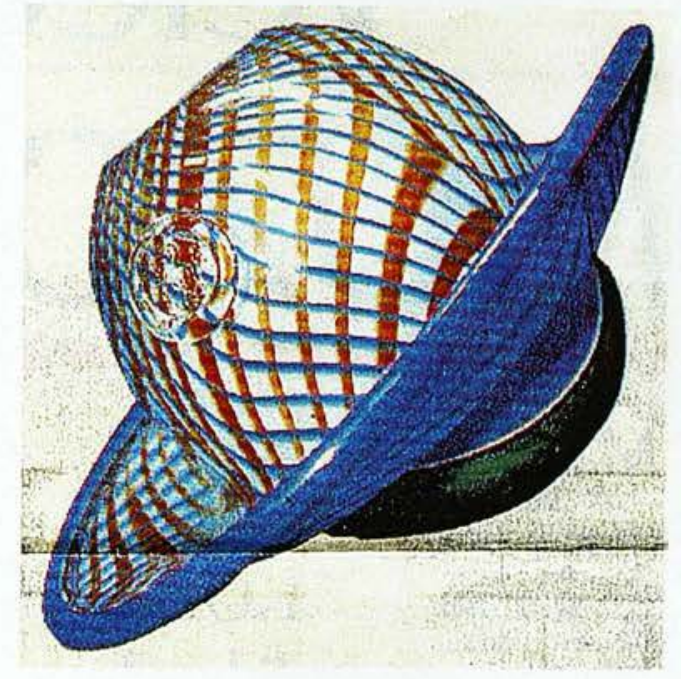

Figure 105 (b)

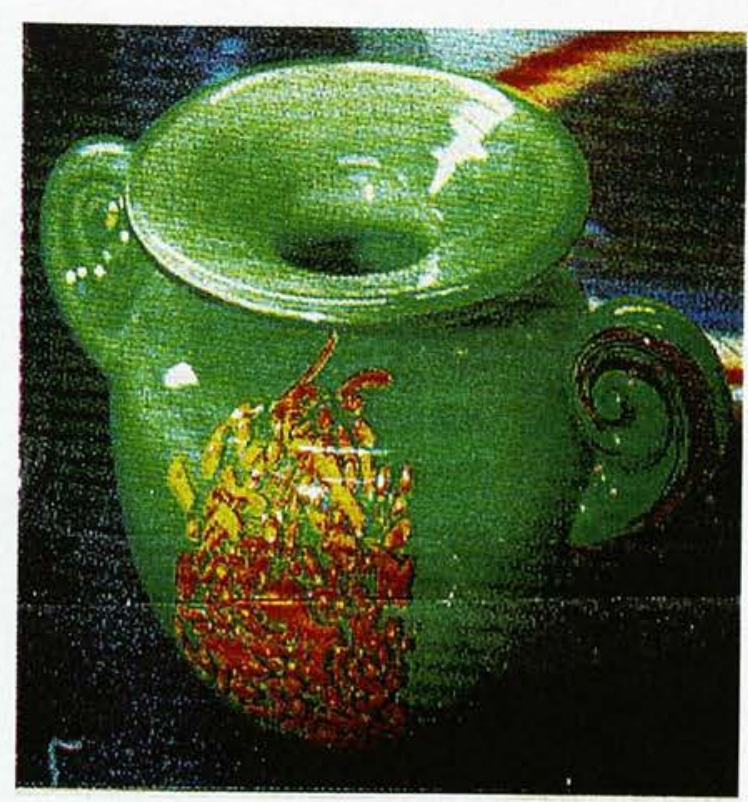

Figure 105 (a)

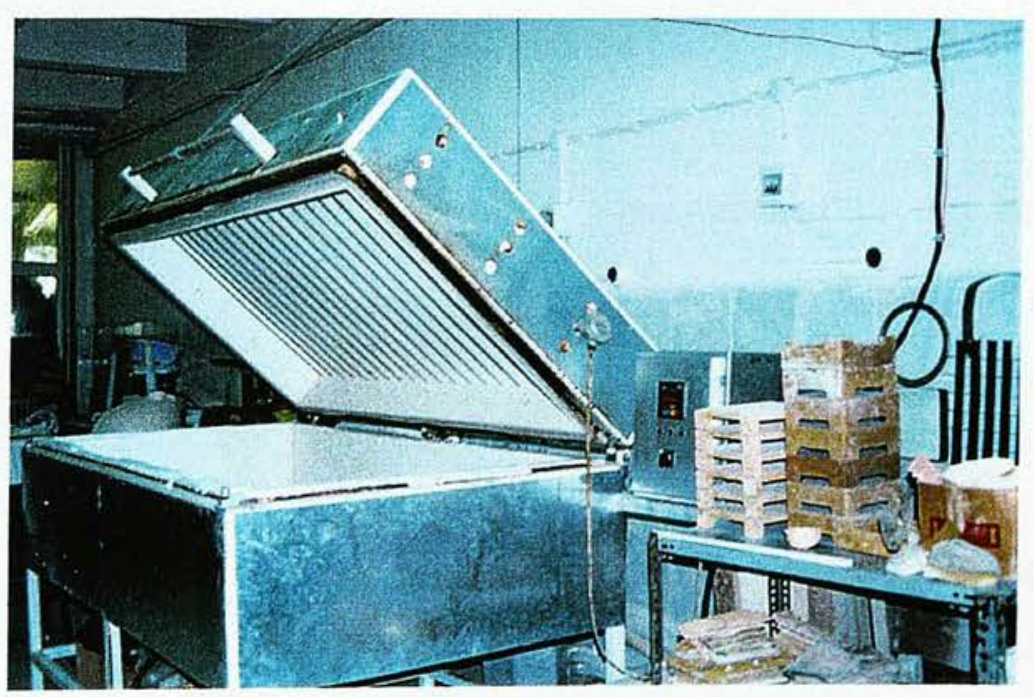

Figure 107 
Mr. Bilsen is primarily concerned with the importance of sales rather than production. However mass produced goods, no matter how successfully made, has limitations for their potential sales and cannot reach more than a certain level. In spite of these facts he has given some interesting comments regarding the company's production policy in an interview in 1986. These reflect internal politics, which ignore the role of domestic customers in the production process, and underestimate the taste and understanding of quality of the consumer:

"Paşabahçe has a production order which is completely directed towards the European quality and to matured tastes. By reason of that, the source of the market loses in Turkey are due to its high quality and the unmatured quality of mentality of the people who use it. In other words, Paşabahçe is too high for the existing customer quality in Turkey. ${ }^{224 ”}$

In 1994 Paşabahçe was exporting glass to more than 70 countries $^{225}$, this grew by 1999 to 104 different countries ${ }^{226}$ and they were understandably proud of this achievement. Over the five years the success of increasing exportation by over 30 different countries indicates the importance placed on serial production and demonstrates the way in which the factory has focussed its policies on foreign markets.

We should examine this phenomenon in the context of the political and economic situation. In Turkey in the 1980s there were laws and regulations which limited importation to protect the goods manufactured within Turkey, this

\footnotetext{
223 Interview with Bilsen, Engin.

224 Anonymous, "El Üretim Müdürümüz Bilsen'in Murano Izlenimleri", Paşabahçe (Sept. 1986), No. 21, p 5.

${ }_{225}$ Anonymous, "Beykoz'dan Paşabahçe'ye (Yeni Koleksiyon Serileri)", Antik \& Dekor (1994), No. 26, p 164.

226 Focus on Paşabahçe.
} 
however reduced the possibilities for exportation and commerce between countries. After the change in government in the 1980 s during the period of late president Turgut Özal (1927-1993, presidency 1989-1993, for the chronological list of Turkish Republic Presidents see Appendix F) new regulations were introduced.

Becoming a member of the European Community was discussed for many years as was entering the Customs Union ${ }^{227}$. Regulations and changes were needed in order to link these affected industries within Turkey. The glass industry which is a major, well-developed and established industry in Turkey was especially affected as were a number of subsidiary industries which worked closely with the glass industry. For instance, construction, automotive, pharmaceuticals and food and beverage industries. Turkey had to adjust itself to the liberal regulations of the Customs Union, however these regulations offer only minimal protection ${ }^{228}$. After these adjustments the Turkish Glass Industry was able to rival industries in more developed countries for market access because the adjustments provided equal opportunity to compete. Turkey, however, is affected by other factors e. g. cheap goods flooding the internal market from third world countries. Turkey is therefore in the position of having to abide by European regulations as well as applying its own internal regulations ${ }^{229}$.

All these economic phenomena and the changes taking place in the country's economic politics need to be digested to overcome the problems, this is a slow

227 The Customs Union is a step on the way to becoming a member of the European Union.

$228 \quad$ Bayburt, $\mathrm{p}$ XI

$229 \quad$ Bayburt, p 3. 
process. Paşabahçe needs to form its own approach to this complex and large scale development. One of the most important elements for Paşabahçe must be the establishment of foreign trade. This will allow it to survive independently, and therefore the company's production politics and economic policy relies generally on foreign trade and automated serial production. By implication, therefore, artistic glass and hand made glass production is viewed as a poor investment of both time and money. 


\section{6. TURKISH CONTEMPORARY GLASS ART}

\section{AND EDUCATION}

In 1882 after the Tanzimat reforms there was an effort toward westernisation in Turkey, the liveliness which this induced became tangible with the opening of Sanâyi-i Nefise Mektebi or Academy of Fine Arts, in Istanbul. After the Tanzimat reforms and with the westernisation during the 1840s Armenian, Italian and French $^{230}$ civil engineers and architects had authority and influence on the town planning and decoration of the period. This formed the foundation for the construction of many valuable buildings which reflected the art movements of the period. Changes occurring within the social structure and the formation of cultural and traditional elements were slow. When Sanâyi-i Nefise Mektebi was first established it offered just three programmes, painting, sculpture and architecture, later more were added. Alongside this academy there were more new schools launched and these were the places that would give birth to the education of Turkish artists of the future who would revitalise Turkish art.

In Turkey painting, sculpture and architecture were directed by academic education, when this is seen in an international context, an earlier development in Turkey than in other countries is apparent. Despite this early development, the idea of glass as a fine art material was fairly late in conception. The first attempt again came from the Mimar Sinan University's ${ }^{231}$ Fine Art Faculty, 
Ceramic Department, after the 1980 s, when it was attempted to place glass into an academic structure.

As a third-year student in 1985-86 it was not difficult to observe the inadequacies apparent in the introduction of glass to the university as the only real change was to the name of the department. Likewise it was clear that in the following years the same lack of direction was evident in the shortfall of qualified academic staff, materials and knowledge; this produced mistakes in both approach and understanding. Today, 15 years later, it is evident that their approach to the subject was not as thorough as it could have been. To overcome the difficulty involved in hot glass, technical and aesthetic support is required, without these the interests of the students will be depleted. With glass as part of the Ceramics Department there is a more appealing alternative.

When glass is used without the complications of heat, like stone or marble, it is an attractive material for the creation of three-dimensional, sculptural works. One enthusiastic student, Cenan Uyanusta (b. 1953), who wanted to keep her interest in glass going was compelled to utilise this cold method and was fortunately very successful. On the other hand in Marmara University one of the tutors, a painter, Ali Ismail Türemen (b1942, Istanbul), chose glass ${ }^{232}$ as a material to transform the figures described in his paintings into three dimensions. He encouraged his designs specifically in that direction. Another artist who displayed an interest in glass was Fahri Kaplan, who reported ${ }^{233}$ that whilst studying art philosophy in London in 1974, he had taken glass making 
lessons. Likewise Paşabahçe's retired glass master, Yusuf Görmüş, was naturally very interested in glass making.

Compared to other arts in Turkey, such as painting, sculpture and ceramics, which have many workshops, the prominence of only these two individuals is resonant of the fact that only a small number of people in Turkey have an interest in hot glass. The production of these two is judged on the complexity of form in terms of colour and decoration, the controlling aspect of functionality and the importance of commercial and experimental looking objects. The glass of Yusuf Görmüş resounds with the aim of utilising the techniques of Venetian glass, (Figures $105 \mathrm{a} / \mathrm{b}$ ) he stated in an interview ${ }^{234}$ that when he was a boy he saw some Venetian glass brought by sailors to Istanbul and stored these images carefully in his memory. Naturally the knowledge and experience of Yusuf Görmüş has, over the years, made a huge contribution to Şişecam and his teaching of glassblowing was extremely valuable in the training of glass blowers for the factory. However, it is clear that regardless of this knowledgeable master no other artists were exposed. Looking from this angle towards industrial and commercial production there was not any development of artistic glassmaking.

The glassmaker, Fahri Kaplan, on the other hand, saw the potential market for hand made everyday items and in this way he is commercially driven to supply this demand with his rather ordinary and brightly coloured pieces. (Figure 106) In the description of his products, he says, 
With this sentence he summarises the mentality of his approach to glass. Sadly, this is the way in which he is trying to encourage buyers for handmade glass in Turkey as he had previously come to the conclusion that people were not buying glass due to its natural quality of being breakable. Ironically, he is trying to eliminate the natural characteristics of glass. In an interview he mentioned,

" that it was difficult for people to believe that Turkish glass would be of the same standard as Venetian glass" ${ }^{236}$.

Even on its own, this sentence summarises a poorly directed approach. Why should he think that Turkish glass should be of the same standard as Venetian glass? Why, when it has an established past, tradition, form, decoration and is an art with its own applications should it reflect the specifications of another culture, or imitate this culture and attempt to reproduce its quality? At the start of the last century this cultural complexity and admiration for other cultures and rejection of the past and its identity meant that artists tried to imitate other arts and as one would expect were unsuccessful. This might also happen to glass and will provide no benefits for it.

At this point, one should not conclude that the forming of glass through blowing techniques is the only way of using glass as an artistic material. Although there is an established glass blowing tradition today in Turkey, it is not for the production of artistic works. Likewise, casting, fusing, slumping and similar 
techniques are not used to produce artistic glass, as these are not traditional techniques. Although the majority perceive that the use of glass in architecture only involves the simple combining of various coloured glasses without any further artistic application. Therefore, the artists are currently content to create purely decorative objects.

In modern Turkey, there is a current theorising about the use of glass as an art material in order to advance it; there have inevitably been mistakes made in regards to this, but there have also been some positive steps taken. In Marmara University in Istanbul, in the fine arts department, the formation of a young glass department promises an encouraging future for contemporary Turkish glass art. A confident, determined and diligent artist and head of the department, Ersun Özken, has forged some very constructive plans for the future of glass art. On the $23^{\text {rd }}$ of July 1999 through visits made to the department and interviews made at that time were heartening and inspiring in regards to the positive formation of glass art in Turkey. The approach to glass by the academics, the structure of the course and the interaction between the students and the material were well perceived and assimilated. They attempt to supply the equipment needed in order of importance. They have prepared specific areas for the execution of glass cutting and kiln work. It was clear that Mr. Özken was very proud of the kiln, which he had put together with his own hands, overcoming technical and financial hurdles. (Figure 107) Both the materials of its construction and its specifications, combined with its dimensions, are clearly the focal point of the department and the catalyst for the creation of contemporary glass making. Both the creation of the figurative and three dimensional forms, which can be seen in figure 108 , and the forms in figures $109 \mathrm{a} / \mathrm{b}$ which are a 


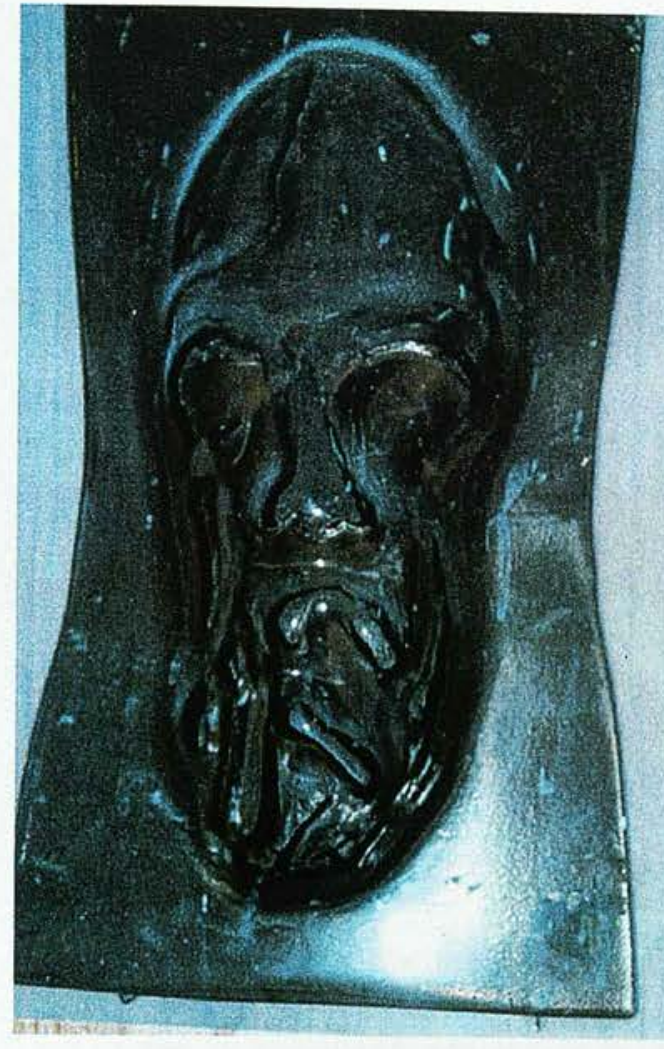

Figure 108

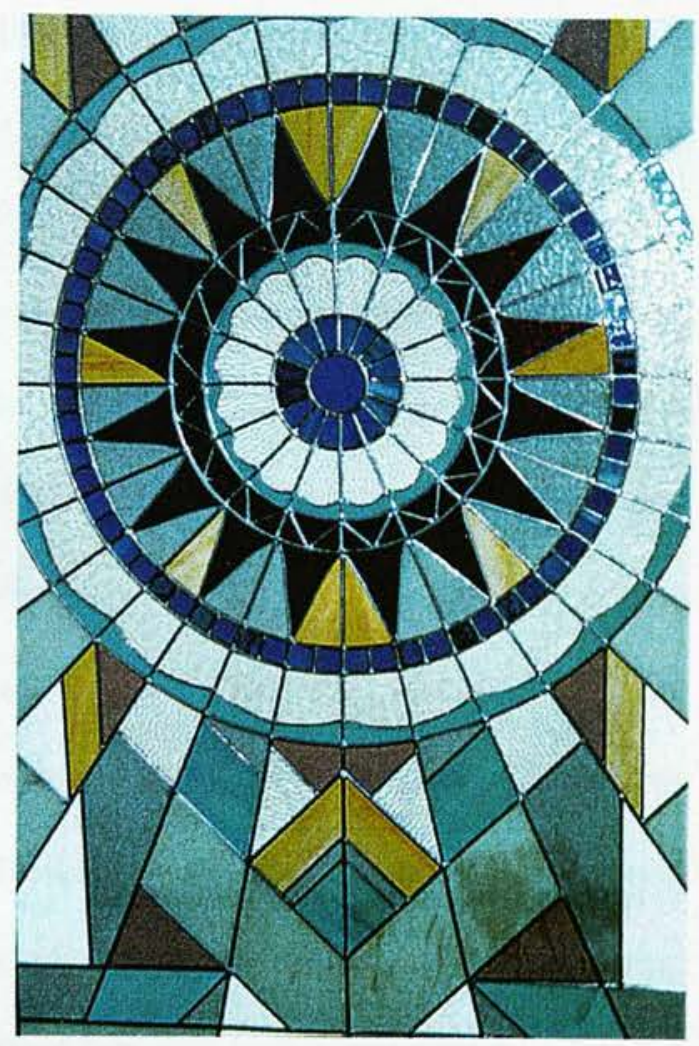

Figure 109 (a)

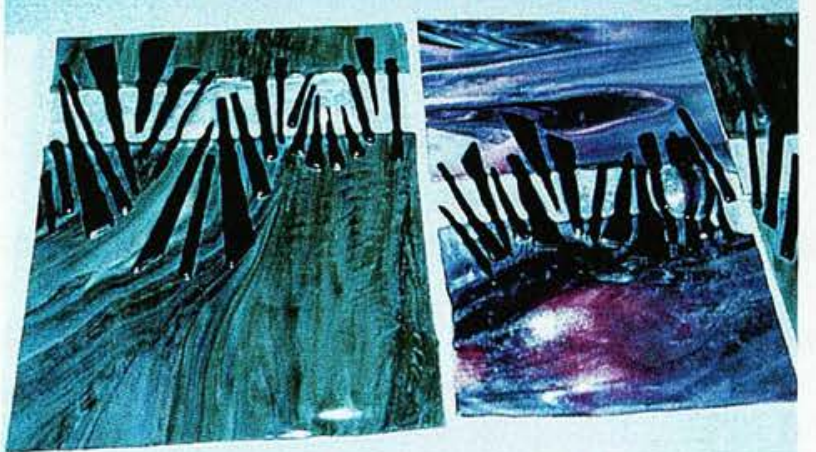

Figure 109 (b)
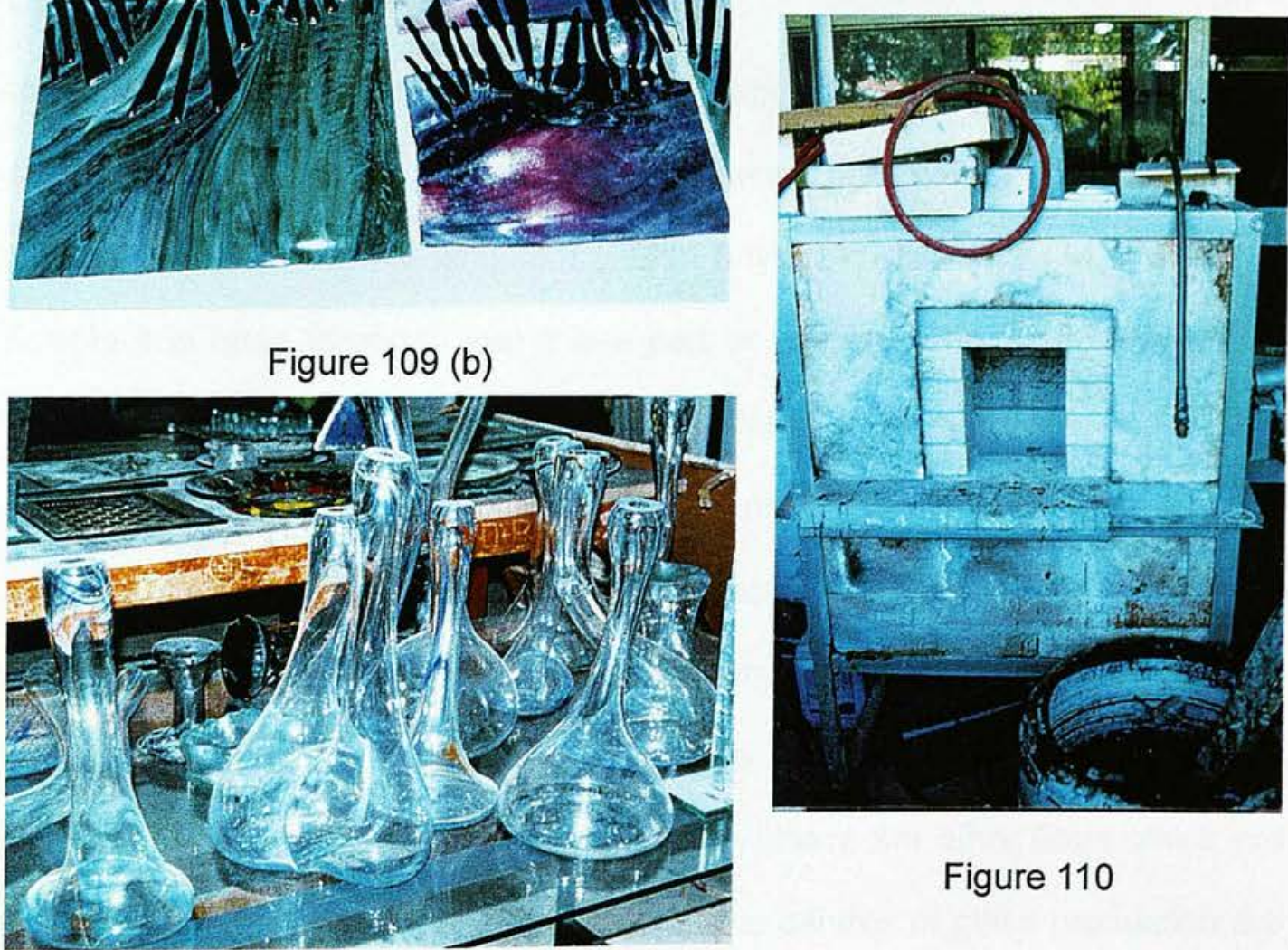

Figure 110

Figure 111 
combination of colours and textures and the inherent structural qualities of glass with the addition of hot and cold working, are the tangible realisation of ideas given dimension. Even though hot glass is a technique still to be fully realised, it is just a further extension to be made as the institution has a furnace and even with the mistakes that have been made, it is a good starting point for the department. (Figure 110) Mr. Özken was particularly aware of the importance and place for hot glass alongside other applications of glass. In accordance with this, although his furnace was not yet running, he did not put off the experimentation with form using hot glass techniques. In fact he brought forms from a workshop in Akbaba village in the region of Beykoz, which produced lampshades and decorative forms, for the experimental studies of his students. The forms in figure 111 are made by freehand blowing techniques and created a meaningful background for the students to learn different techniques and research into textures connected with forms.

In July 1999 I made a field trip to Akbaba village, Beykoz, in order to observe a small workshop. The workshop is approximately 10 kilometres from Paşabahce Şişecam Factory, on the landward side of Beykoz region, an area which is so remote it is often forgotten that it is a part of Istanbul. The production of this workshop is mainly through glass blowing, the workers here are mostly from Şişecam but there are also apprentices taken on to work with the masters brought from Şişecam. The workshop appears as a bright and productive space, even if it does not conform to western standards of health and safety rules. It has furnaces, annealing kilns, moulds and other equipment necessary for glass production. (Figures $112 \mathrm{a} / \mathrm{b} / \mathrm{c}$ ) Nearby, there are other firms which are engaged with glass decoration. (Figure 113) The centres of glass production are 


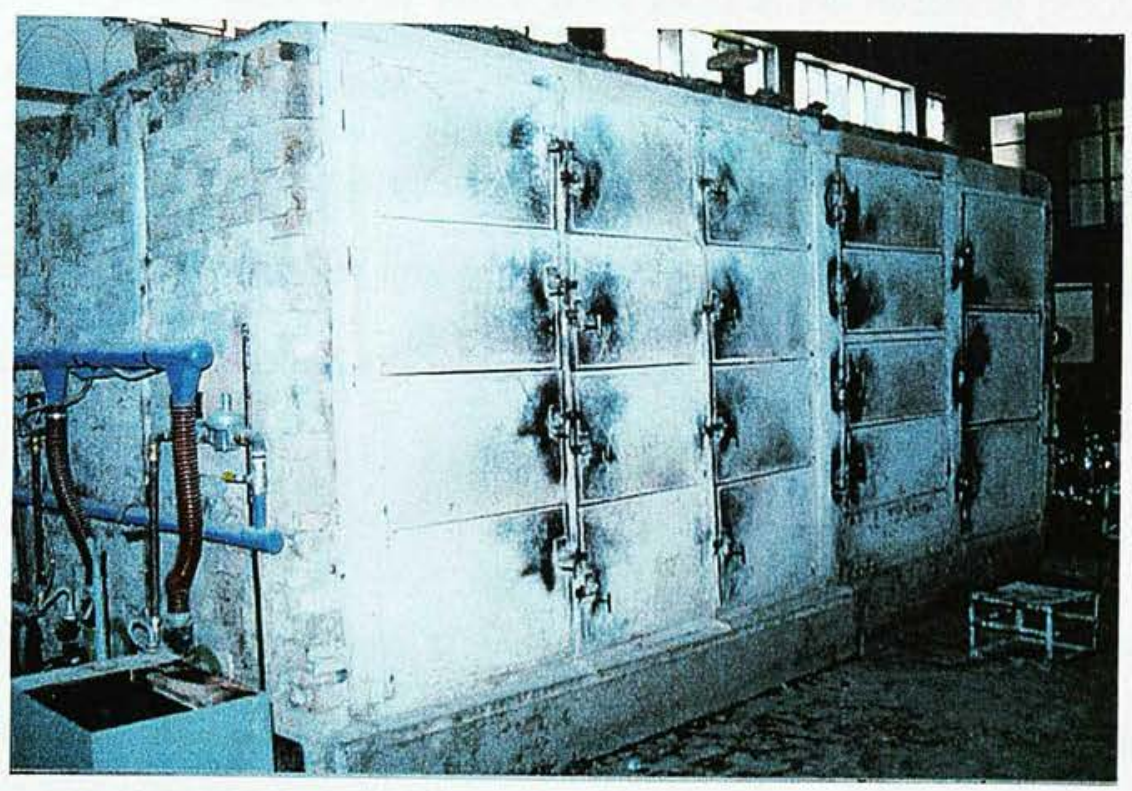

Figure 112 (a)

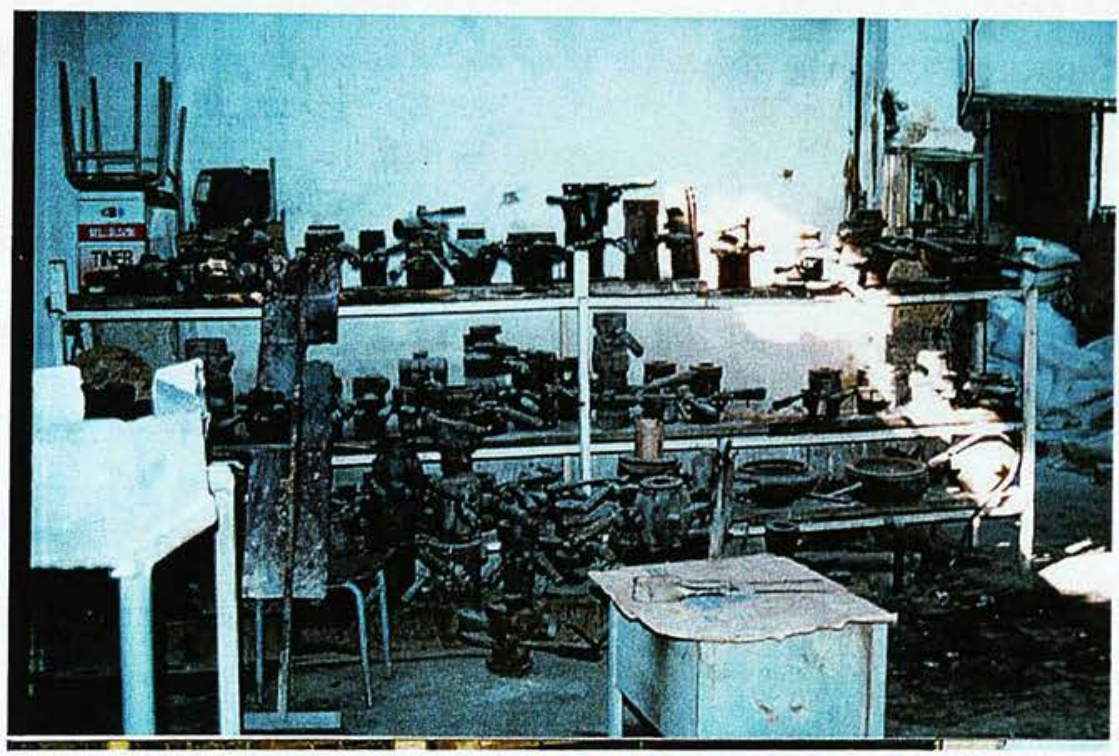

Figure 112 (b)

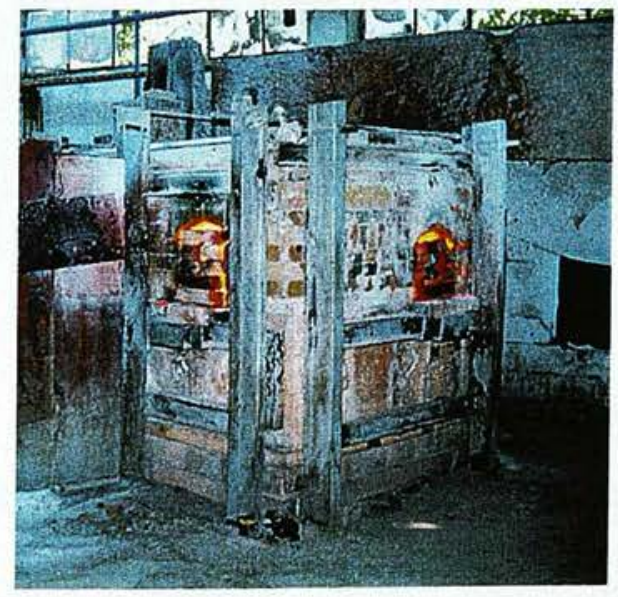

Figure 112 (c)

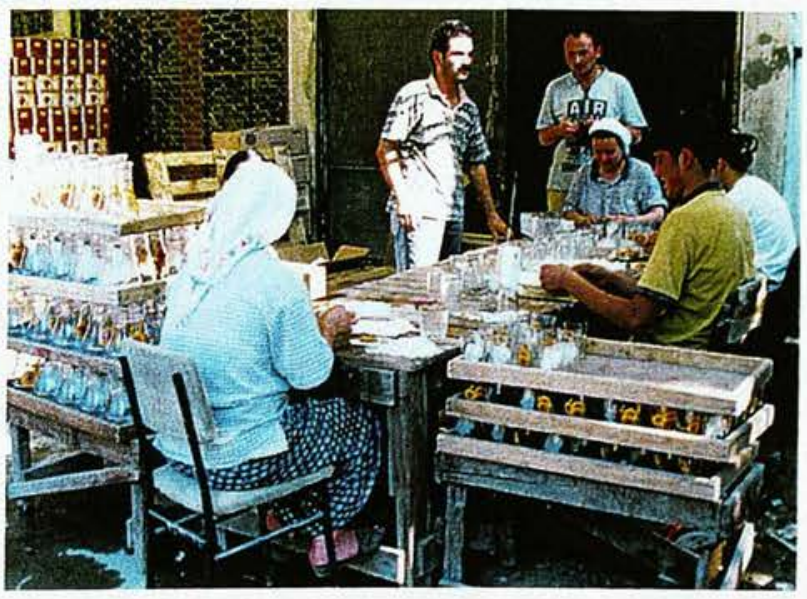

Figure 113 
abundant and are supported by the region's roots in the historical production of glass. Likewise, the presence of Şişecam helps to maintain other, smaller workshops. The continuation of these firms helps to keep the glass phenomenon on the agenda and in practice. Over 200 years glass production has become the symbol of this region and with the existence of these firms it will continue to be.

The level of glass production at Marmara University is, on the one hand, reminiscent of the early days of the studio glass movement in their experimentation with glass, and, on the other, having progressed a long way in a very short time it is clear that the level they are at is only a constructional procedure. Of course, with more research and contributions from inside and outside the department and with the application of progressive ideas this glass department could shortly begin to graduate enthusiastic and creative students, who will take an important role in the glass scene. This is one of the most positive steps undertaken in Turkey so far in regards to approaching and using glass as an art material.

\section{6. 1. TURKISH GLASS ART EDUCATION: THE BACKGROUND}

It is undeniable that social, cultural, political and economic progress and development during the 1960 s affected the general structure of Turkey, as has been the case with other communities in the past. With the changes in economy and economic policies pertaining to the public's directions and goals, the 
demand for works of art and art education were inevitably affected. By looking at the effects of economic fluctuations in society, we can observe the changes in government expenditure and budgeting with respect to education. It is nevertheless, obvious that the results are relative and insufficient to reach a definite conclusion. The economist Thomas Torrance makes this comment on the subject:

\begin{abstract}
"The total amount of a developing country's education expenditure - even if it is low or high-cannot be comparable with the amount of a developed country. The reason for the difference is directly proportional with the necessities of that country at the time. ${ }^{237 .}$
\end{abstract}

The countries that have overcome almost all of their major problems, and have a well-developed and functioning capitalist system have led studio glass art development. Besides that, the topic needs to be evaluated under the knowledge of healthy budget spending and the availability of generous private sponsorship in developed countries. It is important when making an economic analysis between countries that essential data such as national income per capita and the purchasing power is looked at from a comparable basis. Nowadays, the relationship between the variables or the comparison between the country data are made through econometric models. It is also possible to make a comparison by the projection of economic history instead of any econometric models ${ }^{238}$. On the other hand, this is too extensive and broad in scope for this study, and would form a research study in itself.

237 Interview with Dr. Thomas Torrancs, Dept. of Economics, Heriot-Watt University/ Edinburgh on 14. 05. 1998.

${ }_{238}$ Thanks to Prof. Oya Köymen for sharing her knowledge. Correspondence on 27. 02. 1998, Dept. of Economics, Bosphorus University, Istanbul, Turkey 
The principal factor is an educational institution's ability to meet the demand for a high quality work force as part of any proposed development plans. In a developing county like Turkey, educational institutions must have a reliable and well-established basis from which they can support and accelerate the developments of industry and technology in economic and social areas. Education has been carried out by trial and error methods for many years in Turkey and in some cases models taken from the other countries were adapted to serve the needs. As a result, this lack of harmony produced the need for new arrangements, but it had not been possible to construct a planned and productive system. We are nevertheless heading towards many new applications to eliminate the problems in education and proportional imbalance in the number of teachers available to students. It is an undeniable fact that free education brings some advantages, however, the situation in Turkey has veiled the need for attention to the imbalance caused by the difference of income levels of individuals. Therefore, since the contribution to education was optional, it did not produce the required outcome, reaching society at large and causing spending cuts in educational budgeting. The importation of educational models from other countries caused social, cultural and even religious differences and time was wasted trying to reconcile the gaps caused by these differences. An economic damage originated by the rapid turnover of schoolbooks and the application of different systems in each school caused confusion and a demand for some schools above others. Due to these circumstances, private school chains demanding high fees were initiated in Turkey. The problem between the population demanding higher education and the institutions responding to this demand created the obligation of the entrance examination for universities. On the other hand, because of the regional and personal differences of the 
educational programs ${ }^{239}$ in high schools and also the insufficient supervision systems, the equal availability of opportunities could not be offered to the students. The grading system in the entrance examination of universities has constricted the number of vocational graduates, and resulted in them being disadvantaged. It has also put pressure on young people to shun commercial, vocational, artistic and technical institutions in favour of being able to go on to higher education.

Following the foundation of the Turkish Republic in 1923, the new alphabet, a transition from Arabic alphabet to Latin was constituted through the revolutions of Mustafa Kemal Atatürk. Although education had a healthy foundation with the new mentality on école, it was transformed to the present structure progressing in many incarnations over three quarters of the century. In the 1970s pilot schemes for the compulsory education ${ }^{240}$ of children between the age of 6-14 started and had the targets of, on the one hand, providing mental and physical development and on the other allowing development in a convenient environment and the opportunity to make conscious decisions about their own lives depending on their individual desires. Provision of the sub-structure to provide extensive application of eight years' education all over the country, is another important factor like the finalisation of the education programme and application of the law. Time and financial investments are required to gain expertise and for re-evaluation which are musts in merging all the elements during the construction phase of a common structure. The quarter century phase of this application between 1971-72 educational year in which the pilot 
application has started and 1997-98 educational year in which eight years uninterrupted compulsory education was realised, which will have an important impact on the majority all over the country, and which has started to be applied compulsorily due to international treaties and laws and may be deemed as a global example. It is true to say that the Turkish glass art education, established after a 25-year delay, has followed a phase of natural development. The start and completion of this behaviour occur within the same time phase and are affected by the same economic, cultural, social and political changes.

The efforts to overcome the confronting difficulties during the settlement of a stable and successful education system have produced big losses in education from kindergarten to higher education in terms of finance and time. However the transformation period, which became a part of life and almost a tradition in education, cannot be solely responsible for a 25 year delay in the introduction of glass art education, or the introduction of glass as a material to the artist. However, if the economic, political, social and cultural reasons are accepted as small pieces of the whole picture, it should be possible to get feed back through the examination of these factors. The anxiety and limited assets of the economy; the continuously needed reforms of the education system; the fluctuations of the political scene; imbalanced and unstable administrations and the military coups repeated over 30 years did not provide education with any opportunity to develop to an adequate level.

The cultural transformations of the same period constituted a different side to the puzzle. The Hippie movement starting in the early 1960 s affected Turkey as well, changing the styles and habits in fashion, accessories, life style and music. 
Westernisation was exaggerated, considered important and turned out to be only an imitation. While the number of people listening to Classical Turkish songs and western songs with Turkish lyrics (deploring the classical style) increased dramatically, traditions and cultural ties were questioned and a break from them assumed to be the only way to become part of the modern western world. Kitsch products and reproductions became popular and technological products were used directly without a proper time frame for acceptance or an adaptation period. Televisions, having no broadcasting service due to lack of interest in telecommunications and even electricity, were assumed to be the most important piece of everyday consumer life, to the extent that they were even decorated by small hand knitted items - televisions used as an exhibition shelf. While practical applications of modernisation started to reshape everyday life, comparisons were made between the excellence of hand made and machine made products. The basis of self-sufficiency inherent in traditional arts started to disappear when they were forced to expand and compete due to economic conditions. Folk culture was exchanged for modernisation with its high demand on mass production, which exchanged commonly used everyday traditional objects for those made of plastics and steel; hand made carpets representing dreams, hopes and everyday life for batch fabrication. In this process, myths, beliefs, traditional workings and symbols started to loose their meaning and a transition period took place where machinery took a major role over traditional arts. At this time when the confusion and refusal of traditional culture existed, it was almost impossible to introduce a new material to art production where even the oldest arts, paintings and sculpture had been replaced by the use of coloured prints and plastics. 
This period, in which the traditional arts and crafts had continued for centuries, faced the risk of annihilation and was the beginning of the end for many of them. The "cultural" structure and development reached a high level during Özal period- by introducing communication and connections abroad - started a period which resulted in important changes in the minds of Turkish people. The opinion that 'life is constructed on commerce', which had never existed during the Ottoman period, was so successfully applied that, as a result, there occurred an important attack on cultural ideals and interest in art and artistic works increased. Briefly, over the past 20 years through the efforts of Turgut Özal in foreign trade, communication, cultural exchange, and arts which resisted change and continued to exist, began to come alive again. The real westernisation took place at this time and Turkish handicrafts have become popular again. 


\section{6. 2. LOOKING AT THE GLASS DESIGN AND}

\section{DESIGNER}

In every design study, whatever the material used, factors such as human environment, function and need provide the foundation for the direction of a new design. The main principles appropriate to the realisation of a design follow these factors. As the author Jens Bernsen stated:

"Design is not an isolated activity, it is an integral part of the process of product development. $^{241 "}$

For this reason, whatever the object being designed, factors such as its material, its purpose, its user and the methods of production are continuously interacting throughout the period of its development.

A work of art created in glass has certain inherent considerations, for instance, the nature of the material must be at the forefront, therefore applying this necessary qualification to design is the controlling principle in the choice of glass as the material. As a matter of fact, a design must utilise the material which is most suited to its realisation. Likewise, glass requires a design which embodies its own peculiar properties. When functionality is thrown into consideration the designs of the past barely differ from those of today. The quality of glass which dictates it is an outer skin containing an inner space, means that glass utensils for eating, drinking and storage have not changed drastically in their basic design. All that has changed is the understanding of

$241 \quad$ Bernsen, Jens, Why Design? (London, 1989), p 34. 
form which comes when the functionality is transformed into application. The development of glass design knowledge was a phenomena formed through the mutability and novelty of forms.

As machinery gradually became a part of everyday activity, the ebb and flow of life accelerated and concepts such as efficiency and using time in a productive manner found a niche and became an integral part of the wheel of life. As this type of lifestyle snowballed, the success of the new capability for serial and large scale production became the very purpose of production. Inescapably, designs were directed to demonstrate development in this direction. Designs had to be suitable for the principles of industrial production, and for the capacity of technical developments, as well as being efficient in terms of time. Catching the spirit of the time necessitates the simplification of forms in an attempt to make production more manageable and this became the main principle behind the ideas of industrial designers.

The shaping of the public's understanding of glass in Turkey today is a result of the huge influence that the industrial production of Şişecam factory has had for over half a century. Glass production under the control of industrial product designers was made on the basis of mass production and for this reason there never existed an artistic identity for the products, therefore they could not progress further than simple clean and pleasant looking table ware. In modern Turkey glass designers work towards serial production and as a result of this the general public has no idea of what it is possible to do or to create in glass. At this point it will be useful to consider Prof. Önder Küçükerman, (b. 1939) an 
industrial designer who has given direction, through his designs, books, articles and work, to the glass phenomena in Turkey.

\section{THE INFLUENCE OF "ÖNDER KÜÇÜKERMAN" ON}

\section{GLASS ART IN TURKEY}

Önder Küçükerman, a pioneering academic, has, in his writings over the past 30 years, reminded the Turkish people that the concept of glass in Turkey has carried varying significance other than that of simple window glass. In doing this he has brought the history of Turkish glass and traditional Turkish glassmaking onto the agenda once more. Due to his special interest over many years and his approach to glass, his wide range of connections and outgoing personality, he has been considered practically the only living authority on glass in Turkey. He was an important figure for the media and for many in the glass business, and in all subjects connected to glass his counsel was sought. It was Önder Küçükerman who directed the new understanding of glass in Turkey.

He was working as both an industrial designer and design teacher and this affected his outlook and approach towards glass, which was focussed by both his own education and profession. In his appraisal of glass he inevitably reflected the point of view of his design origins. The visits made by Küçükerman to Scandinavian countries and his interaction with glass designs from these countries has caused his own glass designs to be subjected to their influences. As an industrial product designer he had the opportunity to have his designs realised by the Turkish Bottle and Glass Factory which has one of the biggest 
markets for glass in Turkey. This provided him with the opportunity to become more familiar with glass.

His personality, which is that of an explorer and educator, directed him to write in many fields, not only design: Carpet making, jewellery making, tile making, shoe making, observations and travel notes and many more including glass. Indulging the breadth of one's knowledge can have a negative effect in detracting from individual issues; becoming versed in many subjects may hinder the development of fluency in one. However, Önder Küçükerman has written books on Turkish glass and articles on the history of Turkish glassmaking since Ottoman times and traditional Turkish glassmaking. Also he has completed research on these subjects which had not been covered before. In these writings he discussed product making which reflects both the past and tradition, however, he approached them purely from the point of view of commenting on manufacturing techniques and design. For these reasons, although he clearly cared for the subjects and meticulously researched them in great depth, the knowledge he gathered was fundamentally narrow and encyclopaedic. Regardless of how poetic the prose, his writings contributed nothing of substance to the study of glass as a material for the artist.

In 1987, Küçükerman attempted to unite glassmakers in a project called "Camköy".242, this however, did not come about and was due, according to Önder Küçükerman, to political causes. The idea was to bring together glass makers at Beykoz which has been the centre for glassmaking since the $19^{\text {th }}$ century, in the $18^{\text {th }}$ century the Ottomans had a similar idea ${ }^{243}$. During the first 
stages of its foundation the purpose of the project was to rejuvenate traditional glassmaking and an effort to direct it towards a tourist market. At the same time this project was intended to enhance the union between the new technology and traditional glassmaking, it was an important step to promote this partnership. The issues this project were to tackle was how to revive the past and encourage people to produce works in areas which had been the traditional centres of production, also to hopefully reinvigorate lost cultural elements. However, even if these aims had been realised today, with its imitation of the traditional form and décor, this project would have created a craft village geared towards glass production for tourists rather than an artistic or even an economic endeavour. Undoubtedly, this project was not directed towards serial industrial production or highly developed technical output. In the proposal for this project there is no consideration for the relationship between traditional glassmaking and studio glass art. Therefore, it does not contribute to the use of glass as an art medium.

Despite the new shoots of growth, for many years previously, there was no existing understanding of studio glass. However, for the time being there exists a strong industry which produces and forms glass and naturally when the opportunity arose Önder Küçükerman wanted to contribute something from his profession. Nevertheless, his mentality as a designer and inclination for industrial production inevitably caused him to repeat designs en masse. In connection with these points he displayed his ebullience in his writings at the transformation of glass designing which could be geared towards the manufacture of glass that may be produced without even the touch of the 
human hand. He considered this to be a success of contemporary designers and he even expressed these feelings in an article written in 1995:

"In glassmaking although the talents descended from the past can create significant and beautiful objects, nowadays machinery at the same level compounded by design knowhow can also produce very valuable products. ${ }^{244 \text {, }}$

On the $60^{\text {th }}$ anniversary of the foundation of the Turkish glass industry, he congratulated Şişecam factory which had done away with traditional hand mastering and design brought glass production in Turkey onto an international level by becoming mechanised.

Küçükerman has written many works on Turkish glass, glassmaking and its history due to his deep interest in industrial serial production. One cannot deny that he has made a significant contribution in this area. However, his extensive knowledge of design has caused him to approach glass not as an art medium but only as a design tool and by reason of this, studio glass understanding could not find a developing area for itself in Turkey whilst it was excluded from his entrepreneurial support and creative design skills.

From the beginning, industrial glass production has made huge developments with the support of many people and our hearts desire is to see the same support and development for studio glassmaking and the use of glass as an art medium. For a designer with such explorative spirit, research drive and idealism Küçükerman surprisingly cared very little for the promotion or creation of studio Küccükerman, Önder, “Cam Sanatında El Ustalığından Makina Ustalığına”, Sanat
Çevresi (June 1995), No: 200, p 13. 
glassmaking within factories. Despite the fact that he maintained good relationships with the factories and was accepted as an authority, he neglected to bring such an important aspect onto the agenda, which was very unfortunate for Turkish contemporary glass art.

Approximately 30 years ago Önder Küçükerman started to develop his interest in glass for the first time - about this time the studio glass movement was starting to shake the world, various countries' attitudes were changing in response to this movement and Pilchuck was being built in Seattle - if he had not been an industrial product designer but rather more interested in the plastic arts, perhaps a ceramist with an interest in glass, he may have placed more emphasis on the value of studio glass instead of industrial production. The question of "what would have happened if...?" is unanswerable but will nevertheless remain in the minds of many.

\section{CONCLUSION}

Glass art, having existed as a tradition in Turkey for hundreds of years, will naturally command its own niche when it begins its development in the direction of contemporary practice. This progression has already been witnessed in ceramics, a medium, like glass, which is strongly rooted in Turkish tradition. The development of the Turkish tile making tradition, taking place in an academic environment, has helped to inform modern ceramic art and artists. There is a harmonious confluence between traditional ceramics, contemporary interpretations thereof and the use of clay as an art material. This is an indication of a positive progression which may also be applied to glass art in 
Turkey. Nowadays, in ceramics, there is an effort to preserve tradition whilst at the same time expanding into contemporary production: it protects its identity whilst allowing the artist the freedom to be creative. When this development occurs in glass, and there is no reason why it will not, then it bodes well for a bright future.

Contemporary ceramic art formed in Turkey in and around the 1960s, in the academic environment of Mimar Sinan University. Here many renowned ceramic artists were nurtured before progressing to positions of authority within the ceramic fraternity. Art galleries in Turkey were also influential in providing support to the burgeoning ceramic art and its artists. Likewise, the beginnings of the American studio glass movement took place in academic institutions, and the art galleries that took an interest in its development helped to accelerate American studio glass art. Without doubt, after the inception of a Turkish movement, galleries here will show a similar degree of support for glass art and artists. Fortuitously, in Turkey, there is a long established history of industrial involvement in glass and this has helped to place glass in the forefront of the public consciousness. Simply, glass is an accepted and familiar medium for the consumer, from here it is a relatively easy step to accept as a contemporary art object. The above examples occupy a position from which we can extrapolate that the initial development of glass will more than likely take place in an educational institution and its growth will be benefited by the intervention of galleries and industry.

The link between contemporary art and traditional forms is developed over a long period, in fact this period is a never ending but a continuously developing 
phenomena. The balance between form, decoration and methods of application created by the transferral of tradition into contemporary life is seen as a sign of development. In a society, if there is a tradition, there is the capability to turn this tradition into contemporary practice. In Turkish glass art the style formed from tradition is by necessity the biggest source of inspiration and support for today's artists.

In Turkey there is an effort to provide an opportunity for the development of glass in an academic environment and to broaden the scope of glass use as an art medium for students. In order to make the most emphatic advancements in this direction and to enable the most imaginative and practical use of glass it is imperative to learn from those movements which are more mature. Thus it is of great importance to observe and analyse a movement which has had a widespread impact on academic learning. This is naturally the American studio glass movement because it developed primarily within educational institutions whereas in other countries the development of glass art was through apprenticeship structures or factory based organisation. However, in many of these countries glass art has moved from its original arenas into academic development in educational institutions and the steps made here in regards to the development of artists and their sphere of influence have been the most compelling. In America, right from the beginning of the movement, great strides were made in the development of glass art, the main contributing factor to this must be the immediate involvement of glass in higher education which was enabled and encouraged by the political structure and the American "go-getting" culture. 
In light of observations made from this model it will be possible to take more measured steps in directing the development of a Turkish studio glass movement. Thus the benefits to contemporary Turkish glass of studying the American studio glass movement lie in the necessity of avoiding developmental difficulties, in pinpointing advancements which can be translated to a Turkish context and in shortening the gap which has developed in the use of glass as an artistic medium.

However, when considering the possibilities for cross fertilisation from the American movement it is vital to retain the characteristics which make Turkish glass individual, these should not be obscured in the drive towards establishing a glass movement in Turkey. It is important not to imitate but to assimilate. In bringing Turkish glass on to the agenda a balance must be found in order to build a bridge between tradition and culture and contemporary production. 
CHAPTER 3.

\section{THE AMERICAN STUDIO GLASS ART MOVEMENT}

\section{PREFACE}

American contemporary glass art and glass art education since the 1960s has gone through many developments and changes. It has pioneered the start of a new movement which has spread throughout the world and changed the understanding of glass art. The inclusion of this section is necessary in order to enlighten those specific developments in studio glass which, when examined and reassessed, will be beneficial to Turkey and other countries that endeavour to develop their own studio glass direction. This section analyses the origin and development of the Studio Glass Movement, which started in America with Harvey Littleton and takes into account the impact of various artists and educators who pioneered the spread of the studio glass movement throughout the rest of the world. It also contains a personal interview with Harvey Littleton, in which he expresses his views concerning the studio glass movement. The important contribution of American glass art education to glass art, the point of its arrival in this historical period and the changes to aesthetic understanding during this period are all considered. 
CONTENTS OF CHAPTER 3.

3. 1.

THE WAY FORWARD? THE AMERICAN STUDIO GLASS

MOVEMENT AND HARVEY LITTLETON

3. 2.

AMERICAN GLASS: ART AND EDUCATION

(SINCE 1962-PRESENT)

3. 2. 1. PILCHUCK GLASS $S C H O O L$

3. 2. 2. CHANGING AESTHETICS 


\section{STUDIO GLASS MOVEMENT AND}

\section{HARVEY LITTLETON}

In the early sixties Harvey Littleton (b. 1922, Corning) was a key figure and an originator who became the "Father of the Studio Glass Movement". He was very keen to explore the possibilities of using glass as an art medium, despite the initial lack of material, facilities or a wide knowledge of glass.

In 1962, Harvey Littleton's Toledo, Ohio workshop started a new era for glass. Although glass was not a new material for functional and domestic use, his determination and the people who supported him were the two main factors that brought this extraordinary medium to the attention of artists, designers and craftsmen.

There have been many works written on and much debate about the subject since then. Many differing points of views from several artists have been published. Countless interviews have been given by Littleton, and even the smallest details and memories regarding the first workshops in 1962 have been described. Every memory was evaluated and, for example, glass artist Michael Taylor (b. 1944, Lewisburgh) expressed his memory of Sam Herman (b. 1936), one of Littleton's first students from the educational year of 1963-64, as below: 
"...in Harvey's studio when I was there, I asked, whose bicycle is this? He said it is Sam Herman's. And Sam had just left and gone to start the programme at the RCA. ${ }^{245}$ "

With hindsight the progression of glass and its development as an art material is clearly visible. The existence of glass as an art medium in our lives is undeniable. At this point, to answer the question why Harvey Littleton became the originator of the movement and what factors carried him to it we should, instead of repeatedly referring to historical facts, consider his background, training and upbringing.

Harvey Littleton inevitably had an affinity with glass quite different from most others due to his starting point of Corning, New York in 1922. This small village, as his birthplace, remains the site of the most famous Corning Glass Works around the world and Littleton's father was the director of research in this company for many years ${ }^{246}$. From the early years of his childhood, he was mentally, spiritually and physically close to glass and was able to find ample opportunities for development in this direction. Littleton recalled his childhood memories regarding his father in an interview:

"When my father was interested in glass as a cooking material he brought home a type of battery jar and my mother baked a cake in it. We talked about glass in the family. When my father was doing research on strengthening glass, he brought glass home for us children to break. ${ }^{247 "}$

\footnotetext{
245 Interview with Taylor, Michael E., Prof., Rochester Institute of Technology, Rochester, New York, on 06. 03. 1996, Edinburgh, U. K.

246 Southern Highland Craft Guild, Folk Art Centre, Asheville, North Carolina, Generations, exh. cat., 1995, p 3.

247 Yokohama Museum of Art, Yokohama, Expanded Glass; Traditional and Contemporary, exh. cat., 1995, p 244.
} 
Even though nobody else from his family was interested in glass as an art medium, Littleton was familiar with Frederick Calder (1863-1963), an ambiguous figure in the history of modern glass, who lived nearby. Calder had begun his career as a designer in England, he emigrated to the United States in 1903 and founded the Steuben Glassworks. He witnessed the rise of Tiffany, worked at the same time as Lalique and Marinot ${ }^{248}$ and developed his capabilities in production over some eighty years. He has tried to design nearly everything without concentrating on one style or technique, whether it was $\mathrm{NeO}$ Classical, Art Nouveau, Venetian ${ }^{249}$, casting, pate de verre, millefiori, cire perdue (lost wax) or intarsia ${ }^{250}$. Littleton admired Calder's imaginative approach.

This admiration led him to develop the idea of using glass as an innovative art medium even at that time. In fact, if one assesses the issue from this point, it is quite possible to give him the title, the father of the Studio Glass Movement; this is neither coincidental nor chance. It is obvious that by using his knowledge and experiences, he reached a constructive synthesis during his years of work.

The first torso Littleton made in 1942, (Figure 114) he dismissed as a student's work of art, then in 1946 he made and exhibited the second torso, (Figure 115) and declared it his first glass work, both were formed by the casting method. When working at the Corning Glass Plant during the summer vacations, he developed an intimacy with glass blowing methods. Being employed as the hand-blown cookware inspector in 1941 and with the introduction of a

\footnotetext{
248

$249 \quad$ Cooke, Frederick, Glass, London, (1986), p 53.

250 Battie, David and Cottle, Simon, eds., Sotheby's Concise Encyclopaedia of Glass, London, (1995), pp 198-199. "Pate de verre, French 'glass paste'. Ancient technique, revived in France during the second half of the $19^{\text {th }}$ century, of melting in a mould ground glass, to which was added a fluxing medium and colouring agent (this was either powdered coloured glass or metallic oxide). Millefiori, Italian, "thousand flowers" Term used to describe mosaic glass used in ancient and Venetian glass as well as in paperweights. Intarsia has a layer of coloured glass with an etched design sandwiched between two colourless layers."
} 


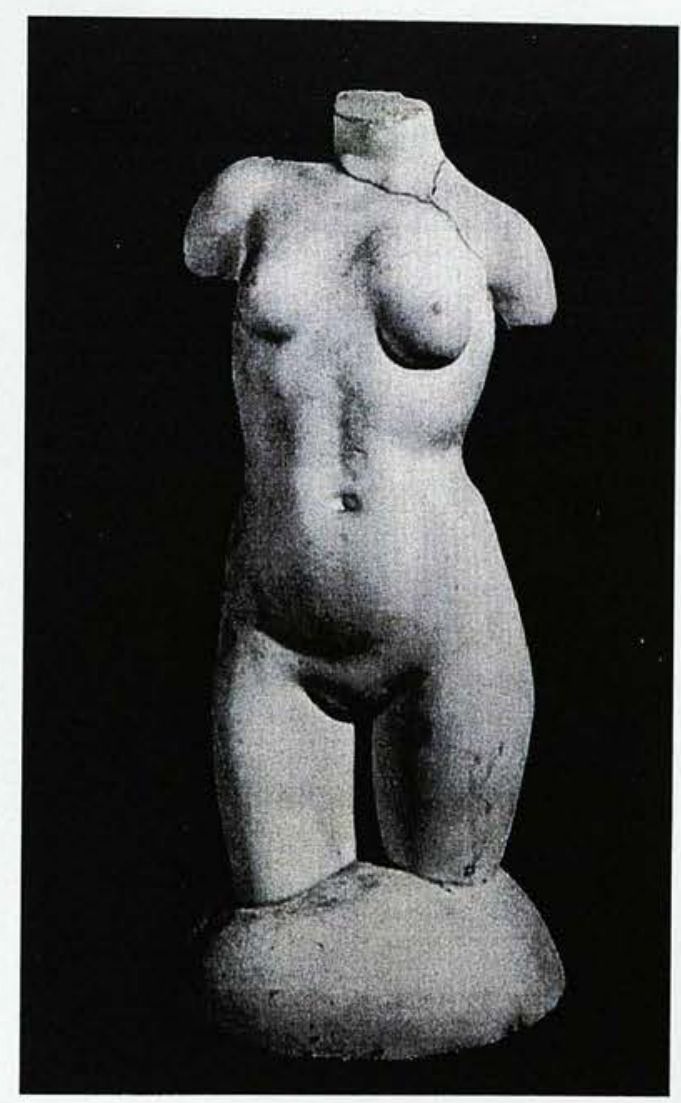

Figure 114

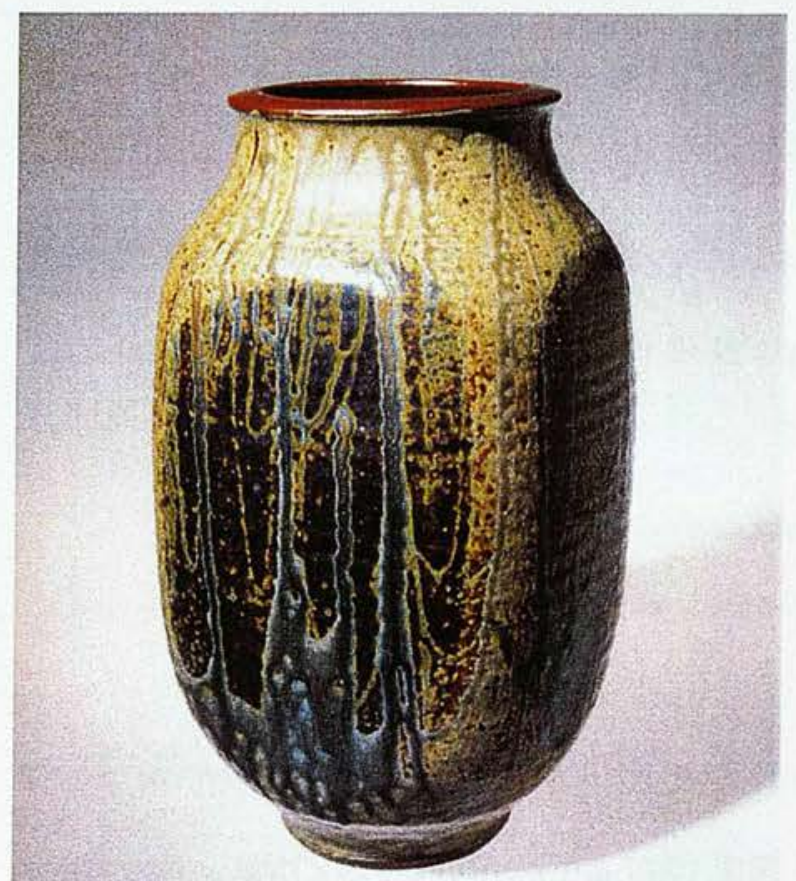

Figure 116 (a)

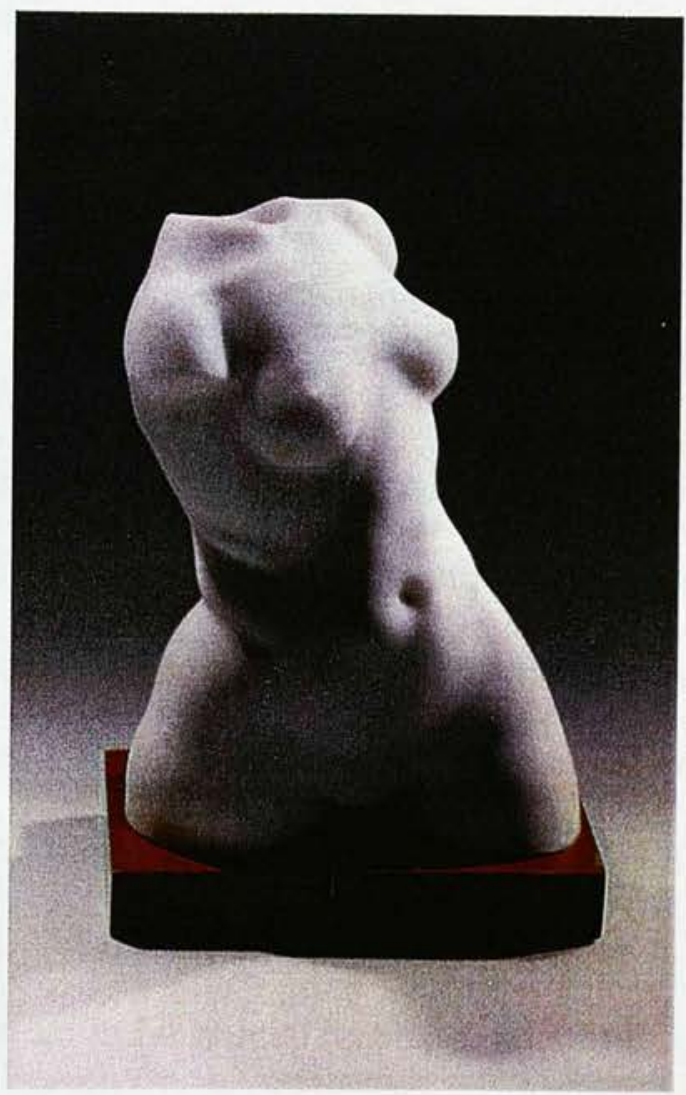

Figure 115
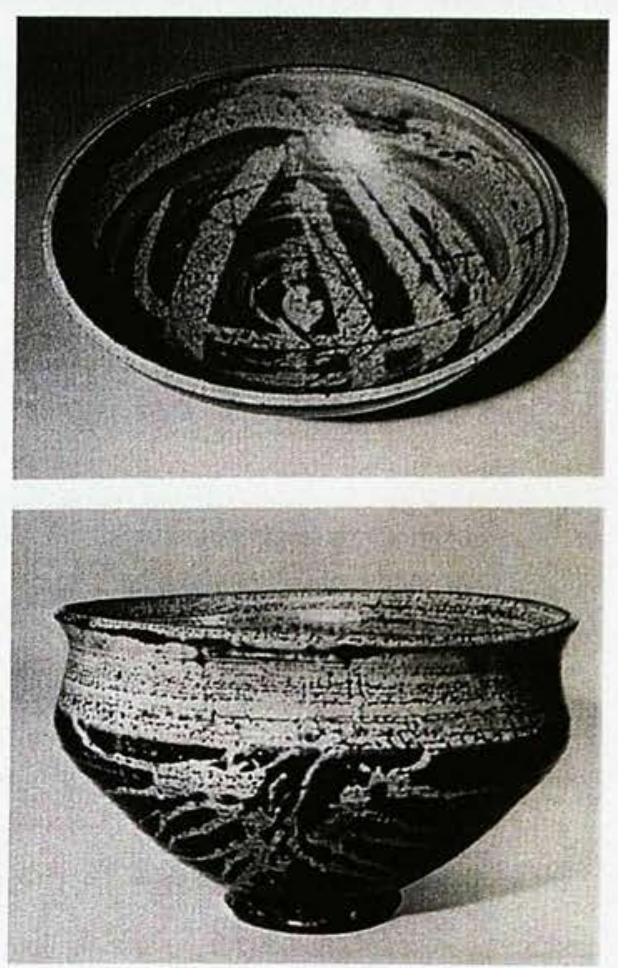

Figure 116 (b) 
production method similar to pate-de-verre the following summer at Vycor Multiform Project Laboratory ${ }^{251}$ he became very familiar technically with glass. Likewise, when he returned to Corning after three years military service, he became expert in another direction by taking a course in the production of photographic images on photosensitive glass in Corning Glass Works.

Small incidents and the general ebb and flow of life merged to form the foundations of Littleton's approach to glass and played a defining role in his development. For instance, he started work in Toledo/Ohio, which has been an important centre for the glass industry since the $19^{\text {th }}$ century. His experiences in the ceramics department of Toledo Museum of Art, which has one of the best historical glass collections in the country, and his meeting with Otto Wittmann, the director of the Museum, can be assumed to be crucial turning points in the development of the studio glass movement during this period. Afterwards, each step taken by Littleton produced further constructive development. His visit to Spain for a small research project to see the works of French artist, Jean Sala, of whom he heard prior to his visit in 1957 to France, and his call upon Sala's former studio in Paris during his stay in Europe accelerated the driving wheel in his mind. Littleton recalls the day in Sala's workshop:

“...he also showed me the little courtyard out beyond the studio and gave me two of his tools which were rusting away in the corner there. ${ }^{252 \text { " }}$

Even small details like the gift of two rusting tools increased his drive and motivation, and strengthened his faith that he could work with glass in a studio

$251 \quad$ Byrd, Joan Falconer, Harvey K. Littleton - A Retrospective Exhibition, High Museum of Art, (Atlanta, 1984), p 6.

252 Littleton, Harvey K., "Littleton Remembers...", Glass Art, Vol. 4, No. 1, p 21. 
environment. His interview with Sala widened his horizons and witnessing the form and use of various tools and the material provided answers to many of his questions. Following his meeting with Sala, which occurred during a visit to Italy with his family to see the workshops in Naples, he faced hostility from the glass workers in a number of small glass factories on Murano Island. This reaction was mainly due to the workers' fear and reluctancy to reveal their traditional methods and secrets. This underlying fear was the result of Littleton's conclusion that it was not necessary for glass production to be solely factory based, but it would in fact be feasible to achieve the desired creative production in a small studio. Below, Littleton recalls his Murano experience, which played a very important part in the beginning of the movement and it helped him to gain confidence for his further actions:

"I realised that there was nothing that I couldn't build. ${ }^{253 \text { " }}$

The accumulation of various data and the answers he gleaned for his many questions evaporated all doubt in his mind at this point. Following his return to the United States, he built a furnace for himself from an old, round, up-draft kiln. By the time he began to explore the possibilities of glass, the American Craft Council (ACC) had organised an exhibition of the work of Louis Comfort Tiffany and the Corning Museum of Glass mounted Glass '59: A Contemporary Worldwide Survey ${ }^{254}$. This exhibition not only showed an intensive common interest

253 Interview with Harvey Littleton on 02. 07. 1997, Spruce Pine Studios, North Carolina, U.S.A. Byrd, p 10. 
towards the subject, but was also proof that a lot of people were not apathetic to glass as an art material.

Finally, everything started to move forward faster and more cohesively. Littleton was invited to the third National Conference of American Craft Council in Lake George, New York to share his experiences of glass abroad. Likewise, Michael and Frances Higgins, from Chicago, two artists working with glass, were also selected. They were the founders of the society of Midwest DesignerCraftsman in 1954, and were among the first artists to give shape to flat glass by using techniques such as moulding, slumping and laminating; they evaluated glass on a studio basis. Their confidence was shown during this Conference by giving support to Littleton for his efforts to bring the glass into the working studio environment. They were also involved in the group which formed to organise the first workshop in the garage of Toledo Museum of Art, Ohio in 1962. Littleton declared his opinion about the use of glass as an art medium in the Conference and in his speech, he stated that glass should be:

" ...as a medium for the artist, rather than a revival of glassblowing by the individual, because I felt that glass had great potential as a medium for the artist. ${ }^{255}$ "

This statement was the likely core of the manifesto of studio glass movement, it became ingrained into the thinking for the future and embodies the attitude of the studio glass movement which encompassed the world. As a ceramic artist making functional forms for domestic use, Littleton was obliged to make vases, pots and jugs according to the directions, wishes and demand of buyers. 
(Figures $116 \mathrm{a} / \mathrm{b}$ ) His wish to make ceramic sculptures gradually went beyond domestic production and this desire was especially strengthened ${ }^{256}$ after seeing the expressionistic pots of Peter Voulkos (b. 1924, Montana) in the 1950's. By disregarding the established tradition and uses of ceramic objects, he adopted clay as a material for sculptural expression for the next generation. The basic forms are changed in regards to the dimensions and by proving the "meaninglessness" of functionalism, a new era started in studio ceramics. This caused another spark within Littleton who had a high capability for interpretation and evaluation. In relation to this, he exhibited the first abstract forms created from carved cullet pieces in 1960. (Figure 117) The fourth ACC National Conference was the turning point in 1961. Following a speech he gave evaluating the opportunities for supporting his opinions during the conference, he received a proposal from Toledo Museum of Art to solve his space problem. Naturally, his modest demands and the well-known sentence below had a great effect on receiving this proposal:

“... All I need is a garage ${ }^{257 "}$

A rarely used place in the bowels of the building of Toledo Museum of Art, Ohio was suggested to Littleton for a weeklong workshop with the confidence and the support of Otto Wittman. A new era started in glass art with two workshops held in March and June 1962. (Figure $118 \mathrm{a} / \mathrm{b}$ ) Of course, there were some artists working on glass before 1962 like Edris Eckhardt, the Higginses, Earl McCutchen, John Burton Eugene Winters and Maurice Heaton ${ }^{258}$. These artists

$256 \quad$ Littleton, Harvey K., Glass Blowing-A Search for Form (New York, 1980), p 7.

257 Byrd, p 11.

258 Labino, Dominick, "The Artist and Glass-Resurgence of Interest in Creative Glass Blowing", Visual Art in Glass, (1968), p 115. 


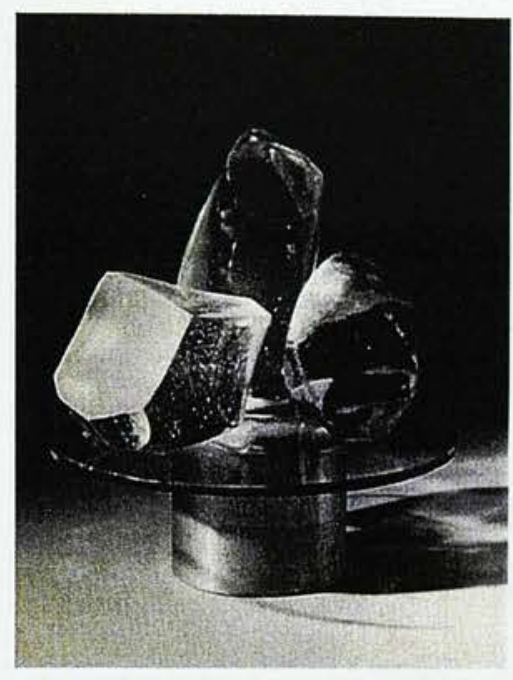

Figure 117

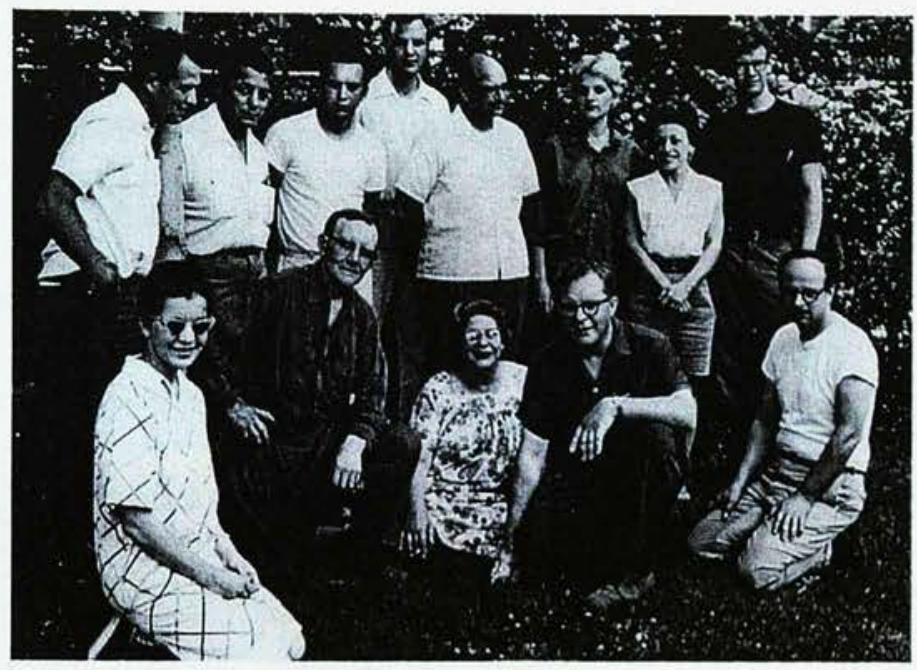

Figure 118 (a)

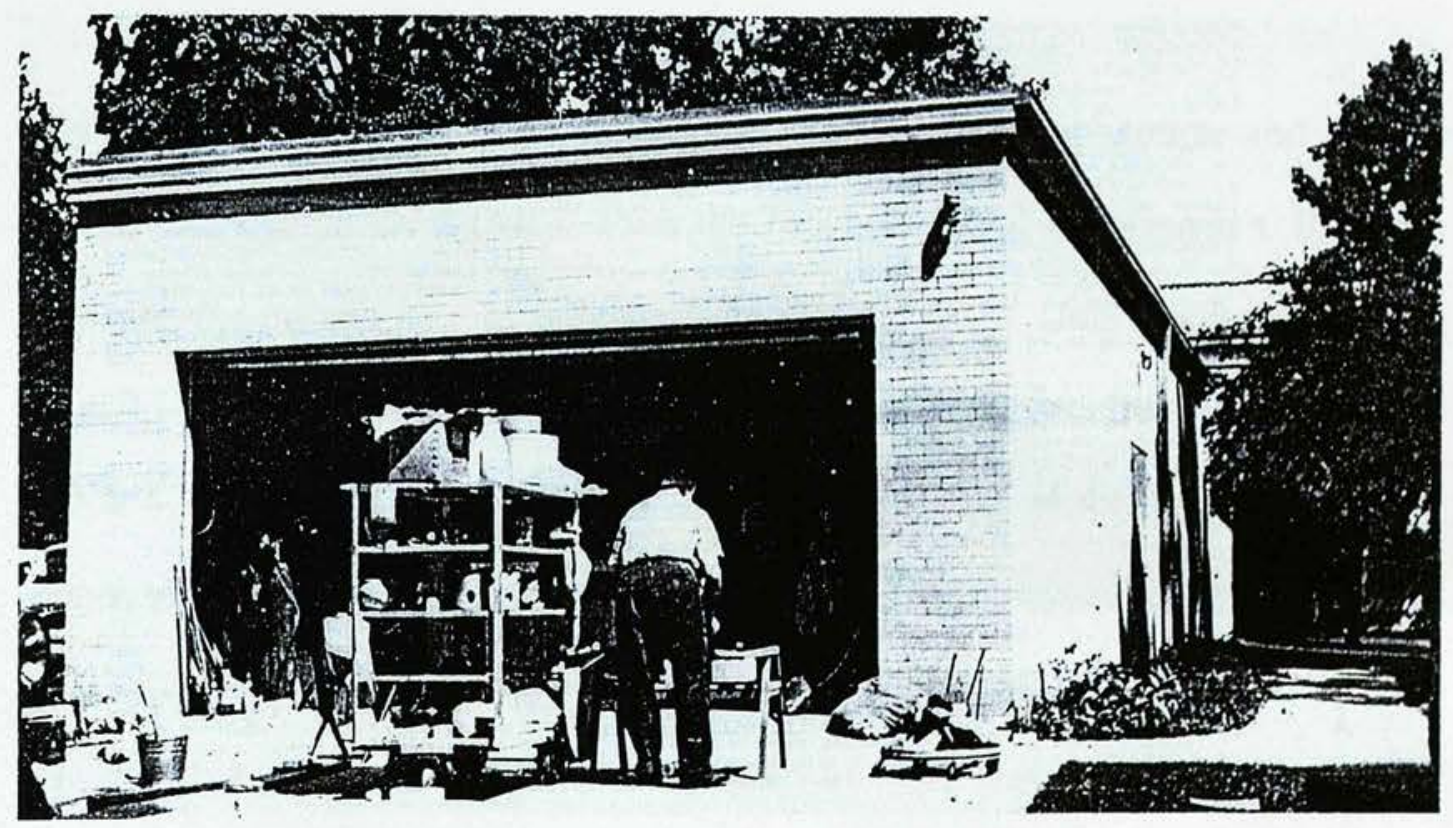

Figure 118 (b)

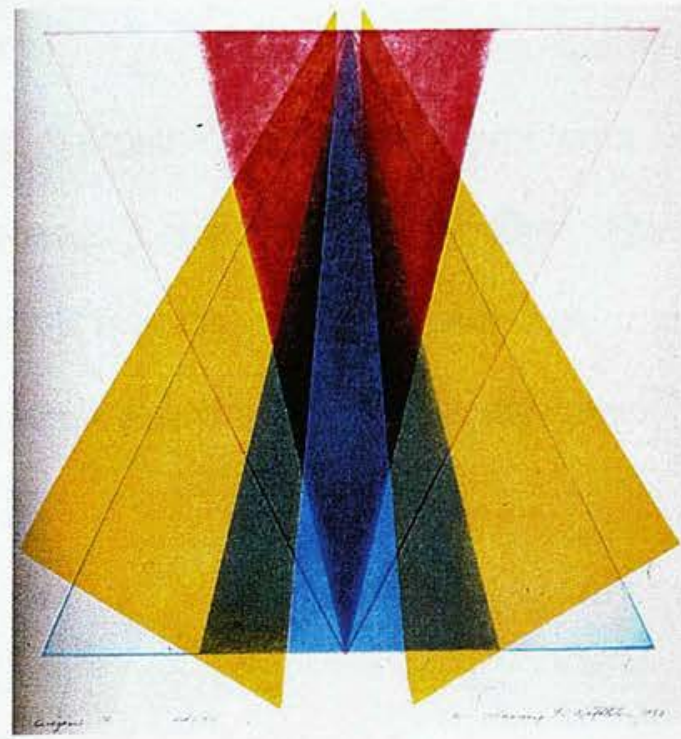

Figure 119 
were using techniques like fusing, casting, laminating, lampworking and enamelling. But none of them were working with hot glass. Harvey Littleton's new approach to glass production seemed to be impossible for many artists and turning his methods into reality quite reasonably gave him the title of the pioneer of the studio glass movement. It can be clearly seen, through a general look at the history of studio glass art, that in reality, nothing has been formed in a moment, in a week or even in a month. It is hard to deny that Littleton was the appropriate person at the right time, in the right place.

Being aware of his potential, he intelligently used his knowledge and energy and his out going character to form the required social environment. Besides, like him, the people he met were keen and hardworking. Until the first workshop held in Toledo Museum of Art in March 1962 however, there was nobody helping Littleton when he was rushing around, preparing articles for conferences, trying to prove the possibilities of the process by melting glass pieces in the small pot of the ceramic kiln at his home, getting the tools from Jean Sala's workshop in France, or when he was dragged out of the Italian glass blowing workshops. Then, at the first workshop in March 1962, Dominick (Nick) Labino (1910 -1987), a researcher in John-Manville Fiberglas Division, was the person who overcame the technical problems and therefore the next step was for Littleton and Labino to work together. Thus, it was Labino who provided the solution to a glass batch problem that enabled the use of clear glass marbles for studio glass, which are generally called 259 "JM 475 marbles". 
In my interview with Harvey Littleton, in his studio, he modestly professed to only having moved a rock from its place which started an avalanche in regards to studio glass art. Today nearly forty years have passed since that rock was moved. In this time thousands of students and hundreds of artists have grown up with American glass art. Likewise, each year there are many books and numerous articles published on this subject. Littleton feels that there is a consensus amongst many that on the subject of glass everything has been done, that it is repeating itself, and that there is much doubt over its future: he, on the other hand, gives the answer that he has never lost his faith in the future of glass. In 5000 years of glass art history many things have been done, but Littleton believes that as long as new people are attracted to glass, glass has a great future, each time a new person is attracted to glass, there are new ideas, there are new things happening.

The formation of Turkish contemporary glass art, the attempt to develop glass artists in an academic frame work, and the support available for the study of this subject, is one indication of the existing potential for the further development of glass and its continuing spread across the globe. In this vein, glass artist Michael Taylor mentions that in Spain, Portugal, Israel and India glass programmes are in the process of starting. Like Littleton, he rejects the idea that glass art has reached its conclusion:

“I don't believe that everything new had stopped in glass and nothing new going to happen, that's nonsense. I still see it's very optimistic. There are absolutely new things are going on. ${ }^{260,}$ 
Undoubtedly, there will be other countries following these. Littleton's aim is to give glass into the hands of young people and education is a major part of this.

Littleton's creative and bold personality has not faltered over the years. As an artist he was open to the novelty involved in the discovery of new subjects, and in 1975 he directed his interest in glass towards the development of using glass plates for printing. For a certain period, as well as working with hot glass, he continued his work in the development of this printing technique, for example he designed colourful and geometric prints, which were similar to his glass arrangements. (Figure 119) Over the last years he was mainly focussed on this subject. The print making studio at Spruce Pine Studios became focal point for artists concerned with this process and the atmosphere created by the turnover of artists, the tempo of work and the contributions from these artists allowed Littleton to bring the novelty of working with glass face to face with many artists. Simultaneously then, he had created an art environment in his home surroundings.

Whilst being busy with his printmaking works in the mid 1980s, he also produced an industrial glass batch which developed over the years through his work with Dominick Labino. He became competent in marketing this batch and made a respectable reputation for himself. In my interview with Harvey Littleton, he mentioned that this business, the Spruce Pine Batch Co., was developed due to many young artists' lack of knowledge of glass compositions and their enforced use of poor quality glass. This batch uses very fine silica for simplicity of melting in small furnaces, also it allows for a longer time interval for the artist to work before it cools. Littleton is rightly proud of the fact that Pilchuck Glass 
School uses his batch and that the glass artist Lino Tagliapietra (b. 1934, Murano) said that after using glass from all over the world his batch was the best. Unsurprisingly, he plans to expand his company ${ }^{261}$.

On the $1^{\text {st }}$ and $2^{\text {nd }}$ of July 1997 during my visit to and interviews undertaken at Spruce Pine Studios, North Carolina, it was possible to observe the existing, and unending innovative ideas of this artist who is now over 70 . He has created the perfect environment for himself, his studio and home, in a forest clearing without interruption and interference, he has the serene atmosphere beneficial to creativity and productivity. At first glance it clearly shows the existence of an artist and the organisation of the interior and its neatness necessarily makes work easy, likewise the coherent structuring of his social and scientific pastimes allows him to concentrate and use his imagination for creativity. Various galleries and display areas create different atmospheres for different collections. His interest in perfume bottles (Figures $120 \mathrm{a} / \mathrm{b}$ ), his kilims which exhibit different design compositions from different regions and his glass objects from recent glass art history (starting from 1850s) show his eccentric and colourful personality. Merely meeting him and experiencing his daily routine provides the answer for why it was he that pioneered the studio glass movement.

From his first torso, which was a realistic figure, to his first blown works and later still the transformation of these forms, shows impressive development. This transformation and never ending journey of creativity exhibits the connection between his works and the material. Figures $121 \mathrm{a}$ and 121b show the forms created during the first five years of his experimentation with blowing.

$261 \quad$ Interview with Harvey Littleton. 


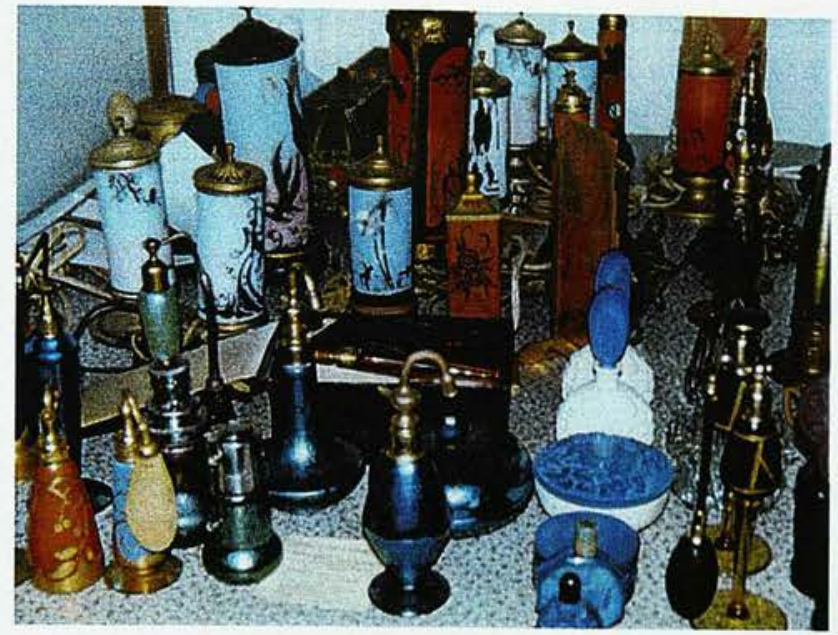

Figure 120 (a)

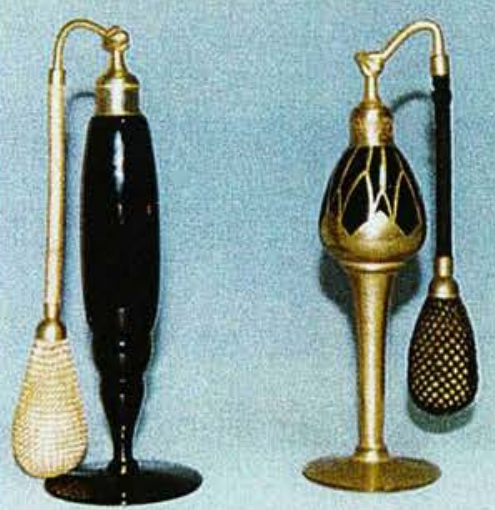

Figure $120(b)$

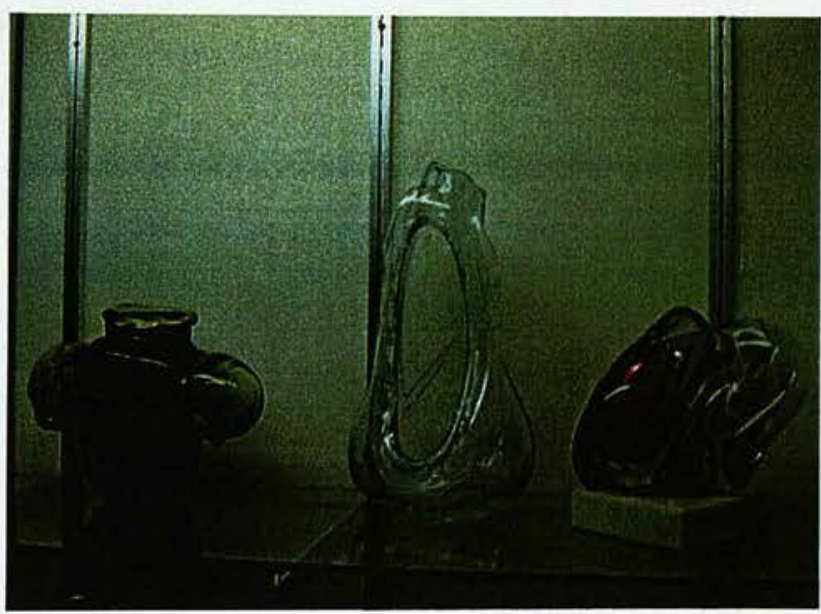

Figure 121 (a)
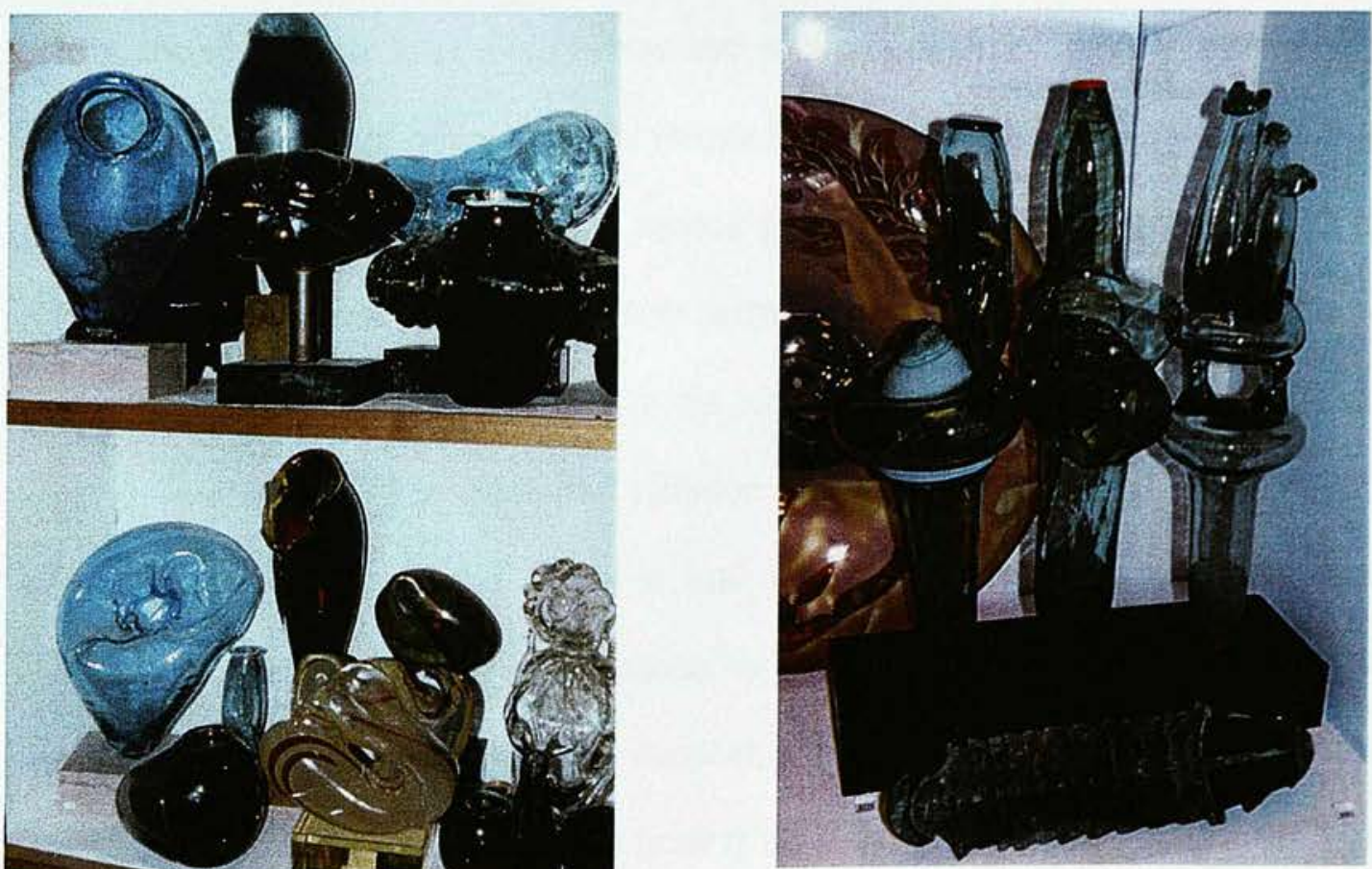

Figure 121 (b)

Figure 122 
They reflect his investigations into the boundaries of the material, he is trying to discover both his and the material's capabilities. The fluidity of glass and the balance of its hot and cold aspects is discovered through blowing and at some point, allowing glass to form itself, has formed the outline of Littleton's first phase of glass works. Even this initial fad is not his own style, the majority of artists who experiment with glass do so in this style and it is one which appears in other periods. For example, 'Three Green Vertical Forms', (Figure 122) belonging to the glass artist, Sam Hermann, (who worked for a period with Harvey Littleton), reflect this period's general characteristic and the existence of this phase which he has been through. Following the end of my first year meeting in glass, as a ceramic artist, the forms I had created by blowing, indicated that I had been through this phase; (Figure 123) the movement and fluidity in my work and the soft round forms which comes from the nature of blowing.

Littleton initially exhibited works with flowing, drooping shapes and organic forms, these aspects later were turned into a combination of rhythm and twisted liveliness. Gravity and other physical forces interact with traditional glassblowing and this is an aspect which many novice glassblowers including Littleton find difficult to overcome initially. His first forms were many facetted with much movement, however, after the 1970's his forms become much more controlled, smooth and simple. It is clear that Littleton during this first period was excited about getting to know the material and seeking answers to the technical difficulties, which he faced. At the same he was teaching his ideas to students and looking for financial and moral support; amongst all these problems he did not have time to focus himself into finding an artistic identity for his forms. His 


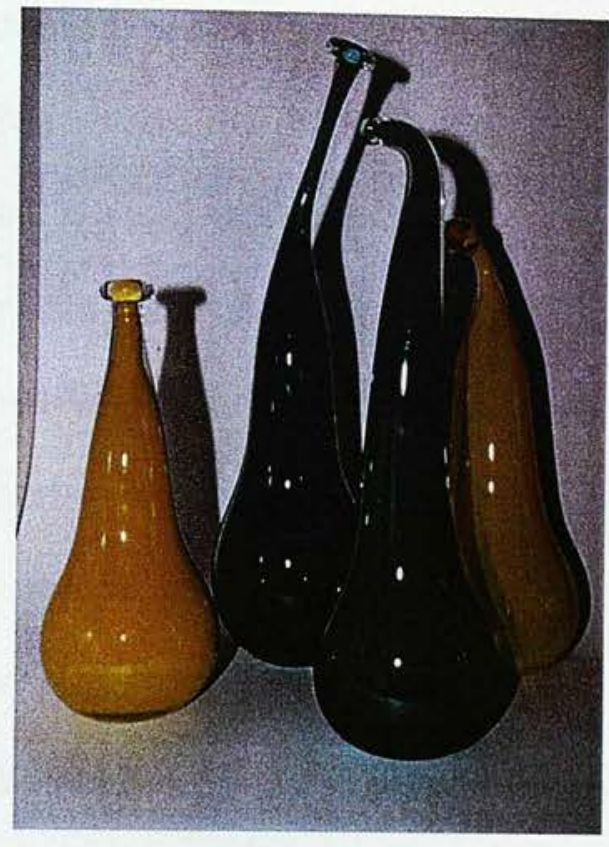

Figure 123

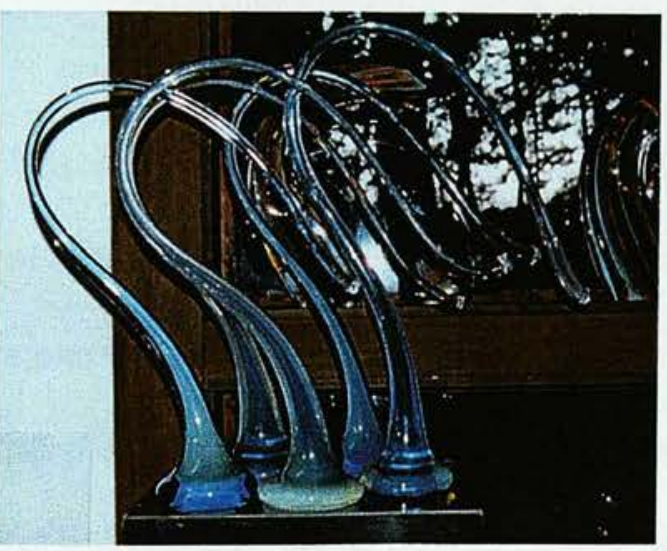

Figure 124 (b)

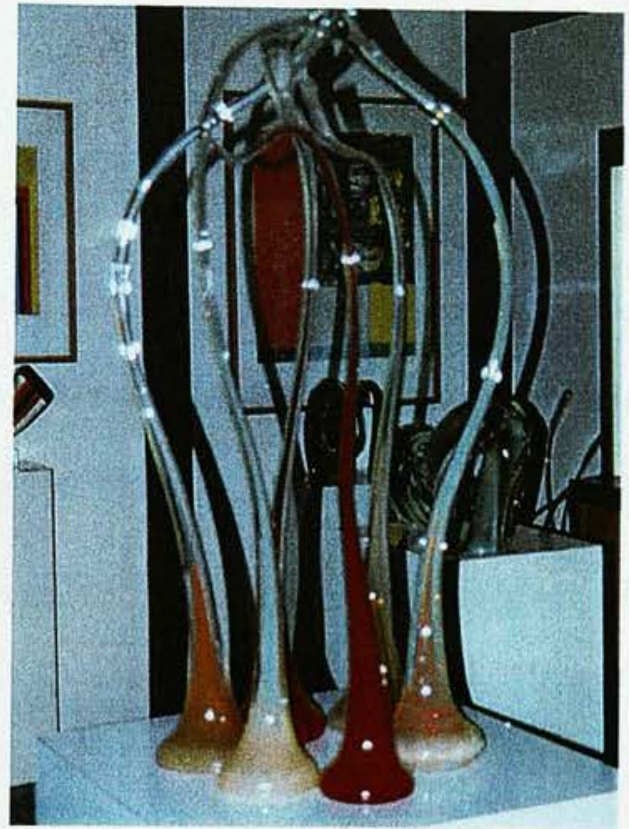

Figure 124 (a)

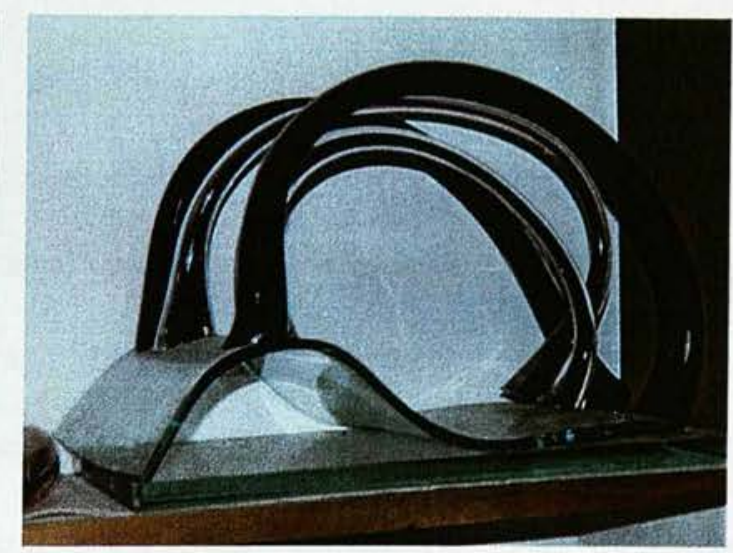

Figure 124 (c)

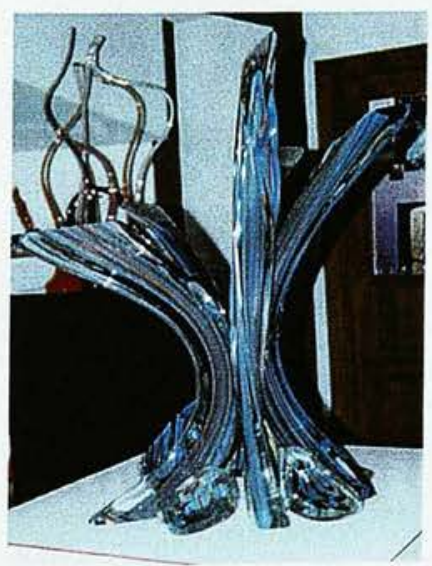

Figure 125 (a)

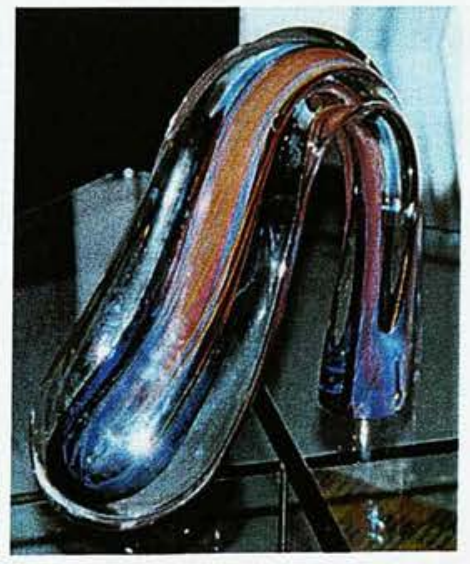

Figure 125 (b)

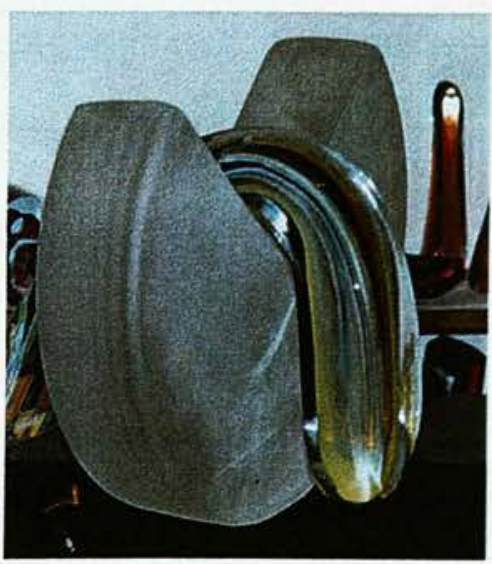

Figure 125 (c) 
close friend and artistic counterpart ${ }^{262}$ Erwin Eisch (b. 1927) also had great influence on his artistic output of this period. It is possible to perceive in his early pieces, with their drooping movement, a search for simplicity, but moving on from this simplicity of form, (Figures $124 \mathrm{a} / \mathrm{b} / \mathrm{c}$ ) he had a break through, which enabled him to reflect, in his works, his own artistic identity. This journey indicates the way an artist keeps developing through their own work, no matter which direction it takes, and designs will be constantly kneaded with new ideas and applications. As glass artist and teacher, Henry Halem (b. 1938, New York) says there is no end to discovery and learning:

"It is my belief that, regardless of who we are or how old we grow, we always remain a student. $^{263 "}$

The dynamism and fluidity running through Littleton's forms from this period has directed him towards new coloured and geometric compositions. (Figures 125 a/b/c) In his three dimensional designs, made in his last phase of glassmaking, he displays from time to time the beautiful optical qualities of refraction and reflection, but continues to make use of an organic fluidity. With this new approach the dimensions of his works became greater, more solid and more sculptural; at the same time the fluidity of the glass preserves a conscious narrative. (Figures $126 \mathrm{a} / \mathrm{b} / \mathrm{c} / \mathrm{d}$ ) At this point the maturity in choice of colour and the harmonies between them move from coincidence to design and have become the focal point of his works and their general characteristics. 


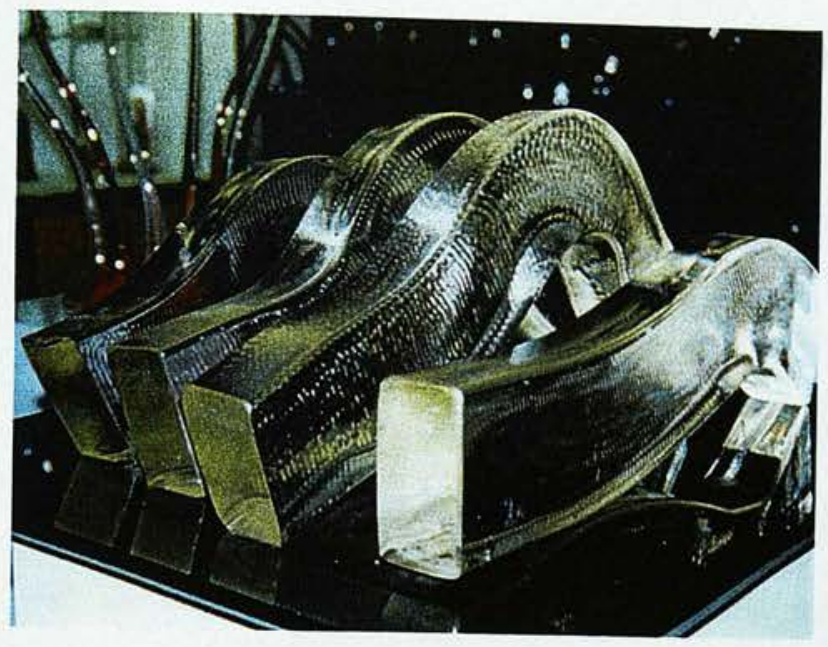

Figure 126 (a)

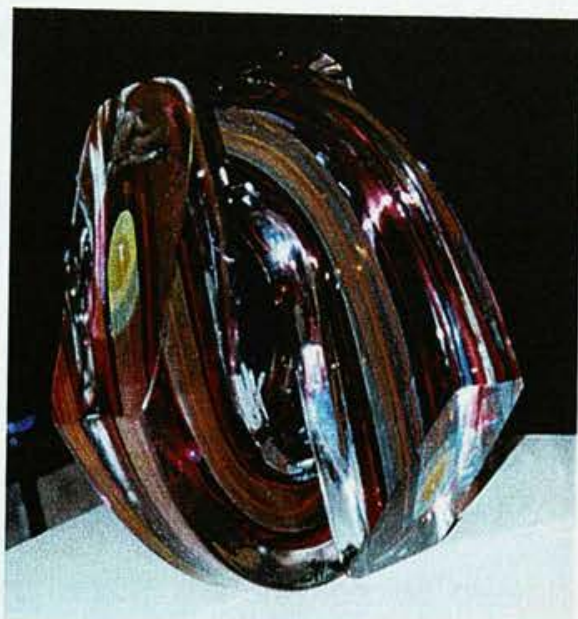

Figure 126 (b)

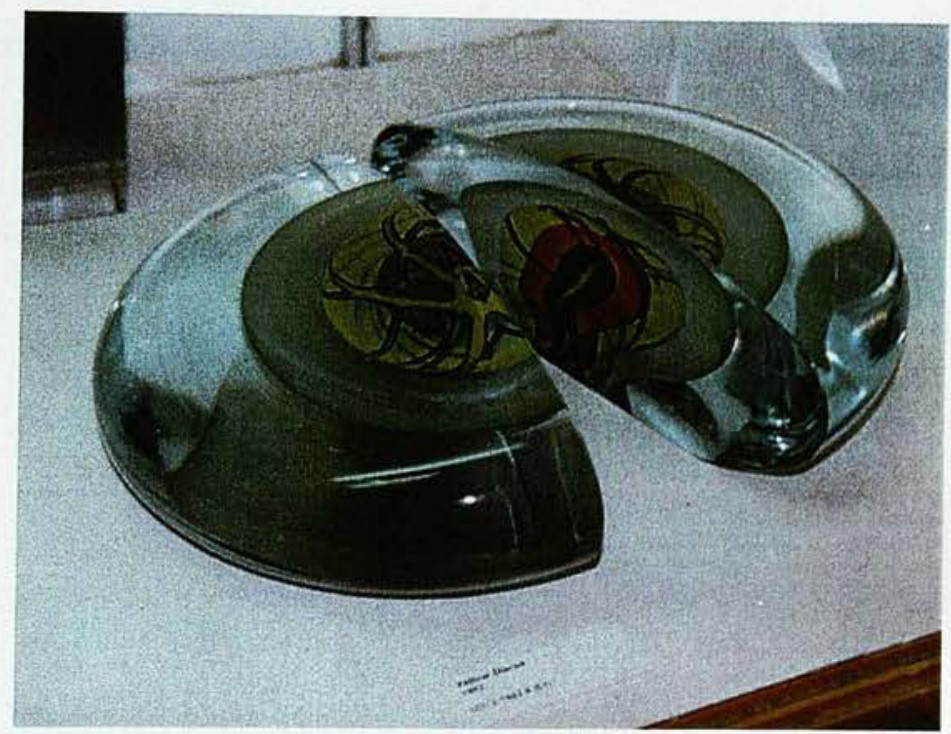

Figure 126 (c)

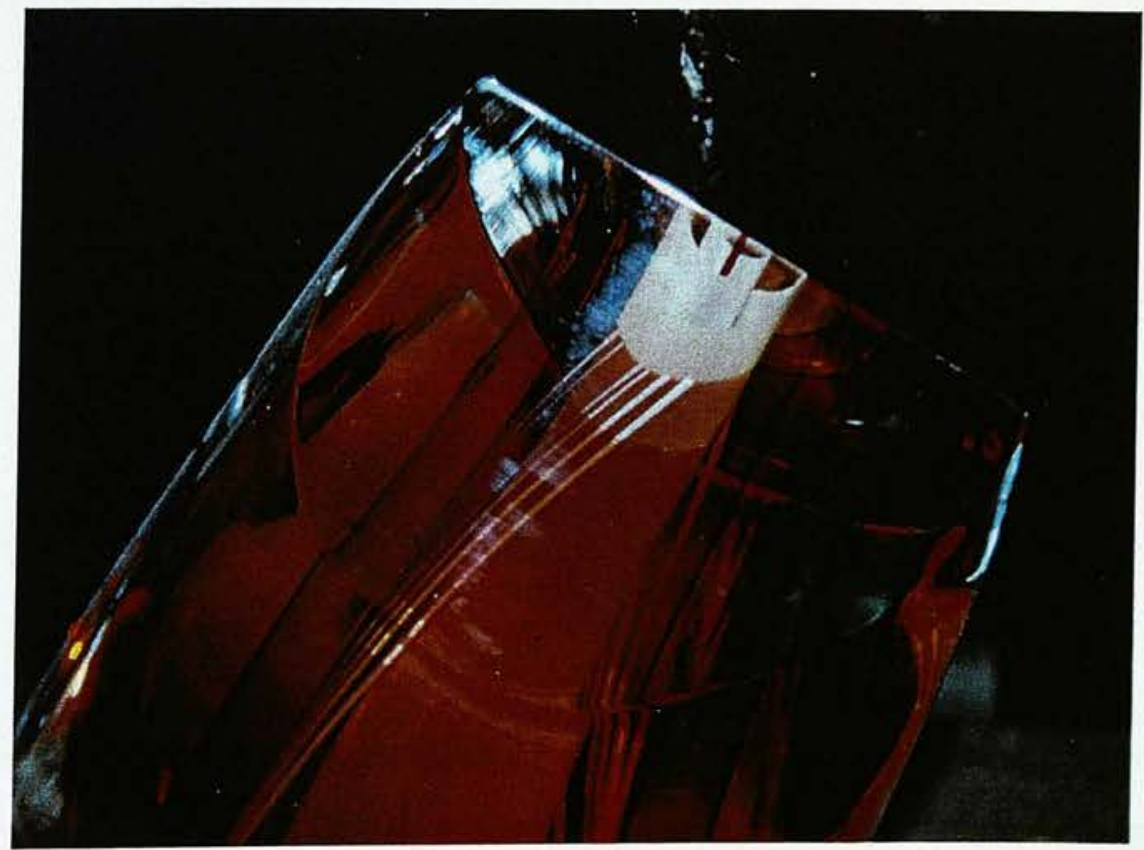

Figure 126 (d) 
In March and June of 1962 Littleton organised his first glass workshops. The participants in these workshops were neither engineers nor specialists, they were just friends of Littleton ${ }^{264}$, nevertheless they were enthusiastic and happy due to their natural excitement at the novelty. At this point, the important thing was having the opportunity and capability to use glass. One way or another they were generally satisfied by looking at the small blown pieces and were enjoying the pleasure of learning something new after each experience or mistake. These artists settled throughout the USA and different countries and started to use glass as an art medium in the academic sense. Littleton's inspired ideas developed unhindered and this movement which started in the USA spread rapidly throughout the world ${ }^{265}$.

264 Interview with Harvey Littleton on 02. 07. 1997, Spruce Pine Studios, North Carolina, U.S.A. For the students of Harvey Littleton and an indication of their spread to different institutions see Appendix E. 


\section{2. AMERICAN GLASS: ART AND \\ EDUCATION (SINCE 1962-PRESENT)}

At first sight, American contemporary glass art education is impressive due to its numerous educational institutions, which provided exceptional development to glass art and contributed a huge amount of interest in its evolutionary growth. Some of these institutions have confirmed their positions and earned themselves impressive reputations.

In the early 1960s, the choice of institution was not wide for students who wished to work with glass. Today, the art students who choose glass as a medium require a well-structured course for their careers. In the summer of 1961, Crafts Horizons magazine indicates some of the opportunities for study in their national survey. The result is only five glass courses in 130 educational institutions in 36 States, Canada and Mexico ${ }^{266}$. In spite of this, during the following years, the numbers increased until in 1971 there were more than fifty glass departments in various academic institutions in the USA ${ }^{267}$. There were astonishing results which came out of Glass Art Society Membership and Education Roster in 1995, showing the existence of 145 schools with glass programs in America and elsewhere in 34 years $^{268}$. Although this incredible acceleration does not reveal linearity between the development of these courses and the future, it confirms that glass has made an enormous effort over the last thirty years to find a solid place for itself. Yet again, probably the next

$266 \quad$ Anonymous, "Travel and Study", Craft Horizons, (1961), Vol. 21, No. 3, p 36.

267 Layton, Peter, Glass Art (London, 1996), p 30.

268 Oldknow, Tina, Pilchuck: A Glass School (Seattle, 1996), p 247. 
decade will reflect the real longevity of this educational hunger in the glass scene.

In the $17^{\text {th }}$ century glass was America's first industry ${ }^{269}$ and was involved in the production of window glass, bottles and tableware. The shake-up of this situation comes at the end of the $19^{\text {th }}$ century with Louis Comfort Tiffany. During the period of Tiffany and Calder ${ }^{270}$ glass began to reflect a certain character, their wont was to bring their own artistic personality to the forefront. The initial impetus began with Tiffany's extraordinary designs and gained momentum with the import ${ }^{271}$ of René Jules Lalique's ornamental, functional and decorative objects. Glass production in the 1950's was running abreast of technological developments and its dominant output was factory production, here, the items had a specific commercial identity as dictated by market research, this involved more than one person completing the designs. In spite of these established ways of working the likes of Harvey Littleton and those seeking something new were not deterred and due to their efforts the studio glass movement was established.

Following the role of Harvey Littleton in American studio glass art and during the first tentative steps of this movement it has developed into a phase of improvement with the contribution of students who have graduated and gone into education. At the start and formation of any new phenomena there is obviously no guarantee that it will continue to develop. It must necessarily harmonise with a cultural and social structure, be accepted and likewise be

\footnotetext{
$269 \quad$ Zerwick, Chloe, A Short History of Glass (New York, 1990), p 71.

270 See Chapter 3. 1. The Way Forward? The American Studio Glass Movement and Harvey Littleton, p 138.

$271 \quad$ Bayer, Patricia and Waller, Mark, The Art of René Lalique (London, 1996), p 10.
} 
affiliated with the artist's aesthetic view and approach. In this case, capitalism shows itself to be one of the most powerful players. For the continuation of art, individuals must primarily be independent with the freedom to create objects. This creation has to come from an education leading to a stage where there is the possibility and time for the conception of art. During this time, the material, energy and labour invested has a value from an economic point of view; this value is capital. Along with the appreciation and compliments, which an artist needs, he also needs a public who will value his works enough to buy them, and thus allow him to continue with his art, and this point is very important. In capitalist countries, especially in America, works of art can find buyers at a reasonable price. This gives the artist a much greater freedom with his designs, producing competition and the possibility for innovation. When the artist knows that there exists a high potential and an existing buyer population he is more likely to balance his anxiety over the continuation of his livelihood with his experiments in design and his commercial production. Artists in other countries with less advanced capitalist structures find buyers for their works outside their countries, and this provides a potentially lucrative escape route for their creativity. Therefore, in these countries experimental art becomes an indicator of capitalism. For example in the old Czechoslovakia ${ }^{272}$, Bohemian glass was popular since the middle ages, but in more recent times it has found a market outwith its borders due to the modest level of earning within Czechoslovakia and the penchant in the West for Bohemian arts. In more capitalist societies, such as America, production is both for internal consumption and exportation. Finally then, it is not the elements of production which dictate the sale and 
valuation of the works but the social, cultural and economic values of each country.

Following the start of the American studio glass movement many specialist galleries across America were opened, it is remarkable that they should serve solely the purpose of displaying glass. At the start of the movement it was relatively easy for a glass graduate to find a teaching position in an academic institution, however in the late sixties and early seventies the US military's intervention in the Vietnam War caused a perturbation in the politics and economy of America. The changes in the country during this period effected the investments of many institutions and because of this it became much harder for graduates to find academic positions. Efforts therefore to establish small private businesses and workshops as an alternative increased. The motives of selling of their completed works, finding a niche in the free market and selling more, have directed efforts into the establishment of specialist galleries. As these galleries began to make money the value of the works increased. This growth and liveliness within the glass world started particularly during the period of the foundation of Pilchuck Glass School in Seattle. It displayed developments that continue to this day and thus has become one of the most important centres of glass in America. Nowadays, many galleries in Seattle exhibit only glass and those, which display other art objects, increasingly give glass a dominant position. Thus, the market formed for glass in Northwest America grows in importance daily. The existence of a clay tradition in the Northwest helped significantly with the acceptance of glass art in the region. 
In July 1997, during a research trip to Seattle, I visited the well-known William Traver Gallery and interviewed the director of the gallery, William Traver. The information gained from this interview supports the idea that financial contributions made by individuals and companies interested in the subject of glass provided an important boost to the formation of American studio glass art. For example, the Haubergs ${ }^{273}$ made an important contribution to the foundation of Pilchuck Glass School, providing land and continued support, likewise they visited William Traver in relation to the establishment of a glass gallery, which not only formed a starting point for this idea, but has also inspired other art lovers and collectors to follow in their steps. The atmosphere they created has played an important role in the formation of an environment for glass art. In relation to this subject, William Traver states:

"...people who supported it early on came to every exhibition and bought the work, and knew the importance of having/buying work, in order to keep the artist around. They have to be supportive in order to make you remain and without exception they would buy the work without question. ... Even though it was not necessarily the best work, but they felt, it can only get better and it was important to support. ${ }^{274}$

This chain of events has played a very important role for the continuation and the development of the studio glass movement. It is possible to observe the extent of the developments within this movement with hindsight and to then reach a conclusion. Comparing the works of artists during the early years of the movement with those done by the same artists nowadays shows naturally both artistic and conceptual developments. Many technical problems have been

\footnotetext{
$273 \quad$ See Chapter 3. 2. 1. Pilchuck Glass School, p 162.

274 Interview with Traver, William, Director of William Traver Gallery, Seattle, Washington on 10. 07. 1997.
} 
solved, there are new innovations and they have been directed towards new techniques of application. The scale of works has increased, colours, textures and fields of application have undergone vast changes. This shows that in American glass art the progression from functionality to form has developed through the education system and has come to the forefront in contemporary glass works.

Starting with Harvey Littleton and his efforts to form glass through blowing and to re-evaluate the material in order to create an art object and the efforts of those at Pilchuck trying different application methods and repeating experiments for themselves, there is evidence of positive results which are beginning to evolve. Today, in America and other countries involved in contemporary glass art, it is apparent that glass blowing is not the materials only artistic application. The changes in techniques, over this period of time, have shown great developments and much variety and have expanded to another stage in its development. The point arrived at by childish experiments with hot glass, dropping glass straight from the furnace onto the floor ${ }^{275}$, and trying to create contemporary art works, has multiplied with the obvious benefits of academic education.

As an artist who has discovered the form at a point far from his initial starting point, (Figure 127) Dale Chihuly (b.1941), creates large-scale installations based on colour and technique, utilising natural forms of great fragility and rhythm which combines with the play of light to create a new period of expression in his work. (Figure 128) An artist said to be of the new generation and one of Chihuly's

275 See Chapter 3. 1. The Way Forward? The American Studio Glass Movement and Harvey Littleton, p 138. 


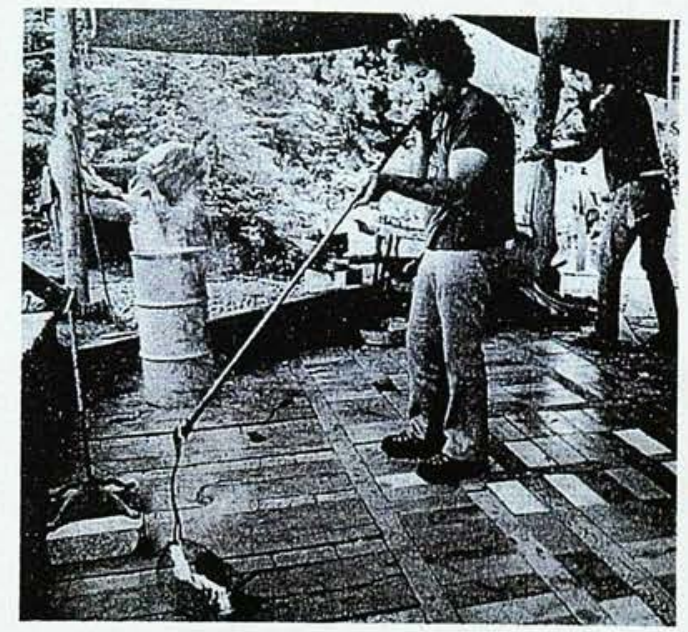

Figure 127

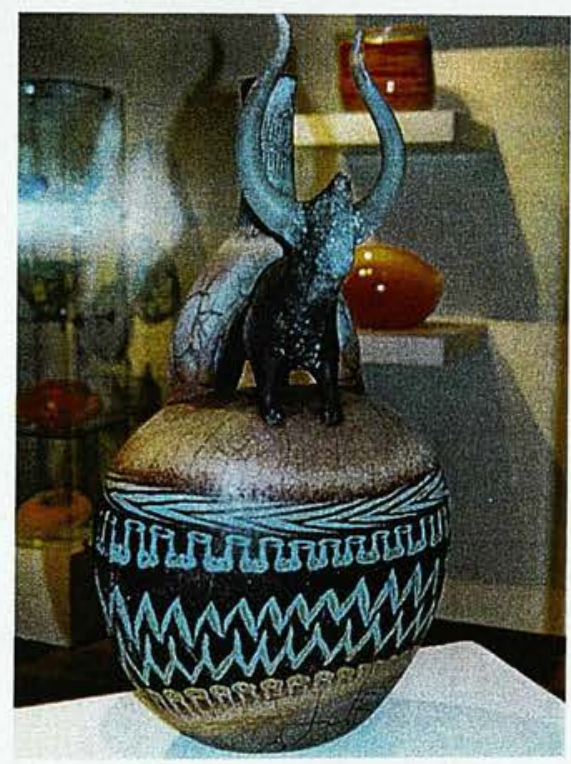

Figure 130

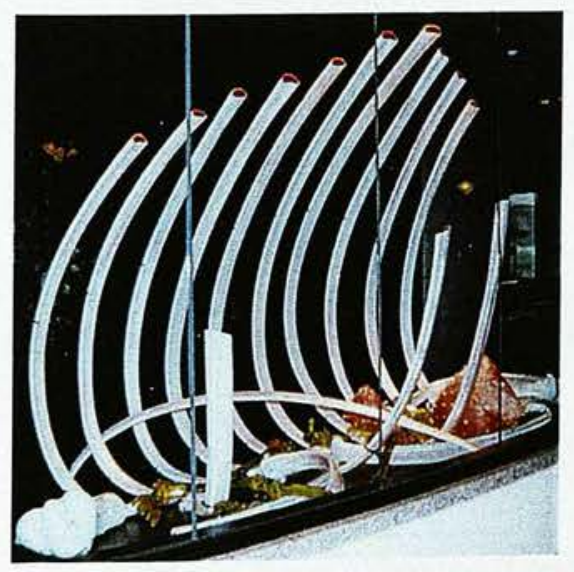

Figure 129 (a)

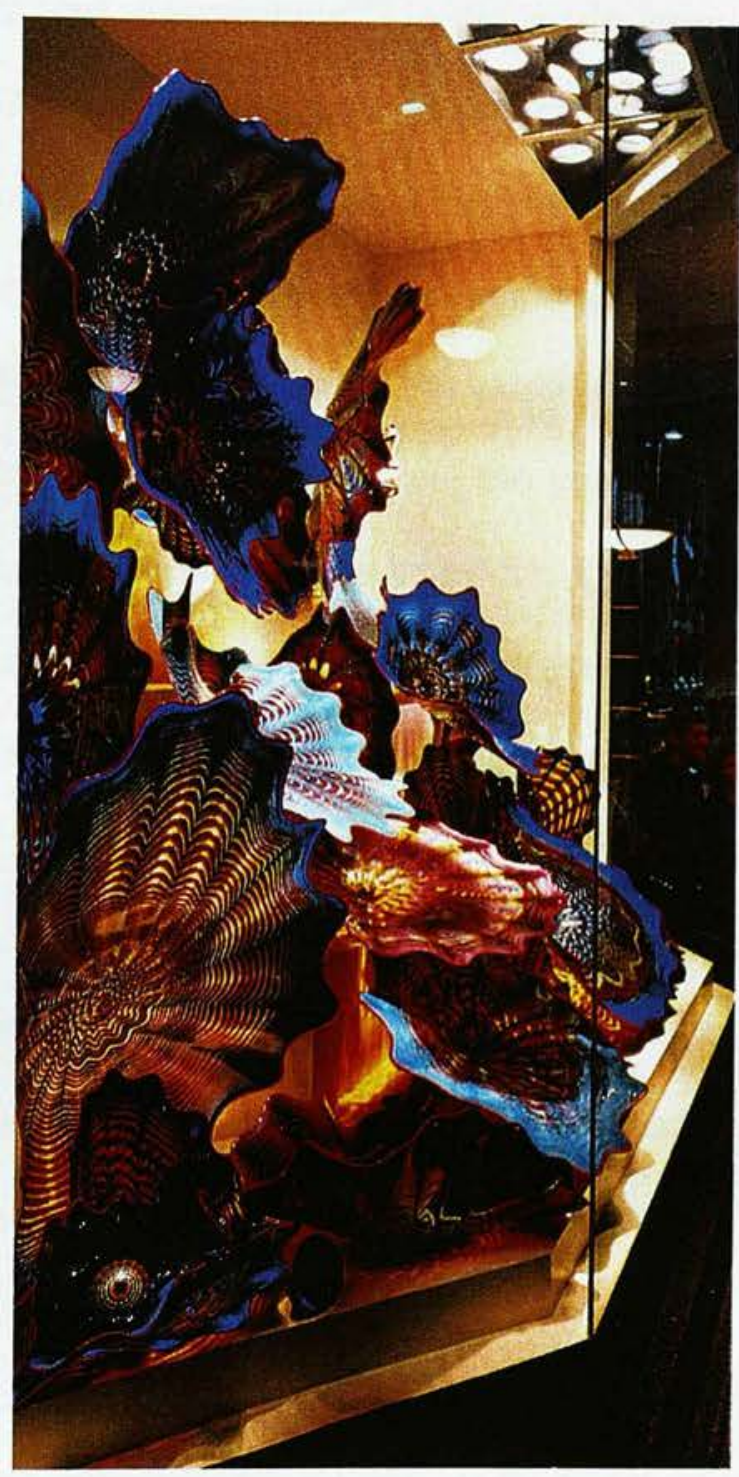

Figure 128

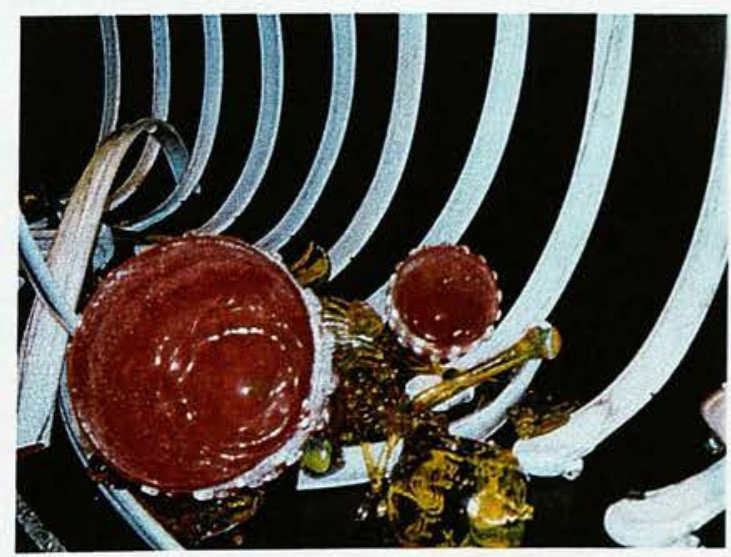

Figure 129 (b) detail 
students is William Morris (b. 1957, California), who, along with Lino Tagliapietra, is considered one of the best glassmakers ${ }^{276}$ in the world today. Nowadays, it is possible to see that he is one of the best exponents of glass used for artistic purposes. In both subject and narrative Morris differs from Chihuly, however he maintains Chihuly's boldness and productivity. (Figures 129 a/b detail) In his extraordinary installations he demonstrates the extent to which glass has developed to an astonished audience. In Figure 130, the connection between past and present which is viewed in his objects takes the form of a visual feast, which converts their tactility to something both incomprehensible and therefore untouchable. On this point, the works created by Chihuly are what separates him from other glass artists, but most importantly for his evaluation as a significant glass artist is whether he has made worthy contributions and brought his mastery of glass to the art. Evidently, there is no tangible way of measuring simply the artistry of a glass artist and probably there is no need to anyhow. The most important point is, as the author and furniture maker, the late David Pye, said:

"If some things are 'good' appearance while others are not, why are the 'good' ones good and the 'bad' ones bad? What causes the difference?...supposing that they are good, who is the better for it? Does it really matter? ${ }^{277}$,

A notable and worthy point here is that there are artists who have given their heart and soul to the medium and from the beginning they have displayed an unwavering passion and constructive energy towards the exploration of the material.

$276 \quad$ Layton, Peter, Glass Art (London, 1996), p 33.

Pye, David, The Nature and Aesthetics of Design (London, 1978), p 96. 
For thousands of years man has been acquainted with this material, but as it spread into studio glass from an academic environment artists have been introduced to it and their horizons in regards to its use as an art material have been broadened. The accepted starting point for the spread of this movement is after 1962, when its presence became apparent particularly in European countries and schools, and arriving at its eventual influence in Turkey are two prongs which comprise the subject of this study; the birth of the movement and its current point of arrival. The main focal point is the start of this movement in an academic environment. It is well known that prior to the 1960 s large centres of glass production and their studio departments were present at Orrefors and Stauben, sculptors, painters and other designers were producing objects with contemporary meanings. The point, which draws attention, is that these designers had no connection with glass making and worked only on a sheet of paper, and generally valued glass merely as a surface. A good example of this was an exhibition called "Asian Artists in Crystal" in 1956 in Washington and New York ${ }^{278}$. Visiting artists produced the designs and American designers and craftsmen realised the forms, amongst these forms were those made by two Turkish designers, one of whom was the famous painter, Bedri Rahmi Eyüboğlu. Purposefully approaching the different use of the material and seeking and working in new directions was a notable endeavour.

In Europe, particularly in Czechoslovakia, apprenticeships have existence for many years, but now the Academy of Applied Arts in Prague with Stanislav Libensky, has been established, similarly, in Britain there has been a tradition of 
Victorian Crystal manufacturing and a dominance of cutting and engraving practices, but in the 1930s the Stourbridge College of Art and Technology ${ }^{279}$, the Royal College of Art and much earlier, in 1911, the glass programme beginning with stained glass and developed in the 1940 s by Helen Munro Turner at Edinburgh College of $\mathrm{Art}^{280}$ were also instituted and it is these establishments, amongst others, which have formed the nucleus for the formation of contemporary glass art.

In other countries, in which the spread of this movement has shown its influence, artists that produce works of international contemporary glass are undoubtedly manifold. The assimilation of this movement, its conversion to an application and its natural period of development, not just with blowing, but also on the subject of the use of glass, has thrown up a number of glass artists who have played important roles in the development and use of different techniques. Klaus Moje's (b. 1936) distinguished style of fused, kiln formed, wheel cut mosaic glass forms with the reflections of traditions contemporarily interpreted. (Figure 131) Keith Cummings (b. 1940) as an artist and teacher of glass art, plays an influential role in the art of glass. He produces kiln-formed objects, which hold a synthesis between the mixture of various mediums with glass, and his works successfully combine forms of different textual qualities on the surface of his glass works. (Figure 132) Another artist, Bertil Vallien (b. 1938), pushes the boundaries of the technique, with his large scale works and new approaches brought to the technique of sand-casting. (Figure 133) He produces successful works which reflect the past in a modern form and medium. An artist who undoubtedly has an influential position in British glass art is Ray Flavell, 


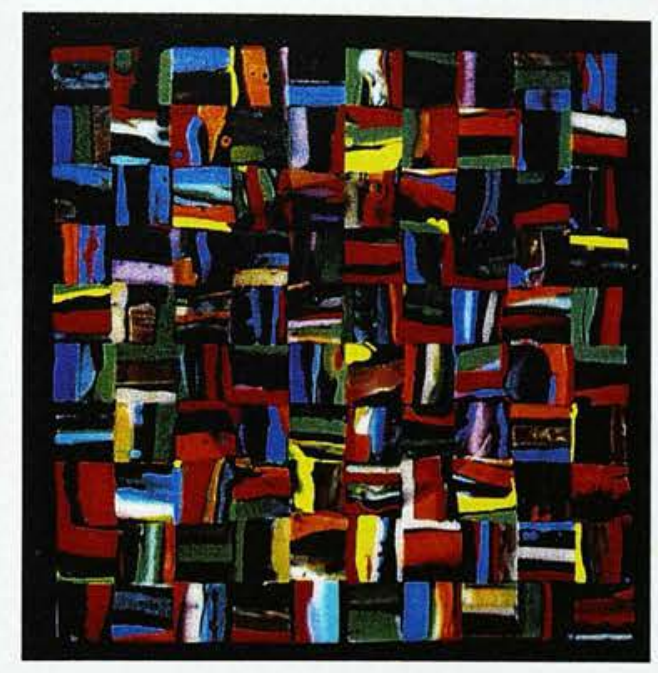

Figure 131

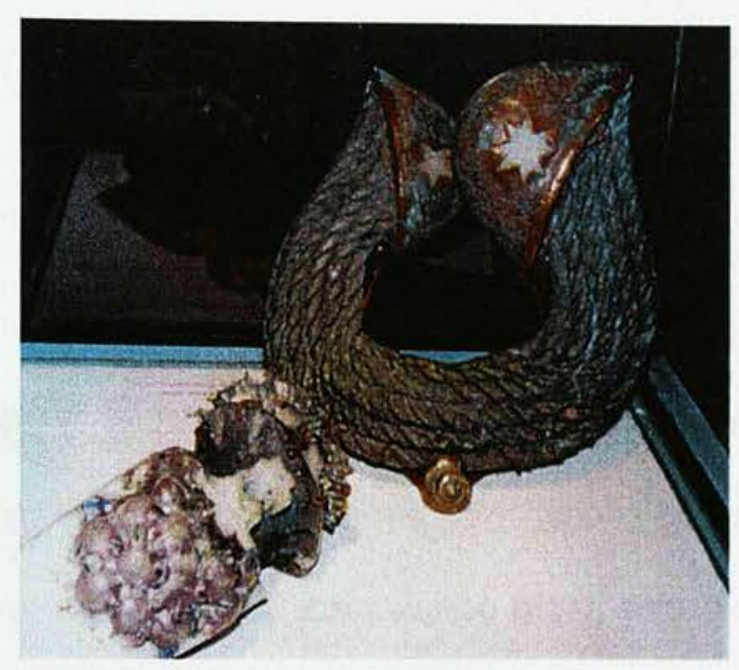

Figure 132

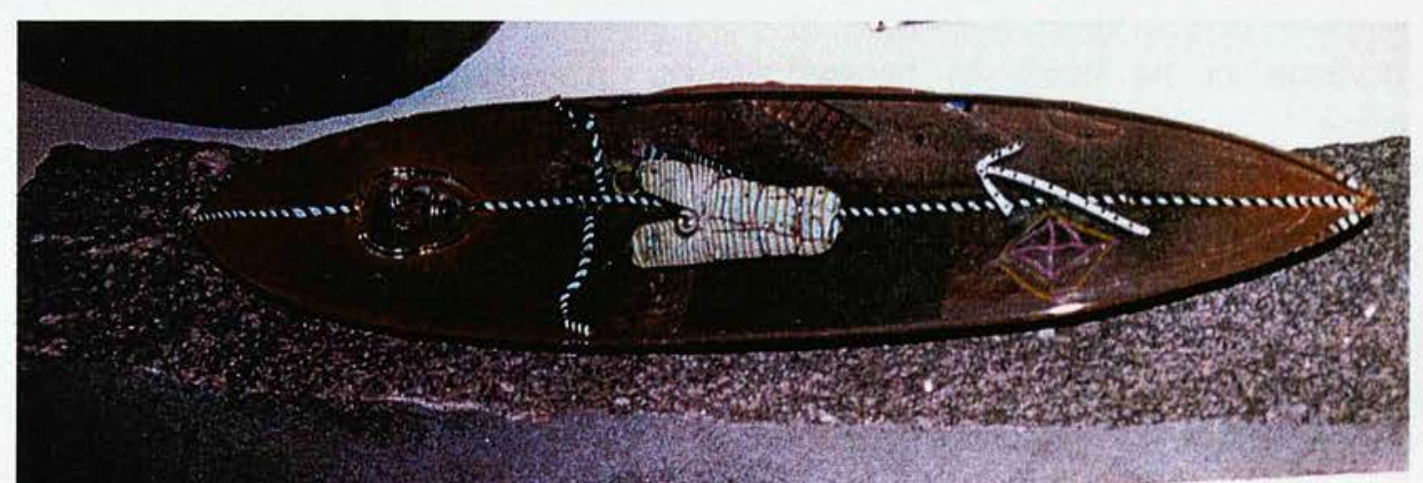

Figure 133

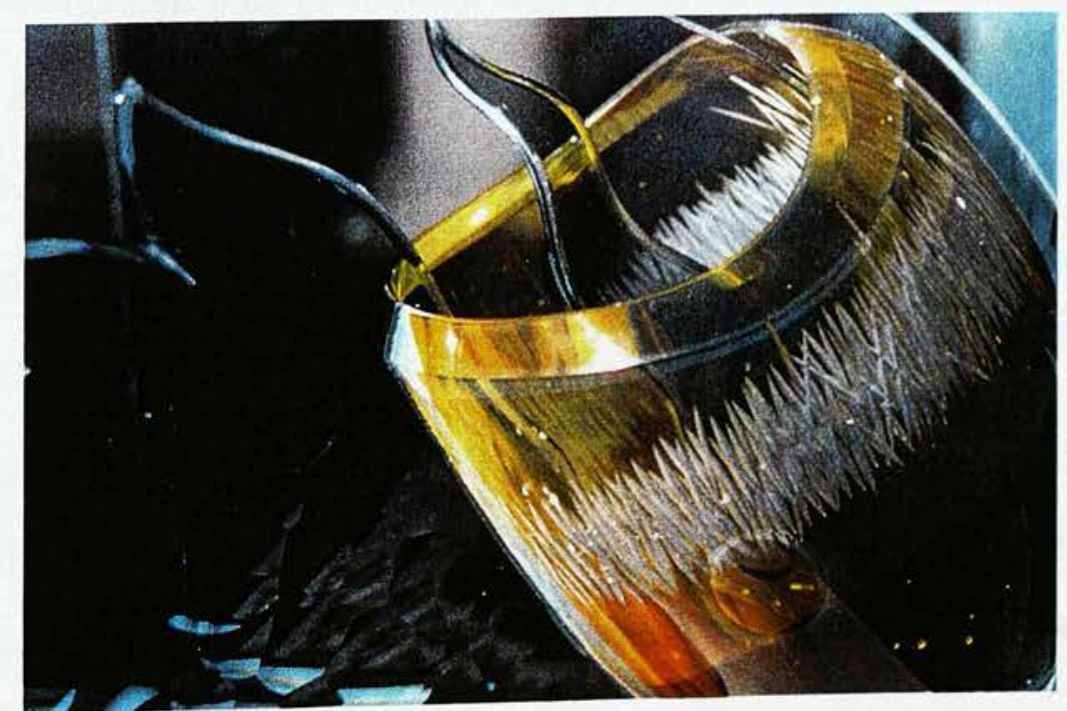

Figure 134 
(b.1944), in these examples he occupies a unique place. (Figure 134) His works express fluidity and energetic organic forms brought together with precision and accuracy.

It is of no consequence as to where in the world this development occurred, on this subject there is a common language. With the increase in communications between countries, distances have shortened and all these interactions have amalgamated. Nowadays in many countries there are established glass schools which are graduating new artists, and in various countries these programmes are at different stages of formation. One only needs to look at the American example to see the dimension of the spread of glass art in academic environments. Nowadays, in America, there are over 100 institutions of higher education providing undergraduate and postgraduate glass courses and graduating hundreds of students each year. Amongst these institutions, Kent State University - Kent/Ohio, Rhode Island School of Design - Providence/New York and Rochester Institute of Technology - Rochester/New York are the most renowned and this is due to the high level of education they offer and the artists that have attended their courses. In addition to these courses, others exist and offer a full range of classes, but are not necessarily part of a college or university programme. Some of these are Haystack Mountain School - Deer Isle/Maine, The Penland School - Asheville/N. Carolina and The Studio of the Corning Museum of Glass - Corning/New York. Regardless of their popularity, their academic/artistic staff and the expansion of their programmes, even though they are successful establishments; Pilchuck still stands apart due to its enlightening ideals, its educational programme, its sole focus on glass and its social ambience. 


\section{2. 1. PILCHUCK GLASS SCHOOL}

A unique glass school, Pilchuck, as well as being historically the first of its kind, has grown remarkably from its beginning until the present day. It is an independent school that has gained a strong international reputation for its work in glass and undoubtedly is the most widely referred to within the glass society. Its inspiring geographical situation, continuing financial support, contributions from artists and its professional advertising campaigns are obvious reasons for its success in becoming a legendary school among students of glass. (Figures $135 \mathrm{a} / \mathrm{b})$

From the time of its foundation until now, the success of Pilchuck Glass School has far exceeded the dreams of Dale Chihuly who took the first steps of setting up the school. Now, reflecting on this amazing accomplishment in such a short period of time gives him great personal satisfaction.

Pilchuck's story goes back to 1968 , the year that Chihuly started teaching at Haystack Mountain School of Crafts. The idea of establishing a school on the Pacific Coast equivalent to Haystack came to him when he obtained financial support in 1971. From the beginning, he knew the difficulties of finding help, but he was inspired to find individuals and associations who admired his effort and faith and supported him. Chihuly was sponsored by The Union of Independent Colleges of Art for $\$ 2000$ and this was the foundation for the fulfilment of his 

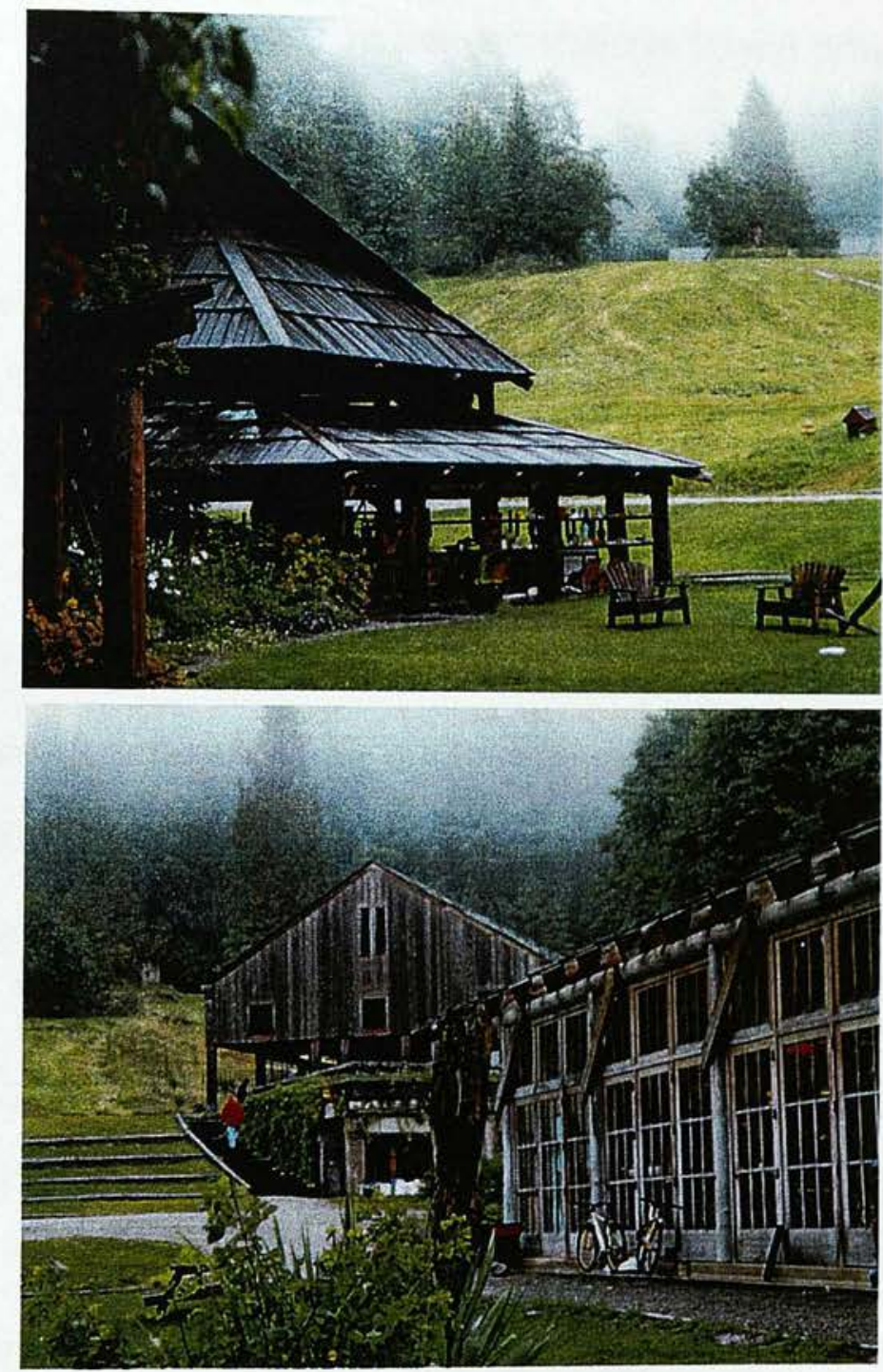

Figures 135 (a) and (b)
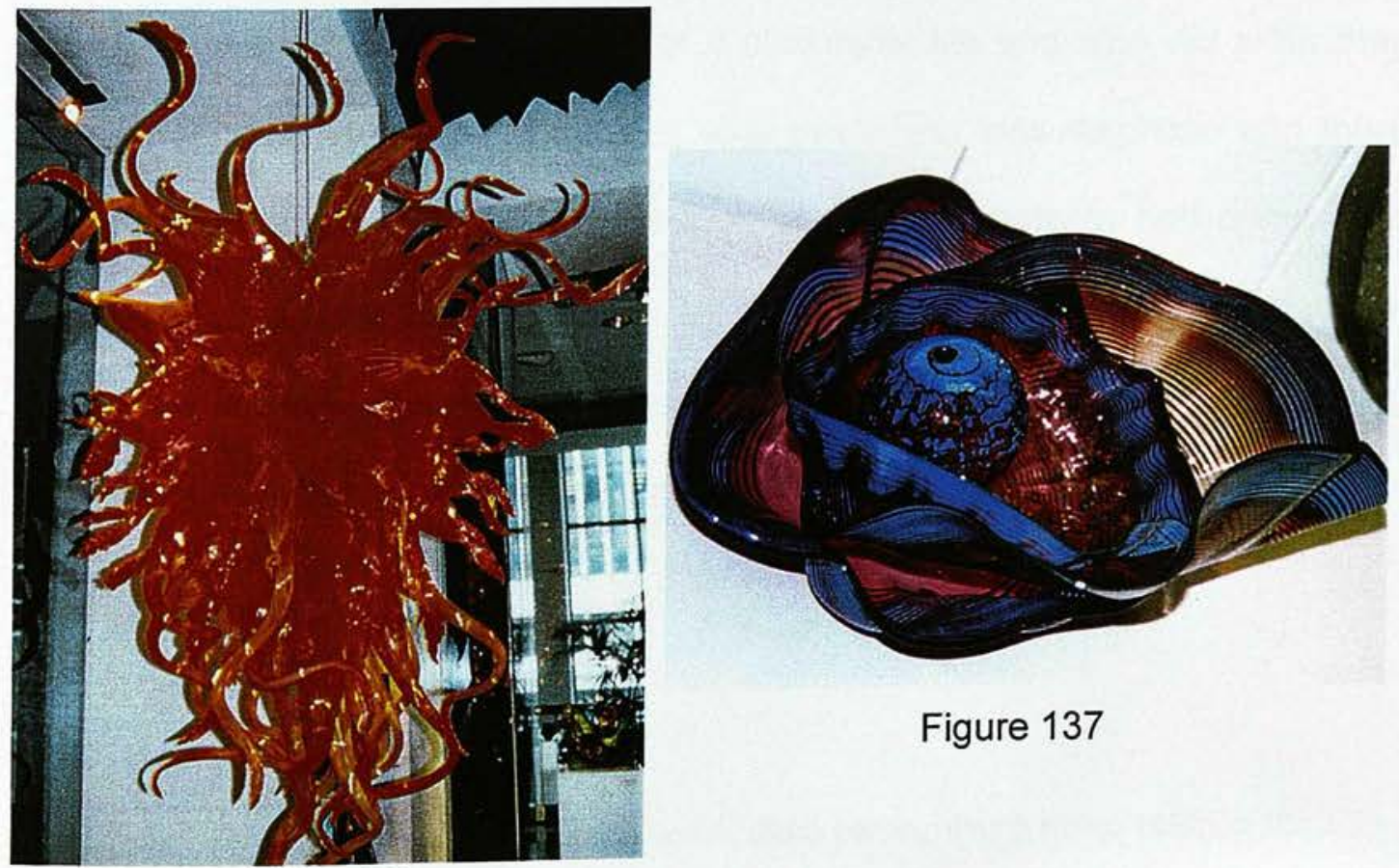

Figure 137

Figure 136 
life's ambition. He then invited 16 talented students from 8 different art schools that were the members of UICA consortium ${ }^{281}$.

Certainly the spark was the first UICA grant, but without people like John $\mathrm{H}$. and Anne Gould Hauberg - art patrons from Seattle - who lent their tree farm on which the school was built, this could have remained merely a dream for Chihuly. Their bounty and their sincere friendship encouraged him, also it played an important role in bringing the school to where it is today. Following the first Pilchuck summer, Hauberg's continuous financial assistance gave the school an opportunity to develop its strong foundation for the future. Being very aware of that fact, Chihuly has always talked about them with appreciation:

\footnotetext{
"Thanks in large part to John's uncommon generosity, Pilchuck not only survived but flourished. And for that, a whole lot of us are profoundly grateful. ${ }^{282 n}$
}

In the beginning, despite the absence of electricity, shelter and other necessary facilities, the project could be declared a great success. The first sixteen students gained good experience of a communal life and also did what they came for, blow glass... For the first year everything was dogmatic and there was barely any institutional organisation at all. The students had come from different disciplines but they were all keen to use glass as an art medium. Because of the limited access to the furnace, they used their time wisely, doing ceramics, jewellery or simply walking in the woods and sketching. 
In the quarter of a century since the school was built, many things have changed. Today, Pilchuck's name is known and universally respected. The army-surplus tent roof has gone and nobody needs to sleep in hollow tree trunks or tepees now (ironically, camping is not permitted today!) ${ }^{283}$, and its unofficial educational role has changed to a well-structured, organised course.

Naturally, Dale Chihuly's method of teaching has played a very important role in the formation of the courses at the school. Today's Pilchuck has become a creative, inspiring and encouraging place for glass artists, mostly because of Chihuly's keen interest to direct the school in his own ideas of teaching.

Chihuly's teaching methods are based on a very simple and straightforward idea. He wanted to leave theory behind and directed his students to the end product. The knowledge of using material is important for the student and also a certain level of technical knowledge will reduce the difficulties that the student faces whilst working with glass. On the other hand however, the creation of a form and the realisation of ideas are more important than a fantastically skilled technical application. He wanted his students to be unique in their own way and work with their own initiative through to completion. Occasionally he was criticised for this approach and some students were not satisfied with the attention that they received. Chihuly also believes in the importance of a harmony between the master and his apprentice. He believes that it is important to work as part of a team but to keep their individuality. On looking back to the years when he started teaching, he recalls the days in Pilchuck: 
"All I did was bring people together, assign them work times, and have them work. ${ }^{284,}$

Over a quarter of a century has passed and the teaching methods have barely changed at Pilchuck. Marjorie Levy, Executive Director of Pilchuck Glass School in 1997, talked about these same ideas during my interview with her:

\footnotetext{
" The idea; you get good artists and good students, put them together and make them work and they work together. If you just stack two people in a room together, one will learn from the other. We are now just a little more formal than that. Just a little. ${ }^{285,}$
}

For the first couple of years, Chihuly focussed on creating the school, more than concentrating on constructing a formal education. For him, the most important aspect was to create an inspiring and comfortable environment in which to achieve remarkable results. On his past experiences at Haystack and RISD he knew he could form the basis of the school solely on the use of glass.

His approach to teaching was constructed from some basic ideas in the vein of Abstract Expressionism, although he didn't want to ignore the importance of craftsmanship and skill completely. Henry Geldzahler, former curator of Twentieth Century Art at the Metropolitan Museum of Art, New York, expresses his view on this subject in 1986:

"Dale Chihuly occupies a rare position: His works is sometimes shown with crafts and sometimes with the work of painters and sculptors in art galleries. ${ }^{286 n}$

285 Interview with Levy, Marjorie, Executive Director of Pilchuck Glass School, Seattle, on 08. 07. 1997. 
This mixture of craftsmanship and artistry can be seen in his most attractive and beautiful works where the most graceful of style and movements allow us to feel his spirit through his work. His early works are living, breathing objects which float in a frozen moment allowing the viewer to imagine what will happen next. He eliminates repetitive motions, as he disregards the monotony of scale. He creates well-balanced installations from the same forms, which are perfectly adjusted in a relationship between fullness and emptiness in conjunction with inner and outer space. (Figure 136) His works echoed throughout the world with his stunning touring exhibition "Chihuly: Venetians" which was completed after four years of work in 1991. He combined eye-catching colours with skilled glass blowing. At the end, in the abundance of similar forms he created wholeness. Although his forms were exquisitely decorative and tended to be visually pleasing, they were neither symbolic nor simply conveying messages to the viewer. (Figure 137) Originating the contrast between visual attractiveness and non-functionalism in his works still draws a lot of attention in the art world.

In the beginning of 1970 s when Pilchuck began to have a definite agenda, it initiated a new direction to the studio glass movement. Stretched, squeezed bubble forms or instantly appeared abstract shapes made by glassblowing did not continue in their popularity and glassblowing was not the only technique to be dealt with anymore. Other techniques were added to the repertoire of glass as a material, for example sandcasting, lampwork and kiln work. (Figures 138 a/b/c/d) Contemporary glass art achieved a new spirit with Pilchuck's experimental point of view. 


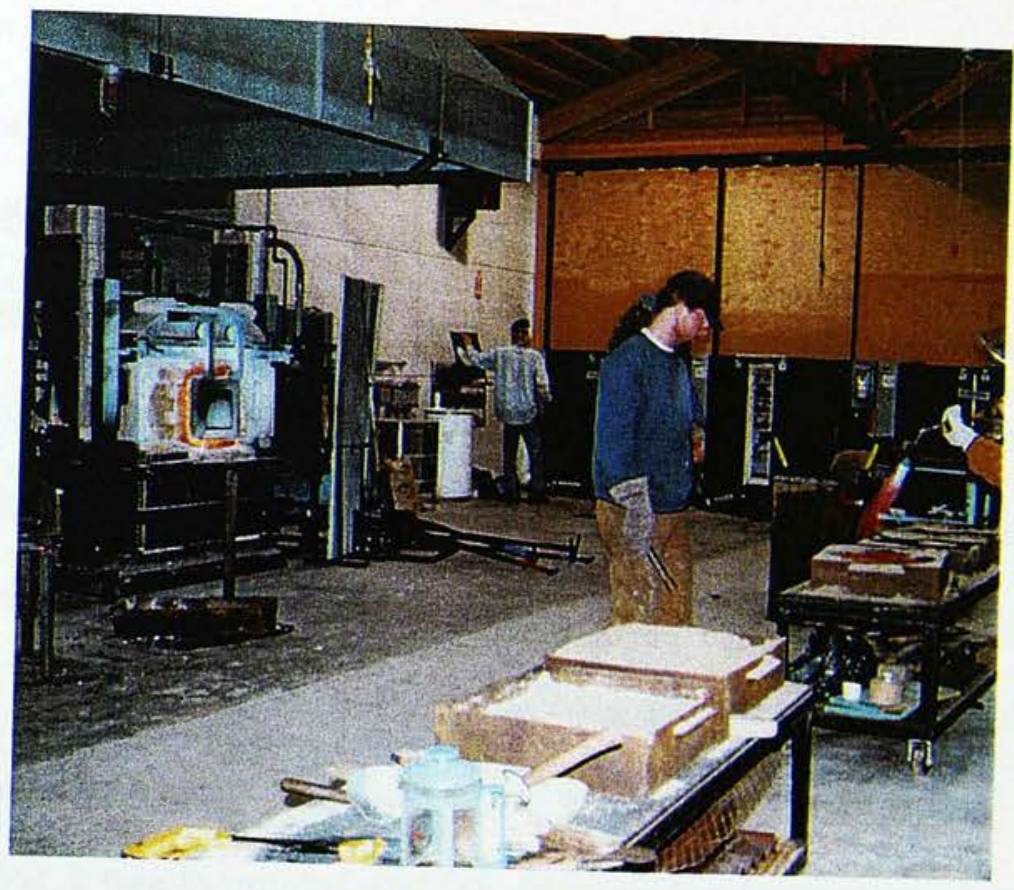

Figure 138 (a)

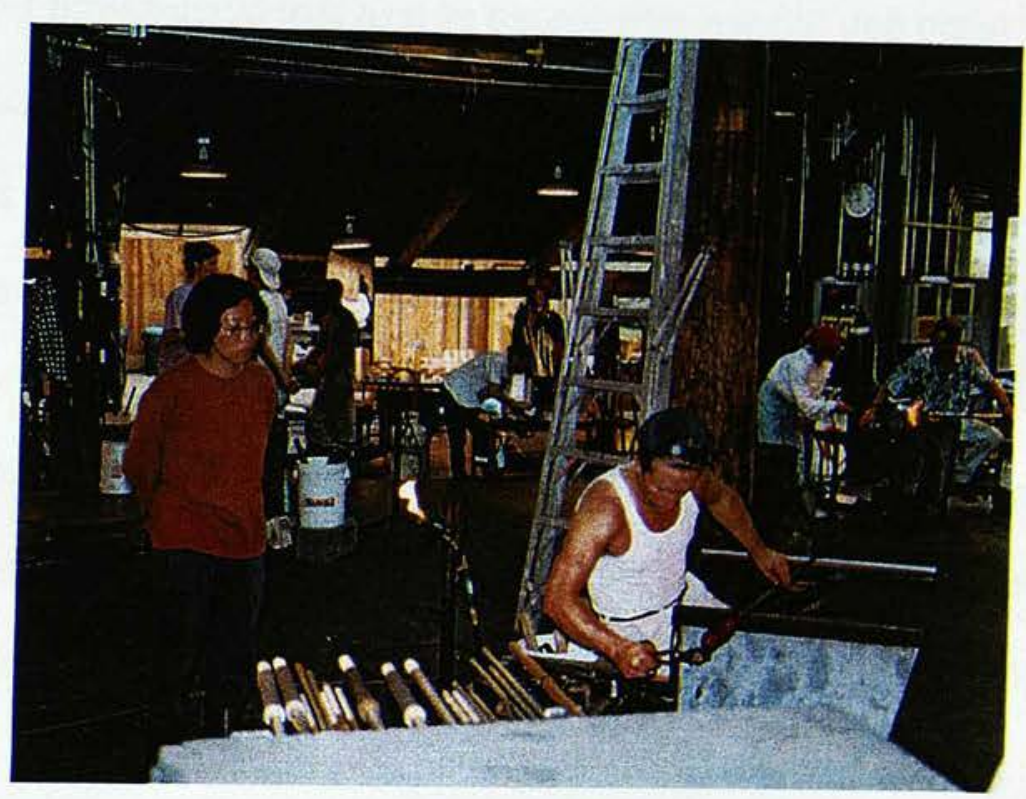

Figure 138 (b)

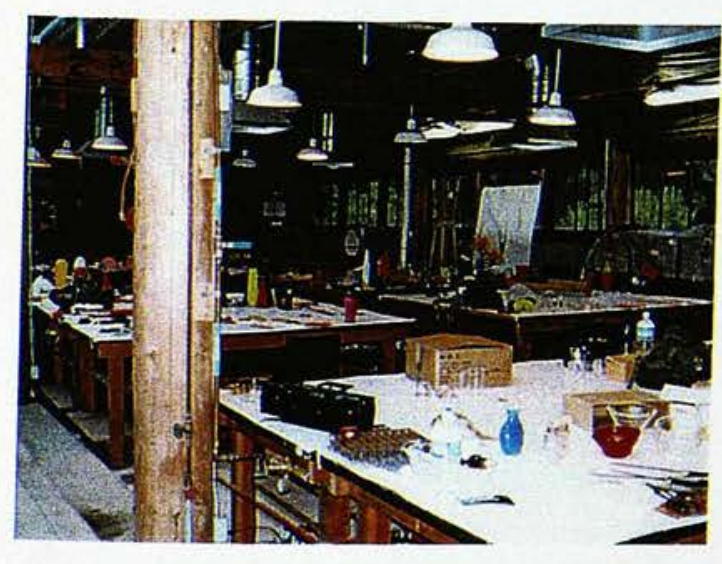

Figure 138 (c)

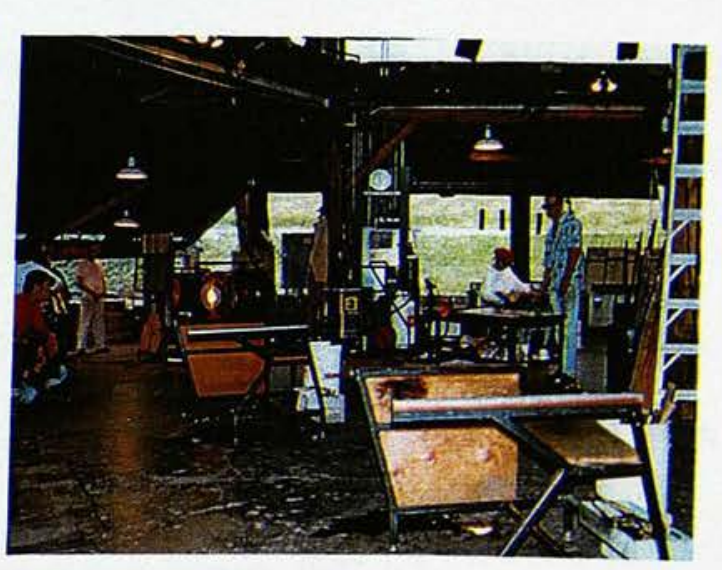

Figure 138 (d) 
Through institutional influences, individual efforts and experiences, Pilchuck Glass School has improved and developed since the first summer in 1971. In 1986, for the first time, the school had a waiting list for every class and now offers a resolved, established and well-organised course. Throughout the summer, it offers five residential sessions. Artists can study glass blowing, casting (kiln, sand), neon/flame working, architectural glass, stained glass, mosaics, glass engraving and also glass plate printmaking ${ }^{287}$. Each course has one or two teachers and two or three teaching assistants. Because the school is more expensive when compared to other similar kind of educational organisations, it has to provide enough attention for the students as well as very intense and professional teaching to people who want to use glass to make art. The school has an extensive library of glass literature, including books, periodicals and audio/visual materials. Many demonstrations and lectures are held in the library for the use of students. The video filming of events has been taken very seriously since Chihuly started to prepare proposals for the school's educational formation. In 1972, he introduced a multi-media, photography and video course as an extension to glass, but later on he pulled out these additions from the main programme and it only remains as a simple videotaping event ${ }^{288}$.

Considering the short period of learning/working time, only two weeks, many studios are open for twenty-four hours except on weekends. Most of the students who go to Pilchuck are from other art colleges, some of whom have never worked with hot glass but wish to and have never had the opportunity to do so. Some students know a little about glass and are willing to learn more, and some, a very small percentage, go to Pilchuck simply for curiosity or a 
vacation. Marc Levy gets excited in an interview when she talks about the people who come to Pilchuck only for a holiday: Because it's so beautiful, and it's summer time, it can seem like a vacation. ${ }^{289}$

Although Pilchuck does not offer an academic degree, its course is also revered amongst glass artists. With the burgeoning numbers of glass art graduates and establishing artists all eager to experience Pilchuck and its influential history, it is likely that it will maintain its prestigious position for a long time to come.

\section{2. 2. CHANGING AESTHETICS}

Almost every decade has witnessed a shift in emphasis within the social structures of communities. The atmosphere created by this social and cultural change blends naturally into everyday life. In every society there is a desire for continuity and to be part of history. Incorporating this desire with new ideas, contributions from individuals and their effects and the developments in new technology throws societies into another phase which will display its own developments and mutations. The location is not important to this mutability because it simultaneously affects societies which are at a similar stage of development. With this spread and its acceptance by different societies this movement is given a universal identity. The changes which directly effect societies, as a part of life, may start with the understanding of art, fashion, decoration and music, but reach as far as changing the capability of language and thought and, at this extreme, derive from the desire to make new 
approaches in aesthetics. The products, which rose or fell in popularity due to the changes in style, provide an account of these changing aesthetics.

In the latter half of the $19^{\text {th }}$ century the recognition and understanding of the changes $^{290}$ in glass art entered a new phase in the amalgamation of technological developments, ideas, decoration and the drive towards new experimental ways of working. For example the designs of gardener, Sir Joseph Paxton $^{291}$ (1803-1865), for a greenhouse, led to the later development of prefabricated buildings. This derived from the idea of placing large glass sheets $^{292}$ into an iron framework. The completion of Crystal Palace in 1851, in such a short space of time, was a brilliant example of this new application. The Great Exhibition of the Works of Industry of All Nations in the Crystal Palace ${ }^{293}$ opened the door onto new dimensions for the use of glass and later, it demonstrated its effects through the changed use of the material in architecture. This interaction has been discussed in detail in section 2.1 on the Glass in Turkish Architecture, which provides beautiful examples of these styles and demonstrates its conversion to a universal form and likewise, the distance between the countries has been demolished. This influence comes from the same purpose, but adapts itself to the passage of time displaying itself in different forms. The new understandings of construction are evident in the building of the Eiffel Tower, likewise in the following period, skyscrapers are a

290 See Chapter 3. 1. The Way Forward? The American Studio Glass Movement and Harvey Littleton. Tiffany, Lalique and Calder, p 138.

291 Head gardener to the sixth Duke of Devonshire at Chatsworth. First he became a horticulturist, then a designer and an architect. He had designed many great houses, public parks and buildings.

292 Anthony, John, Joseph Paxton (G. B., 1992), pp 12, 14 and 34. See also Chadwick, George F., The Works of Sir Joseph Paxton (G. B., 1961), pp 99, 137 and 138. Paxton's other glasshouses: The Capesthorne Conservatory (1840), Holker Conservatory (1840), The Great Conservatory (completed 1840-41), The Lily House (1850), Crystal Sanitarium (1851), Glass roof for the Royal Exchange (1851), Sydenham Crystal Palace (1854)

293 See Chapter 2. 1. The History of Turkish Glass, p 37. 
further example of this. Observed events and developments provide an index of a formal and logical order of creation. On closer inspection, it is possible to observe that the seeds of the changes in aesthetic meaning occurred at the right time and in the right place and then flourished.

As well as being evident in architecture, these changes were present in the aesthetic and social movements starting with the Art and Crafts movement, in the latter half of the $19^{\text {th }}$ century and have created a conscious foundation on the subject to reach new interpretations and synthesis. Art Deco, in the first quarter of the twentieth century, was fed with the understandings of the movements of the past and has got its structure and power from its roots in these movements. The changes occurring in the social structure of this time are surely informed by the changing of aesthetic understanding. In other words the structure of every concept is based on those, which have gone before, and constitutes a conduit for the one following. However, these developing and changing periods in time relate to the changing economics and politics by imbuing them with different characteristics.

On the subject of glass, the formative aesthetic changes are a result of a natural drive for innovation and novelty. By the 1950s glass products, which were adapting themselves to the parallel lifestyle changes in technology, were becoming modernised and the outlines more simplified, with bold and attractive colours $^{294}$. During the 1960 s glass was affected by the studio glass movement and entered a new phase of configuration and experimentation. In this period, production of studio glass was in opposition to the methods of mass production 
of its recent history, the design understanding, emphasis on decoration, and the efforts to make the design an affordable product through serial production. Harvey Littleton's statement that "technique is cheap" is a demonstration of the style of living and changing ideals of society. Here, attention is drawn to the same behavioural and ideological approach which is repeated through different periods of time. Dada especially reacted to the use of traditional values in the artistic creation. This reaction, combined with a revolutionary approach towards the variety of material involved in expression, prepared society conceptually for the movements which follow it. From this point of view, Harvey Littleton's use of glass, his desire to demolish the past in order to take a new direction, shows a similarity with the concept behind Marcel Duchamp's (1887-1968) "readymades,295. The "anchor of hope" which the Dadaists threw into the sea of nothingness ${ }^{296}$ is in fact the same departure point for the both these artists. The purpose is to demolish the values of the past in order to dive into new explorations. This was repeated in varying forms a few times with intervals of approximately thirty years. Initially these ideas and practices were considered to be both eccentric and absurd. Likewise, a third and similar artistic reaction appeared in the 1990s with Damien Hirst (b. 1965). Hirst attempted to create a concept of alienation by way of producing an uncomfortable feeling through works which reflect an awareness of life and death ${ }^{297}$. He has found a parallel to the reaction faced by the freakishness of Duchamp's urinal ${ }^{298}$. Here, the changes forced by Duchamp onto the new aesthetic values and the evaluation

295 Richter, Hans, Dada-art and anti-art (London, 1965), pp 88-91.

$296 \quad$ Richter, p 93.

297 Tate Gallery, London, The Turner Prize 1992, exh. cat., 1992, no page number.

298 The work is called "Fountain". 
of the style and understanding of the approach of the artist, comes to the forefront $^{299}$.

These three artists converge at a specific point, this point is glass and as such, from an aesthetic angle for expression it is powerful, and from an artistic angle it is acceptable as an effective material and this dominance is remarkable. Harvey Littleton has a rapport with a certain material, his discovery of glass as an art material and his effective interaction between himself, the artist, and the material is symptomatic of this; this intimate relationship is not as visible in the works of the other two artists. In spite of this Marcel Duchamp's huge sheet of New York bred ${ }^{300}$ dusty glass, "The Great Glass", shows a departure from the physical anxiety of painting, only desiring to produce visual works which reflect his ideas. Similarly, Damien Hirst creates in his work a formal system, which has a necessary use and value of glass. In his essay author Richard Shone states:

"...and the vitrine have become hallmarks of his work; almost everything he does is viewed through glass, the pane acting as a frame to cool down the spectator's gaze. ${ }^{301 "}$

During this century there was a reaction to two World Wars, which eventually developed into mass protests and demands for peace during the sixties, such as the protests in America during the Vietnam War, then during the 1990s in reaction to the excesses of idols and brand names of the previous ten years there became an increased environmental and social awareness. Changes

\footnotetext{
$299 \quad$ Roth, Moira, Difference/Indifference-musings on postmodernism, Marcel Duchamp and John Cage (Amsterdam, 1998), pp 37-38.

$300 \quad$ Roth, pp 22-23.

301 III. International Istanbul Biennial, Istanbul, text by Shone, Richard, Damien Hirst, exh. cat., 1992, no page number.
} 
formed in aesthetic understandings, even though the names, times and places have changed will continue to repeat in differing formats and with different slogans. This discussion on the subject of glass has become manifest with the start of the studio glass movement and the aesthetic changes that have accelerated throughout this period. Any anxieties surrounding its evolution were demolished and a free flowing development occurred.

When aesthetic values, the changing scene of technological developments and changing social and economic times are taken into account, comments like 'everything in glass has been done' and 'there is nowhere else for it to go' become meaningless ${ }^{302}$. Today, glass, as an art material, has taken its place with other media, and has been accepted by contributing positive values to the expression of the artist. In the economic, political and social structures of society, every change and progression has created innovation in each branch of art and these same developments have been apparent in glass art. Without the benefits of hindsight, it would be difficult to evaluate and qualify the period in which one lives, this is a quandary which makes it difficult, if not impossible, to ascertain what direction glass art will take and what developments it may inspire. The developed technology of today and the contributions of new artists exhibit a refreshing potential. The formation of new aesthetic understandings and new approaches promise a brilliant future for glass. 
CONCLUSION

Whether it has been a branch of art or not, in every subject there is an intentional conception which needs to be developed. This period, from its beginnings, enters a positive progression in development, however, this point in time primarily has its importance as the spark which ignites the movement. There is naturally a digestion period for the assimilation of data in regards to making mistakes and gaining experience. In education, in this case glass art education, artistically, ideologically and technically, whether productive conclusions have been reached or not, the debate over changes can only be concluded after this period.

At this point, learning the behaviour and nature of glass is necessary to form the foundation of the whole study. The purpose of contemporary glass art education is not simply to raise master glass blowers, but to teach the principles of working with the material; to deliver adequate comprehension in the student; to provide an opportunity to develop the skills involved in using the material; to widen the horizons and to open a door into the practical and imaginative use of glass. These points, when assessed, derive from the evaluation of the American studio glass movement and are of value to the development of this movement in the institutions of other countries. When transposed to these countries, specifically Turkey, there will be a number of changes which are due to the history and culture of glass in that particular country, however some of the main elements gleaned from the American movement will without doubt be of use in the instigation of the discipline of studio glass in other countries around the world. 
CHAPTER 4.

\section{"MARCHING ON" - A GLASS EXHIBITION BY LÂLE ANDIÇ}

\section{PREFACE}

The education I have received at Edinburgh College of Art, over the last four years, has proved to be a very constructive and productive period. In this time, I have got to know the material and developed technical and artistic knowledge and skills. With the aim of exhibiting my works of the last two years, I have arranged two exhibitions: one on the $19^{\text {th }}$ of May until $2^{\text {nd }}$ of June 1999 , in V. M. Art Gallery in Karachi, Pakistan, entitled "Marching On"; the other, a year later in June 2000 in Edinburgh College of Art, a continuation of the former and as part of my study. This chapter is an analysis of my works and exhibitions, with a consideration of their relationship with Turkish glass art and serves as an example of the use of glass in contemporary art. 


\section{"MARCHING ON" - A GLASS EXHIBITION BY}

\section{LÂLE ANDIÇ}

"Glass is like a magic castle. Once inside you are affected by a spell which will not let you leave $e^{303 \text { " }}$

Following my introduction to glass as an art material, my curiosity was immediately aroused to discover more about it and therefore, I thrust myself into an exciting phase of becoming more intimate with glass. The relationship expressed between glass and the individual is of a more intense nature than with any other material I have come across. Glass is a challenging medium, which drives the artist to control it and to strive to progress with it, this keeps the relationship between the two fresh and alive and ensures the artist never loses interest.

My works symbolically represents the banners traditionally used by various Islamic denominations on occasions such as celebrations, marches, demonstrations and meetings, these are known as Alem. The dimensions and appearance of my work derive from those pole- mounted percussion instruments used by the Mehter Takımı - Janissary Band of the Ottoman court, a musical institution with a pedigree dating back to the late $13^{\text {th }}$ Century. The 
works were created in 1998 and 1999, using casting, lampworking ${ }^{304}$ and blowing techniques.

As an artistic material, glass has many attributes. It grasps the light, its reflective ability shows depth to great advantage and its natural appearance enhances the narrative qualities of the work. Making use of this potential, I have attempted to give contemporary expression to a historical visual theme, taking the form and image out of their traditional - cultural roles.

Conceptually and formally these works express messages that reflect Turkish Eastern and Islamic cultures. The calligraphy, the oriental motion of forms, which bear this calligraphy, and the order of their orchestration exhibit a certain cultural assimilation in their harmony, implying a ceremonious atmosphere. In my works there is a cultural triumvirate, separately these individual elements exude an Eastern atmosphere, however combined they have a much stronger effect. The Alems, calligraphy and instruments of Ottoman military bands make up this triumvirate. The Alems, which demonstrate a form of devotion to an idol in a crowd, have a one to one interaction with the band instruments in particular.

In Arabic Alem represents a sign, giving direction ${ }^{305}$, they bring together people who come with one purpose and keep them fast. However, Alems are for one reason important to point to a leader present in a crowd. It is possible to gather Alems in three main categories: flag banners, used in battles or to represent a leader; to depict various Islamic denominations and the beliefs of each sect;

\footnotetext{
$304 \quad$ Thanks to Jochen Holz and the After Dark Studios, Edinburgh, whose skills were influential in the creation of these lampwork pieces.

305 Tezcan, Hülya and Tezcan, Turgay, Türk Sancak Alemleri (Ankara, 1991), p 3.
} 
and as mosque Alems. Originally, Alems were sometimes made of wrought copper and coated in gold leaf (tombak), or sometimes formed in cast brass. Memluk Alems were also used as battle weapons, with their long, pointed forms they were known to be used for maiming and slaughtering ${ }^{306}$. On the other hand, Ottoman Alems were far removed from these purposes, with soft, curved outlines they made for graceful and decorative intentions. Mosque Alems are generally composed of a crescent and star design, and do not utilise calligraphy. The calligraphy in denominational Alems usually show Allah's name and those of the prophet and the caliph. As well as these, Maşallah ${ }^{307}$ and calligraphic art play based on symmetry are a general theme of these Alems.

Every form used as an Alem presents a formative image. This image is sometimes a crescent, which, according to tradition, first started as a white crescent on a red flag, and following the conquer of Istanbul a single star has been added in front of the crescent. At other times this formative image is a sun, star, dagger, or an assimilation of a traditional form and occasionally occurs in the shape of the 'Hand of Fatima' or 'Sword of Ali ${ }^{308}$. One of the most beautiful and modern approaches to the use of the crescent form in mosque Alems can be seen in the Faisal Mosque, (Figure 139) here, in 1985 in Islamabad, Pakistan, a huge tent-like mosque was built. The crescent here is central and gigantic, its form pushes the modernisation of the main mosque and minarets into relief as it is the only absolute symbol of a mosque. 


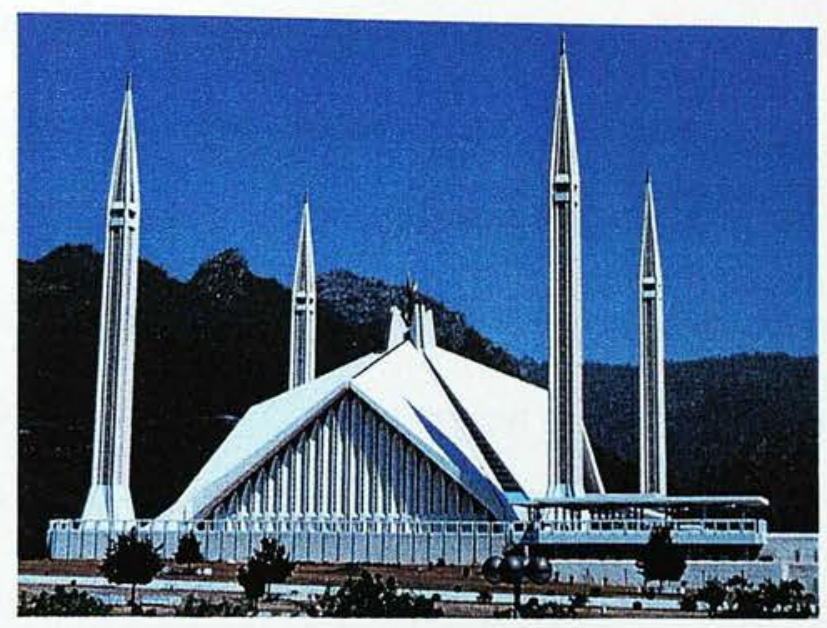

Figure 139

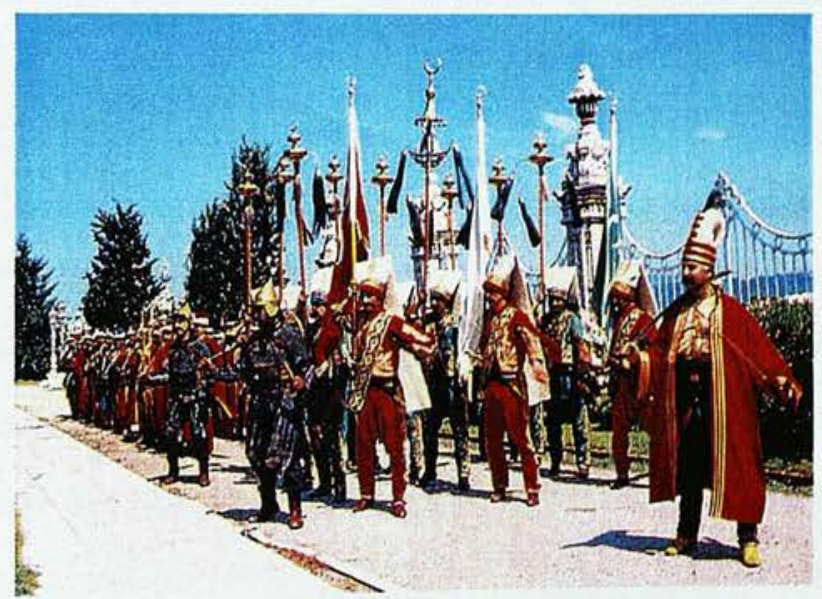

Figure 140

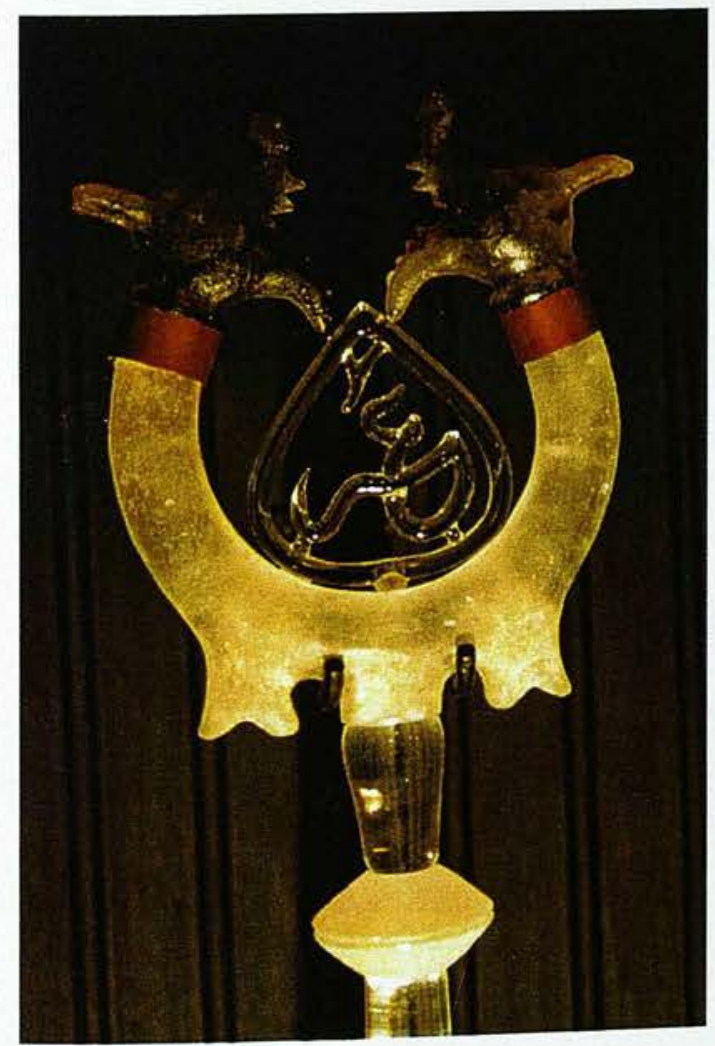

Figure 141 (a)

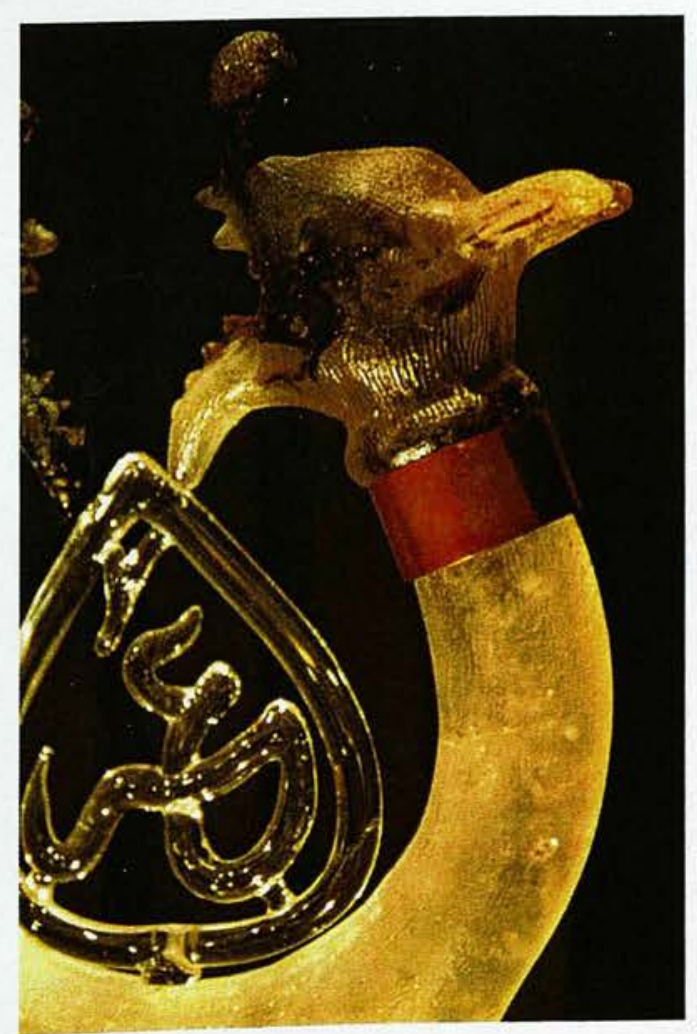

Figure $141(b)$ detail 
It is well known that throughout time Turkish Sultans used their banners as a symbol of sovereignty, likewise the drum and the Turkish battle band were given a similar importance. After the $15^{\text {th }}$ century, Mehter Takımı (Figure 140) became organised and was accepted as a formal government establishment, with its high-ranking officers ${ }^{309}$. The purpose of this band was to encourage the soldiers, boost their morale and stir their spirits, at the same time as this, they were to frighten the enemy. David Nicolle, in his book called Janissaries, discusses the enchanted atmosphere created by Mehter Takımı, referred to by Evliya Çelebi :

"...five hundred trumpeters raised such a sound that the planet venus began to dance and the skies reverberated...All these players of the drum, kettle-drum and cymbals marched past together beating their different kinds of instruments in rhytmic unison as if Chama-Pur's army [the traditional foe of Alexander the Great] was marching by. ${ }^{310 "}$

One aspect of the idea behind the music made by Mehter Takımı was to scare the enemy, Alems were also used in this fashion, and this relationship is worth examining as both forms were created with the purpose of intimidating the enemy and flaunting their own strength. (Figures $141 \mathrm{a} / \mathrm{b}$ detail) From time to time, the protective value already held by the Alems was increased by the addition of protective amulets, containing religious prayers and blessings, and long horse hairs tied to the neck of the Alem. These Turkish horse tail banners have provided the army with a mystic visual character, the soldiers who carry them move one day ahead of the army ${ }^{311}$ and this indicates the importance given to them. The belief in the protective value of the Alem, when seen with the 
influences of traditions and culture has a connection with the belief in the evil eye ${ }^{312}$. In this way therefore, it demonstrates a form of natural behaviour. In his book Ottomans, author Andrew Wheatcroft describes the holy, enchanted and powerful atmosphere created by Alems:

"When the sacred banner of the Prophet was removed from its forty silk coverings in its chamber at the heart of the palace and, unfurled, was carried slowly through the outer courts, men bowed before it as in prayer, calling on the name of Allah. ...They [banners] reminded the Faithful that the Prophet himself had fought against unbelief; under his banner, those who died in battle would pass straight to paradise. ${ }^{313}$,

I plan to reflect this military effect, by displaying it in my works. These straight, free-standing forms arranged in a regimented formation, either side by side or facing one another, may appear monotonous if they were not separated by size and detail, giving individual character to the forms. The desired visual image is to present the individuality of each form in the contrived arrangement to the audience. Naturally therefore I desire to install my works in a narrow, corridorlike space. (Figure 142) This space will draw the audience in and encourage them to continue through, this allows the audience to interact with the work as they inspect it. The calligraphy is dominant for those who understand it as it makes them feel a member of the community which the symbols represent. After the exhibition in Karachi a member of the audience became so emotional that he said he wanted to pray, another especially admired the bridge between the material and the forms: 


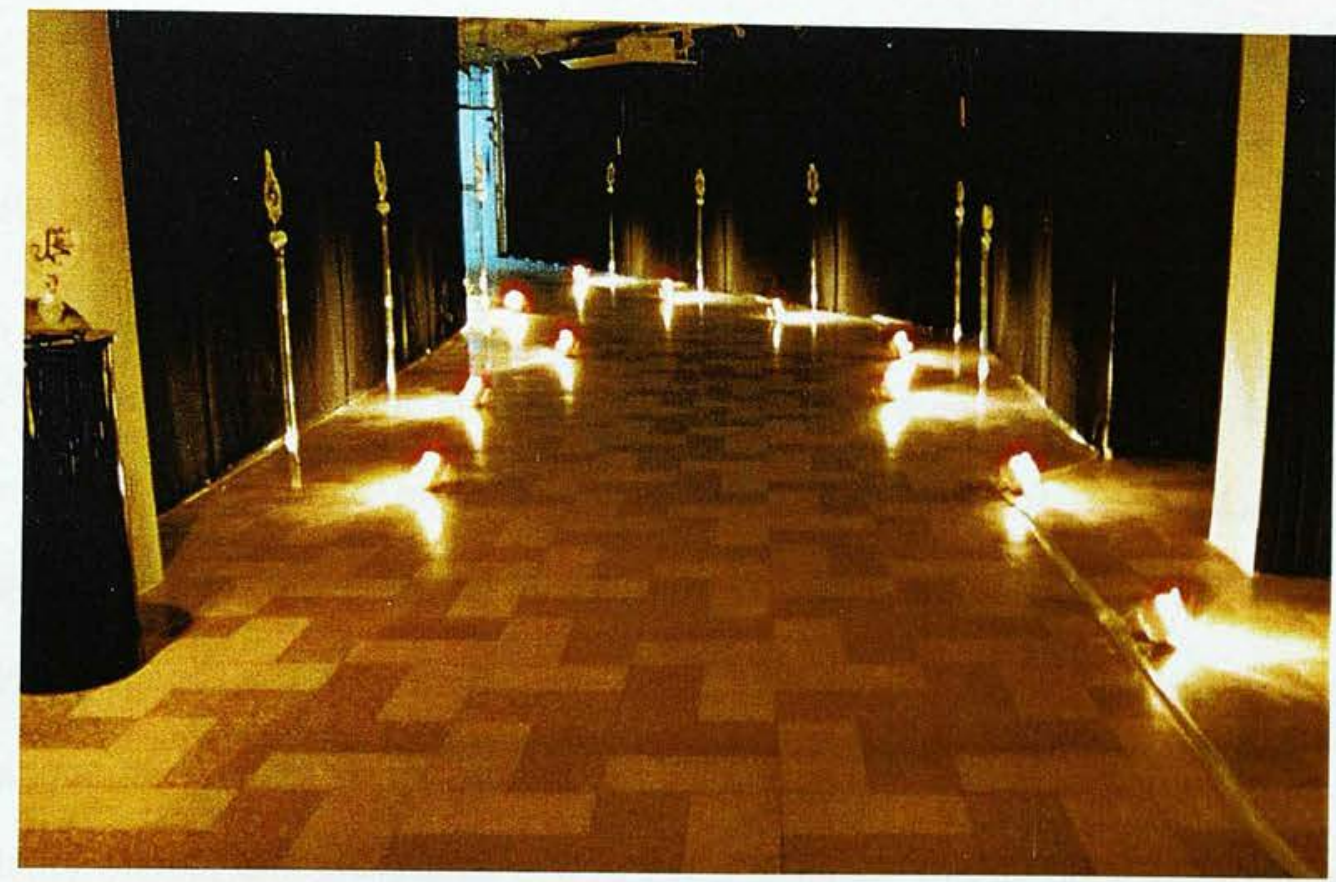

Figure 142

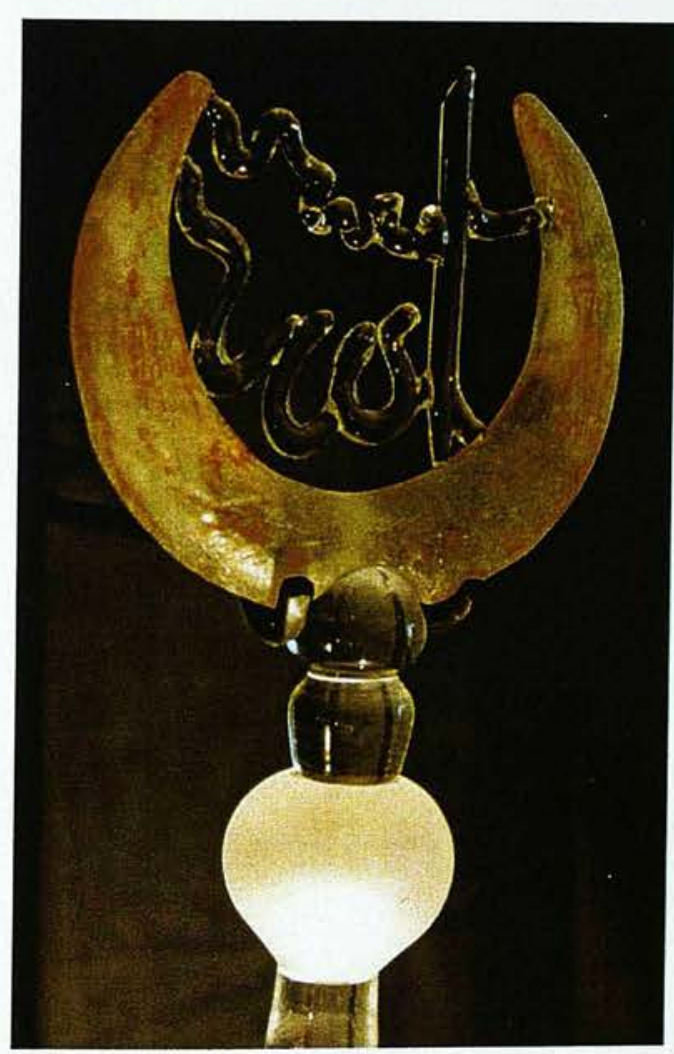

Figure 143

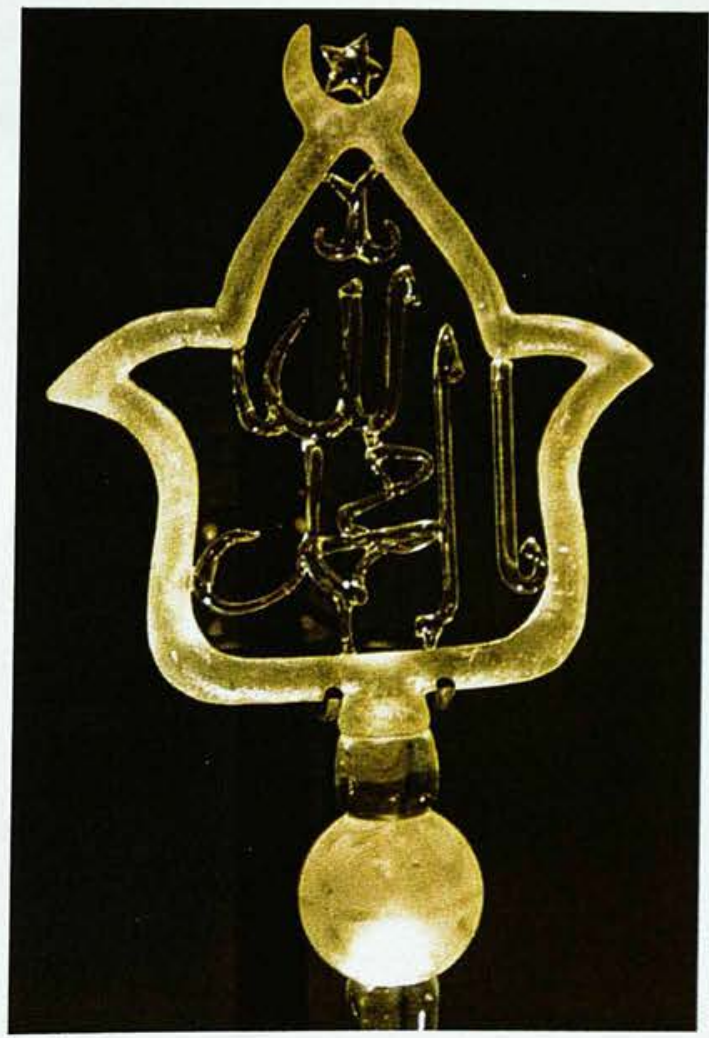

Figure 144 
"...How fortunate to be able to create such beauty in a medium that enhances the object $^{314 "}$.

This is indicative of the successful fruition of my ideas in regards to the atmosphere that I hoped to create.

The place of calligraphy in my works is as important as the other two elements. In the Turkish language, following the Atatürk reforms, the use of the Latin alphabet took the place of Arabic letters. Even though nowadays both the government and the public use modern Turkish, Arabic as the religious language of Islam is not unusual to the populace. Turkish calligraphic art has many effects and influences and is still a powerful and admired component of society. When this calligraphic art was used on the Alems, containing verses from the Koran, the aim was to express how with the help of God victory was at hand. At the beginning, the focal point of my work was the denominational Alems. For this reason, the names of Allah, Muhammed and Ali are the most commonly written. (Figures 143 and 144) The close relationship between the Islamic religion and the calligraphy and their interaction is summarised clearly in an anecdote by Caliph Ali:

"The art of calligraphy is hidden in the teaching of the master,

its essence is achieved through repetition,

and it exists to serve the religion of Islam. ${ }^{315 "}$

314 V. M. Art Gallery, Karachi, Marching On, exh. notes, 1999. Comments made by Abdulkadir, A.

$315 \quad$ Petsopoulos, Yanni, Ed., Tulips, Arabesques and Turbans, Decorative Arts from the Ottoman Empire (London, 1982), p 160. 
Ottoman Alems are different from denominational Alems, as such they are generally dedicated to the Sultan and aim to form his Tuğra ${ }^{316}$ in a skilful and beautiful manner. (Figure 145) Similarly, with the purpose of reflecting the Sultan's wealth and power, valuable jewels and metals were used.

In Turkish crafts of the past, even objects whose function was negligible, there was still great attention to detail and decoration. This is a mark of the extraordinary respect shown to each individual object. For example, tools known as 'Makta', which are used whilst sharpening the calligraphy pens to prevent the sharpener becoming blunt on the surface beneath ${ }^{317}$, are made from Ivory, bone or metal and are incredibly delicate in their ornate beauty.

(Figure 146) This same sensitivity is also at the forefront of the designs of Alems.

Therefore, my purpose in choosing Alems as my theme is to lay their forgotten beauty and functional value open to the contemporary eye. It is not strange that Alems should come to life in the calm dignity of colourless glass, the variety in surface produces a contrast in the light reflecting through the piece and this attracts the eye. This reincarnation shows glass to be the most appropriate material to re-state the splendour of these forms.

Calligraphy in its concept is timeless ${ }^{318}$, it successfully reflects the past, and the perception of its more recent heritage can be overlooked. The classic application of calligraphy in my work is balanced by a contemporary arrangement. The narration is in connection with the present, but the content is

316 Derman, Uğur M., Letters in Gold- Ottoman Calligraphy from the Sakıp Sabancı Collection, Istanbul (New York, 1998), pp 37-38. The Tuğra a calligraphic emblem or treatment of the reigning sovereign's name that would be official so long as that sovereign remained on the throne. The earliest example is the simple tuğra of Sultan Orhan Gazi (reign 1326-59).

317 Çağman, Filiz and Aksoy, Şule, Osmanlı Sanatında Hat (Istanbul, 1998), pp 24-25.

318 Petsopoulos, p 170. 

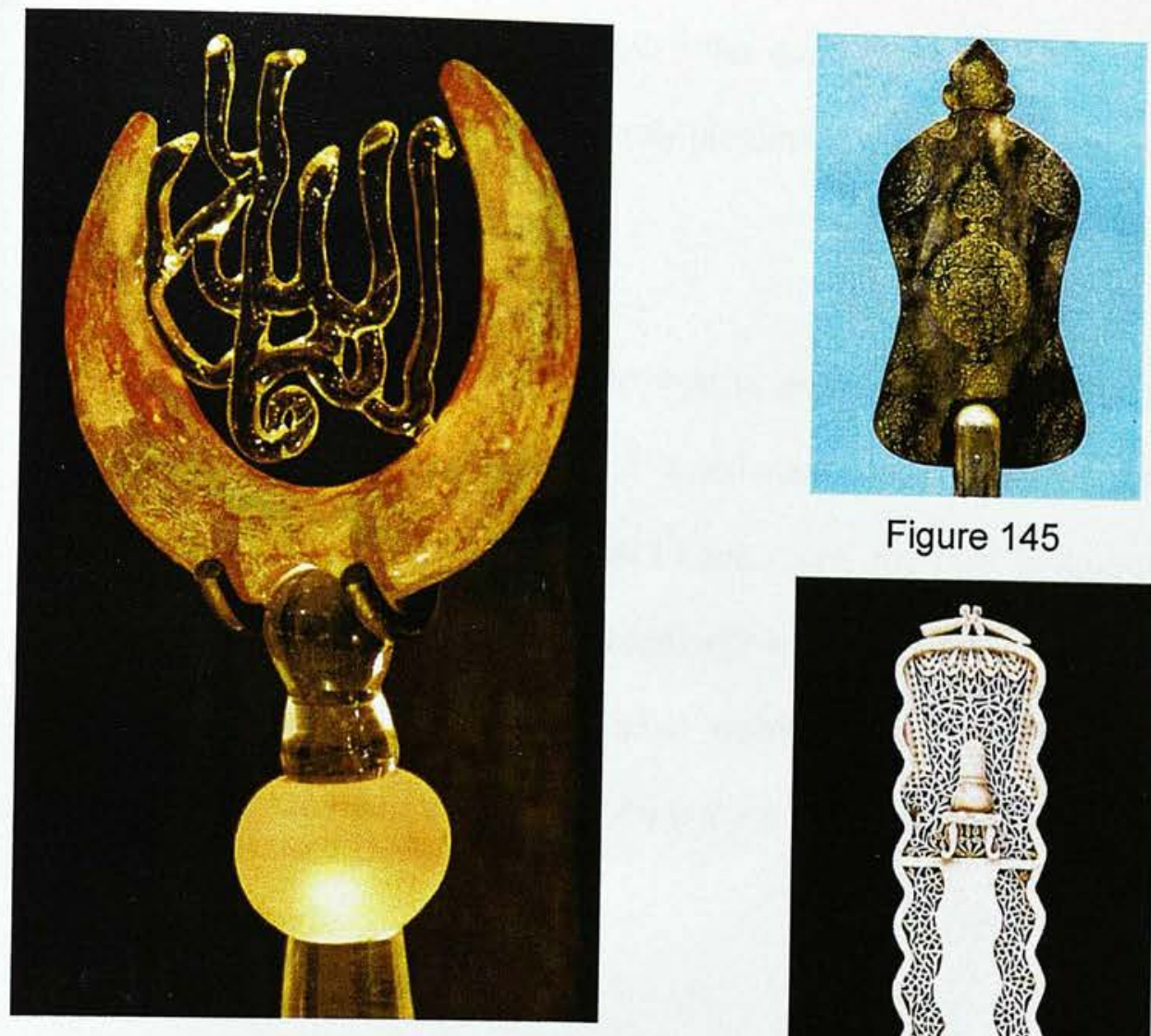

Figure 145

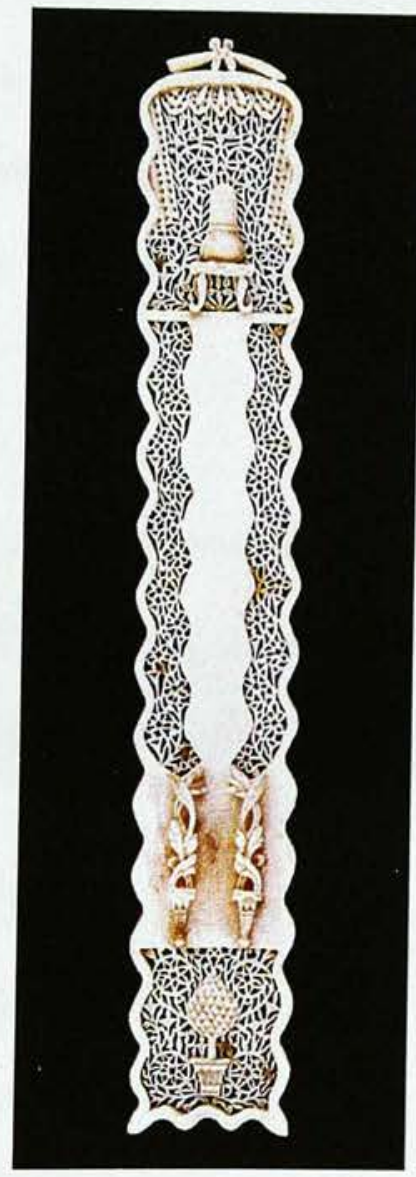

Figure 146
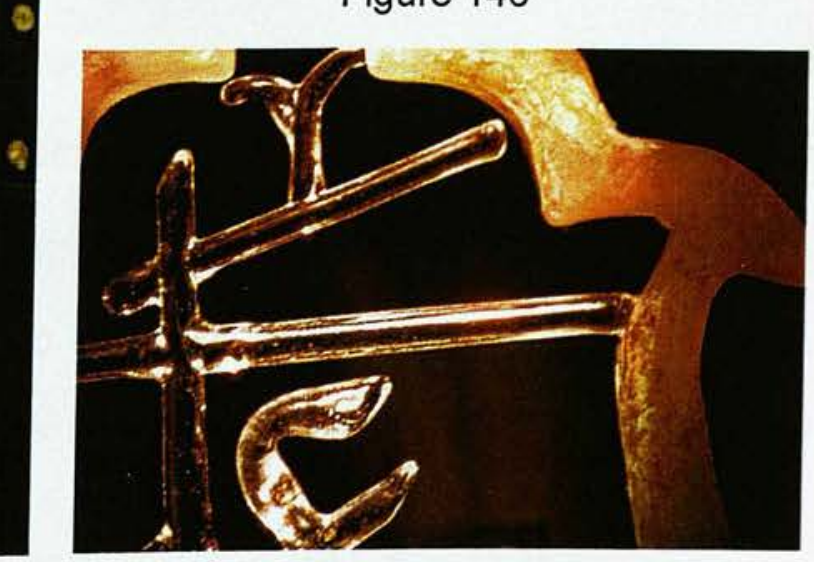

Figure 148

Figure 149 detail 
from the past. This does not demolish the context, but moulds it into a form close to modern values and then gently disturbs it. (Figures 147, 148, 149 detail and 150)

In previous years I have been interested in animal figures and organic forms and in the showing the effects of weathering and decay in these forms. However with my current work I feel I have found my own language and they are the transmission of my ideas. I realised here that I had come to a fork in my journey of discovery. Upon their initial viewing, the works exhibit a definite cultural basis, however when they are put into context with one another this is enhanced.

The works are powerful in their devoutness, also they hold a powerful artistic meaning, with the use of light and an aesthetic approach. Lighting also plays an important role in the works. In connection with religion, there is great importance placed on the use of light in Mosques and on its introduction into the building ${ }^{319}$. The awareness and belief in the existence of God is strengthened by the magnificent contrasts of light and shade. On this point, the shadows created in my works by the calligraphic writings add another dimension to their meaning. The lighting, from the floor, and at a specified distance, angle and power gathers directly onto the forms, in the darkened atmosphere this effect draws all attention to the pieces. (Figure 151) It does not however stop here, the background is also dark and the shadows are reflected with sharp edges and increased organic dimensions onto the walls, each rising up with greatness, these shadows increase the visual effects of the Alems. A slightly unearthly 

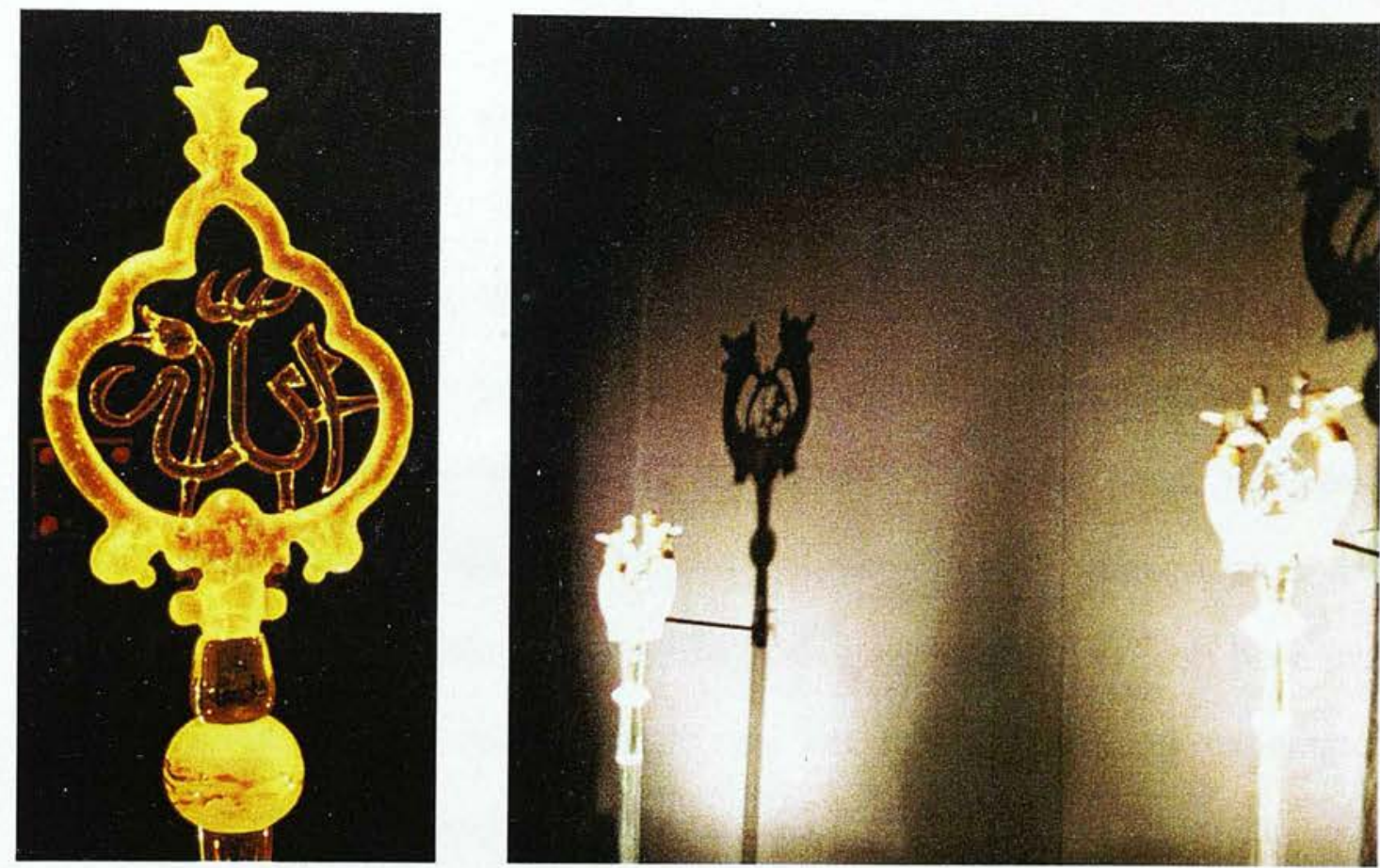

Figure 150

Figure 151

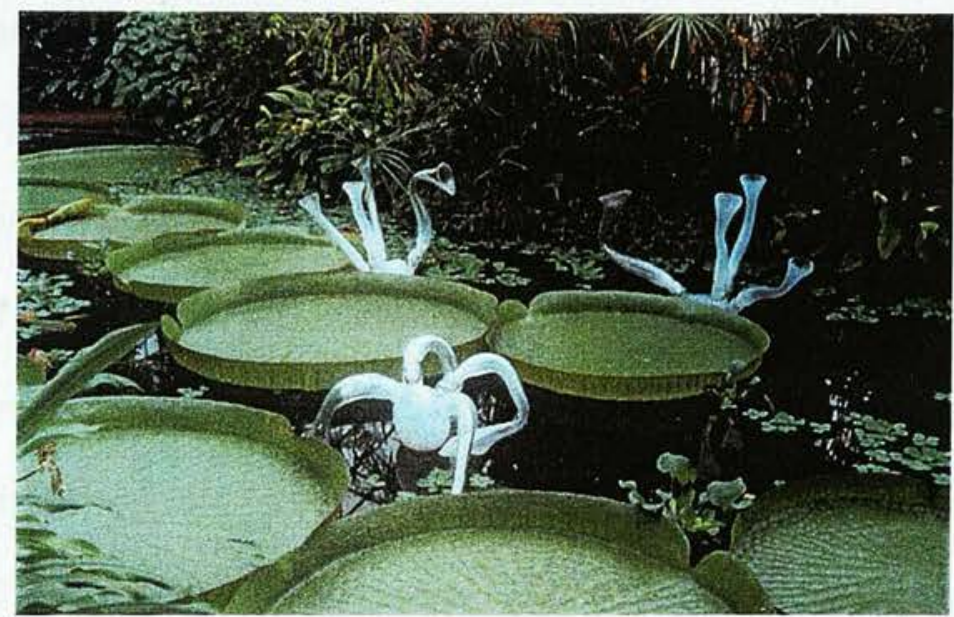

Figure 152

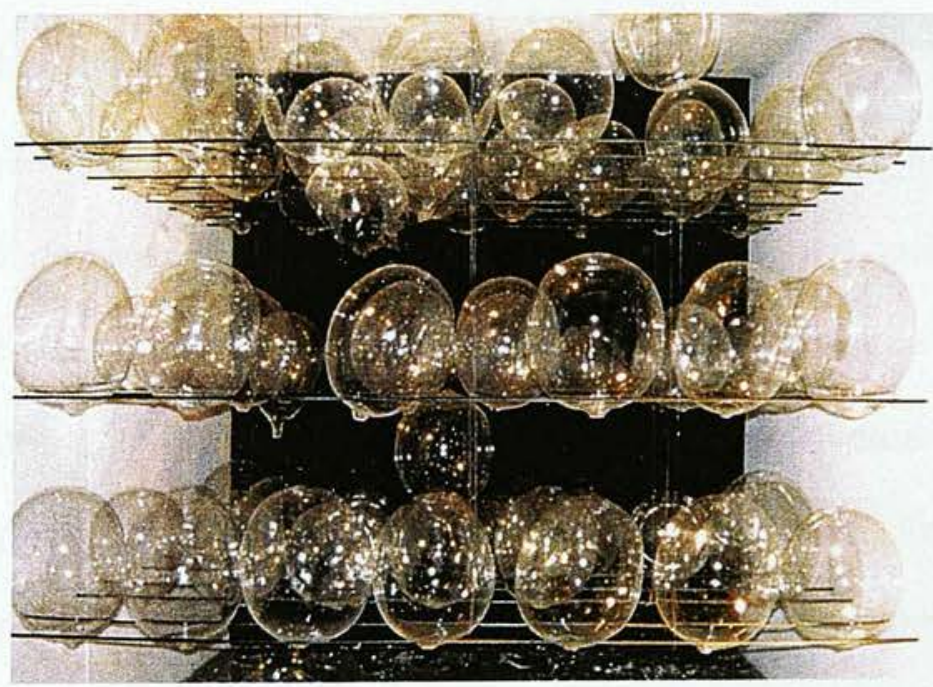

Figure 153 
effect. The visual contrasts created by the use of different textures and qualities of glass are enhanced by the play of light on the glass.

The discovering the use of glass as an art material requires much time and energy. The glass artist must be enthusiastic, selfless and resolute, these form an important triangle for the artist in his attempts to master glass. For years working with clay and experimenting with specific glazes, regardless of the chemical and physical differences between clay and glass, has been beneficial in developing an early maturity with the knowledge, skill and experience gathered in technique and in application. Studying in Britain, under the wellknown glass artist, Ray Flavell, has afforded me the possibility to work in a country where the use of glass as an art material has been considered its forte for a long time. Its artists are internationally renowned and numerous objects are displayed in exhibitions up and down the country. Here, through the eye of a teacher, I have found the opportunity to make comparisons between the application methods of the education, taking the art into consideration, and the interaction between the student and teacher and then evaluated the point reached at the end. I have been influenced by Tim Morgan's plasters and sands eroding between two sheets of glass; by Anna Norberg's electrical chairs; Colin Rennie's other worldly organic forms (Figure 152); and Steffan Orlowski's giant bubbles (Figure 153). However, in my own forms, I did not want to and I did not give up the dominating factor of my own traditions and culture. In Turkish culture there are some deeply ingrained elements, it is possible to narrate these with glass, this entrusts them with another meaning and value. Turkish society has a deep-rooted heritage and historically grand past, these values are priceless, and the society has to own them and afford to them their deserved 
position. I consider myself as one of the starting points for contemporary Turkish glass art. Hundreds of years ago great importance was given to glass and objects made from glass, mosques were lit with it, as were Turkish baths, Turks have drunk şerbets out of it, they have sprinkled rose water from it and they have decorated the path of Sultan with it. All these uses have been sieved through hundreds of years and during this time glass has maintained its identity, nowadays, this identity must be regained with the attentions of artists, like myself, who bring contemporary interpretations to the narration of glass and reclaim its spirit. The success of the application of this interaction, hopefully in the near future, will place Turkish glass art into a unique position in contemporary glass art. 


\section{CONCLUSION}

In glass, it is clear from the examples of, design, decoration, application and its field of use and understanding that both the Seljuks and Ottomans had a distinguished historical identity, which has been preserved until today. As in other areas of the crafts, Turkish glass art has its own specifications which belong to its own periods, and these have harmonised with the structure of the societies that took the place of those which went before and have affected one another. From one side, traditions and cultural concepts have to amalgamate with social, economical and political structures of this period. On the other hand, the glass pieces which take into consideration external influences and gel with their style have been left to follow a natural line of development.

In Turkey, a form of glass art has existed for hundreds of years: this was through the relationship between master and apprentice and this has not been sufficient to beget contemporary glass art. For the continuation of an art form it is necessary to develop with a contemporary style and for this to take place it requires the structure of an academic environment. Glass art necessarily develops interacting with its society and its existing social and cultural sources, this process completes its structure. Likewise, the skilled and innovative artists involved in this venture need to adapt their art to the cultural and social structures of their community. After society accepts the ideology as its own, and following its progression into the stage of application, its place in history is confirmed. This is then part of the cycle, which goes on to provide a source for the concepts which come afterwards. 
Simultaneously, this education must not restrict itself in only one institution, but needs to be spread, bringing differing views, styles and understandings of art onto the agenda, through cross-fertilisation. The direction of the bestowed continuity and development, in regards to finding moral and financial support needs to have the existing potential emphasised and given life.

The subject at hand in this study, the spread of the studio glass movement in America, which began with Harvey Littleton, is only one aspect of the phenomena. Of course, this movement was by no means instigated in a single moment, nor did it remain in a single country. The elements at the core of the foundation of this movement lie in the glass making traditions and their mutations over time of both North America and Europe. Points which commanded thorough investigation were the analysis of the world-wide effects of the movement, necessarily done on a country by country basis, and also the glass art that was already in existence during the half century before this movement started which prepared the foundations for its development.

The economic politics of glass making naturally acquired a different character through the passage of time. Glass developed from a material which satisfied the needs of daily life into a medium for art. From the point of view of reaching this understanding a country must arrive at an understanding of consumer culture. Turkey lacks the supply and demand for glass, these necessarily must be in balance with an interaction between them. In modern Turkey within the glass market there is liveliness around imported glass, proving that there are potential buyers and that the public has an involvement in this material. If strong foundations are made in education to govern the use of glass as an artistic 
material, then the students who develop from this base will become glass artists. The various styles and techniques developed uniquely by these artists will ensure the presentation of glassworks to the public which address different visual tastes and interests. Each society already has foundations based on tradition, and after being visual and educationally satiated it will find an approach to glass as an art material and create a place for it within its own structure. In addition to this, Turkey has an existing glass industry orientated towards mass production. This industry is devoted to quantitative production, the correlation between these two factors illustrates its criteria on a spending and earning relationship. A company of such scale will make artistic investments in the form of studio glass, however the income from this will be inconsequential and as such the company must defer to earning in terms of prestige and make only strategic investments. Those responsible for these investments by necessity reach the same visual and educational maturity as does society. On this point, giving glass education an academic surrounding in order to instigate its growth and prepare an environment is of utmost importance. Those who maintain an interest in glass and the artists educated in it will bring a new approach to glass art education and will provide different directions for thought on the structure of glass education. In time this will provide the grounds for the acceptance of and the settlement for the desired understanding of glass art.

I have prepared this study as a glass artist; it therefore takes a different approach to other previously completed works on Turkish glass art and I hope it shall prove useful for those undertaking further study. The furthering of glass art in Turkey is dependant upon its establishment in education, it is beneficial to 
look at the evolution of the glass movement in the USA and its progression to other countries, in order to assess those elements which may be transposed to Turkey and the points which it is necessary to develop in a more Turkish context. The contributions I will make to the development of students in an institution of art will be directed by my own personal works and in the future the dawning of new horizons for glass artists educated in Turkey will make me very happy. 


\section{APPENDIX A}

\section{A LIST OF GLASSWARE}

This list of glassware ${ }^{1}$ consists of the produce of the Ottoman Empire, sent for 'The Great Exhibition of the Works of Industry of All Nations 1851' by the Central Committee of Constantinople, on the part of the Ministry of Commerce (and by the order of the Sublime Porte).

This collection of upwards of 3300 objects is arranged under the several divisions of the Vegetable, Animal and Mineral Kingdoms, and into two general classes of Raw Materials and Manufactures. The numbers are not serial, but continuous, and each article is separately labelled.

(1448-1453) Glass porringers, with saucers and covers. Manufactured at the Imperial Glass House of Indgirkeny, Constantinople. Glass cups

$(1499,1500)$ Glass porringers and saucers

(1501, 1503) Narguilé, glasses and plates

(1504, 1505) Glass jugs

$(1506,1507)$ Glass Hash-ab, or sherbet bowls, with covers and saucers

(1508) Crystal decanter and glass. Manufactured at The Imperial Glass House of Indgir-keny, Constantinople.

(1980)

Window glass-Manufactured at the Glass-House of Groseshli. 


\section{APPENDIX B}

\section{OPACITY AND OPACIFIERS}

Opacity $^{2}$ is the result of light interference inside and at the surface of a glaze or glass. There are three different ways of achieving this and some oxides give opacity by a combination of effects. The popular opacifier is one which does not dissolve in the molten substance but remains as suspended isolated oxide particles. In the following diagram these effects are considered as three areas of the periodic table and they involve oxides and individual elements. The refractive index of the suspended particle must differ from that of the glass phase and irregularly shaped particles are the most effective. The particles may be a finely divided raw material that has not related and dissolved. Opacity increases as the difference in the refractive indices of the glass increases and the dispersal phase becomes larger.

Bone Ash: This is one source of Calcium Phosphate. It is used as a flux in bodies where the calcia does the fluxing and the phosphorus pentoxide acts as a glass former in the melt and also checks over rapid fusion. Bone Ash is produced from thoroughly cleaned bones, which are then finely ground. The process involves the cleaning of the bones followed by steam treatment to remove the fat. After washing the bones are then calcined in an air steam sufficient to ensure complete oxidation of any remaining organic matter. The calcined bone ash is then ground, usually in wet pans. Afterwards the clear liquid is decanted and the remainder dried in flat kilns. Bone ash contains $67 \%$

$2 \quad$ The valuable information collated in Appendix B was provided with kindness by Prof. Dr. Zeliha Mete. Correspondence on 21. 02. 2000, Dept. of Chemistry, Dokuz Eylul University, Izmir, Turkey. 
to $85 \% \mathrm{Ca}_{3}\left(\mathrm{PO}_{4}\right)_{2}, 3 \%$ to $10 \% \mathrm{Ca} \mathrm{CO}_{3}, 2 \%$ to $3 \% \mathrm{Mg}_{3}\left(\mathrm{PO}_{4}\right)_{2}$ and a little caustic lime $\mathrm{CaF}_{2}$. Bone ash is used in glass as an opacifier. In spite of its large percentage of calcia its fluxing action is checked somewhat by the phosphorus pentoxide $\left(\mathrm{P}_{2} \mathrm{O}_{5}\right)$ which produces a stiff melt. It can be used to assist tin oxide so that less tin oxide is required.

Tin Oxide: Tin dioxide, Stannic oxide ( $\mathrm{SnO} 2)$. There are two types of tin oxide. They are the white dioxide ( $\mathrm{SnO} 2)$ and the black monoxide $(\mathrm{SnO})$, Stannic and Stannous oxides. Both oxides give opacity to glazes and glasses. Both are practically inert below $1150 \mathrm{C}$ being finely divided particles and having a refractive index different from the surrounding glass. The white tin oxide gives a pleasing creamy white opacity. The amount required varies according to the composition and the temperature. The black tin oxide gives unpleasant grey cloudiness to a glass. Tin oxide is a popular white opacifier in spite of its high price. It holds its place because it gives a more pleasant opacity than its cheaper rivals. For example calcium phosphate, used as an opacifier sometimes turns grey and even brown.

Zinc lons: Increase the formation of nuclei so that a large number of small particles can form and produce high scattering power.

Calcium Phosphate: [Ca3(PO4)2], the most probable opacifier in phosphate opaque glasses. 
Zinc Phosphate: [Zn3(PO4)2], under the light of the above mentioned information, the opacification power of Zinc phosphate becomes noticeable and an economic opacifier. 


\section{APPENDIX C}

VETRI A FILI GLASS BLOWING TECHNIQUE
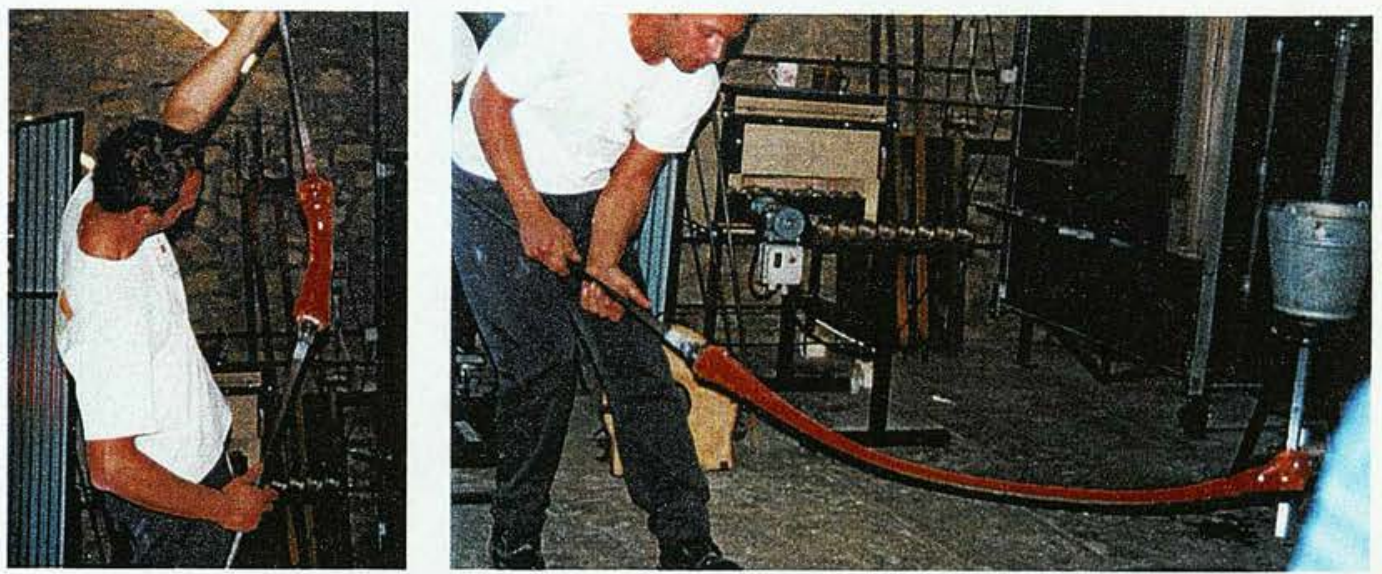

Figures 1 (a) and (b) : Pulling glass canes. Each coloured cane is coated in clear glass, this insures the seperation of each line.

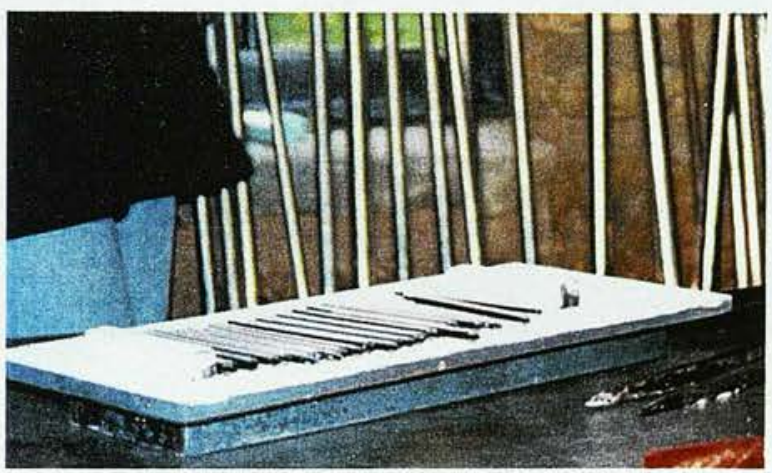

Figure 2 : Lengths of glass canes are laid side by side on a flat surface and heated, in the furnace or in the glory hole. A prepared gather of glass is then rolled in one direction across the end of the canes, resulting in a tube.

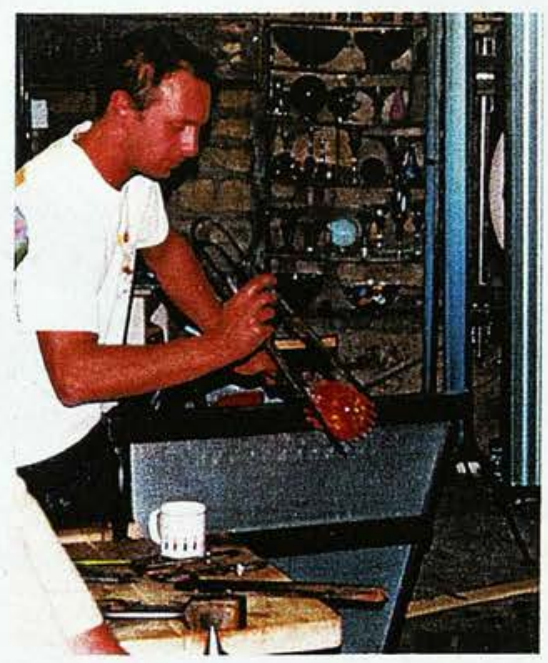

Figure 3 : End of the tube is closed with the jacks prior to blowing into further manipulation. 


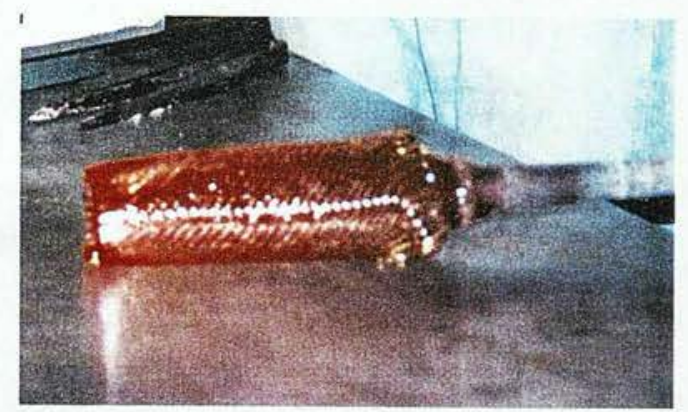

Figure 4 : Next, they are smoothed and cooled on a marver.

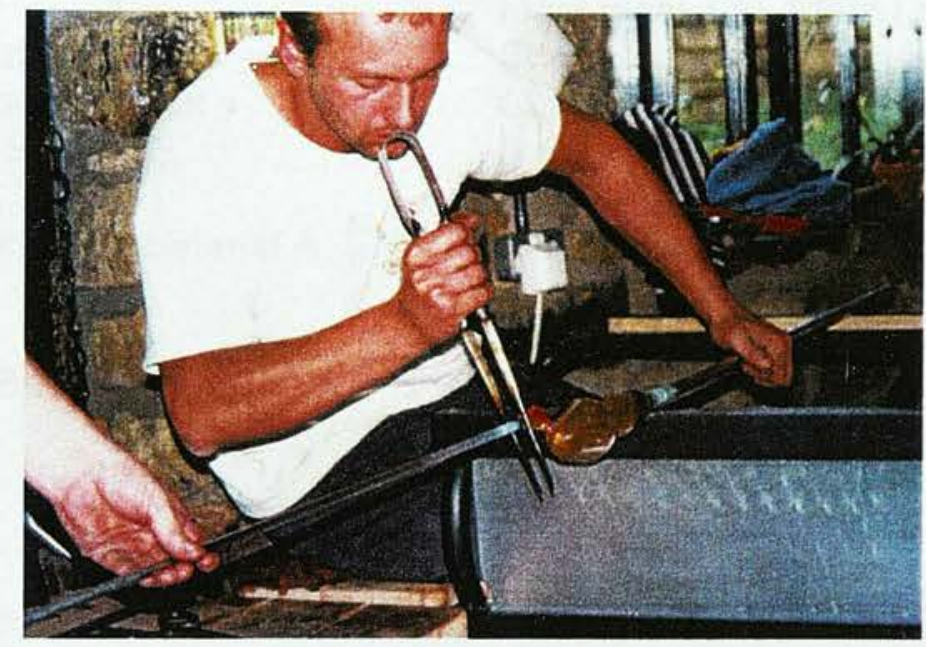

Figure 5 : After reheating, the bubble is blown and its shape formed, extra elements are added to the object. e. g. stem, foot.

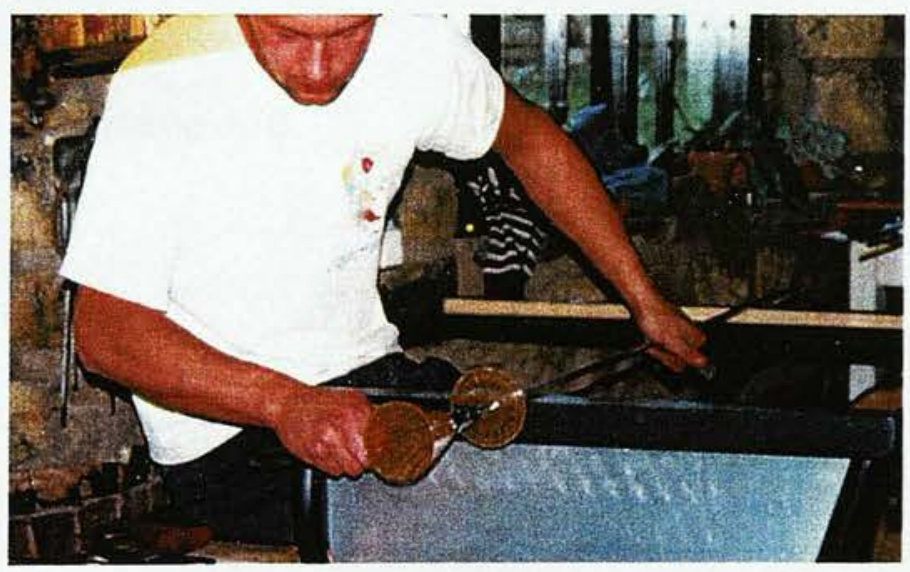

Figure 6 : The piece is then finished to its specific design, in this case it has been blown and a stem and foot added to form a goblet. 


\section{TURKISH GLASS INDUSTRY}

\section{Flat Glass Business}

\section{Companies}

Trakya Cam San. A. Ş.

Trakya Plant

Otocam Plant

Mersin Plant

Çayırova Cam San. A. Ş.

Kaplanma Camlar Plant

Cam Işleme San. A. Ş.

Camtaş Düzcam Pazarlama A. Ş.

\section{Products}

Float glass ( I. II Float Line)

Automotive glass

Float glass (III. Float Line)

Sheet \& patterned glass

Climate \& solar control glass

Safety \& security glass, insulating glass, mirror

Marketing Company

\section{Packaging Business}

\section{Companies}

Topkapı Şişe San. A. Ş.

Topkapı Plant

Çayırova Plant

Anadolu Cam San. A. Ş.

Camiş Ambalaj San. A. Ş.

Tezsan Takım Tezg. San. ve Tic. A. Ş.

Ferro Döküm San. ve Tic. A. Ş.

Camiş Makina ve Kalıp San. A. Ş.

Cam Ambalaj Pazarlama A. Ş.

\section{Products}

Glass containers

Green bottles

Glass containers

Paper \& cardboard packaging

CNC machine tools

Nodular cast iron

Moulds for glass containers \&glassware

Marketing Company for glass

containers

\section{Glassware Business}

\section{Companies}

Paşabahçe Cam San. ve Tic. A. Ş.

Paşabahçe Plant

Kırklareli Plant

Mersin Plant

Denizli Cam San. ve Tic. A. Ş.

\section{Products}

Marketing company

Machine and hand-made glassware, lead crystal

Mechanical glassware \& borosilicate glass

Mechanical glassware

Hand-made crystal ware 
Paşabahçe Perakende Satış. Ltd. Şti. Retailer of glassware

Paşabahçe Schott Cam San. Tic. A. Ş. Mechanical glassware

\section{Chemical Business}

\section{Companies}

Soda San. A. Ş.

Soda Plant

Kromsan Plant

Cam Elyaf San. ve Tic. A. Ş.

Camiş Madencilik A. Ş.

Camsar San. Ana Malları Paz. A. Ş.

Mitracam Plastik San. ve Tic. A. Ş.

Oxyvit Kimya San. ve Tic. A. Ş.

Şişecam Bulgaria Ltd.

\section{Services Companies}

\section{Companies}

Cam Pazarlama A. Ş.

Camiş Menkul Değerler A. Ş.

Camiş Sigorta Hizmetleri A. Ş.

Camiş Elektrik Üretimi Otoproduktor

\section{Products}

Soda ash

Chromium chemicals

Glass fiber reinforcements (mat, rovings chopped strand) polyester, gelcoat

Sand, limestone, dolomite, feldspar mining

Marketing company for soda ash \& chromium chemicals

Glass-reinforced plastics

Speciality chemicals for animal feed Representative office

\section{Products}

The Group's foreign trade company

The Group's securities company

The Group's insurance company

The Group's power generation company 


\section{APPENDIX E}

\section{HARVEY LITTLETON'S GLASSMAKING FAMILY TREE}

The input of Harvey Littleton was influential in the spread of the Studio Glass Movement, the spark he ignited was important to its development and later on the philosophy of this movement made its foundation in the academic environment. The works done with this philosophy in mind started to bear fruit. Hundreds of students who are interested in glass come from different branches of art and various academic units and through their experiments to find new uses for glass as an artistic medium, they bring many different approaches and contributions to glass. The dispersion started with the students and the artists who attended Harvey Littleton's workshops in March and June of 1962. It picked up speed with the course at the University of Wisconsin, in Madison, during September 1962. The graduates, from these workshops and courses, spread to different art schools around the country and began to form and shape glass art education.

I have compiled this family tree over the period of my studies as an aid to myself and to others wishing a clear over view of the dynamics of the spread of influential individuals involved in the studio glass movement through various institutions. I found it necessary to accumulate this data myself, as there was no comprehensive or lucid work on this subject. The most important point to be considered in the formation of this family tree is its systematic and chronological structure and its provision of a source which can be qualified in an historical context. For this reason, I decided that the starting point of the overall structure should be Harvey Littleton, below him on the next tier are the engineers and artists who supported him through the initial formation of the Studio Glass 
Movement. This second tier comprises the team which worked with Littleton and formed the core idea of teamwork in glassblowing, which has since been widely accepted as the natural process of working with glass in contemporary glass art application. This structure can be expanded and developed with the amalgamation of the hundreds of students which graduate from art schools each year. However, the purpose of this family tree is to show both visually and methodically the beginnings of the American studio glass art movement. In this way therefore, beginning with the first workshop and listing the names of artists it is possible to see developments and directions taken towards the establishment of other workshops especially in the direction of educational and academic advancement. Next, the process continues from this stage to the other tiers below these artists. After the 1963-64 academic year, following the rapid spread of this movement on both national and international basis, it is difficult to keep track of all these involved. Nevertheless, a couple of names stand out as being very important. Therefore, the family tree continues up until 1970 with a long interval between 1964 and 1970 in order to include these artists.

On the subject of Harvey Littleton and the glass family tree, this research study, in regards to American glass, has placed great dominance upon it and the period of time over which it has developed. For the completion of the details which are missing and for them to be gathered it will take someone living in America or the artist himself, who was involved in the development of this movement. It needs to be reduced to the level of an individual as some of the data does not exists in the currently available sources, likewise, when it is present examples differ from source to source, compounding its unreliability. It 
therefore needs to be confirmed by the individuals involved in order to provide conclusive proof. This has a depth which can create another research subject on its own. However, in order to form a qualified starting point and from the angle of providing a source for people who are interested in the subject, this family tree is important to provide further information on the subject. 


\section{LITTLETON, HARVEY}

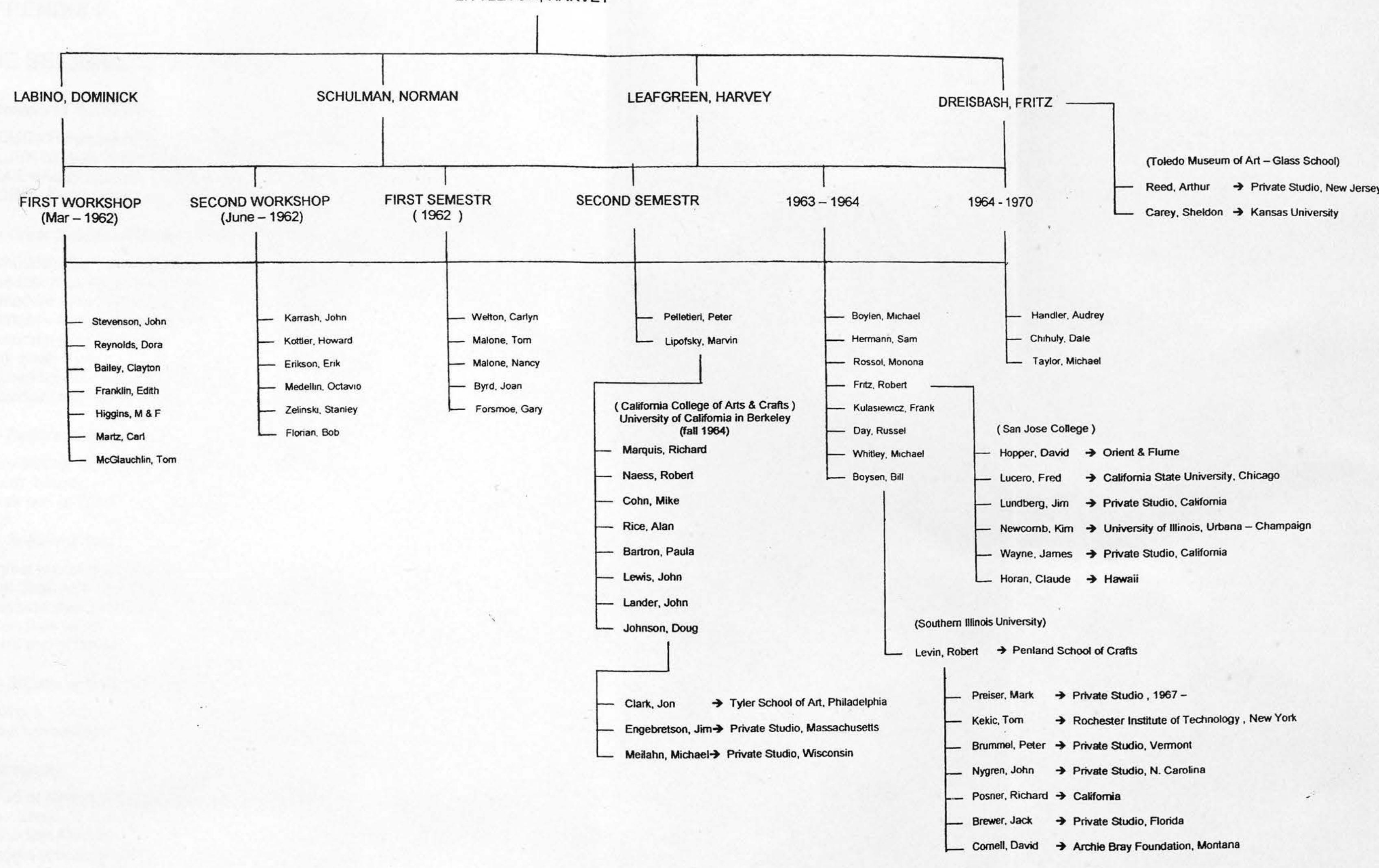




\section{APPENDIX F}

\section{THE SELJUKID DYNASTIES ${ }^{3}$}

Ancestors of the Seljuks

TUQUQ=Tımuryalık=Paighu=Yabghu

SELJUK his son; died at the age of 107

ISRAIL=Paighu Arslan, his elder son, end Mikail, a younger son.

TÜGRÜL BEY, Çagri Beg (died in 1061), Ibrahim ibn Inal, sons of Mikail.

The Great Seljuks of Persia, 1037-1157

Ruknûddin Abu Talib Tügrül

Adueddin Abu Saça Alp Arslan

1037-1063

Celaleddin Abul Fath Malık Shah

1063-1072

Nasireddin Mahmut Bargiyaruk

1072-1092

Ruknûddin Abul Muzaffar

1092-1094

Malık Shah II and

Giyaseddin Abul Saça Muhammad

1094-1104

Müizeddin Abul Marit Sencer

1104-110?

1117-1157

The Seljuks of Syria

Tutuş brother of Malık Shah of Persia

? -1095

Ridwan his son

1095-1113

Dukak son of Tutuş

1095-1103

The Seljuks of Iraq

Mahmut proclaimed ruler by Sencer

1131-1134

Malık Shah and Muhammed

1134-1152

Süleyman their brother

$1152-1159$

Arslan their uncle

$1159-1175$

Tügrül son of Arslan

$1175-1194$

The Seljuks of Rum 1077 to about 1308

Kutulmus

$?-1064$

Suleyman his son

1077-1086

Interregnum

Davud or Mahmud Kılıçarslan

1092-1107

Melık Shah

1107-1116

Ruknûddin Mesud

$1116-1156$

Izzeddin Kılıçarslan II

$1156-1188$

Gıyaseddin Keyhüsrev

Ruknûddin Süleyman Shah

$1192-1196$

$1196-1203 / 4$

Izzeddin Kılıçarslan III

1204- ?

Gıyaseddin Keyhüsrev I

$1204-1210$ 
The Triumvirate consisting of Keyhusrev II's Three Sons

Izzeddin Keykâvus ||

Ruknûddin Kılıçarslan IV

Aleaddin Keykûbad II

Gıyaseddin Keyhüsrev III

The Mamluks entered Konya in 1277

Gıyaseddin Mesud II

Aleaddin Keykûbad III

Glyaseddin
1246-1283?

1246-1264

1246-1257

$1264-1283$

The Beyliks which sprung up in Asia Minor after the Collapse of the Seljukid Sultanate of Rum
AYDIN
C. $1300-1403$
ÇANDAR
c. $1292-1406$
DÜLGADIR
c. ? -1373
ERTENA
c. $1335-1381$
EGREF
c. $1299-$ ?
GERMIYAN
c. $1303-1429$
HAMID
c. $1300-1426$
ISFENDIYAR
c. $1385-1459$
KARAMAN
c. $1256-1483$
MENTEŞE
c. $1380-1425$ ?
RAMAZAN
? - ?
SARUHAN
c. $1300-1410$
THE OSMANLIS
Late $13^{\text {th }}$ century onwards

\section{OTTOMAN SULTANS ${ }^{4}$}

Osman Gazi
Orhan Gazi
Murat I
Beyazıt I
(Interregnum)
Mehmet I
Murat II
Mehmet II
Beyazıt II
Selim I
Süleyman I, The Magnificent

Osman Gazi

reigned

1282-1326

1326-1362

1362-1389

1389-1402

1413-1421

1421-1444, 1446-1451

1444-1446, 1451-1481

$1481-1512$

$1512-1520$

$1520-1566$

\footnotetext{
4 Mansel, Philip, Constantinople- City of the World's Desire, 1453-1924 (London, 1995), p 439 and Freely, p 335
} 
Selim II

Murat III

1566-1574

Mehmet III

1574-1595

Ahmet I

$1595-1603$

Mustafa I

1603-1617

Osman II

$1617-1618,1622-1623$

Murat IV

1618-1622

Ibrahim

Mehmet IV

1623-1640

1640-1648

Süleyman II

1648-1687

Ahmet II

1687-1691

Mustafa II

1691-1695

Ahmet III

$1695-1703$

Mahmut I

1703-1730

Osman III

1730-1754

Mustafa III

1754-1757

Abdülhamit I

1757-1774

Selim III

1774-1788

Mustafa IV

1788-1807

Mahmut II

1807-1808

1808-1839

Abdülmecit I

1839-1861

Abdülaziz

Murat $\mathrm{V}$

1861-1876

1876

Abdülhamit II

1876-1909

Mehmet V

1909-1918

Mehmet IV, Vahidettin

1918-1922

Caliph Abdülmecit II

1922-1924

\section{TURKISH REPUBLIC PRESIDENTS ${ }^{5}$}

Mustafa Kemal Atatürk

1923-1938

Ismet Inönü

Celal Bayar

1938-1950

Cemal Gürsel

1950-1960

Cevdet Sunay

1961-1966

Fahri S. Korutürk

1966-1973

Kenan Evren

1973-1980

Turgut Özal

1982-1989

Süleyman Demirel

1989-1993

Ahmet Nejdet Sezer

$1993-2000$

2000- 


\section{LIST OF ILLUSTRATIONS}

All illustrations and photographs are the work of the author unless otherwise indicated.

1 Crystal structure of an alkaline silica glass

2 Crystal structure of a silica glass

3 Vessel, core moulding method, Egypt, possibly Malqata, $18^{\text {th }}$ Dynasty, (1400-1336 BC), V\&A Museum, London

4 Mosaic glass, eastern Mediterranean, V\&A Museum, London

5 Cameo glass, Portland vase, c. $1^{\text {st }} \mathrm{C} B C / A D$, British Museum, London

6 Cage cup, c. 300 AD, The Corning Museum of Glass, New York, photo Whitehouse, David

7a Luck of Edenhall, enamelled and gilt, Syria, $13^{\text {th }}$ Century, V\&A Museum, London

7b Luck of Edenhall, the leather case, English or French, $14^{\text {th }}$ Century, V\&A Museum, London

8a Beaker, gilt and enamelled, Egypt, probably 1260-77, V\&A Museum, London

8b Beaker, gilt and enamelled, Syria, c. 1300, The Louvre, Paris, photo Dolez, Albane

9 A chunk of glass found in Serçe Limanı, Turkey, $11^{\text {th }}$ Century, Bodrum Museum, Bodrum

10a Vessel, Serçe Limanı, Turkey, $11^{\text {th }}$ Century, Bodrum Museum

10b Beaker, Serçe Limanı, Turkey, $11^{\text {th }}$ Century, Bodrum Museum, photo Özet, Aynur

11 Vessel and detail of a handle, Serçe Limanı, Turkey, Bodrum Museum, $11^{\text {th }}$ Century, photo Özet, Aynur

12 The display of the Serçe Limanı ship and its contents

13 Serpent stemmed glasses, $17^{\text {th }}$ Century, V\&A Museum, London

14 Siphon glass, probably Germany, $17^{\text {th }}$ Century, V\&A Museum, London

15 Opening of The Great Exhibition of the Works of Industry of All Nations, Crystal Palace, South Side, 1851, photo The Illustrated London News 
16 The Great Exhibition of the Works of Industry of All Nations, Crystal Palace, 1851, entrance to the Turkish Department, photo The Art Journal

17 The Great Exhibition of the Works of Industry of All Nations, arms of all nations, 1851, photo The Illustrated London News

18 The Great Exhibition of the Works of Industry of All Nations, pipes and marpitches, 1851, photo The Illustrated London News

19a Sunderland Glass Centre, Sunderland

19b Sunderland Glass Centre, Sunderland

20 Various Ottoman gravestones, photo Inman, Nick

21a Mosque lamp, enamelled and gilt, Cairo, mid $14^{\text {th }}$ Century, the blazon is that of a Silahdar (sword bearer) at the Mamluk Court, British Museum, London

21b Mosque lamp, gilt and enamelled, Egypt, c. 1342-45, made for a building of Kafur al-Rumi, Treasurer to the Mamluk Sultan of Egypt al-Salih Ismail, V\&A Museum, London

21c Mosque lamps, Persian and Turkish, V\&A Museum, London

21d Mosque lamp, Syrian, made in 1313, enamelled and gilt, inscribed with a dedication to Saif ad-Din Qijlis an-Nasiri, arms bearer to the Sultan anNasir Muhammad, British Museum, London

22a/b/c Stained glass windows of Notre Dame Cathedral, Paris

23a/b Stained glass windows of Iskele Mosque, Istanbul

24a/b Stained glass windows of Şemsi Paşa Mosque, Istanbul

25a/b Stained glass windows of Yeni Valide Mosque, Istanbul

26 Miniature, makers of stained glass windows, Sürname-I Humayun, Topkapı Palace Museum Library, Istanbul

27a/b The Crystal Staircase, Dolmabahçe Palace, Istanbul

27c The Crystal Staircase, detail, Dolmabahçe Palace, Istanbul

28 Crystal chair, Dolmabahçe Palace, Istanbul, photo Küçükerman, Önder

29a/c/d Chandeliers and candelabras, Dolmabahçe Palace, Istanbul

29b Chandelier weighing 4.5 ton, Dolmabahçe Palace, Istanbul, photo Yücel, Ihsan

30a/b The staircase, Danny Lane, 1991, Glass Gallery, V\&A Museum, London 
31 The glass kiosk, Dolmabahçe Palace, Istanbul, photo Küçükerman, Önder

32 The glass fountain, Crystal Palace, 1851, photo The Illustrated London News

33 The glass fountain, Dolmabahçe Palace, Istanbul, photo Küçükerman, Önder

34 Alabastron, Anatolia, 6 BC, core moulding, photo Canav, Üzlifat $35 / 36$ Vessels, Anatolia, $1^{\text {st }}, 2^{\text {nd }} A D$, blown, Kütahya Archaeological Museum $37 \mathrm{a} / \mathrm{b} / \mathrm{c}$ Seljuk handcrafts, Anatolia, photo Grube, Ernst J.

38 Kubad-Abad Palace, $13^{\text {th }}$ Century, Konya, photo Aslanapa, Oktay

$39 \mathrm{a} / \mathrm{b}$ Glass plate and detail, decoration of the outer rim of the plate, $13^{\text {th }}$ Century, Konya/Karatay Medrese Museum, photo Öney, Gönül

40a Glass goblet, Mamluk period, c. 1280, photo Carel, John

40b Detail, glass goblet, Mamluk period, c. 1280 , photo Jenkins, Merilyn

41 Boss decorated glass beaker, $13^{\text {th }}$ Century, Anatolia or Syria, Adıyaman Museum, photo Öney, Gönül

42 Bottle, decorated with the name of the Seljuk Sultan "Imad al-Din Zangi", $12^{\text {th }}$ Century, British Museum

43 Humbara pieces, $16^{\text {th }}$ Century, Naval Museum, Istanbul

44a/b Miniature and details, glassmakers, Sürname-i Humayun, Topkapı Palace Museum Library, Istanbul

45a/b Miniature and details, glassmakers, Sürname-i Humayun, Topkapı Palace Museum Library, Istanbul

$46 / 47$ Iznik pottery, $16^{\text {th }}$ Century, photo Carswell, John

48 Glass lamp with lotus flower decoration, Topkapı Palace Museum, Istanbul, photo Charleston, R. J.

49a Caftan with lotus flowers pattern, photo Johnstone, Pauline

49b Iznik bowl with lotus flower decoration, photo Carswell, John

49c Iznik border tiles, $16^{\text {th }}$ Century, photo Wilson, Eva

50 Greek Hydria, 'Pictorial and Plastic Narrations on the Subject of the Production of Ceramics', July 1994, $8^{\text {th }}$ CIMTEC Ceramics Congress, Italy, Paper by the Author and Prof. Sevim Çizer

51 Celebration of the Preston Guild, photo The Illustrated London News

52 Tekfur Palace, Istanbul, photo Revaş 
53 The Helmet made by Venetian goldsmiths for Suleyman 'The Magnificent', photo Levey, Michael

54 Maydanozlu, Beykozware, photo Şentürk, Şennur, Istanbulluoğlu, Ari

55 Vase, Beykozware, photo Şentürk, Şennur, Istanbulluoğlu, Ari

56 Bird forms, Beykozware, photo Şentürk, Şennur, Istanbulluoğlu, Ari

57a Drawings of turbans, photo Nicolle, David and Hook, Christa

57b Covered bowl with turban shaped knob design, photo Şentürk, Şennur, Istanbulluoğlu, Ari

58a Pistol shaped bottle, $17^{\text {th }}-18^{\text {th }}$ Century, V\&A Museum, London

58b Pistol shaped bottle, Beykozware, photo Şentürk, Ş., Istanbulluoğlu, Ari

59 Sultan Abdulhamit I, photo Gouffier, Choiseul

60a Iznik dish, painted with tulip motifs, c. 1520-1550, British Museum

60b Iznik bowl, painted with tulip motifs, c. 1520-1550, British Museum

61a Caftan with tulip design, photo Revaş

61b Caftan with tulip design, photo Johnstone, Pauline

62 Painting by Hendrik Gerritszoon Pot, 'Flora's Wagon of Idiots', photo Lodewijk, Tom

63 Painting by Jan Brueghel, photo Lodewijk, Tom

64a/b Tulip pagodas, photo Lodewijk, Tom

65 Black glass tulip vase, designed by florist Barlow, $19^{\text {th }} \mathrm{C}$, Pavord, Anna

66 Tulip shaped glass form, designed by Bertil Vallien, Kosta Boda

67/68 Coloured glass forms, Beykozware

69 Covered bowl with fruit shaped knob design, Beykozware, photo Şentürk, Şennur, Istanbulluoğlu, Ari

70 Gülabdans, Beykozware, photo Şentürk, Şennur, Istanbulluoğlu, Ari

71 Gülabdans, Beykozware, photo Şentürk, Şennur, Istanbulluoğlu, Ari

72 Çeşm-i Bülbül Jug, Beykozware, photo Şentürk, Ş., Istanbulluoğlu, Ari

73 Çeşm-i Bülbül Dish, Beykozware, photo Şentürk, Ş., Istanbulluoğlu, Ari

74 Venetian latticinio glass dish, Museum of Industrial Art in Prague, photo Hetteš, Karel

75 Whirling Dervishes at the ceremony of Sema, photo Goodwin, Jason $76 \mathrm{a} / \mathrm{b} / \mathrm{c}$ Çeşm-i Bülbül forms from Paşabahçe, Beykoz, Istanbul

77 Rod formed pendant and beads, Mediterranean, V\&A Museum, London

78 Sculptural idols with the eye motif, photo Black, Jeremy and Green, Anthony 
79 Example of an eye bead attached to a child's clothing

$80 \mathrm{a} / \mathrm{b}$ Glass eye beads

81/82 Glass beadmakers, Izmir/Cumaovası, Görece

83 Glass beadmakers' workshop, Izmir/Cumaovası, Görece

84 Empty Rakı bottles for the manufacture of the beads, Izmir/Cumaovası, Görece

85 Some tools for bead making, Izmir/Cumaovası, Görece

86/87 Bead making, Izmir/Cumaovası, Görece

88a/b Decorative beads, Izmir/Cumaovası, Görece

89 Traditional glass bead making furnace, Izmir/Cumaovası, Görece

$90 \mathrm{a} / \mathrm{b} / \mathrm{c}$ Various designs for glass bead furnaces, photo Küçükerman, Önder

91 Prayer beads

92 Reverse painting on glass, photo Şentürk, Şennur

93 Reverse painting on glass, 'Muhammed Ali', photo Şentürk, Şennur

94 Reverse painting on glass, Hicaz Railway, photo Şentürk, Şennur

95 A triangular tile with repeating units and botanical elements, photo Ünver, Süheyl

96 Portrait of Sultan Mehmet II, by Gentile Bellini, $15^{\text {th }} \mathrm{C}$, London National Gallery, photo Revaş

97a/b Hookahs with transfer decoration

98a/b The foundation and building site of the Paşabahçe Factory in 1935, photos Paşabahçe archive

99 Ismet Paşa is laying the first foundations of the Paşabahçe Factory, photo Paşabahçe archive

100 The telegraph sent by Atatürk, photo Paşabahçe archive

101a/b Paşabahçe Factory and Factory Shop in 1999, Paşabahçe, Istanbul

102a/b Beykozware produced in Paşabahçe Factory, Istanbul

103 Poster in Paşabahçe Factory Shop, Istanbul

104 A glass form, designed by Önder Küçükerman, made by Paşabahçe, 1973, photo Küçükerman, Önder

$105 \mathrm{a} / \mathrm{b}$ The glass forms of Yusuf Görmüş, photo Aydın, Gülden

106 The glass forms of Fahri Kaplan, photo Gonenc, Elif

107 Glass forming kiln, 1999, Marmara University, Istanbul

108 Glass form, 1999, Marmara University, Istanbul

109a/b Decorative glass panels, Marmara University, Istanbul 
110 Glass furnace, Marmara University, Istanbul

111 Blown forms, Marmara University, Istanbul

$112 \mathrm{a} / \mathrm{b} / \mathrm{c}$ The glass workshop in Akbaba village, Beykoz, Istanbul

113 Another glass workshop around Beykoz, Istanbul

114 The first torso made by Harvey Littleton, 1942, photo Byrd, Joan F.

115 The second torso made by Harvey Littleton, 1946, photo Byrd, Joan F.

$116 \mathrm{a} / \mathrm{b}$ Various ceramic forms made by Harvey Littleton, photo Byrd, Joan F.

117 Carved cullet pieces made by Harvey Littleton, photo Byrd, Joan F.

118a/b The two workshops held in March and June 1962, Toledo Museum of Art, Ohio, photo Frauenau and Littleton, Harvey, "Littleton Remembers"

119 Print from glass plates made by Harvey Littleton, photo Kessler, Jane Q.

$120 \mathrm{a} / \mathrm{b}$ Perfume bottles, Harvey Littleton, Spruce Pine Studios, N. Carolina

121a/b First blown forms, Harvey Littleton, Spruce Pine Studios, N. Carolina

122 'Three Green Vertical Forms', Sam Hermann, 1970, V\&A Museum, London

123 Blown forms by the author, 1996, Edinburgh College of Art 124a/b/cForms, Harvey Littleton, Spruce Pine Studios, N. Carolina 125a/b/cForms, Harvey Littleton, Spruce Pine Studios, N. Carolina 126a/b Forms, Harvey Littleton, Spruce Pine Studios, N. Carolina 126c/d Forms, Harvey Littleton, Spruce Pine Studios, N. Carolina 127 Dale Chihuly blowing, Pilchuck, 1972, photo Oldknow, Tina

128 Pacific First Persian Installation, Dale Chihuly, 1991, Pacific First Centre, Seattle, Washington, photo Bannard, Walter D. and Geldzahler, Henry $129 \mathrm{a} / \mathrm{b}$ Installation, William Morris, Pacific First Centre, Seattle, Washington, 1997

130 Blown form, William Morris, Pacific First Centre, Seattle, Washington, 1997

131 'Untitled', fused, kiln formed mosaic glass, 1989, Klaus Moje, photo Edwards, Geoffrey

132 Kiln-cast glass and mixed media, Keith Cummings, UK Glass Exhibition, 1998, City Art Centre, Edinburgh

133 'Destination X', sand cast with coloured glass and mixed media, Bertil Vallien, 1986, the Glass Gallery, V\&A Museum, London

134 Blown forms assembled with flat glass, Ray Flavell, UK Glass Exhibition, 1998, City Art Centre, Edinburgh 
135a/b Pilchuck Glass School, Seattle, 1997

136 Chandelier, Dale Chihuly, Seattle, 1997

137 'Sea Form', Dale Chihuly, 1985, the Glass Gallery, V\&A Museum, London

138a/b Pilchuck Glass School, Seattle, 1997

138c/d Pilchuck Glass School, Seattle, 1997

139 Faisal Mosque, Islamabad, Pakistan

140 Mehter Takımı, photo Military Museum

141a/b Works of the Author, 1998-1999, Edinburgh College of Art

142 'Marching On', exhibition by the Author, May 1999, V. M. Art Gallery, Karachi, Pakistan

143/144 Works of the Author, 1998-1999, Edinburgh College of Art

145 Gold gilded silver Alem with the Tuğra of Sultan Murad IV, photo Tezcan, Hulya, Turgay

146 Ivory Makta, $18^{\text {th }}-19^{\text {th }} \mathrm{C}$, Museum of Turkish and Islamic Arts, Istanbul, photo Çağman, Filiz and Aksoy, Şule

147/148 Works of the Author, 1998-1999, Edinburgh College of Art 149/150 Works of the Author, 1998-1999, Edinburgh College of Art

151 Works of the Author, 'Scottish Glass 2000', Dundee

152 Blown forms, Colin Rennie, 'Botanics Exhibition', 1998, Edinburgh

153 Blown forms, Steffan Orlowski, 1997, Edinburgh College of Art 


\section{TRANSLITERATION FOR TURKISH}

The spelling and pronunciation of Turkish words and titles are all in official modern Turkish. The Turkish alphabet consists of 29 letters, with 6 of these written differently from English.

Below is a useful guide to the pronunciation of Turkish letters:

C is pronounced "j" as in "jolly"

Ç is pronounced "ch" as in "chocolate"

G is always hard as in "great"

Ğ is an almost silent, soft guttural sound, which lengthens the preceding vowel.

I is pronounced similarly to the "e" in "open" or "le" in French.

$\mathbf{J}$ is pronounced like the French "j" in "Jacques"

Ö is pronounced "ir" as in "irksome"

Ş is pronounced "s" as in "sugar"

Ü is pronounced like the German "ü" in "über" 
alla Turchescha: glass products made in Europe specifically for export to Turkey in $18^{\text {th }}$ century.

aşurelik: oriental pudding bowls.

Beykozware: $18^{\text {th }}$ and $19^{\text {th }}$ century glass products which were produced in the same district of Istanbul, such as Paşabahçe, Çubuklu and Incirköy.

Beylik: estate of a Bey, various Anatolian regional principalities.

camköy: 'glass village', an unrealised project in 1987 to unite glassmakers around the Beykoz area.

çeşm-i bülbül: 'nightingale's eye', a wide range of Beykoz production formed by using vetri a fili technique. This technique arranges white and coloured glass rods in sequence to shape a distinctive swirling pattern.

derviş: 'dervish', member of a Sufi brotherhood, following a defined spiritual path.

Evliya Çelebi: a seventeenth century traveller, scholar and musician who wrote a book of his personal recollections from his travels.

filgözü: 'elephant eye', a type of window glass which is circular and swollen in shape, mostly found in the excavations of Kubad-Abad Palace in Beyşehir.

fustat: the gilded and enamelled glass made in Egypt.

gülabdan: rose-water sprinklers.

hoşaf: pleasant water, hoşaf is similar to şerbet, but less sweet and condensed than şerbet.

humbara: very thick glass grenades thrown by cannons and in the form of coloured balls. 
hydria: a pitcher used to carry water that has one vertical and two horizontal handles which help to support it whilst it is carried on top of the head.

Jannisaries: the new troops, the empire's infantry corps.

kandil: an Islamic religious festival in connection with Muhammed.

karlık: a form of jug that cools its contents with snow which has been placed in a little pouch near the handles.

kem göz: evil eye.

küfi: the characteristic Arabic script.

lâledan: a single tulip vase, also known as şukufedan.

lâlezari: lover of tulips.

latticinio: an Italian expression used for the description of vetro a filigrana in the past. It includes three blowing techniques slightly different from each other using coloured and white canes.

makta: an instrument used whilst sharpening the calligraphy pens to prevent the sharpener becoming blunt on the surface beneath.

Maşaallah: God be praised.

maydanozlu: 'with parsley', transparent cut glasses decorated with botanical motifs, especially with a parsley leaf motif.

Mevlevi: whirling dervish, a follower of Mevlana.

nargile: 'hookah', water-pipe.

nakkaş: a decorator who specialises in the painting of floral designs and manuscripts.

nazar: malicious look or thought directed at one's belongings or loved ones. Speculative superstition.

paşa : 'pasha', high civic or military official.

Ramazan: 'Ramadan', the Islamic time for fasting, it continues for 30 days. 
rakı: a popular Turkish alcoholic drink.

rovzen making: see şemsiye.

Sanâyi-i Nefise Mektebi: the first name of Mimar Sinan University, Fine Arts Faculty in Istanbul.

Sema: religious dances of the whirling dervishes.

Surname-i Hümayun: a miniature book made by nakkaş Osman, ordered by Sultan Murad III for the occasion of his son's, Şehzade Mehmed, circumcision in c. 1585 .

şehzade: son of a Sultan, prince of the Ottoman dynasty.

şemsiye: 'umbrella', a kind of locally made coloured window glass, embedded in the stucco of window grills, sometimes also called as rovzen making.

şerbet : 'sherbet', see hoşaf.

şukufedan: see lâledan.

şukufe perveran: lover of flowers.

tespih: prayer beads.

Tanzimat: reformation in Ottoman dynasty in 1839.

tuğra: 'tughra', a calligraphic emblem or treatment of the reigning sovereign's name.

Tulipomania: the craze for tulip in Europe in $17^{\text {th }}$ century. vetro a filigrana: see latticinio.

vetri a fili: see çeşm-i bülbül. 


\section{BIBLIOGRAPHY}

Adar, Ali Gökçen, "Koleksiyoncu Gözü ile Cam Dünyasında Opalinler”, Antik \& Dekor (1994), No. 24, 28-32.

Asheville, S. Highland Craft Guild, Folk Art Centre, Generations, exh. cat., 1995.

Akurgal, Ekrem, The Art and Architecture of Turkey (Oxford University Press, 1980).

Allen, Jamey D., Magical Ancient Beads (Singapore, 1998).

Alpözen, Oğuz, Bodrum, Antik Halikarnassos (Ankara, ND).

Ankara, Türk Camcılığı Sergisi, exh. cat., 1947.

Ankara, Sekiz Yılık Mecburi Eğitim Kitapcığı, Inf., 1997.

Anonymous, "Evil Eye Protector/lt is not polite to stare", Alta Vista, stare.html Anonymous, Alta Vista, Anglican Prayer Beads. html

Anonymous, "History of Glass Gilding-From Roman Times to the Present",

www. Eagle-nest-design.com/verra eglomise.htm

Anonymous, Paşabahçe (August and July, 1985), No. 7-8, cover.

Anonymous, Focus on Paşabahçe, The Founding of Paşabahçe,

http://focusmm.com.au/pasabahce/co_id.htm

Anonymous, My-Turkey.com, www.homestead.com/mkturkey/rulers.html

Anonymous, "El Üretim Müdürümüz Bilsen'in Murano Izlenimleri”, Paşabahçe

(September, 1986), No. 21, 5.

Anonymous, “Beykoz'dan Paşabahçe'ye (Yeni Koleksiyon Serileri), Antik \&

Dekor (1994), No. 21, 164-165.

Anonymous, "Travel and Study", Craft Horizons (1961), Vol. 21, No. 3.

Anthony, John, Joseph Paxton (G. B., 1992).

Arıbal, Rıfat, "Türklerde Camcılık", Şişe ve Cam (July, 1967), No. 31, 14-15.

The Art Journal - Illustrated Catalogue of the Industry of All Nations, The Great Exhibition/London, 1851 (Dover, 1970).

Asheville, Folk Art Center, Generations: Harvey Littleton, John Littleton, Kate Vogel, exh. cat., 1995.

Aslanapa, Oktay, Turkish Art and Architecture (London, 1971).

Atıl, Esin, Turkish Art (Washington, 1980).

Aydın, Gülden, “Şişecam'ın Gözbebeği”, Hürriyet/Pazar (27 $7^{\text {th }}$ of April 1997).

Balıkcıoğlu, Ertuğrul, "Camda Venedik Kalitesi”, Hürriyet - Tatil (14 ${ }^{\text {th }}$ of 


\section{December 1996).}

Bannard, Walter D. and Geldzahler, Henry, Chihuly Form From Fire (Tacoma, 1993).

Barillari, Diana and Godoli, Ezio, Istanbul 1900-Art Nouveau Architecture and Interiors (Florence, 1996).

Barr, Sheldon, Venetian Glass: Confections in Glass 1855-1914 (New York, 1998).

Bart, George L., Turkey; Its History and Progress: From the Journals and Correspondence of Sir James Porter, Continued to the Present Time (London, 1854).

Bass, George F., Bodrum Sualtı Arkeoloji Müzesi'ndeki Batıklar ( Ankara, 1996).

Bass, George F., "The Nature of the Serçe Limanı Glass", Journal of Glass Studies, The Corning Museum of Glass (1984), Vol. 26.

Battie, David and Cottle, Simon, Eds., Sotheby's Concise Encyclopaedia of Glass (London, 1995).

Bayburt, Sinan R., "Gümrük Birliğinde Türk Cam Sanayii”, MA Thesis, Unpublished, Ist. Uni. Sos. Bil. Enst. Maliye Ana Bilim Dalı (Istanbul, 1994), 1-127.

Bayer, Patricia and Waller, Mark, The Art of René Lalique (London, 1996).

Bayraktar, Nedret, "Osmanlı Devri Cam Sanatı", Paşabahçe (Feb. and March 1985), Year 1, No. 2 and 3, 3.

Bayraktar, Nedret, Istanbul Cam ve Porselenleri (Istanbul, 1982).

Bayramoğlu, Fuat, Türk Cam Sanatı ve Beykoz Işleri (Istanbul, 1974).

Bayramoğlu, Fuat, Türk Cam Sanatı ve Beykoz Işleri (Ankara, 1996).

Bayramoğlu, Fuat, "Beykoz Işi Cam Eşya”, Türkiyemiz (October, 1982), No.38, 1-7.

Bayramoğlu, Fuat, “Glass Distinction”, Turquoise (Spring, 1990), 20-21.

Bernsen, Jens, Why Design? (London, 1989).

Black, Jeremy and Green, Anthony, Gods, Demons and Symbols of Ancient Mesopotamia/An Illustrated Dictionary (London, 1992).

Blair, Sheila S., Bloom, Jonathan M., The Art and Architecture of /slam 12501800 (Yale University Press, 1994).

Blair, Sheila S., Islamic Inscriptions (Edinburgh, 1998).

Blunt, Wilfrid, Tulipomania (Middlesex and Melbourne, 1950). 
Boesen, Gudmund, Venetian Glass at Rosenborg Castle (Copenhagen, 1960).

Brown, Patricia F., Venetian Narrative Painting in the Age of Carpaccio (London, 1988).

Brown, Sarah, Stained Glass-An Illustrated History (London, 1994).

Bruhn, Jutta - Annette, Designs in Miniature: The Story of Mosaic Glass (Corning, New York, 1995).

Büyüktunçay, Attilâ, "Ortaçağ Islam Dünyasında Camcılık", Şişe Cam (Nov.Dec. 1979), 20.

Byrd, Joan Falconer, Harvey K. Littleton - A Retrospective Exhibition, High Museum of Art (Atlanta, 1984).

Canav, Üzlifat, TŞCFAŞ Cam Eserler Koleksiyonu (Istanbul, 1985).

Carswell, John, Iznik Pottery (London, 1998).

Cennini, Cennino, The Book of the Art of Cennino Cennini-A Contemporary Practical Treatise on Quattrocento Painting, Tran. from the Italian, with Notes on Mediaeval Art Methods by Christina J. Herringham (London, 1899).

Chabel, Malek, Symbols of Islam (Paris, 1997).

Chadwick, George F., The Works of Sir Joseph Paxton (G. B., 1961).

Charleston, R. J., "The Import of Western Glass into Turkey: Sixteenth Eighteenth Centuries", The Connoisseur (May, 1966), 18-26.

Charleston, R. J., "The Luck of Edenhall- A Notable Acquisition for the Nation", The Connoisseur (1959), 35.

Cooke, Frederick, Glass (London, 1986).

Corning, The Corning Museum of Glass, Seven Glass Sculptures, exh. cat., ND.

Cousins, Mark, Twentieth Century Glass (London, 1995).

Cowling, Elizabeth, The Magic Mirror-Dada and Surrealism from a private collection (Edinburgh, 1988).

Çağman, Filiz and Aksoy, Şule, Osmanlı Sanatında Hat (Istanbul, 1998).

Deer, W. A., Howie, R. A. and Zussman, J., Rock Forming Minerals (London, 1963).

Demir, Çiğdem E., “Camın Öyküsü”, THY (April, 1996), 30-37.

Derman, Uğur M., Letters in Gold - Ottoman Calligraphy from the Sakıp Sabancı Collection, The Metropolitan Museum of Art (New York, 1998).

Derman, Uğur M., Türk Hat Sanatının Şahaserleri (Ankara, 1990). 
Diba, Layla Soudavar, "Glass and Glassmaking in the Eastern Islamic Lands:

Seventeenth to Nineteenth Century", Journal of Glass Studies, The Corning Museum of Glass (1983), Vol. 25, 187-193.

Diderot Pictorial Encyclopaedia of Trades and Industry, Manufacturing and the Technical Arts in Plates Selected from L' Encyclopédie, ou Dictionnaire Raisonné des Sciences, des Arts et des Métiers of Denis Diderot, Vol. II (New York, 1959).

Dodsworth, Roger, Glass and Glassmaking (Great Britain,'1993).

Dolez, Albane, Glass Animals (New York, 1988).

Dorigato, Attilia and Klein, Dan, Eds., International New Glass (Verona, 1996).

Du Ry, Carel J., Art of Islam (West Germany, 1970).

Dubin, Lois Sherr, The History of Beads - from 30000 B. C. to the Present (Great Britain, 1987).

Ebeltoft, Glasmuseum/Denmark, Fujita/Littleton Exhibition, exh. cat., 1989.

Edinburgh, Huntly House Museum, Turkish Decorative Arts, exh. cat., 1958.

Edwards, Geoffrey, Ed., Klaus Moje-Glass / A Retrospective Exhibition,

National Gallery of Victoria (Melbourne, 1995).

Eriksen, Svend and de Bellaigue, Geoffrey, Sèvres Porcelain (London, 1987) Ettinghausen, Richard and Grabar, Oleg, The Art and Architecture of Islam 650-1250 (Middlesex, 1987).

Ettinghausen, Richard, Ipşiroğlu M. S. and Eyüboğlu, S., Turkey - Ancient Miniatures/UNESCO (Italy, 1961).

Frauenau, Glasmuseum Frauenau, Harvey K. Littleton, exh. cat., 1992.

Finlay, George K. S. G., Observations on the Causes of the Rapid Conquests of the Ottoman Turks in Europe (U. K., 1856).

Freely, John, Inside the Seraglio / Private Lives of the Sultans in Istanbul (London, New York, Victoria, Ontario, Auckland, 1999).

Freeman, Edward A., Ottoman Power in Europe, Its Nature, Its Growth and Its Decline (London, 1877).

Geldzahler, Henry, Dale Chihuly-Objects de Verre, Musee des Arts Decoratifs, Palais du Louvre, trans. Jean-Luc Olivie (Seattle, 1986).

Goodwin, Godfrey, A History of Ottoman Architecture (London, 1971).

Goodwin, Godfrey, Islamic Architecture: Ottoman Turkey (London, 1977).

Goodwin, Godfrey, Sinan:Ottoman Architecture and Its ValuesToday (London, 
Goodwin, Jason, Lords of the Horizons (London, 1998).

Goodwin, Jason, Ufukların Efendisi Osmanlılar (1998); trans. Armağan Anar (Istanbul, 1999).

Gouffier, Choiseul, Voyages Pittoresque de la Gréce (Paris, 1787), Vol III.

Gönenç, Elif, “Her Renkte Ayrı Bir Ruh”, Aktüel (15-21 Feb. 1996), 110-111.

Grimshaw, Rex W., The Chemistry and Physics of Clays and Other Ceramic Materials (London, 1971).

Günalp, Reha, "TŞCFAŞ Cam Eserler Koleksiyonu", T. Iş Bankası Kültür ve Sanat Dergisi (March 1990), Year 2, No. 5, 81-85.

Güven, Zeynep, “Transparan Heykeller”, Hürriyet-Pazar (5 ${ }^{\text {th }}$ of May 1996). Haggar, Reginald G., The Concise Encyclopaedia of Continental Pottery and Porcelain (Netherlands, 1960).

Hakim Bey, "The Evil Eye”, Alta Vista, Evil_eye. html.

Halem, Henry, Glass Notes: A Reference for the Glass Artist (Ohio, 1996).

Hetteš, Karel, Old Venetian Glass, trans. Ota Vojtíšek (London, 1960).

Hodge, Jessica, Lalique (London, 1999).

The Holy Bible, (Cambridge, New York, Melbourne, Sydney, New Rochelle, London, ND).

The Illustrated London News, Supplement (Gratis) to the Illustrated London News, (London, March 8, 1851).

The Illustrated London News, (London, September 10, 1842).

Inalcık, Halil, The Ottoman Empire - The Classical Age 1300 - 1600 (London, 1973)

Inalcık, Halil and Quataert, Donald (eds), An Economic and Social History of the Ottoman Empire (Cambridge University Press, 1994), Vols. 1 and 2. Inman, Nick, Ed., Istanbul (London, 1998).

International Financial Statistics Yearbook, (International Monetary Fund, 1997, Washington), Vol. L.

Irwin, Robert, Islamic Art (London, 1997).

Istanbul, The University of Istanbul, Department of Fine Arts, $1^{\text {st }}$ International Anatolian Glass Symposium, sym. cat., 1990.

Istanbul, Military Museum / Askeri Müze, Harbiye, Geçmişten Günümüze Mehter, info. cat., ND.

Istanbul, III. International Istanbul Biennial, Damien Hirst, exh. cat., 1992. 
Jargstorf, Sibylle, Glass in Jewelry (USA, 1991).

Jenkins, Marilyn, Islamic Glass (The Metropolitan Museum of Art, 1986).

Kämpfer, Fritz and Beyer, Klaus G., Glass-A World History; trans. Edmund Launert (London, 1966).

\section{Kalkınma Planı 1963-67: Turkey, (1964).}

Kelsey, Tim, Dervish (England, 1996).

Kessler, Jane Q., Luminous Impressions/Prints from Glass Plates (Charlotte, 1987).

Klein, Dan and Lloyd Ward, The History of Glass (London, 1997).

Kuzudişli, Zeynep, “Geleneksel Türk Camcılığı - Yaşayan Camcılığımız”, 4. Boyut (April, 1990), No. 2, 19-22.

Küçükerman, Önder, Glass Beads - Anatolian Glass Bead Making (Istanbul, 1988).

Küçükerman, Önder, "Glass Galore at Dolmabahçe Palace - Dolmabahçe Sarayı ve Ünlü Kristalleri”, Skylife, (Turkish/English) (November 1997), 49-60.

Küçükerman, Önder, Cam Sanatı ve Geleneksel Türk Camcılığından Örnekler (Ankara, 1985).

Küçükerman, Önder, "19. Yüzyıldaki Sanayileşme Hareketinin Sembolü Olarak Beykoz Işi Camlar”, Antik \& Dekor (1997), No. 40, 102-111.

Küçükerman, Önder, “Anadolu'nun 3000 Yıllık Kimlik Ürünü Göz Boncuğu Üzerine Danimarka'da Bir Seminer ve Bir Geliştirme Projesi Önerisi”, Sanat (November, 1993), No. 3, 4-15.

Küçükerman, Önder, "Gerçek Mavi Göz Boncuğu”, Tasarım (March, 1993), No. 32 , 109-113.

Küçükerman, Önder, "Cam Sanatında El Ustalığından Makina Ustalığına”, Sanat Çevresi (June, 1995), No. 200, 12-13.

Labino, Dominick, "The Artist and Glass - Resurgence of Interest in Creative Glass Blowing", Visual Art in Glass (1968).

Lawson, Emma, Ed., Sotheby's Art at Auction (London, 1998).

Layton, Peter, Glass Art (London, 1996).

Le Gall, Dom Robert, Symbols of Catholicism (Paris, 1996, USA, 1997).

Leach, Maria, Ed., Funk and Wagnalls Standard Dictionary of Folklore, Mythology and Legend (London, 1972).

Levey, Michael, The World of Ottoman Art (Norwich, 1975). 
Lightfoot, C. S. and Arslan, M., "Anadolu Antik Camları", Yüksel and Imhan Kol (Ankara, ND), 8-10.

Lightfoot, C. S. A Catalogue of Glass Vessels in Afyon Museum / Afyon Müzesindeki Cam Eserler Kataloğu, English/Turkish (Oxford, 1989).

Littleton, Harvey K., “Littleton Remembers...”, Glass Art, Vol. 4, No. 1. Littleton, Harvey K., Glass Blowing-A Search for Form (New York, 1980).

Lloyd, E. Herman, Clearly Art: Pilchuck's Glass Legacy (Hong Kong, 1992).

Lodewijk, Tom, The Book of Tulips (London, Sydney, Johannesburg, Toronto, Auckland, 1979).

London, Crafts Council, Contemporary British Glass, exh. cat., 1993.

London, Tate Gallery, The Turner Prize 1992, exh. cat., 1992.

Marson, P., Common Comodities and Industries - Glass (Bath, New York and Melbourne, ND.)

Mansel, Philip, Constantinople-City of the World's Desire, 1453-1924 (London, 1995)

Mentasti, Rosa Barovier, Venetian Glass 1890 - 1990, trans. Matthew McParland (Verona, 1992).

Meredith-Owens, G. M., Turkish Miniatures (London, 1969).

Middlemas, Keith, Continental Coloured Glass (London, 1971).

Moor, Andrew, Architectural Glass Art - Form and technique in contemporary glass (London, 1997).

Newark, Tim, The Art of Emile Gallé (London, 1995).

New York, Metropolitan Museum of Art and also in Washington, National Gallery of Art, Kristalle Asya San'atı, exh. cat., 1956.

Nicholson, Paul T., Egyptian Faience and Glass (Great Britain, 1993).

Nicolle, David and Hook, Christa, The Janissaries (Great Britain, 1995).

OECD Economic Surveys Turkey 1981-85, (Organisation for Economic CoOperation and Development, 1982, Paris).

Official Descriptive and Illustrated Catalogue of Great Exhibition of the Works of Industry of All Nations 1851, Spicer Brothers (London, 1851), Vol.III.

Oldknow, Tina, Pilchuck:A Glass School (Pilchuck Glass School, Seattle,1996) Ormancı, Remzi, "Güzel Sanatlar ve Goblecilik", Şişe ve Cam (September, 1963), No. 10, 5 and 24.

Önder, Mehmed, "Selçuklu Devrine Ait Bir Cam Tabak", Türk Sanat Tarihi 
Araştırma ve Incelemeleri II, Istanbul Devlet Güzel Sanatlar Akademisi (Istanbul, 1969), 1-5.

Öney, Gönül, Anadolu Selçuklu Mimari Süslemesi ve El Sanatları (Ankara, 1988).

Özet, Aynur, Dipten Gelen Parılı, Bodrum Sualtı Arkeoloji Müzesi Cam Eserleri (Ankara, 1998).

Pallis, Alexander, In the Days of the Janissaries (London, 1951).

Paul, Tessa, The Art of Louis Comfort Tiffany (London, 1996).

Pavord, Anna, The Tulip (London, 1999).

Petsopoulos, Yanni, Ed., Tulips, Arabesques and Turbans, Decorative Arts from the Ottoman Empire (London, 1982).

Pilchuck, Pilchuck Glass School Information Booklet, 1997.

Pina, Leslie, Popular '50s and '60s Glass (Atglen-USA, 1995).

Polak, Ada, Glass-Its Makers and Its Public (London, 1975).

Porter, James Sir, Observations on the Religion, Law, Government and Manners of the Turks (London, 1771).

Pye, David, The Nature and Aesthetics of Design (London, 1978).

Quataert, Donald, Ottoman Manufacturing in the Age of the Industrial Revolution (Cambridge University Press, 1993).

Rawson, H., Properties and Applications of Glass (Amsterdam, 1980).

Revaş Reklamcılık, Istanbul-The Cradle of Civilisations, (Istanbul, 1998).

Rice, Tamara T., The Seljuks in Asia Minor (London, 1961).

Richter, Hans, Dada-art and Anti-art (London, 1965).

Roth, Moira, Difference/Indifference-musings on postmodernism, Marcel Duchamp and John Cage (Amsterdam, 1998).

Sarpellon, Giovanni, Lino Tagliapietra, trans. by Heidi Wenyon (Venice, 1994).

Shand, E. B., Glass Engineering Handbook (New York, 1958).

Shelby, James E., Introduction to Glass Science and Technology (Cambridge, 1997).

Sotheby's Concise Encyclopaedia of Glass, (London, 1991).

Spillman, Jane Shadel, Glass from World's Fairs 1851 - 1904, The Corning Museum of Glass, Corning (New York, 1986).

Şentürk, Şennur, Cam Altında Yirmi Bin Fersah (Istanbul, 1997).

Şentürk, Şennur, Istanbulluoğlu, Ari, Beykoz Camları /Beykoz Glass, A 
catalogue to accompany the exhibition "Beykoz Glass" at Yapı Kredi Vedat Nedim Tör Museum. (Istanbul, 1997).

Tait, Hugh, Five Thousand Years of Glass (London, 1991).

Taqî-ud-Dîn Al-Hilâlî, Muhammad \& Khân, Muhammad Muhsin, Translation of the meanings of The Noble Qur'an in the English language (Madinah, K. S. A., ND.).

Temel Britannica, Ana Yayıncılık and Britannica Corporation (1992), Vol. 4.

Tezcan, Hülya and Tezcan, Turgay, Türk Sancak Alemleri (Ankara, 1992).

Théma Larousse, Sanat ve Kültür: Türk-Islam (1994) Vol. 6.

Tooley, Fay V., The Handbook of Glass Manufacture (New York, 1984).

Turner, W. E. S., "Glassmaking in Turkey", Journal of the Society of Glass Technology, (1950), Vol. 34, 91-95.

UNESCO Statistical Yearbook, goes back to 1964 (United Nations, 1966).

Vose, Ruth Hurst, A Collector's Guide to Antique Glass (London, 1996).

Walker, Barbara G., The Woman's Dictionary of Symbols and Sacred Objects (USA and Canada, 1988).

Ward, Rachel, Ed., Gilded and Enamelled Glass from the Middle East (London, 1998).

Western Carolina, Western Carolina University, North Carolina Glass '90, exh. cat., 1990.

Wheatcroft, Andrew, The Ottomans (London, 1993).

Whitehouse, David, Glass of the Roman Empire (Corning, New York, 1988).

Wilson, Eva, Islamic Designs (London, 1997).

Wisconsin, Milwaukee Art Centre, Harvey Littleton/Glass, exh. cat., 1966.

Yokohama, Yokohama Museum of Art, Expanded Glass; Traditional and Contemporary, exh. cat., 1995.

Yokohama, Yokohama Museum of Art, Treasures from the Corning Museum of Glass, exh. cat., 1992.

Yucel, Ihsan, Ed., Dolmabahçe Palace (Istanbul, 1995).

Zerwick, Chloe, A Short History of Glass (New York, 1990). 

journals are important as they present articles on glass, which could be overlooked in such an abundant area as crafts. They have been prepared in order to present this information in an easily accessible format.

\section{CRAFTS MAGAZINE INDEX}

(Crafts Magazine is published bi-monthly by the Crafts Council)

\begin{tabular}{|c|c|c|c|c|}
\hline Num & aber \& Date & Subject & Title & Author \\
\hline *2 & 1973 & Education & Glass at Stourbridge & Marigold Coleman \\
\hline * 4 & Sept./Oct. 1973 & Stained Glass & A Personal View (Ed Carpenter) & Diana Walls \\
\hline * 8 & May/June 1974 & Studio & Czech Glass & John Cook \\
\hline * 10 & Sept./Oct. 1974 & Blowing & Dominick Labino & Wendy Evans \\
\hline * 19 & Mar./Apr. 1976 & Education & The Wrong Direction? & Lecture RCA \\
\hline * 22 & Sept./Oct. 1976 & Studio & Emile Galle & Philippe Garner \\
\hline$* 22$ & Sept./Oct. 1976 & Blowing & Hot Glass Now & J. Christensen \\
\hline * 22 & Sept./Oct. 1976 & Studio & Running A Glass Workshop & Simon Pearce \\
\hline * 27 & July/Aug. 1977 & Blowing & Basic Glass & Ray Flavell \\
\hline * 28 & Sept./Oct. 1977 & Education & RCA \& Stourbridge Glass & Survey \\
\hline * 34 & Sept./Oct. 1978 & Studio & An Afternoon With Marinot & Ada Polak \\
\hline * 39 & July/Aug. 1979 & Studio & Contemporary Glass & Ray Flavell \\
\hline$\star 40$ & Sept./Oct. 1979 & Education & Art Schools (Purgatory or Paradise) & Survey \\
\hline$\star 45$ & July/Aug. 1980 & Studio & Aperitif & Survey \\
\hline * 46 & Sept./Oct. 1980 & Kiln Work & New Ideas in Kiln-Worked Glass & Ray Flavell \\
\hline * 46 & Sept./Oct. 1980 & Education & The Neglected Lesson & Survey \\
\hline * 52 & Sept./Oct. 1981 & Studio & Clear Cut And Full - Blown & F. Adamczewski \\
\hline * 52 & Sept./Oct. 1981 & Education & Trained to Survive (Jewellery) & Belinda Burt \\
\hline * 52 & Sept. Oct. 1981 & Studio & Recent Czech Glass & Alena Adlerova \\
\hline * 52 & Sept./Oct. 1981 & Studio & Fall from Grace & Penny Sparke \\
\hline * 54 & Jan./Feb. 1982 & Crafts & For Better - Or Worse & E. Lucie - Smith \\
\hline * 54 & Jan./Feb. 1982 & Crafts & The Myth of the Happy Artisan & Chris Frayling \\
\hline * 57 & July/Aug. 1982 & Education & Slaves, Servants and Citizenship & Lionel March \\
\hline * 59 & Nov./Dec. 1982 & Stained Glass & Can We Expect A Stained-Glass.. & Martin Harrison \\
\hline * 61 & Mar./Apr. 1983 & Studio & The Glass Menagere & Peter Layton \\
\hline * 62 & May/June 1983 & Education & Careers in Glass & Interview \\
\hline * 64 & Sep./Oct. 1983 & Studio & Breaking the Mould & Diana Hobson \\
\hline * 67 & Mar./Apr. 1984 & History & Studio Glass Since 1945-Dan Klein & Tanya Harrod \\
\hline * 68 & May/June 1984 & Miscellaneous & Glass Mecca & Susan Hoyal \\
\hline$* 70$ & Sep./Oct. 1984 & Miscellaneous & GAS Conference & Peter Layton \\
\hline * 71 & Nov./Dec. 1984 & Blowing & Paintings in Glass & Pauline Solven \\
\hline * 74 & May/June 1985 & Studio & Glass Engraving & David Peace \\
\hline * 75 & July/Aug. 1985 & Blowing & Double Act- R.Woodman-N.Wilkin & Rosemary Hill \\
\hline * 76 & Sep./Oct. 1985 & Miscellaneous & Glassmakers Abroad & Exhibition Notes \\
\hline * 77 & Nov./Dec. 1985 & Miscellaneous & Contemporary Glass & Exhibition Notes \\
\hline * 79 & Mar./Apr. 1986 & Stained Glass & Beleschenko on Beleschenko & A. Beleschenko \\
\hline * 79 & Mar./Apr. 1986 & Studio & Fragments Against Ruin - Danny Lane & Abigail Frost \\
\hline * 79 & Mar./Apr. 1986 & Stained Glass & Amber \& Pearl -Amber Hiscott,David Pearl & David Briers \\
\hline * 79 & Mar./Apr. 1986 & Neon & Lighted Lines - Peter Freeman & Judy Walker \\
\hline * 79 & Mar./Apr. 1986 & Studio - Casting & Casting from Nature - Colin Reid & Penny Sparke \\
\hline * 79 & Mar./Apr. 1986 & Stained Glass & Hong Kong Jazz - Jane McDonald & Gillian Darley \\
\hline * 79 & Mar./Apr. 1986 & Studio & Gentle Ornament - Ann Smyth & Peter Dormer \\
\hline * 81 & July/Aug. 1986 & Miscellaneou & Studio Glass Exhibitions & Exhibition Notes \\
\hline * 82 & Sep./Oct. 1986 & Blowing-Bottles & Bottlers - Catherine Hough, David Tayld & Colin Voake \\
\hline * 88 & Sep./Oct. 1987 & Studio & Lowe Profile - Liz Lowe & Rosemary Hill \\
\hline * 89 & Nov./Dec. 1987 & History & Ancient \& Modern & Patricia Baker \\
\hline
\end{tabular}


* 90 Jan./Feb. 1988

* 91 Mar./Apr. 1988

* 92 May/June 1988

* 95 Nov./Dec. 1988

* 96 Jan./Feb. 1989

* 97 Mar./Apr. 1989

* 98 May/June 1989

* 105 July/Aug. 1990

* 106 Sep./Oct. 1990

* 108 Jan./Feb. 1991

* 110 May/June 1991

* 110 May/June 1991

* 111 July/Aug. 1991

* 113 Nov./Dec. 1991

* 113 Nov./Dec. 1991

* 118 Sep./Oct. 1992

* 118 Sep./Oct. 1992

* 118 Sep./Oct. 1992

* 119 Nov./Dec. 1992

* 120 Jan./Feb. 1993

* 123 July/Aug. 1993

* 123 July/Aug. 1993

* 126 Jan./Feb. 1994

* 127 Mar./Apr. 1994

* 127 Mar./Apr. 1994

* 130 Sep./Oct. 1994

* 130 Sep./Oct. 1994

* 134 May/June 1995

* 135 July/Aug. 1995

* 138 Jan./Feb. 1996

* 138 Jan./Feb. 1996

* 139 Mar./Apr. 1996

* 142 Sep./Oct. 1996

* 144 Jan./Feb. 1997

* 144 Jan./Feb. 1997

* 145 Mar./Apr. 1997

* 145 Mar./Apr. 1997

* 146 May/June 1997

* 147 July/Aug. 1997
Studio

Studio

Blowing

Education

Symposium

Stained Glass

Stained Glass

History \& Studio

Miscellaneous

Symposium

History

Exhibition

Studio

Studio

Exhibition

Exhibition

Miscellaneous

Studio

Engraving

Studio-Pate de verre

Stained Glass

Miscellaneous

Miscellaneous

Studio

Miscellaneous

Studio - History

Studio

Stained Glass

Studio

Studio - Blowing

History

Miscellaneous

History

Conference

Exhibition

Studio

History

Studio

Exhibition
Thinking Big - Amanda Brisbane

Glass Chimera -Keith Brocklehurst

Glass Magician - Simon Moore

A Glass Education

Interglass Symposium

Mark Angus

Lawrence Lee

Sam Herman

Contemporary Glass Exhibition

Soviet Symposium

Premier Glass - Darlington Crystal

Canadian Glassworks

Blaschka - Bohemian Glassworkers

Diana Hobson - Pate-de-verre

Derix Glass Studios - Germany :

Into the Glass House

Obituary - Ronald Wilkinson

Heart of Glass - Clare Henshaw

Laurence Whistler

The Alchemist - Karen Vincent

Divine Inspiration - Ahmed Moustafa

Magnifying the Debate

Moving Story - The Glass House

Annette Meech - Glassmaker

A Touch of Glass - V \& A

Czech Mates- Libensky, Brychtova

Glass Act - Ben Dunington

Sources of Inspiration- M.Traherne

Esential Elements - Keiko Mukaide

A Blow for Independence-N.Wilkin

Glass of Its Own - Whitefriars

New Glass Gallery

Whitefriars Glass

Casting in Caithness

The Camberwell Collection

Bright Lights - Rebecca Donaldson

Future Perfect

Lookout - Wendy Hooper

Simon Moore - Glass
Jane Norrie

Charles Hajdamah

Fiona Adamczewski

Craftnotes

Craftnotes

Jane Lamacraft

Lawrence Lee

Tanya Harrod

Exhibition Notes

Craftnotes

Margot Coatts

Exhibition Notes

Exhibition Notes

Jeremy Theophilus

Exhibition Notes

Exhibition Notes

Craftnotes

Ralph Turner

Alan Powers

Margot Coatts

Theophilus

Peter Dormer

Craftnotes

Craftnotes

Pamela Johnson

Jennifer Opie

Pamela Johnson

Tanya Harrod

Edmund de Vaal

Edwina Larner

Margot Coatts

Craftnotes

Exhibition Notes

Craftnotes

Exhibition Notes

Liz Hoggard

Dan Klein

L. Hoggard -M. Field

Exhibition Notes 


\title{
G. A. S. (GLASS ART SOCIETY)
}

\author{
Annual Journals
}

\begin{tabular}{|c|c|c|c|}
\hline Date & Title & Author & Source \\
\hline $\begin{array}{l}1976 \\
1979 \\
1979 \\
1979 \\
1979 \\
1983-8 \\
1989 \\
1991 \\
1991 \\
1991 \\
1991 \\
1991 \\
1991 \\
1991 \\
1992 \\
1992 \\
1992 \\
1992 \\
1993 \\
1993 \\
1993 \\
1993 \\
1993 \\
1994 \\
1995 \\
1995 \\
1995 \\
1995 \\
1996 \\
1996\end{array}$ & $\begin{array}{l}\text { Working with Hot Glass Conference } \\
\text { Health Hazards } \\
\text { First National Directory of Production Studios } \\
\text { Littleton's Furnace } \\
\text { H. Littleton: "The Core of Everything" } \\
\text { Historical Revivals in Glass } \\
\text { Pate de Verre Process } \\
\text { The Future of Glass Education } \\
\text { Is There Life in Your Art, Your RelationshipsYour Educa } \\
\text { Twenty Years of American Glass Education } \\
\text { Looking for a European Position: Remarks on New Glass... } \\
\text { Glassmaking Health and Safety: Update 1991 } \\
\text { The Rise of Glass Art: A Personal View } \\
\text { Should Making Art Be a Career ? } \\
\text { Swedish Glass } \\
\text { Contemporary Spanish Glass Artists } \\
\text { Cultural Identity } \\
\text { Czechoslovakia:Over the Hurdles-Develop.of the Glass Ar. } \\
\text { The B Team: Past, Present, Our Futures } \\
\text { Glass : A Potential for Prints } \\
\text { Polish Glass Art and Education Since 1950 } \\
\text { Glass Education? } \\
\text { Where were You in 1962? } \\
\text { Fr. the Beginning:A Brief Hist. of the Bay Area Glass Mov. } \\
\text { Southeast Area Glass Schools-25 } \\
\text { Chronology - } 25^{\text {th }} \text { Annual Conference } \\
\text { Glass in Southeast Area Museums } \\
\text { Education } \\
\text { A Day at the Massachusetts Institute of Tech. } \\
\text { G. A. S. Education Roster }\end{array}$ & $\begin{array}{l}\text { Eisch, Libensky, Labino } \\
\text { D. Wood \& A. Morehauser } \\
\text { Survey } \\
\text { H. Littleton (?) } \\
\text { Joan Byrd } \\
\text { D. Revere McFadden } \\
\text { Diana Hobson } \\
\text { Jon Clark } \\
\text { Erwin Eisch } \\
\text { Bruce Chao } \\
\text { Helmut Ricke } \\
\text { Monona Rossol } \\
\text { Paul \& Elmerina Parkma } \\
\text { Susanne K. Frantz } \\
\text { J. W. M. Anderson } \\
\text { Keshava (Antonio L. Sainz } \\
\text { Xavier Melendez } \\
\text { Michael Pavlik } \\
\text { Marina Marioni } \\
\text { Harvey K. Littleton } \\
\text { Ludwik Kiczura } \\
\text { Henry Halem } \\
\text { Panel-The Toledo Conf. } \\
\text { Marvin Lipofsky } \\
\text { Gene Koss } \\
\text { Martha Drexler Lynn } \\
\text { William Daley } \\
\text { Lectures }\end{array}$ & $\begin{array}{l}\text { Newsletter } \\
\text { Journal } \\
\text { Journal } \\
\text { Journal } \\
\text { Journal } \\
\text { Journal } \\
\text { Tech.Journal } \\
\text { Journal } \\
\text { Journal } \\
\text { Journal } \\
\text { Journal } \\
\text { Journal } \\
\text { Journal } \\
\text { Journal } \\
\text { Journal } \\
\text { Journal } \\
\text { Journal } \\
\text { Journal } \\
\text { Journal } \\
\text { Journal } \\
\text { Journal } \\
\text { Journal } \\
\text { Journal } \\
\text { Journal } \\
\text { Journal } \\
\text { Journal } \\
\text { Journal } \\
\text { Journal } \\
\text { Journal }\end{array}$ \\
\hline
\end{tabular}




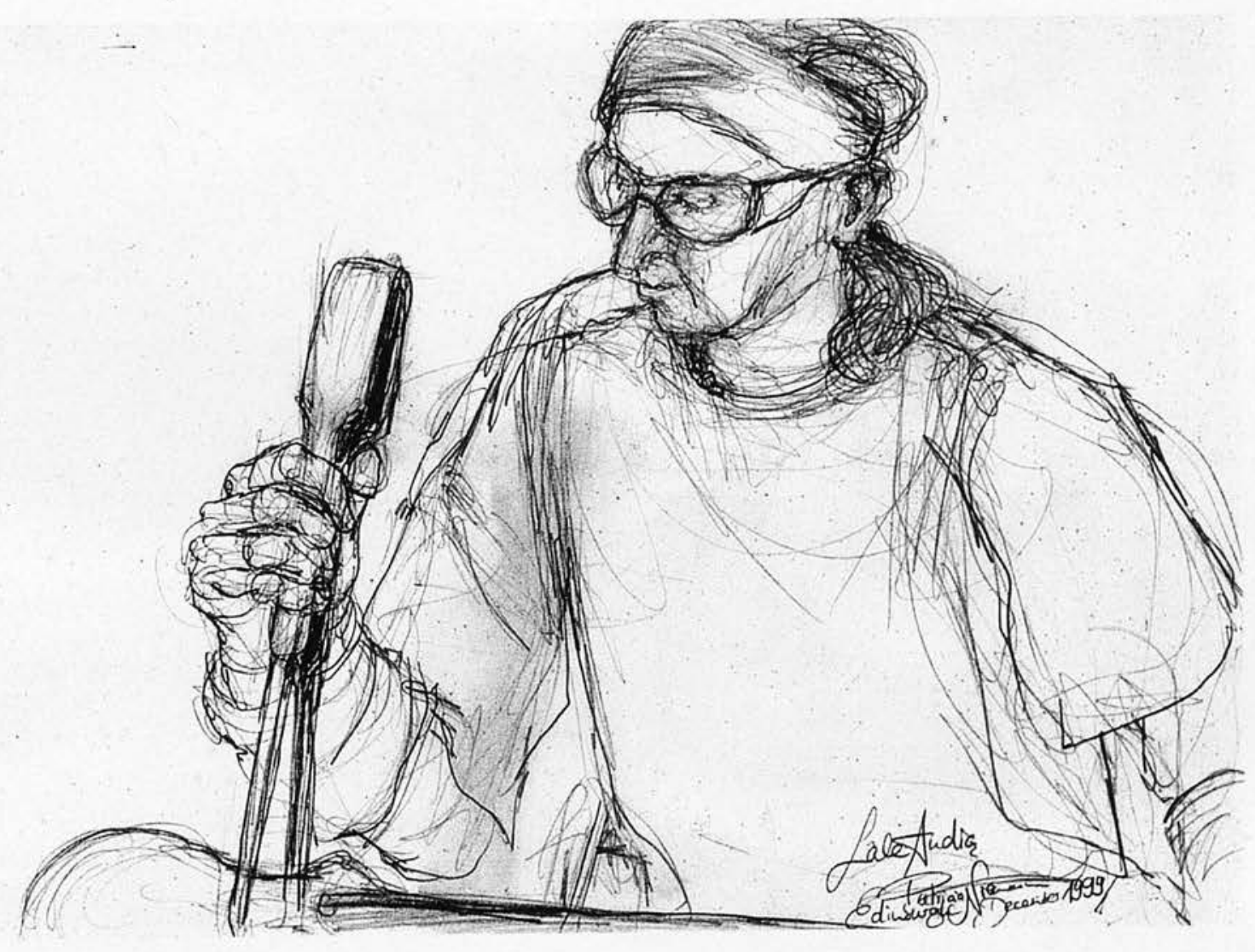

